LUCIANO GONÇALVES RIBEIRO

ESTUDO DA ESTABILIDADE DA REAÇÃO INDUSTRIAL DE FORMAÇÃO DE ÓXIDO DE ETILENO A PARTIR DO GERENCIAMENTO DAS VARIÁVEIS CRÍTICAS DE PROCESSO

São Paulo

2013 


\section{ESTUDO DA ESTABILIDADE DA REAÇÃO INDUSTRIAL DE FORMAÇÃO DE ÓXIDO DE ETILENO A PARTIR DO GERENCIAMENTO DAS VARIÁVEIS CRÍTICAS DE PROCESSO}

Tese de doutorado apresentada à Escola Politécnica da Universidade de São Paulo para obtenção do título de Doutor em Engenharia

Área de concentração:

Engenharia Química

Orientadora:

Profa. Dra. Maria Elena Santos Taqueda

São Paulo 
Este exemplar foi revisado e corrigido em relação à versão original, sob responsabilidade única do autor e com a anuência de seu orientador.

São Paulo, de outubro de 2013.

Assinatura do autor

Assinatura do orientador

Ribeiro, Luciano Gonçalves

Estudo da estabilidade da reação industrial de formação de óxido de etileno a partir do gerenciamento das variáveis críticas de processo / L.G. Ribeiro. -- versão corr. -- São Paulo, 2013. 202 p.

Tese (Doutorado) - Escola Politécnica da Universidade de São Paulo. Departamento de Engenharia Química.

1.Óxido de etileno 2.Seletividade 3.Superfície de resposta 4.Modelos de regressão I.Universidade de São Paulo. Escola Politécnica. Departamento de Engenharia Química II.t. 
A maior injustiça que eu poderia cometer é não dedicar este trabalho à minha esposa Adriana. Sem o seu amor, apoio e incentivo esse trabalho nunca teria passado de um sonho.

À minha filha Mariana, com todo amor $\mathrm{e}$ carinho. 


\section{AGRADECIMENTOS}

Agradeço a minha orientadora, Prof. Maria Elena Santos Taqueda pelo incentivo, apoio, diretrizes e sugestões que contribuíram para a elaboração desse trabalho.

Muitas pessoas que trabalham na Oxiteno, unidade de Mauá, ajudaram na elaboração desse trabalho. Mas cinco merecem um reconhecimento especial: Mauro Buffoni, Sidilene Coimbra Milioni, Marcio Andrade Dias, Nalu Gomes Moura e Joacir Cirino Junior. A contribuição de cada um deles para o desenvolvimento desse trabalho foi muito importante e sou extremamente grato a eles. 


\section{RESUMO}

O desempenho de um processo de produção de óxido de etileno é normalmente avaliado através da seletividade da reação. Neste trabalho, uma unidade produtiva foi estudada com o objetivo de se maximizar a seletividade através da atuação sobre as principais variáveis de processo. Uma análise estatística de um conjunto de dados de processo mostrou que quatro variáveis (vazão de oxigênio, vazão de gás de reciclo, temperatura da reação e teor de clorados) são as de maior influência sobre a seletividade e explicam mais de $60 \%$ das variações ocorridas no processo produtivo. Com base nessa análise de dados, modelos de regressão multilinear foram desenvolvidos e testados com o objetivo de representar o comportamento do processo em função apenas do comportamento dessas quatro variáveis. $\mathrm{O}$ modelo matemático empírico proposto para representar esse processo foi validado estatisticamente e fenomenologicamente, demonstrando consistência com os dados obtidos em processo. O modelo também foi desdobrado em 24 submodelos que representam condições possíveis de operação da unidade e para os quais foram elaboradas superfícies de respostas que permitiram definir a melhor forma de gestão das 4 variáveis críticas conjuntamente, de modo a se obter a máxima seletividade possível para a reação em função desses cenários operacionais.

Palavras chave: óxido de etileno, seletividade, superfície de resposta, modelos de regressão. 


\begin{abstract}
The performance of an ethylene oxide manufacturing process is normally measured by the selectivity reaction. In this work, a production unit was studied in order to maximize selectivity through the development of a strategic plan to main to manage the key process variables. A statistical analysis of a data set indicated that only four variables (oxygen flow, recycle gas flow, temperature reaction and chlorine content) are responsible for the greater influence over the selectivity and explain more than $60 \%$ of process variations. As consequence, regression models were developed and tested in order to represent the process behavior as a function of these four variables. The proposed mathematical model was statistically and phenomenologically validated, demonstrating consistency with the current process data. The model was rewritten in 24 submodels, named deployed models which represent possible operational conditions of the unit. A set of surface responses was defined for each deployed model, providing to identify the best way for the management of these 4 critical variables. Furthermore, this analysis leads to a management tool for achieving the best results in selectivity, as function of the possible operational scenarios for this unit.
\end{abstract}

Keywords: ethylene oxide, selectivity, surface response, regression model. 


\section{LISTA DE FIGURAS}

Figura 1 - Primeiras cadeias produtivas derivadas de etileno 5

Figura 2 - Evolução da capacidade produtiva de óxido de etileno por 7 regiões produtoras

Figura 3 - Distribuição de Consumo da molécula de óxido de etileno para produção de seus derivados

Figura 4 - Representação esquemática da molécula de Óxido de 15 etileno

Figura 5 - Fluxograma simplificado do processo produtivo de óxido de etileno a partir da oxidação direta do ar

Figura 6 - Fluxograma simplificado do processo produtivo de óxido de etileno a partir da oxidação utilizando oxigênio puro

Figura 7 - Representação do triângulo das reações de oxidação de etileno

Figura 8 - Concentração de produtos obtida em reações catalíticas (linha vermelha) e não catalíticas (linha azul)

Figura 9 - Representação do cálculo de energia de ativação de uma reação

Figura 10 - Configuração típica de um reator tubular de leito fixo para produção de óxido de etileno

Figura 11 - Energias de ativação comparativas das reações de oxidação do etileno

Figura 12 - Efeito do catalisador sobre as energias de ativação das reações de oxidação do etileno

Figura 13 - Representação esquemática da superfície de um catalisador de prata

Figura 14 - Representação esquemática da área superficial de um catalisador de prata

Figura 15 - Efeito da presença de Clorados na superfície de um catalisador de prata

Figura 16 - Representação da adsorção do oxigênio em prata. (a) 66 oxigênio adsorvido à prata por ligações tipo "vertical". (b) oxigênio adsorvido à prata por ligações tipo "ponte"

Figura 17 - Representação esquemática da influência de clorados na seletividade da reação de oxidação de etileno 
Figura 19 - Esquema ilustrativo apresentando as principais partes do Box-and-Whisker plots (ou simplesmente box plot)

Figura 20 - llustração da matriz de correlação com algumas variáveis genéricas

Figura 21 - Diagramas dos critérios de seleção do exemplo citado com 8 preditores.(a) $O$ coeficiente de determinação $R_{p}^{2}$ em função do número de regressores; (b) o coeficiente de determinação ajustado, $R_{a, p}^{2}$, em função do número de regressores e (c) é o $\mathrm{Cp}$ de Mallows em função do número de regressores

Figura 22 - Resposta do software Minitab, para os melhores subconjuntos do exemplo do processo cirúrgico

Figura 23 - Fluxograma de Processo Produtivo de óxido de etileno (Sistema de Reação e Absorção de Óxido de etileno) Oxiteno S/A Indústria e Comércio

Figura 24 - Representação de uma interface SDCD / Processo produtivo

Figura 25 - Detalhe do sistema de medição de vazão de etileno. (a) 100 Tubos sensores; (b) Conversor / transmissor

Figura 26 - Detalhe do sistema de medição de vazão de oxigênio. (a) 101 Tubos sensores; (b) Conversor / transmissor

Figura 27 - Simulação do efeito Coriolis em um medidor de vazão 102

Figura 28 - Simulação do Efeito Coriolis em um medidor de vazão. (a) Situação em que não ocorre o fluxo de fluidos pelo medidor; (b) Situação em que ocorre o fluxo de fluidos pelo medidor

Figura 29 - Detalhamento da bobina de excitação de um medidor de 102 vazão com efeito Coriolis

Figura 30 - Tensão senoidal gerada em um medidor de vazão tipo 103 Coriolis

Figura 31 - Detalhe do sistema de medição de vazão de gás de reciclo 104 para o reator. (a) tubo Venturi; (b) Instrumentos de medição da pressão diferencial

Figura 32 - Detalhe do sistema de medição de temperatura da reação 105

Figura 33 - Detalhe do sistema de medição da vazão de gás para o 106 sistema de remoção de $\mathrm{CO}_{2}$. (a) Annubar; (b) Instrumento de medição da pressão diferencial

Figura 34 - Sistema de medição da vazão de clorados para o sistema 107 de gás de reciclo. (a) Orifício integral; (b) Instrumento de 
medição da pressão diferencial.

Figura 35 - Detalhe do instrumento de medição de pressão da reação 108

Figura 36 - Analisador de vazão de clorados para o sistema de gás de 109 reciclo

Figura 37 - Cromatógrafo de processo, modelo CG1000 MarK II 111

Figura 38 - Detalhe dos elementos de medição do cromatógrafo de 113 processo

Figura 39 - Detalhe do detector do cromatógrafo de processo 114

Figura 40 - Espectômetro de massa, modelo Questor IV 115

Figura 41 - (a) Analisador para óxido de etileno (cromatógrafo AT120D - modelo CG1000 Mark II); (b) Caixa quente para condicionamento da amostra

Figura 42 - Cromatograma típico das análises realizadas no 119 cromatógrafo AT120D

Figura 43 - Histograma (média e desvio-padrão) das Seletividades de processo ( $\mathrm{S} 1$ a S6, em \%) calculadas em função das concentrações dos componentes no gás de reciclo. (a) $S 1$; (b) S2; (c) S3; (d) S4; (e) S5; (f)S6

Figura 44 - Cartas de Valores Individuais das Variáveis de Processo medidas nesse estudo. (a) vazão de etileno (FC101) em $\mathrm{kg} / \mathrm{h}$; (b) vazão de oxigênio ( $\mathrm{FC103)} \mathrm{em} \mathrm{kg} / \mathrm{h}$; (c) vazão de gás de reciclo (FR121) em $t / h$; (d) temperatura da reação (TR124B) em ${ }^{\circ} \mathrm{C}$; (e) pressão da reação (PR121) em $\mathrm{kg} / \mathrm{cm}^{2} \mathrm{~g}$; (f) vazão de clorados (FR126) em t/h; (g) teor de clorados (Fator F) em \%; (h) vazão de alimentação do sistema de remoção de $\mathrm{CO}_{2}$ (FR121C) em kg/h

Figura 45 - Variáveis de Processo Codificadas. (a) vazão de oxigênio (X1); (b) vazão de gás de reciclo (X2); (c) temperatura da reação (X3); (d) teor de clorados (X4).

Figura 46 - Validação estatística do modelo matemático proposto Comparação da seletividade calculada via modelo e seletividade real do processo. Desvio $(\%)=($ Seletividade calculada - seletividade real) / Seletividade calculada

Figura 47 - Evolução da Seletividade média mensal do catalisador em função do seu tempo de operação (envelhecimento)

Figura 48 - Validação estatística do modelo matemático proposto, corrigido pelos efeitos do envelhecimento do catalisador Comparação da seletividade calculada via modelo e seletividade real do processo. Desvio $(\%)=($ Seletividade 
calculada - seletividade real) / Seletividade calculada

Figura 49 - Esquema simplificado do processo de competição entre 150 moléculas por um mesmo sítio ativo

Figura 50 - S Simulação do processo - Definição dos componentes que 152 fazem parte do sistema

Figura 51 - Simulação do processo - Definição do modelo de 153 propriedades termodinâmicas

Figura 52 - Simulação do processo - Definição dos blocos e tipo de 155 reator

Figura 53 - Simulação do processo - Definição das reações e 156 parâmetros cinéticos que representam o processo

Figura 54 - Simulação do processo - Definição das especificações do 157 processo

Figura 55 - Simulação do processo - Definição das especificações do 158 processo

Figura 56 - Simulação do processo - Simulação preliminar do processo

Figura 57 - Simulação do processo - Análise de sensibilidade do modelo às variações de vazão de alimentação de oxigênio no processo e temperatura da reação

Figura 58 - Simulação do processo - Análise de sensibilidade do modelo às variações de vazão de alimentação de oxigênio no processo e temperatura da reação

Figura 59 - Simulação do processo - Resultado de uma simulação do processo

Figura 60 - Comportamento da seletividade da reação obtida via 162 simulação de processo

Figura 61 - $\quad 1^{\underline{a}}$ análise exploratória do modelo da equação $71 \quad 171$

Figura 62 - $\quad$ 2a análise exploratória do modelo da equação $71 \quad 176$

Figura 63 - $\quad$ 3a análise exploratória do modelo da equação $71 \quad 180$

Figura 64 - $\quad$ 4aa análise exploratória do modelo da equação $71 \quad 184$

Figura 65 - $\quad$ 5ª análise exploratória do modelo da equação $71 \quad 188$

Figura 66 - 6 6 análise exploratória do modelo da equação 71 


\section{LISTA DE TABELAS}

Tabela 1 - Principais aplicações dos derivados do óxido de etileno

Tabela 2 - Número de unidades produtivas implantadas em função da capacidade de produção (mil t/ano) e da data de início das operações

Tabela 3 - Principais Propriedades Físico-Químicas do Óxido de etileno

Tabela 4 - Intervalos típicos para as variáveis de processo (produção de óxido de etileno via Processo de Oxidação Direta)

Tabela 5 - Equações para o cálculo das Seletividades S1 a S6 da reação de formação de óxido de etileno

Tabela 6 - Estequiometria das reações de oxidação do Etileno

Tabela 7 - Principais propriedades Físico Químicas do Cloreto de Etila (inibidor da reação)

Tabela 8 - Teste de Pearson para a verificação das correlações entre variáveis duas a duas mostradas na matriz de correlação

Tabela 9 - Dados técnicos do Reator de produção de óxido de etileno

Tabela 10 - Variáveis de Processo Coletadas no estudo

Tabela 11 - Variáveis Analíticas Coletadas no estudo

Tabela 12 Variáveis Analíticas que Monitoram a Concentração de óxido de etileno

Tabela 13 - Representação (parcial) dos dados analíticos coletados no processo (em concentrações mássicas)

Tabela 14 - Correlação entre os valores de Seletividade obtidos via medições em Analisadores de Processo

Tabela 15 - Correlações (coeficiente de Pearson) para as variáveis de processo do estudo

Tabela 16 - Codificação das variáveis de processo

Tabela 17 - $\quad$ Análise de Modelos de Regressão Possíveis para o 138 Processo

Tabela 18 - Coeficientes do modelo de regressão multilinear 
Tabela 20 - Codificação das variáveis (modelo de regressão com 140 interações)

Tabela 21 - Análise de Modelos de Regressão (considerando efeitos de interação entre variáveis) possíveis para o processo

Tabela 22 - Coeficientes do modelo de regressão multilinear (considerando interações entre variáveis e coeficientes quadráticos)

Tabela 23 - Análise de variância do modelo de regressão multilinear (considerando interações entre variáveis e coeficientes quadráticos)

Tabela 24 - Parte dos dados para validação estatística do modelo matemático proposto

Tabela 25 - Parâmetros cinéticos das equações de oxidação do etileno

Tabela 26 - Resultados da Simulação do processo de oxidação de etileno

Tabela $27-\quad 1^{\mathrm{a}}$ análise exploratória do modelo e seus objetivos

Tabela 28 - Níveis das variáveis de processo em unidades codificadas e valores reais de processo $\left(1^{\text {a }}\right.$ análise exploratória do modelo)

Tabela 29 - $\quad 2^{\mathrm{a}}$ análise exploratória do modelo e seus objetivos

Tabela 30 - Níveis das variáveis de processo em unidades codificadas e valores reais de processo $\left(2^{\mathrm{a}}\right.$ análise exploratória do modelo)

Tabela $31-\quad 3^{\mathrm{a}}$ análise exploratória do modelo e seus objetivos

Tabela 32 - Níveis das variáveis de processo em unidades codificadas e valores reais de processo $\left(3^{\mathrm{a}}\right.$ análise exploratória do modelo)

Tabela 33 - $\quad 4^{a}$ análise exploratória do modelo e seus objetivos

Tabela 34 - Níveis das variáveis de processo em unidades codificadas e valores reais de processo $\left(4^{\mathrm{a}}\right.$ análise exploratória do modelo)

Tabela $35-\quad 5^{\mathrm{a}}$ análise exploratória do modelo e seus objetivos

Tabela 36 - Níveis das variáveis de processo em unidades codificadas e valores reais de processo $\left(5^{\mathrm{a}}\right.$ análise exploratória do modelo)

Tabela 37 - $\quad 6^{a}$ análise exploratória do modelo e seus objetivos 
Tabela 38 - Níveis das variáveis de processo em unidades codificadas e valores reais de processo $\left(6^{a}\right.$ análise exploratória do modelo)

Tabela 39 - Resumo dos resultados da análise dos modelos 194 desdobrados (direção a ser adotada para cada variável na busca da máxima seletividade) 


\section{LISTA DE ABREVIATURAS e SIGLAS}

A Reagente de uma reação química qualquer do tipo $A+B \Leftrightarrow C+D$

a Coeficiente estequiométrico do reagente de uma reação química genérica do tipo $\mathrm{a} A+\mathrm{bB} \Leftrightarrow \mathrm{cC}+\mathrm{dD}$ ou Coeficiente da equação y $=a^{*} x+b$

$\mathrm{A}_{12}, \mathrm{~A}_{21} \quad$ Parâmetros de ajuste do modelo termodinâmico de Wilson

adj adjacente

ads Adsorvido

AR101 Concentração de oxigênio: gás de reciclo alimentando o reator

AR105 Concentração de oxigênio: gás de reciclo efluente do reator

AR114a Concentração de etileno: gás de reciclo que alimenta o reator

AR114b Concentração de $\mathrm{CO}_{2}$ : gás de reciclo que alimenta o reator

AR114c Concentração de etileno: gás de reciclo efluente do reator

AR114d Concentração de $\mathrm{CO}_{2}$ : gás de reciclo efluente do reator

AR120D Concentração de óxido de etileno: gás de reciclo alimentando reator

AR120E Concentração de óxido de etileno: gás de reciclo efluente do reator

B

Reagente de uma reação química qualquer do tipo $A+B \Leftrightarrow C+D$

b

Coeficiente estequiométrico do reagente de uma reação quíica genérica do tipo $a A+b B \Leftrightarrow c C+d D$ ou Coeficientes da equação y $=\mathrm{a}^{*} \mathrm{x}+\mathrm{b}$

$\mathrm{B}_{0}, \mathrm{~B}_{1}, \ldots, \mathrm{B}_{\mathrm{k}} \quad$ Coeficientes das Variáveis Independentes de um Processo Real

C Produto de uma reação química qualquer do tipo $A+B \Leftrightarrow C+D$

c Coeficiente estequiométrico do produto de uma reação química genérica do tipo $\mathrm{a} A+\mathrm{bB} \Leftrightarrow \mathrm{cC}+\mathrm{dD}$

$C_{A}, C_{B}, \quad$ Concentração dos componentes $A, B, C, D$ envolvidos em uma $C_{C}, C_{D} \quad$ reação química genérica do tipo $A+B \Leftrightarrow C+D$

cat. Catalisador

Cp ou C-p Estatística Cp de Malows

D Produto de uma reação química qualquer do tipo $A+B \Leftrightarrow C+D$

d Coeficiente estequiométrico do produto de uma reação química genérica do tipo $\mathrm{a} A+\mathrm{bB} \Leftrightarrow \mathrm{cC}+\mathrm{dD}$ 

DCE Dicloroetano
E ou Ea Energia de ativação de uma reação
EC Cloreto de etila
Fator $\mathrm{F} \quad$ Teor de clorados na corrente de gás de reciclo
FC101 Vazão de etileno
FC103 Vazão de oxigênio
FCS Field Control Station
FR121A Vazão de gás de reciclo
FR121C Vazão de alimentação de gás de reciclo para o sistema de remoção de CO2
FR126 Vazão de clorados
gE Energia de excesso de Gibbs
GL Número de graus de liberdade de um conjunto de dados.
gIE Número de graus de liberdade com o qual o erro quadrático do modelo de regressão é estiado
gltotal Número total de graus de liberdade de uma amostra
H Entalpia
H0 Hipótese a ser testada estatisticamente (regressão não é significativa)
H1 Hipótese alternativa a ser testada estatisticamente (regressão é significativa)
HIS Human Interface Station
i Número de amostras de um conjunto de dados ou Intervalo de validade ou análise de um conjunto de dados
k ou ki Constante cinética de uma reação química qualquer
k1 Constante cinética da reação de oxidação do etileno a óxido de etileno
k2 Constante cinética da reação de oxidação do etileno a $\mathrm{CO} 2$ e H2O
k3 Constante cinética da reação de oxidação do óxido de etileno a $\mathrm{CO} 2$ e $\mathrm{H} 2 \mathrm{O}$
KE Constante de adsorção para o componente etileno
Ki Constante de equilíbrio de uma reação 
LI Valor estatístico do limite inferior de um conjunto de dados

LS Valor estatístico do limite superior de um conjunto de dados

MC Cloreto de metila

MSEm Média de desvios quadráticos do erro para um modelo com $\mathrm{m}$ preditores

n Número total de dados analisados em um processo ou Número de moléculas de um determinado componente ou Ordem de uma reação

N Numero de observações em um modelo

nãoadj Não adjacente

$\mathrm{p}$

Parâmetro estatístico que representa a significância do estudo de um dado modelo de regressão ou pressão utilizada na representação da equação de estado de Peng Robinson ou pressão de um sistema

P Pressão absoluta de um sistema ou número de variáveis utilizadas em um modelo +1

Pc Pressão crítica

PR121 Pressão da reação

PRESS Prediction Error Sum of Squares

Q1 Valor estatístico do primeiro quartil de um conjunto de dados

Q3 Valor estatístico do terceiro quartil de um conjunto de dados

$\mathrm{R} \quad \mathrm{R}=$ (valor máximo da variável no conjunto de dados + valor mínimo da variável no conjunto de dados) / 2 ou Constante universal dos gases

$r \quad$ Coeficiente de correlação de Pearson entre duas variáveis

$\mathrm{R}^{\star} \quad$ (valor máximo da variável no conjunto de dados - valor mínimo da variável no conjunto de dados) / 2

$\mathrm{R}_{\mathrm{a}, \mathrm{p}}^{2} \quad$ Coeficiente de Determinação (ajustado) de um modelo de regressão

$\mathrm{R}_{\mathrm{p}}^{2}$ ou $\mathrm{R}^{2} \quad$ Coeficiente de Determinação de um modelo de regressão

S Sítio ativo ou Seletividade (genérica) da reação de formação de óxido de etileno

S1,S2,S3, Seletividades da reação de formação de óxido de etileno $\mathrm{S} 4, \mathrm{~S} 5, \mathrm{~S} 6$ 
$S^{2} \quad$ Erro quadrático médio residual

SDCD Sistema Digital de Controle Distribuído

Si Seletividade da reação calculada por uma dada equação específica i

SQR Soma dos quadrados dos resíduos

SQT Soma total dos quadrados

SS Soma do quadrado da diferença entre o valor individual e valor médio de um conjunto de dados

SSE Soma dos desvios quadráticos de um modelo de regressão devido ao erro

SSEp Soma de desvios quadráticos médios dos valores gerados em um modelo

SSfator Soma dos desvios quadráticos de um modelo de regressão devido erro residual

SSmodelo Soma dos desvios quadráticos total de um modelo de regressão

SStotal Soma dos desvios quadráticos totais de um modelo de regressão

T Temperatura ou indicação de matriz transposta

Tc Temperatura crítica

$\operatorname{Tr} \quad$ Temperatura reduzida

TR124B Temperatura da reação

U $\quad$ Energia interna de um sistema

V Volume de um sistema

Var $\mathrm{x}_{\mathrm{i}} \quad$ Variância do conjunto de dados (variável $\mathrm{x}_{\mathrm{i}}$ ).

VC Cloreto de vinila

$\mathrm{Vi} \quad$ Volume molar de um componente puro

Vm Volume molar

X Matriz de observação das variáveis independentes de um conjunto de dados

X1 Vazão de oxigênio

X2 Vazão de gás de reciclo

X3 Temperatura da reação 


$\begin{array}{ll}X_{4} & \text { Teor de clorados } \\ X_{i} & \text { Variável qualquer } \\ x_{i} & \begin{array}{l}\text { Variável independente de um modelo de regressão ou valor } \\ \text { qualquer em um conjunto de dados ou componente } \mathrm{i} \text { em um } \\ \text { conjunto de componentes de uma mistura }\end{array} \\ & \begin{array}{l}\text { Conjunto de dados que representam uma matriz de um modelo de } \\ \text { regressão }\end{array} \\ x_{m} & \text { Valor médio de um conjunto de dados } \\ Y & \begin{array}{l}\text { Matriz de observação das variáveis dependentes de um conjunto } \\ \text { de dados }\end{array} \\ y_{\text {est }} & \begin{array}{l}\text { Valor estimado da variável dependente pelo modelo de regressão } \\ Y_{i}\end{array} \\ y_{i} & \begin{array}{l}\text { Resultados da Variável Dependente (i) de um Modelo de } \\ \text { Regressão }\end{array} \\ & \begin{array}{l}\text { Valor real da variável dependente observada em um conjunto de } \\ \text { dados ou valor qualquer em um conjunto de dados ou componente } \\ \text { i em um conjunto de componentes de uma mistura }\end{array} \\ & \text { Fator de compressibilidade }\end{array}$




\section{LISTA DE LETRAS GREGAS}

$\Delta \quad$ Variação

$\Sigma \quad$ Somatório de um conjunto de dados

$\beta_{0}, \beta_{1}, \ldots, \beta_{k}$ Estimativas dos Coeficientes de um modelo de regressão

$\beta_{\mathrm{M}} \quad$ Matriz dos Coeficientes de Regressão

$\varepsilon \quad$ Erro Experimental de um modelo de regressão

$\varepsilon \mathrm{M} \quad$ Matriz dos erros de um conjunto de dados em estudo para se determinar um modelo de regressão

$\omega \quad$ Fator acêntrico

yi Coeficiente de atividade de um componente de uma mistura

$\lambda$ ij Parâmetro relacionado à energia de interação entre componentes de uma mistura, utilizado na representação do modelo termodinâmico de Wilson 


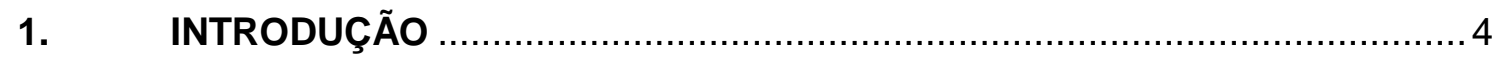

2. OBJETIVOS

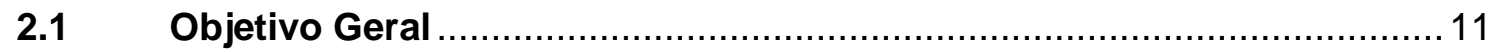

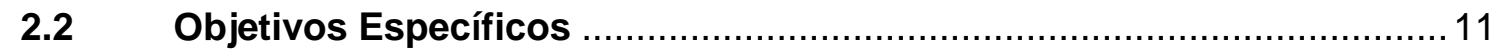

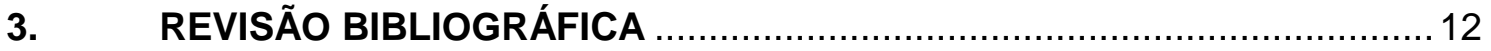

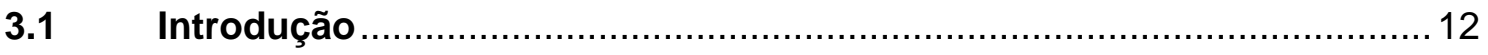

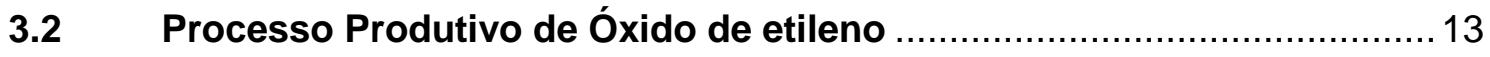

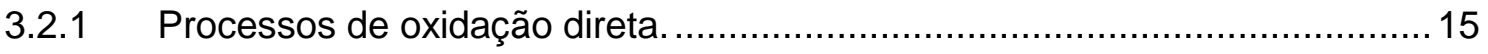

3.2.2 Processo de oxidação direta à base de ar ..................................................16

3.2.3 Processo de oxidação direta à base de oxigênio ........................................... 19

3.3 Mecanismos de Reação de Formação de Óxido de etileno …………......25

3.4 Conceitos para Gerenciamento de Unidades Produtivas de Óxido de

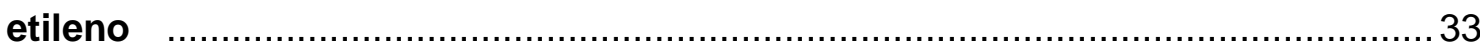

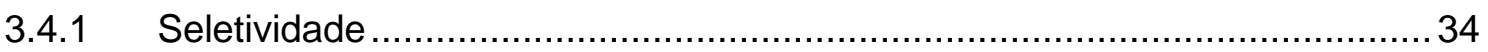

3.4.1.1 Dedução das equações para o cálculo da Seletividade da reação de

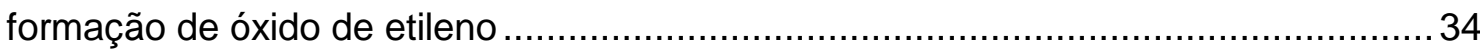

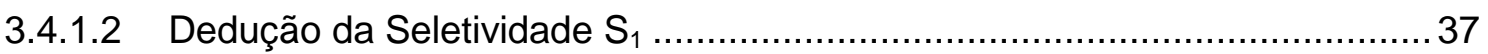

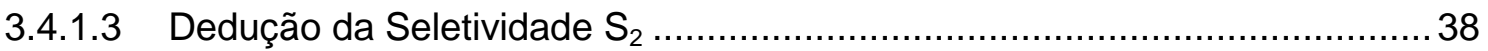

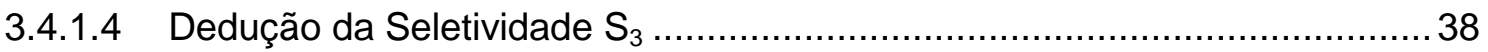

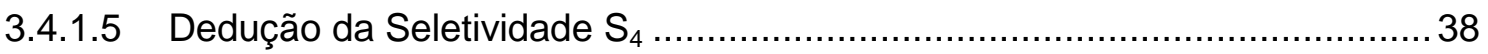

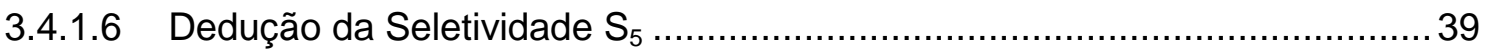

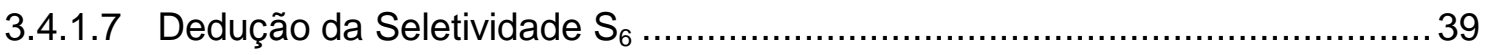

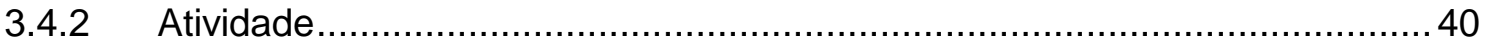

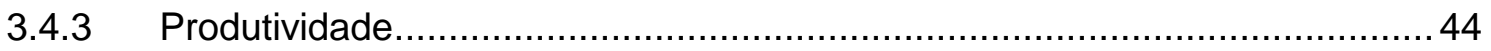

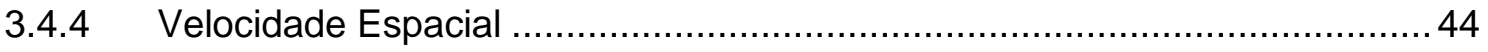

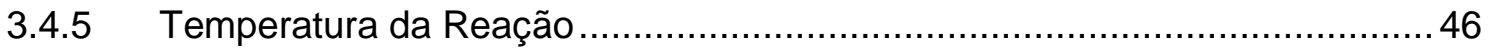

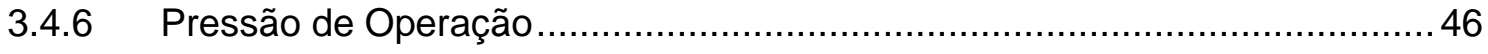

3.4.7 Qualidade das Matérias Primas ..................................................................

3.4.8 Segurança do Processo de produção de óxido de etileno ………………..... 48

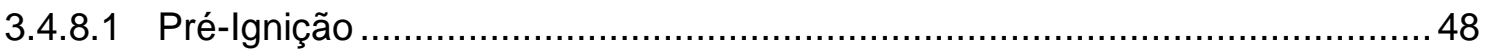

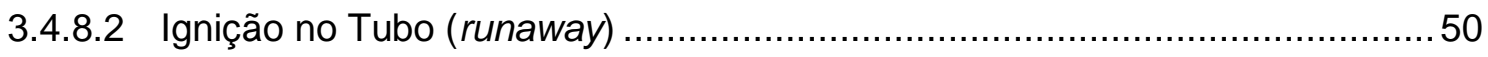




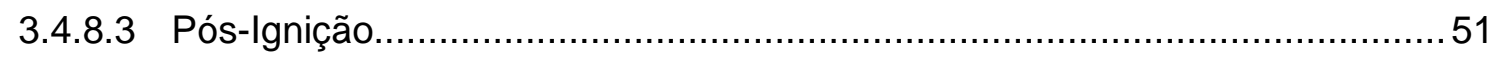

3.5 Reatores para produção de Óxido de etileno ….................................... 52

3.5.1 Simulação de reatores de produção de óxido de etileno...............................54

3.6 Catalisadores para os Processos de Produção de óxido de etileno ......60

3.7 Inibidores da Reação Secundária (elevação da Seletividade da reação de

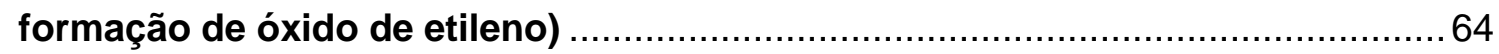

3.8 Métodos estatísticos: análise de um conjunto de dados multivariados. 69

3.8.1 Avaliação Estatística de Dados............................................................... 70

3.8.2 Construção de um Modelo de Regressão ................................................ 70

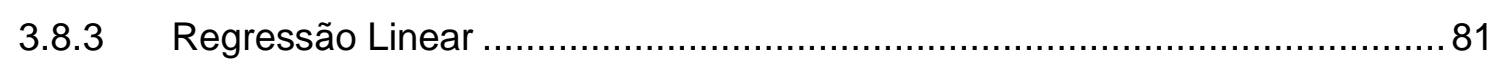

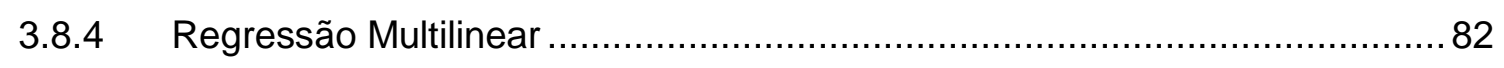

3.8.5 Equacionamento do Modelo de Regressão ............................................... 83

3.8.6 Diagnóstico da melhor adequação dos dados ao modelo .............................. 84

3.8.7 Coeficiente de Determinação.................................................................. 84

3.9 Síntese da Revisão Bibliográfica e Hipóteses Derivadas ....................... 86

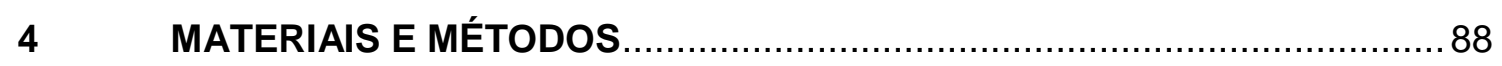

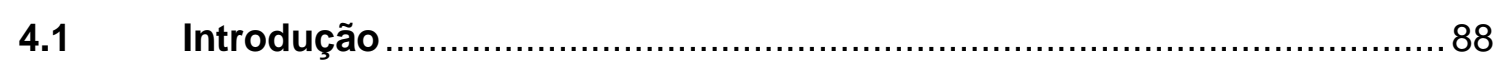

4.2 Descritivo do processo de Produção de óxido de etileno (Oxiteno S/A

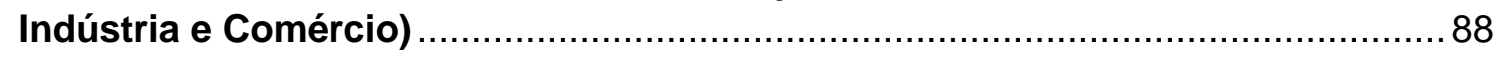

4.2.1 Reação e Absorção de óxido de etileno................................................... 89

4.3 Dados do Reator de produção de óxido de etileno ..................................93

4.4 Seleção de variáveis para o estudo........................................................ 94

4.4.1 SDCD - Sistema Digital de Controle Distribuído.......................................... 94

4.4.1.1 SDCD - Subsistema de Aquisição de Dados e Controle .............................. 95

4.4.1.2 Subsistema de Comunicação ….......................................................... 96

4.4.1.3 Subsistema de Monitoração e Operação ..................................................... 97

4.4.1.4 Subsistema de Supervisão e Otimização....................................................... 98

4.5 Metodologia para coleta e análise de dados do processo produtivo .....98

4.5.1.1 Descrição das medições realizadas no processo produtivo ...........................99

4.5.1.1.1 Medição da vazão de Alimentação de etileno para o Reator ......................... 99

4.5.1.1.2Medição da vazão de Alimentação de oxigênio para o Reator...................... 100

4.5.1.1.3Medição da vazão de Gás de Reciclo para o Reator ................................... 103

4.5.1.1.4 Medição da Temperatura da Reação...................................................... 104

4.5.1.1.5Medição da Vazão de Gás para o Sistema de Remoção de $\mathrm{CO}_{2}$................ 105

4.5.1.1.6 Medição da Vazão de Clorados ............................................................. 106

4.5.1.1.7 Medição da Pressão de Reação ......................................................... 107 
4.5.2 Coleta de dados relacionados às Análises do Processo (Composição do Gás de Reciclo)

4.5.2.1 Medição da composição da corrente de gás de reciclo via Cromatografia gasosa

4.5.2.2 Medição da composição da corrente de gás de reciclo via Espectômetro de Massa

4.5.2.3 Medição da composição de óxido de etileno na corrente de gás de reciclo 116

4.5.3 Metodologia para Análise Estatística dos Dados e Tratamento dos Resultados Obtidos

4.5.3.1 Eliminação de Dados Inconsistentes ....................................................... 122

4.5.3.2 Eliminação de Outliers...................................................................... 123

4.5.3.3 Avaliação de Correlações entre Variáveis ............................................. 124

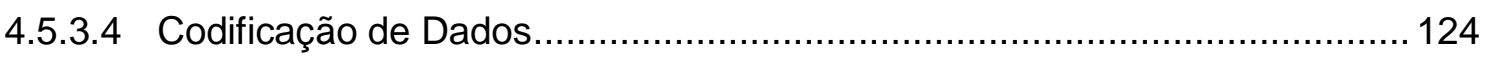

4.5.3.5 Modelos de Regressão Multilinear ...................................................... 125

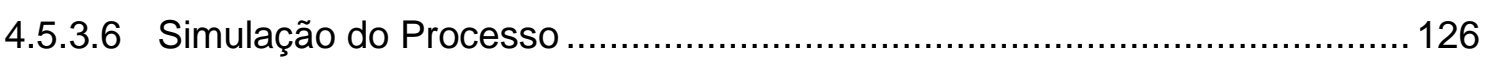

4.5.3.7 Análise exploratória do modelo empregando a metodologia de superfície de

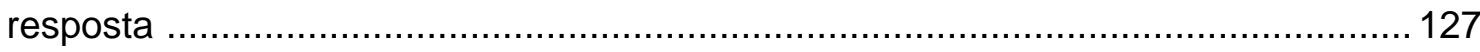

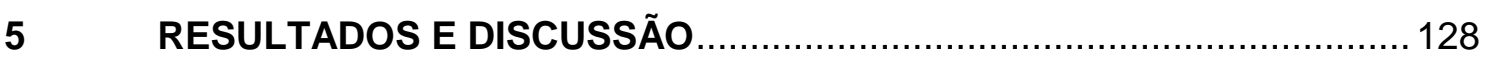

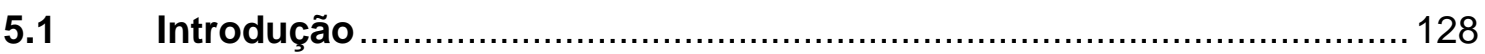

5.2 Análise Estatística dos Dados Analíticos e de Processo ...................... 128

5.2.1 Análises da Composição do Gás de Reciclo............................................. 128

5.2.2 Análise da Seletividade da Reação ...................................................... 129

5.2.3 Análise das Variáveis de Processo ........................................................... 132

$5.3 \quad$ Modelos de Regressão Multilnear ......................................................... 136

5.3.1 Validação do Modelo Matemático Proposto ............................................... 143

5.3.2 Validação Estatística do Modelo Matemático Proposto.................................. 144

5.3.3 Validação Fenomenológica do Modelo Matemático Proposto ...................... 150

5.4 Análise Global do Modelo de Regressão ............................................. 163

5.5 Análise Exploratória do Modelo de Regressão .................................... 168

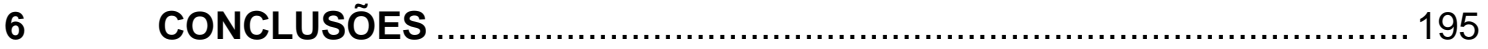

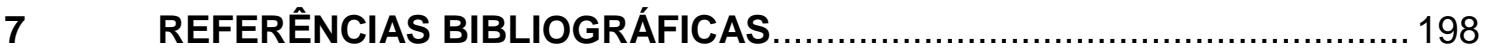




\section{INTRODUÇÃO}

A utilização da molécula de óxido de etileno para fins industriais data do período da Primeira Guerra Mundial, que representa também o nascimento da indústria Petroquímica.

Durante esse período, marcado por uma série de inovações na Indústria Petroquímica, o etileno, gerado em pequenas escalas de produção, apresentava um grande interesse, por ser uma das principais matérias primas utilizadas na produção de gás mostarda.

Os primeiros anos do Pós Guerra foram caracterizados por uma fase de depressão econômica e queda significativa das inovações na Indústria. Entretanto, existiram exceções, como a BASF, que iniciou as primeiras produções em escala industrial do Metanol em 1923 e a Carbide, que neste mesmo ano iniciou a construção do maior complexo Petroquímico até então existente (QUINTELLA, 1993).

Em 1925, a produção em escala industrial de uma série de derivados do Etileno já estava consagrada como indicado na Figura 1 (QUINTELLA, 1993). 


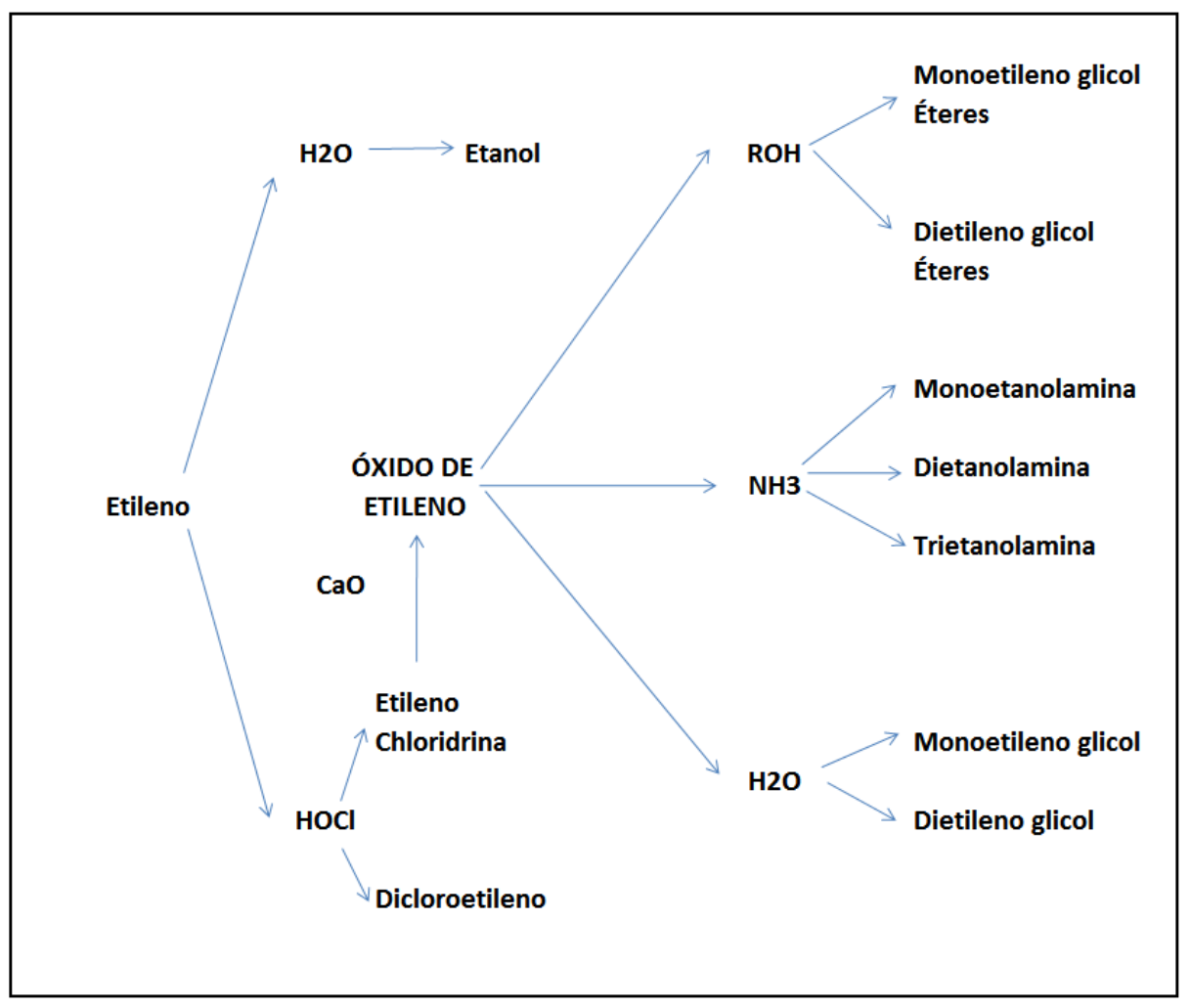

Figura 1 - Primeiras cadeias produtivas derivadas do etileno

A alta reatividade da molécula de óxido de etileno, originária da facilidade da quebra entre as ligações carbono e oxigênio, fez com que a reação dessa molécula com várias outras substâncias fosse estudada ao longo de décadas, permitindo dessa forma a síntese de um grande número de compostos com vasta gama de aplicações industriais, como mostrado na Tabela 1 (OXITENO S/A INDÚSTRIA E COMÉRCIO, 2001).

Tabela 1 - Principais aplicações dos derivados do óxido de etileno

\begin{tabular}{|c|l|}
\hline$\frac{\text { Família de }}{\text { Produtos }}$ & \multicolumn{1}{|c|}{ Aplicações } \\
\hline Etileno glicóis & $\begin{array}{l}\text { Intermediários de síntese para fios, fibras e garrafas de poliéster } \\
(\mathrm{PET}), \text { anticongelantes, resinas para barcos e piscinas, plastificantes, } \\
\text { líquidos para freios, fluidos de refrigeração e arrefecimento. }\end{array}$ \\
\hline
\end{tabular}


(continuação)

\begin{tabular}{|c|c|}
\hline$\frac{\text { Família de }}{\text { Produtos }}$ & Aplicações \\
\hline Etanolaminas & $\begin{array}{l}\text { Agentes de absorção para gases industriais, alcalinizantes para óleos } \\
\text { lubrificantes, detergentes, cosméticos e intermediários de síntese } \\
\text { para alcanolamidas }\end{array}$ \\
\hline $\begin{array}{l}\text { Éteres } \\
\text { glicólicos }\end{array}$ & $\begin{array}{l}\text { Solventes para tintas e vernizes, tíneres, detergentes e componentes } \\
\text { para fluidos de freios. }\end{array}$ \\
\hline $\begin{array}{l}\text { Acetatos de } \\
\text { éteres } \\
\text { glicólicos }\end{array}$ & $\begin{array}{l}\text { Solventes para tintas e vernizes para diversas aplicações (couro, } \\
\text { madeira, metal, etc.) e tíneres. }\end{array}$ \\
\hline $\begin{array}{l}\text { Alquilfenóis } \\
\text { etoxilados }\end{array}$ & $\begin{array}{l}\text { Tensoativos não-iônicos utilizados em formulações de detergentes, } \\
\text { ceras, óleos lubrificantes, defensivos agrícolas, cosméticos, resinas, } \\
\text { polímeros, tintas, lubrificantes, auxiliares na indústria têxtil, de couros, } \\
\text { de cerâmica, de papel e celulose, auxiliar para extração de petróleo e } \\
\text { minérios. }\end{array}$ \\
\hline $\begin{array}{l}\text { Álcoois graxos } \\
\text { etoxilados }\end{array}$ & $\begin{array}{l}\text { Tensoativos não-iônicos utilizados em formulações de detergentes, } \\
\text { cosméticos, tintas, defensivos agrícolas, auxiliares nas indústrias } \\
\text { têxteis, de couros e intermediários de síntese para tensoativos } \\
\text { aniônicos. }\end{array}$ \\
\hline $\begin{array}{l}\text { Esteres de } \\
\text { sorbitan } \\
\text { etoxilados }\end{array}$ & $\begin{array}{l}\text { Emulsionantes utilizados na indústria de cosméticos, óleos } \\
\text { lubrificantes, fragrâncias, têxteis, aditivos para as indústrias de } \\
\text { alimentos e farmacêutica. }\end{array}$ \\
\hline $\begin{array}{l}\text { Polietileno } \\
\text { glicóis }\end{array}$ & $\begin{array}{l}\text { Umectantes e agentes de consistência em formulações de } \\
\text { cosméticos, fármacos, plásticos e resinas, desmoldante para } \\
\text { borracha, estabilizante dimensional para madeira, aditivo para óleos } \\
\text { lubrificantes e auxiliar de processo para cerâmica }\end{array}$ \\
\hline $\begin{array}{c}\text { Aminas graxas } \\
\text { etoxiladas }\end{array}$ & $\begin{array}{l}\text { Adjuvantes para defensivos agrícolas, antiestáticos para resinas, } \\
\text { emulsionantes e lubrificantes para produtos auxiliares têxteis }\end{array}$ \\
\hline $\begin{array}{l}\text { Ácidos graxos } \\
\text { etoxilados }\end{array}$ & $\begin{array}{l}\text { Emulsionantes para a indústria de cosméticos, aditivos para } \\
\text { alimentos, tratamento de água, óleos lubrificantes e auxiliares têxteis }\end{array}$ \\
\hline $\begin{array}{l}\text { Copolímeros } \\
\text { etoxilados e } \\
\text { propoxilados }\end{array}$ & $\begin{array}{l}\text { Tensoativos de baixa espuma para tratamento de água, detergentes } \\
\text { especiais, polímeros e tintas auxiliares de processo para a indústria } \\
\text { têxtil e de sucro-álcool e auxiliar para extração de petróleo }\end{array}$ \\
\hline & s de poliuretano \\
\hline
\end{tabular}


A capacidade produtiva de óxido de etileno tem apresentado um crescimento substancialmente maior que a demanda por esse produto e seus derivados ao longo dos últimos anos.

Especialmente a Ásia e Oriente Médio têm contribuído para esse aumento da oferta do produto, uma vez que, novas unidades com elevadas capacidades produtivas têm sido inauguradas nessas regiões, fazendo com que a competição entre as empresas na conquista de novos clientes e market share se torne ainda mais acirrada.

A Figura 2 mostra a grande expansão da capacidade produtiva nessas duas regiões, quando comparadas ao resto do mundo (CLARKE, 2011).

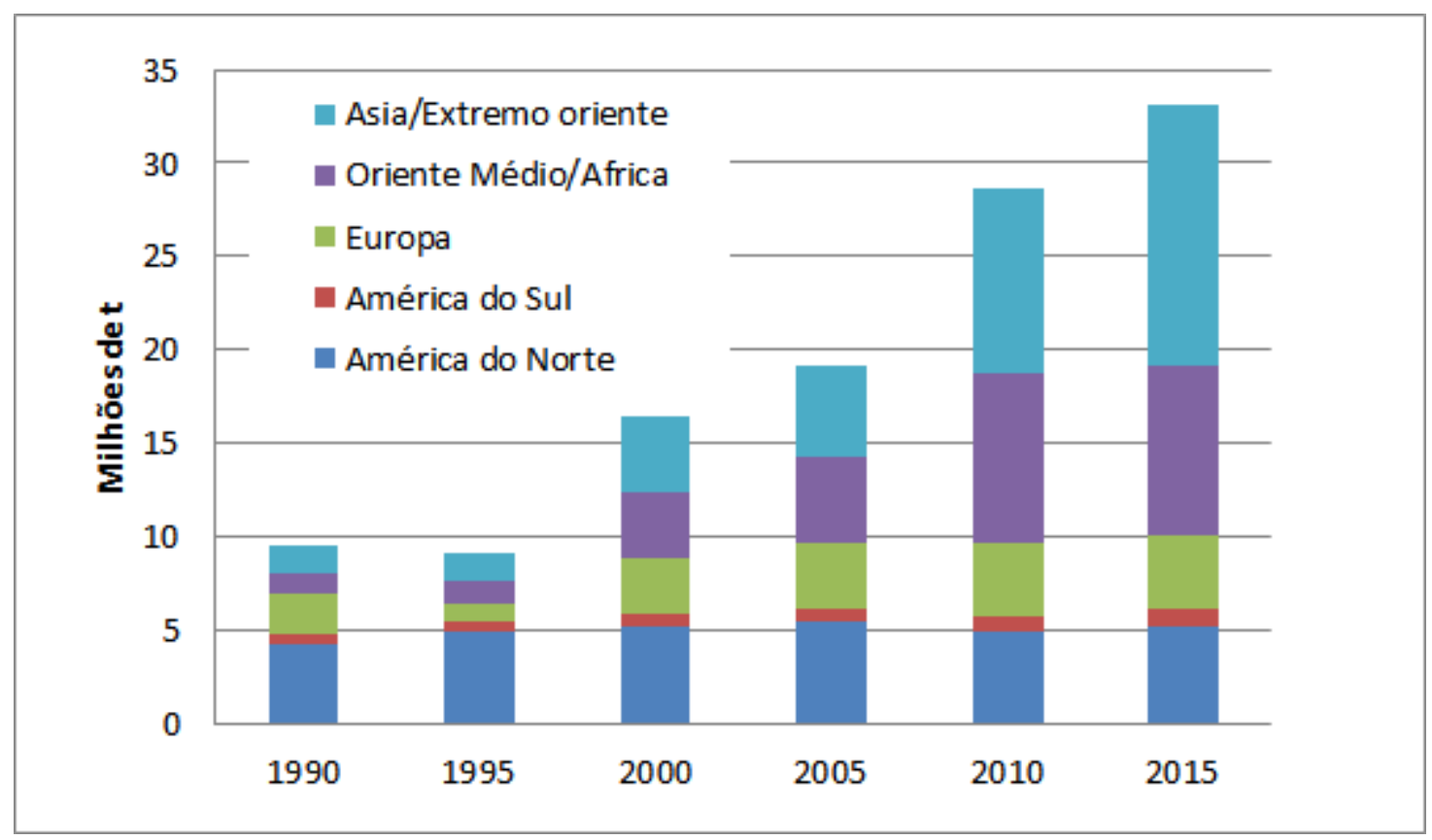

Figura 2 - Evolução da capacidade produtiva de óxido de etileno por regiões produtoras.

A Figura 3 demonstra uma tendência de diversificação do uso da molécula quando se analisa uma evolução ao longo de 15 anos, reforçando sua importância na indústria Química. 
Produção / Consumo 2000

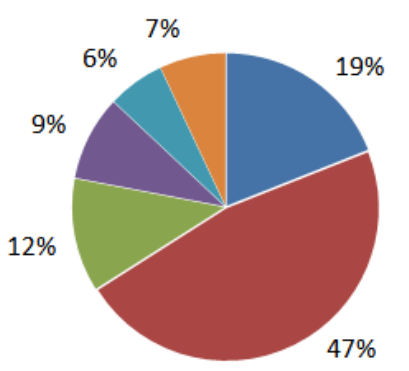

\section{Produção / Consumo 2015}

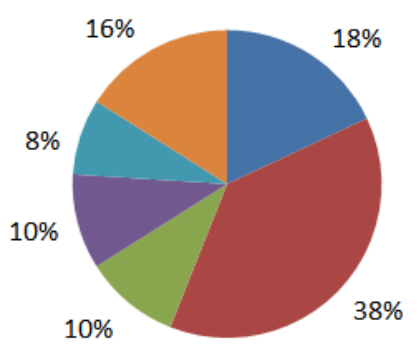

Etanolaminas

Etoxilados

Éter Glicólico

Etoxilados com

várias hidroxilas

Polietilenoglicol

Outros

Figura 3 - Distribuição de Consumo da molécula de óxido de etileno para produção de seus derivados (adaptado de Clarke, 2011).

A Tabela 2 também mostra a tendência de novas unidades produtivas serem projetadas para capacidades produtivas elevadas, dificultando a competitividade de unidades implantadas antes dos anos 2000. Em um cenário como este, a busca por melhorias contínuas na eficiência desse processo produtivo passa a ser fator chave para o sucesso das empresas que competem pela conquista desse mercado consumidor.

Tabela 2 - Número de unidades produtivas implantadas em função da capacidade de produção (mil t/ano) e da data de início das operações (adaptado de Clarke, 2011)

\begin{tabular}{|c|c|c|c|c|c|c|c|c|}
\hline \multirow[b]{2}{*}{$\begin{array}{l}\text { Data de partida da } \\
\text { unidade }\end{array}$} & \multicolumn{7}{|c|}{ CAPACIDADE (mil t) } & \multirow[b]{2}{*}{$\begin{array}{c}\text { Total de } \\
\text { unidades } \\
\text { Produtivas }\end{array}$} \\
\hline & $0-100$ & $101-200$ & 201-300 & $301-400$ & $401-500$ & $501-600$ & $\begin{array}{c}\text { maior } \\
\text { que } 600\end{array}$ & \\
\hline $1964-1965$ & 1 & & & & & & & 1 \\
\hline $1966-1970$ & 1 & 2 & 1 & & 1 & & & 5 \\
\hline $1971-1974$ & 6 & 2 & 3 & 1 & & & & 12 \\
\hline $1976-1980$ & 4 & 5 & 2 & 2 & & & & 13 \\
\hline 1981-1985 & 5 & 4 & 4 & 2 & & & & 15 \\
\hline $1986-1990$ & & 3 & 3 & & 1 & & & 7 \\
\hline 1991-1995 & 10 & 7 & 3 & 1 & 2 & & & 23 \\
\hline $1996-2000$ & 3 & 6 & 1 & 3 & 1 & & & 14 \\
\hline $2001-2005$ & 0 & 0 & 2 & 1 & & & 1 & 4 \\
\hline $2006-2010$ & 3 & 0 & 5 & 4 & 0 & 2 & 6 & 20 \\
\hline
\end{tabular}

Analisando especificamente a produção de óxido de etileno na América do Sul (realizada exclusivamente na Oxiteno S/A Indústria e Comércio), é possível notar (Figura 2) que a participação do continente no contexto mundial é pequena, mesmo com expansões de capacidades realizadas recentemente de modo a reduzir o volume de importações de produtos derivados de óxido de etileno. $O$ cenário futuro não prevê novas expansões em um curto espaço de 
tempo, reforçando a necessidade de se buscar a máxima produtividade em unidades já existentes.

Apesar da demanda por óxido de etileno apresentar um incremento anual na América do Sul semelhante ao PIB brasileiro, onde está o maior mercado consumidor da região, as expansões previstas em plantas ao redor do globo (na maior parte das vezes com capacidades produtivas significativamente superiores a 90.000 t/ano) fazem com que a busca pela excelência operacional se torne questão de sobrevivência das empresas nesse mercado extremamente competitivo.

A unidade produtiva em estudo neste trabalho possui uma capacidade de produção de óxido de etileno de 90.000 t/ano, sendo o processo baseado na oxidação parcial do etileno (em fase gasosa) utilizando oxigênio como agente oxidante sobre um catalisador cuja fase ativa é a prata metálica depositada sobre um suporte inerte de alumina. Simultaneamente ocorre a reação de oxidação completa do etileno gerando $\mathrm{CO}_{2}$ e água. Também são formados traços de outros subprodutos, sendo os principais: acetaldeído, formaldeído e alguns ácidos carboxílicos.

A excelência operacional na produção de óxido de etileno pode ser entendida, nesse contexto, como a utilização dos recursos produtivos da forma mais eficiente possível, gerenciando as principais variáveis envolvidas no processo produtivo de modo a maximizar a produção de óxido de etileno (reação principal desse processo) e minimizar a formação de $\mathrm{CO}_{2}$ (de baixo valor comercial) e água.

Considerando que os principais custos envolvidos nesse processo estão relacionados ao consumo da matéria prima principal (etileno), uma gestão do processo, que favoreça a ocorrência da reação principal (formação de óxido de etileno), garante um custo competitivo para o processo, pois minimiza o consumo de etileno, focando o uso dessa matéria prima para a produção do produto de interesse comercial. 
A maximização da produção de óxido de etileno em relação à produção de $\mathrm{CO}_{2}$ e água representa a chamada seletividade da reação de formação de óxido de etileno. Nota-se, portanto, que a busca por incrementos na seletividade da reação é fator chave para obtenção de um desempenho (econômico e de produtividade) que permita a uma empresa um melhor posicionamento em relação às outras empresas que se beneficiam de seus custos mais baixos de produção, oriundos de suas elevadas capacidades instaladas e dos baixos custos de aquisição da matéria prima principal do processo, o etileno.

Este trabalho está estruturado da seguinte maneira: No próximo capítulo (2) estão definidos os objetivos geral e específico dessa pesquisa. No capítulo 3 é apresentada a revisão bibliográfica relativa a fundamentos teóricos envolvendo o processo de produção de óxido de etileno, bem como conceitos estatísticos utilizados ao longo do trabalho. No capítulo 4, Materiais e Métodos, é apresentada a metodologia de coleta de dados do processo em estudo e são mostrados os detalhes técnicos dos equipamentos e instrumentos utilizados para aquisição de dados. Nesse capítulo também é descrita toda a metodologia utilizada para o tratamento estatístico dos dados visando o atingimento dos objetivos previamente estabelecidos. No capítulo 5 são apresentados os resultados do trabalho e a discussão destes resultados perante a fenomenologia que engloba o processo produtivo em questão. Finalmente, no capítulo 6, apresentam-se as conclusões do trabalho e recomendações para trabalhos futuros sobre 0 assunto. $O$ capítulo 7 fecha essa pesquisa com 0 detalhamento das referências bibliográficas utilizadas. 


\section{OBJETIVOS}

\section{$2.1 \quad$ Objetivo Geral}

O trabalho tem por objetivo: Desenvolver um modelo matemático que represente o comportamento da seletividade da reação de formação de óxido de etileno em função das variáveis que apresentam maior influência sobre a seletividade.

\section{$2.2 \quad$ Objetivo Específico}

Uma vez atingido o objetivo geral do trabalho, busca-se também o seguinte objetivo específico: Definir uma metodologia de gerenciamento das variáveis do processo, de modo a manter a seletividade da reação em seu ponto ótimo durante o maior tempo possível, garantindo também a produtividade desejada para o processo.

Para se atingir esses objetivos, foram realizadas as seguintes atividades:

a) Coleta de dados de um processo produtivo real de óxido de etileno;

b) Análise estatística dos dados, utilizando-se das ferramentas: eliminação de dados inconsistentes com o processo produtivo, análise de regressão múltipla e seleção de variáveis;

c) Elaboração de modelo estatístico para explicar o comportamento da seletividade da reação;

d) Verificação da consistência fenomenológica do modelo empírico via simulação de processo;

e) Exploração do modelo estatístico proposto através da realização de experimentos em condições de interesse para a melhoria do processo com a menor variabilidade possível. 


\section{REVISÃO BIBLIOGRÁFICA}

\subsection{Introdução}

Este capítulo apresenta uma discussão do processo clássico de produção de óxido de etileno desenvolvido em escala industrial nas primeiras décadas do século $X X$ e dos seus fundamentos teóricos, bem como uma revisão bibliográfica em seis áreas específicas:

- Mecanismos de Reação de Formação de óxido de etileno, em que se busca explorar os fundamentos químicos relacionados aos resultados obtidos na seletividade da reação de formação de óxido de etileno.

- Catalisadores para os Processos de Produção de óxido de etileno, em que são descritos os fundamentos teóricos relacionados ao comportamento das reações envolvidas no processo.

- Inibidores da Reação Secundária (aumento da Seletividade da reação de formação de óxido de etileno). Este item busca mostrar a importância da gestão efetiva sobre o teor de clorados no processo produtivo em favor do aumento da seletividade do processo.

- Reatores para produção de óxido de etileno. Nessa etapa são discutidos, de forma simplificada, os principais modelos matemáticos envolvidos na modelagem, simulação e projeto de reatores de produção de óxido de etileno.

- Conceitos para Gerenciamento de Unidades Produtivas de óxido de etileno, em que são apresentados os principais conceitos operacionais relacionados à medição do desempenho do processo produtivo.

- Métodos estatísticos para análise de um conjunto de dados multivariados, em que são apresentados os conceitos, cálculos e metodologia de avaliação para obtenção de um modelo de regressão linear múltipla que represente de maneira satisfatória o comportamento do processo produtivo. 


\subsection{Processo Produtivo de Óxido de etileno}

Kirk-Othmer (2007) descreve com detalhes o processo produtivo de óxido de etileno, que foi inicialmente preparado em 1859, utilizando-se uma reação entre o hidróxido de potássio e a etilenocloridrina. No início do século XX (1914), o óxido de etileno passou a ser produzido em escala comercial, sendo inicialmente desenvolvidas duas rotas de produção: etilenocloridrina e oxidação direta. A oxidação catalítica do etileno foi descoberta em 1931 por Lefort e foi, gradualmente, substituindo o processo via etilenocloridrina.

O primeiro processo em escala industrial utilizando a tecnologia de oxidação direta do ar data de 1937 e foi desenvolvido pela Union Carbide, enquanto que a oxidação à base de oxigênio foi patenteada inicialmente pela Shell em 1958. As principais propriedades físico-químicas da molécula de óxido de etileno são listadas na Tabela 3 (THE DOW CHEMICAL COMPANY, 2008).

Tabela 3 - Principais Propriedades Físico Químicas do Óxido de etileno (adaptado de THE DOW CHEMICAL COMPANY, 2008)

\begin{tabular}{|c|c|}
\hline Estado Físico & Gás liquefeito \\
\hline Cor & Incolor \\
\hline Odor & Éter \\
\hline Ponto de Fusão / Pressão de vapor & $-112,6^{\circ} \mathrm{C} / 1095 \mathrm{mmHg}$ \\
\hline Peso molecular & 44,05 \\
\hline $\begin{array}{c}\text { Ponto de ebulição, } \\
(760 \mathrm{mmHg}, 300 \mathrm{mmHg}, 10 \mathrm{mmHg})\end{array}$ & $\begin{array}{c}10,73^{\circ} \mathrm{C},-11,0{ }^{\circ} \mathrm{C},-66,0{ }^{\circ} \mathrm{C}, \\
\text { respectivamente }\end{array}$ \\
\hline $\begin{array}{c}\text { Densidade do líquido } \\
\left(20^{\circ} \mathrm{C}, 10^{\circ} \mathrm{C}, 0^{\circ} \mathrm{C},-5^{\circ} \mathrm{C},-10^{\circ} \mathrm{C}\right)\end{array}$ & $\begin{array}{c}0,8697 \mathrm{~g} / \mathrm{ml}, 0,8969 \mathrm{~g} / \mathrm{ml}, 0,9039 \mathrm{~g} / \mathrm{ml}, \\
\text { respectivamente }\end{array}$ \\
\hline $\begin{array}{c}\text { Calor latente vaporização, } 760 \\
\mathrm{mmHg}\end{array}$ & $6,16 \mathrm{kcal} / \mathrm{mol}(271 \mathrm{kcal} / \mathrm{kg})$ \\
\hline Pressão de vapor $\left(20^{\circ} \mathrm{C}\right)$ & $1095 \mathrm{mmHg}$ \\
\hline
\end{tabular}

(continua) 
(continuação)

\begin{tabular}{|c|c|}
\hline Viscosidade, $\left(0^{\circ} \mathrm{C},-13^{\circ} \mathrm{C}\right)$ & 0,32 mPa.s, 0,28 mPa.s, respectivamente \\
\hline Solubilidade em água $\left(10^{\circ} \mathrm{C}\right)$ & Completa \\
\hline Ponto de fulgor, vaso fechado & $-57 \stackrel{\circ}{\mathrm{C}}$ \\
\hline Temperatura de auto-ignição no ar & $429^{\circ} \mathrm{C}$ \\
\hline $\begin{array}{l}\text { Limites de Inflamabilidade no ar } \\
\qquad\left(25^{\circ} \mathrm{C}, 1 \mathrm{~atm}\right)\end{array}$ & $\begin{array}{l}\text { O vapor do óxido de etileno é explosivo } \\
\text { quando misturado ao ar em } \\
\text { concentrações entre } 2,6 \text { e } 100 \% \text { e } \\
\text { decompõe-se explosivamente mesmo } \\
\text { na ausência de ar se for aquecido } \\
\text { acima de } 450^{\circ} \mathrm{C} \text {. }\end{array}$ \\
\hline $\begin{array}{l}\text { Solubilidade em Água } \\
\text { (volume/volume) }\end{array}$ & Completa \\
\hline Toxicidade & 270 mg/kg via cutânea DL 50 \\
\hline Reatividade & $\begin{array}{l}\text { Reage facilmente com água, aminas, } \\
\text { fenóis, álcoois, ácidos orgânicos, e } \\
\text { demais compostos contendo hidrogênio } \\
\text { ligado a oxigênio, nitrogênio ou enxofre. }\end{array}$ \\
\hline Temperatura crítica & $195,8^{\circ} \mathrm{C}$ \\
\hline Pressão crítica & $7191 \mathrm{kPa}(71 \mathrm{~atm})$ \\
\hline Volume crítico & $3,184^{*} 10^{-3} \mathrm{~m}^{3} / \mathrm{kg}$ \\
\hline Tensão superficial $\left(0^{\circ} \mathrm{C}\right)$ & $27,6 \mathrm{mN} / \mathrm{m}$ \\
\hline Calor específico $\left(10^{\circ} \mathrm{C}, 25^{\circ} \mathrm{C}\right)$ & $\begin{array}{c}0,471 \mathrm{cal} / \mathrm{g} \stackrel{\circ}{ } \mathrm{C}, 0,268 \mathrm{cal} / \mathrm{g}{ }^{\circ} \mathrm{C}, \\
\text { respectivamente }\end{array}$ \\
\hline Calor de combustão padrão & $-27649 \mathrm{~kJ} / \mathrm{kg}$ \\
\hline Calor de decomposição & $32,11 \mathrm{kcal} / \mathrm{mol}(1412,8 \mathrm{kcal} / \mathrm{kg})$ \\
\hline Calor de formação (gás ideal) & $-1194,8 \mathrm{~kJ} / \mathrm{kg}$ \\
\hline Calor de formação (líquido) & $-1766 \mathrm{~kJ} / \mathrm{kg}$ \\
\hline Calor de polimerização & $22 \mathrm{kcal} / \mathrm{mol}(968 \mathrm{kcal} / \mathrm{kg})$ \\
\hline Calor de fusão & $117,5 \mathrm{~kJ} / \mathrm{kg}$ \\
\hline Condutividade térmica líquido $\left(0^{\circ} \mathrm{C}\right)$ & $0,16 \mathrm{~W} / \mathrm{m}^{\circ} \mathrm{C}$ \\
\hline $\begin{array}{l}\text { Condutividade térmica do vapor } \\
\qquad\left(25^{\circ} \mathrm{C}\right)\end{array}$ & $0,012 \mathrm{~W} / \mathrm{m}^{\circ} \mathrm{C}$ \\
\hline
\end{tabular}




\subsubsection{Processos de oxidação direta.}

A base teórica desse processo é a oxidação catalítica do etileno com oxigênio sobre um catalisador à base de prata.

Em escalas industriais, o óxido de etileno é produzido pela reação entre etileno e oxigênio (ou ar atmosférico), ocorrendo liberação de grandes quantidades de energia, fazendo com que a recuperação de energia seja uma preocupação primordial no projeto de unidades produtivas.

Em função desse comportamento termodinâmico do processo, é necessário o uso de um fluido refrigerante que circula pelo lado do casco do reator, de modo a remover o calor gerado na reação. O controle de temperatura do fluido refrigerante é um dos parâmetros utilizados para controle e determinação da atividade do catalisador (SHELL OIL COMPANY, 1995,1997).

Atualmente a molécula de óxido de etileno (éter cíclico, representado esquematicamente pela Figura 4) é obtida pela reação entre etileno e oxigênio com alto grau de pureza, utilizando um catalisador à base de prata, localizado dentro dos tubos de um reator tubular. A reação principal desse processo é dada por:

$\mathrm{C}_{2} \mathrm{H}_{4}+\frac{1}{2} \mathrm{O}_{2} \stackrel{\mathrm{Ag}}{\rightarrow} \mathrm{C}_{2} \mathrm{H}_{4} \mathrm{O}$

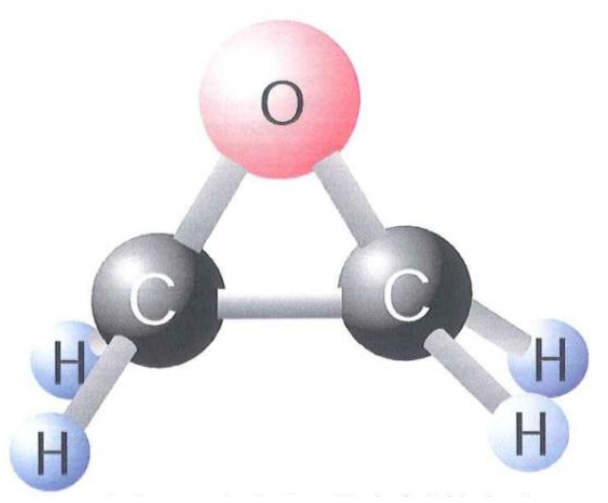

Figura 4 - Representação esquemática da molécula de óxido de etileno (adaptado de OXITENO S/A INDÚSTRIA E COMÉRCIO, 2001) 
Os subprodutos obtidos nesse processo são o dióxido de carbono e a água, oriundos da reação de oxidação total do etileno:

$$
\mathrm{C}_{2} \mathrm{H}_{4}+3 \mathrm{O}_{2} \rightarrow 2 \mathrm{CO}_{2}+2 \mathrm{H}_{2} \mathrm{O}
$$

A reação de oxidação do óxido de etileno também é evidenciada:

$$
\mathrm{C}_{2} \mathrm{H}_{4} \mathrm{O}+2 \frac{1}{2} \mathrm{O}_{2} \rightarrow 2 \mathrm{CO}_{2}+2 \mathrm{H}_{2} \mathrm{O}
$$

Em adição ao óxido de etileno, dióxido de carbono e água, pequenas quantidades de acetaldeído e partes de formaldeído são também produzidos no processo, e podem comprometer a qualidade (pureza) do óxido de etileno, caso ocorra um aumento significativo da produção desses subprodutos (a reação de formação de aldeídos é catalisada pela presença de óxido de ferro nos tubos do reator). O acetaldeído é mais provavelmente formado por isomerização do óxido de etileno, ao passo que formaldeído é mais provavelmente formado por oxidação direta do óxido de etileno (SCIENTIFIC DESIGN COMPANY, 1998).

\subsubsection{Processo de oxidação direta à base de ar}

A Figura 5 mostra um fluxograma típico do processo produtivo à base de ar, que possui três etapas principais: reação, recuperação de óxido e purificação do óxido.

$\mathrm{Na}$ etapa de reação, ar comprimido é bombeado (I) até um filtro de processo (1) onde é purificado para posteriormente alimentar o reator (2) juntamente com o Etileno, em uma corrente que industrialmente é denominada gás de reciclo.

A corrente de gás de reciclo alimenta um reator multitubular de leito fixo, onde o etileno reage com oxigênio produzindo óxido de etileno, gás carbônico e água. O calor da reação é removido pelo bombeamento (II) de um óleo orgânico ou outro produto de alto ponto de ebulição via trocador de calor (B). O calor removido por este fluido é utilizado para alimentação de geradores de 
vapor que garantem a produção de grandes quantidades de vapor de alta pressão, a ser utilizado, tanto na própria unidade de produção de óxido de etileno, quanto em outros processos de outras unidades industriais.

A obtenção de seletividades da ordem de 70 a $80 \%$ é possível através da injeção de inibidores da reação na fase gasosa (entrada do reator), tais como: dicloroetano, cloreto de vinila ou de outros compostos halogenados (SCIENTIFIC DESIGN COMPANY, 1972).

A corrente de processo efluente do reator apresenta concentração na faixa de 1 a $3 \%$ molar em óxido de etileno, sendo resfriada em um trocador de calor (A), para posteriormente ser bombeada (III) a uma coluna absorvedora (3), onde o óxido de etileno é recuperado através de um processo de absorção gasosa realizado pelo contato dessa corrente com uma corrente de água (em baixas temperaturas) que escoa em contracorrente a este fluxo. Como resultado, o óxido de etileno produzido no reator fica dissolvido em água, juntamente com nitrogênio, dióxido de carbono e pequenas quantidades de etileno, etano e aldeídos.

A corrente de gases não absorvidos, que saem pelo topo dessa coluna absorvedora, é dividida em duas porções. A maior parte é reciclada para 0 reator após resfriar a corrente de gás efluente do reator em um trocador de calor (A) e uma pequena fração alimenta um trocador de calor (D) onde é aquecida antes de alimentar o reator de purga do sistema (4).

O principal objetivo do reator de purga (que também necessita de remoção de calor, realizada por um trocador $(\mathrm{C})$, através circulação forçada de produto via bomba (IV)), é garantir que ocorra a reação de boa parte do etileno presente nessa corrente, evitando perdas desse hidrocarboneto para atmosfera.

Essa etapa é necessária, pois o processo exige a realização de uma purga da corrente efluente do reator para reduzir 0 acúmulo de gases inertes, principalmente nitrogênio e dióxido de carbono. A corrente de purga é condensada (D), bombeada (V) e só é enviada para atmosfera após passar em 
uma nova coluna absorvedora (5) onde parte dos hidrocarbonetos de interesse para o processo é absorvida por água que escoa em contracorrente, evitandose perdas no processo. Outra parte, a ser purgada do sistema, passa ainda por um tanque pulmão (6) antes de ser descartada para a atmosfera. Ao final do processo, a purga é composta basicamente pelos gases inertes já citados.

A seção de purificação de óxido de etileno é composta por um conjunto de colunas de destilação $(7,8,9)$ que tem por objetivo garantir a especificação de elevado grau de pureza requerida para o produto. As correntes aquosas, ricas em óxido de etileno, oriundas das colunas absorvedoras, são pré-aquecidas em um trocador ( $E$ ) e alimentam o topo da primeira coluna do processo (7). Nessa etapa do processo, a corrente de fundo (água praticamente isenta de óxido de etileno) é resfriada ( $\mathrm{E})$, bombeada $(\mathrm{VI})$ e reciclada para alimentar as colunas absorvedoras.

A corrente de topo, rica em óxido de etileno e que apresenta pequenas concentrações de dióxido de carbono, nitrogênio, aldeído, etileno e eteno é condensada em um trocador $(\mathrm{F})$ e bombeada (VII) a uma nova coluna de destilação (8), para que seja realizada uma nova etapa de purificação. Nessa coluna, os gases contaminantes, presentes na corrente de óxido de etileno, são separados na corrente de produto destilado, condensados no trocador $(\mathrm{H})$ e enviados para atmosfera, enquanto que o óxido de etileno obtido na corrente de produto de fundo é bombeado (VIII) para coluna de destilação para refino final do produto (9), onde se obtém a produção de óxido de etileno com pureza superior a 99,5\% molar. (KIRK-OTHMER, 2007). O produto final é estocado na forma líquida em uma atmosfera inerte. 


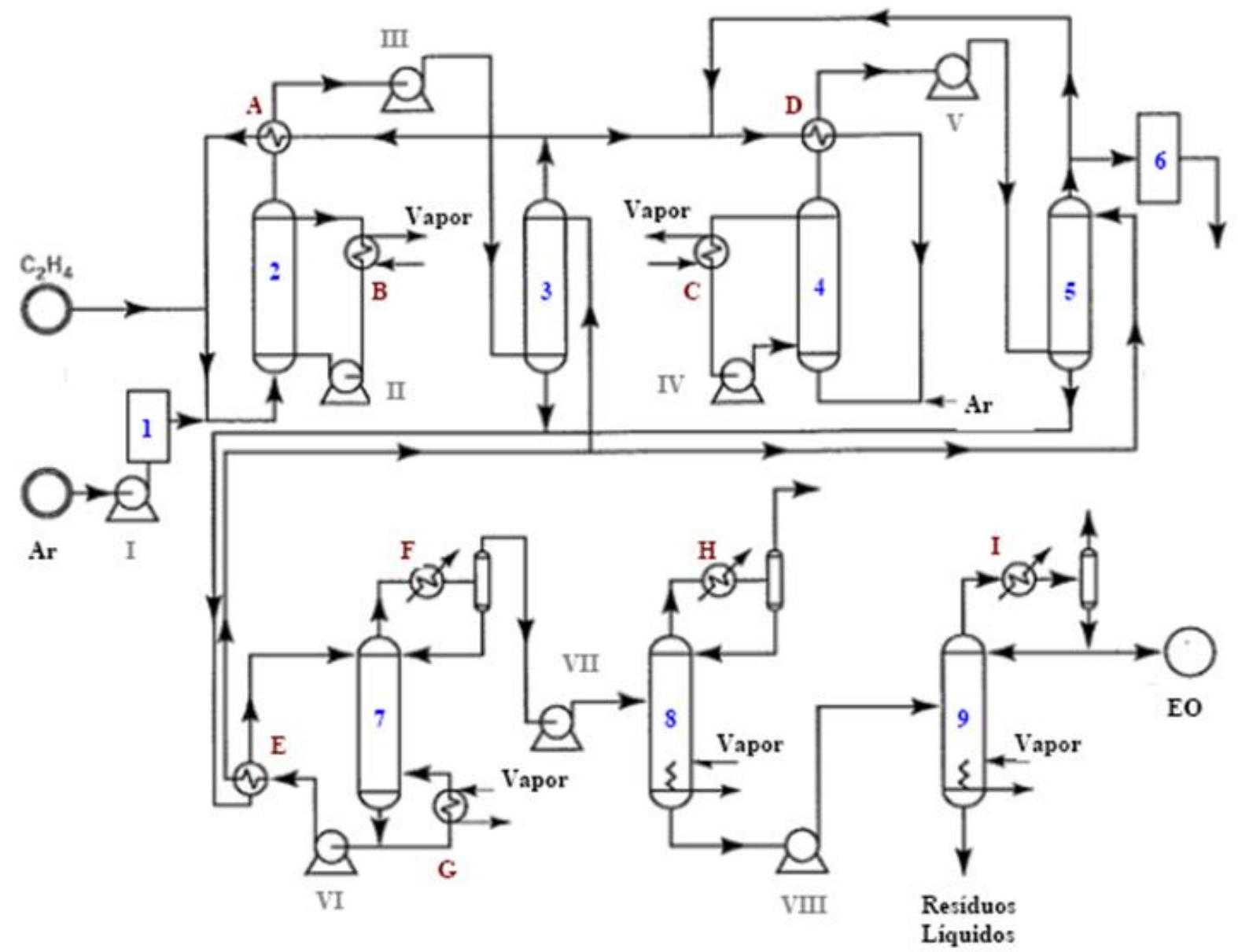

\begin{tabular}{|c|c|c|}
\hline VASOS & BOMBAS & TROCADORES DE CALOR \\
\hline 1 - Filtro de oxigênio & I - Bombeamento de ar & A - Condensador de produto do reator \\
\hline 2 - Reator & II - Recirculação do reator & B - Resfriador da reação \\
\hline 3 - Coluna de absorção & III - Produto do reator & C - Aquecedor do reator de purga \\
\hline 4 - Reator de purga & IV - Recirculação do reator de purga & D - Condensador do reator de purga \\
\hline 5 - Coluna de absorção & V - Purga do sistema & E Resfriador de água de reciclo \\
\hline 6 - Tanque pulmão & $\mathrm{Vl}$ - Água de reciclo & F - Condensador da coluna 7 \\
\hline 7 - Coluna de destilação & VII - Óxido + não condensáveis & G - Refervedor da coluna 7 \\
\hline 8 - Coluna de destilação & VIII - Óxido puro + aldeidos & $\mathrm{H}$ - Condensador da coluna 8 \\
\hline 9 - Coluna de destilação & & I - Condensador da coluna 9 \\
\hline
\end{tabular}

Figura 5 - Fluxograma simplificado do processo produtivo de óxido de etileno a partir da oxidação direta do ar (adaptado de Kirk-Othmer, 2007)

\subsubsection{Processo de oxidação direta à base de oxigênio}

A principal vantagem do processo à base de oxigênio puro em relação ao processo à base de ar atmosférico está no fato de que a quantidade de gases 
inertes introduzidos no processo é bem menor, resultando em um baixo volume de purgas de processo e, consequente, aumento da eficiência do uso das matérias primas (KIRK-OTHMER, 2007).

Do ponto de vista industrial, essa tecnologia elimina a necessidade do reator de purga no processo, mostrado no fluxograma da Figura 5.

No entanto, assim como no processo à base de ar, o volume de dióxido de carbono formado é significativo. Este $\mathrm{CO}_{2}$ deve ser purgado continuamente do gás de reciclo a fim de controlar sua concentração a um nível aceitável, uma vez que concentrações desse componente superiores a $15 \%$ molar influenciam negativamente a atividade do catalisador, além de contribuir para queda da seletividade (CRI CATALYST, 1996). A eliminação de $\mathrm{CO}_{2}$ da corrente de gás de reciclo é realizada através de um sistema de colunas de absorção. A corrente efluente desse sistema, com baixa concentração de $\mathrm{CO}_{2}$ é enviada de volta ao ciclo principal de reação.

Outro ponto de destaque está relacionado à purga de argônio do sistema. $\mathrm{O}$ argônio é uma impureza relevante, presente no oxigênio, e sua concentração pode chegar a patamares da ordem de 30 a $40 \%$ molar no gás de reciclo, se não for eliminado do processo. Concentrações elevadas de argônio reduzem a seletividade da reação obrigando 0 processo a trabalhar com menor concentração de oxigênio, para que seja eliminado o risco da mistura gasosa trabalhar em uma faixa de condição de inflamabilidade (SCIENTIFIC DESIGN COMPANY, 1972).

As baixas taxas de purga em um sistema à base de oxigênio, principalmente quando se trabalha com oxigênio de alta pureza (99,0-99,5\% molar), tornam possível o uso de diluentes que favorecem o uso de altas concentrações de oxigênio no processo, contribuindo para melhorar a seletividade.

A Figura 6 ilustra o fluxograma do processo produtivo a base de oxigênio, bem como os equipamentos utilizados nesse processo. Etileno, oxigênio, e o gás de reciclo são misturados antes de alimentar o reator multitubular (1). A 
semelhança entre a sequência de etapas de processo e equipamentos utilizados é bastante significativa, quando se compara esta tecnologia com 0 processo à base de ar.

A principal diferença está relacionada à inexistência do reator de purga e à existência de uma unidade de remoção de dióxido de carbono (em destaque no fluxograma de processo apresentado na Figura 6). O esquema de remoção do $\mathrm{CO}_{2}$ ilustrado é reconhecido como o processo clássico, baseado na absorção do $\mathrm{CO}_{2}$ em uma solução de carbonato de potássio e minimiza as perdas de etileno no processo (SCIENTIFIC DESIGN COMPANY, 1972). A seção de recuperação do óxido de etileno e as seções de destilação e refino são praticamente idênticas, tanto para o processo à base de ar e à base de oxigênio. 


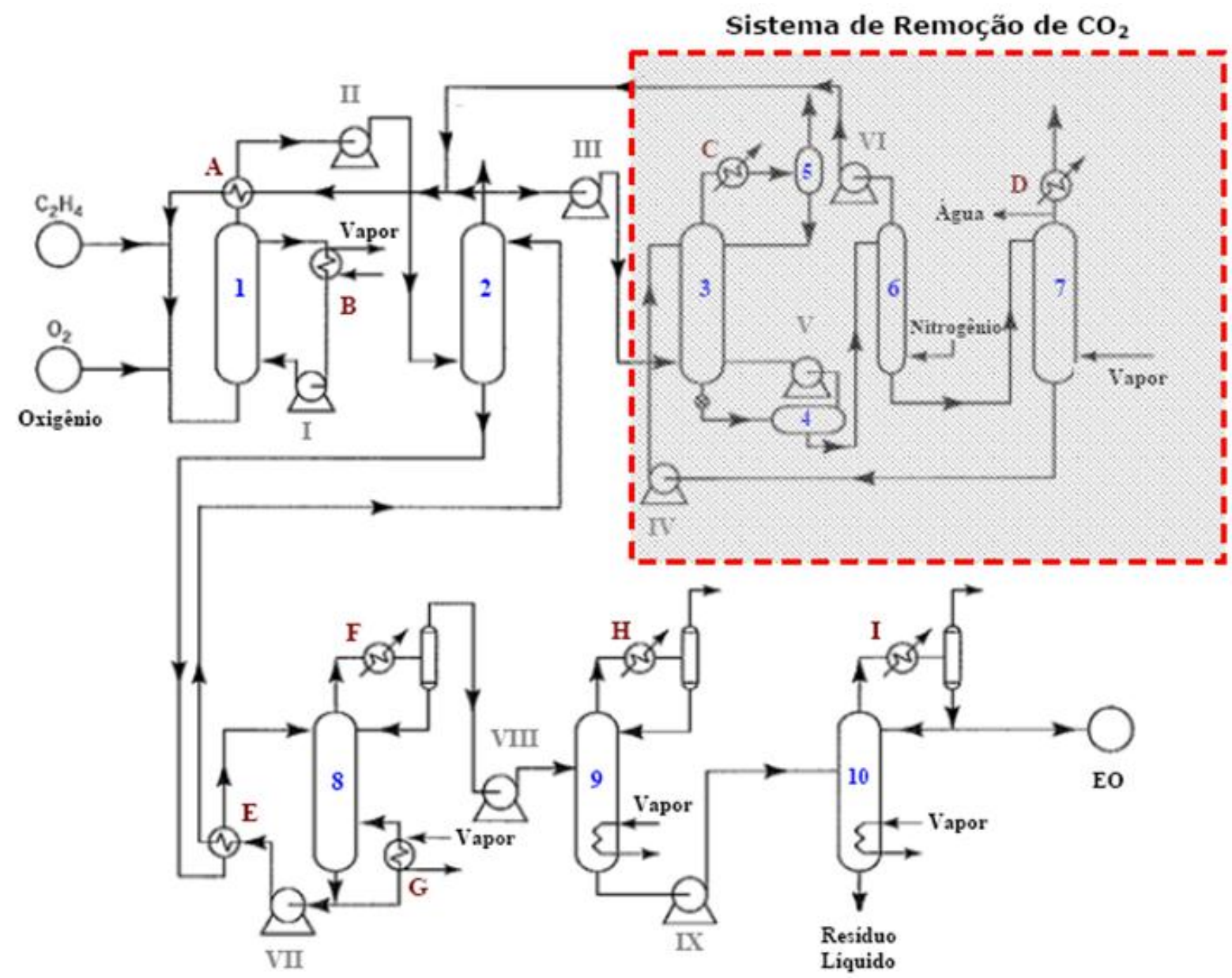

\begin{tabular}{|c|c|c|}
\hline VASOS & BOMBAS & TROCADORES DE CALOR \\
\hline 1 - Reator & I - Recirculação do reator & A - Condensador de produto do reato \\
\hline 2 - Coluna de absorção & II - Produto do reator & B - Resfriador da reação \\
\hline 3 - Reator de purga & III - Recirculação do reator de purga & C - Aquecedor do reator de purga \\
\hline 4 - Tanque pulmão & $\begin{array}{l}\text { IV, V, VI - Recirculação do sistema } \\
\text { de remoção de CO2 }\end{array}$ & $\begin{array}{l}\text { D - Condensador do sistema de } \\
\text { remoção de CO2 }\end{array}$ \\
\hline 5 - Vaso de refluxo e flash & VII - Água de reciclo & E Resfriador de água de reciclo \\
\hline 6,7 - Coluna de remoção de $\mathrm{CO} 2$ & VIII - Óxido + não condensáveis & F - Condensador da coluna 8 \\
\hline 8 - Coluna de destilação & IX - Óxido puro + aldeídos & G - Refervedor da coluna 7 \\
\hline 9 - Coluna de destilação & & $\mathrm{H}$ - Condensador da coluna 9 \\
\hline 10 - Coluna de destilação & & I - Condensador da coluna 10 \\
\hline
\end{tabular}

Figura 6 - Fluxograma simplificado do processo produtivo de óxido de etileno a partir da oxidação utilizando oxigênio puro (adaptado de Kirk-Othmer, 2007).

Quando são comparados os dois processos, algumas diferenças importantes em relação às faixas de controle das variávies relacionadas ao processo reacional, bem como ao desempenho, em termos de seletividade da reação são evidenciados. Os mesmos são apresentados na Tabela 4 (KIRK-OTHMER, 2007). 
Tabela 4 - Intervalos típicos para as variáveis de processo (Produção de óxido de etileno via Processo de Oxidação Direta) (adaptado de KIRK-OTHMER, 2007)

\begin{tabular}{|c|c|c|}
\hline$\underline{\text { Variável }}$ & $\underline{\text { Oxidação via Ar }}$ & Oxidação via Oxigênio \\
\hline Etileno, (\% molar) & $2-10$ & $20-35$ \\
\hline Oxigênio, (\% molar) & $4-8$ & $4-8$ \\
\hline Dióxido de Carbono, $(\%$ molar) & $5-10$ & $5-10$ \\
\hline Temperatura, $\left({ }^{\circ} \mathrm{C}\right)$ & $220-277$ & $220-235$ \\
\hline Pressão, $(\mathrm{MPa})$ & $1-3$ & $2-3$ \\
\hline Perda de carga, $(\mathrm{kPa})$ & $41-152$ & $41-152$ \\
\hline Seletividade $(\%)$ & $63-75$ & $75-82$ \\
\hline
\end{tabular}

Economicamente, é possível afirmar que o processo à base de ar tende a necessitar de investimentos iniciais mais significativos em função da necessidade de se projetar todo o sistema de reator de purga e os demais equipamentos que suportam esse processo unitário.

Outras comparações, não necessariamente relacionadas ao desempenho do processo, são apresentadas em textos específicos sobre o tema (OZERO; PROCELLI, 1984 apud KIRK-OTHMER, 2007). Entre os pontos principais, destacam-se:

- Unidades produtivas de capacidades médias ou grandes (maior que 20 mil t/ano), cuja tecnologia está focada no uso de oxigênio, requerem um menor investimento inicial, mesmo se houver a necessidade de se incluir no projeto um sistema para purificação do ar e obtenção do oxigênio. Porém, para unidades de capacidades menores, os investimentos em tecnologia a base de ar tendem a ser menores. 
- Os custos do catalisador utilizado no processo, bem como das matérias primas etileno e oxigênio também são fatores de importância relevante na escolha do processo. Para um dado tipo de catalisador, o processo a base de oxigênio opera em uma seletividade maior que o processo a base de ar, resultando na necessidade de um volume menor de catalisador para se alcançar um mesmo resultado.

- Processos a base de oxigênio também necessitam de quantidades significativas de vapor para realização do processo de remoção do $\mathrm{CO}_{2}$ gerado na reação, sendo que, por essa óptica, esse processo se torna menos vantajoso do ponto de vista econômico.

- A pureza das correntes de alimentação do processo (etileno e oxigênio) também influencia significativamente os custos de projeto. No caso do oxigênio disponível ser de baixa pureza, as purgas de processo aumentam significativamente e o processo a base de oxigênio não se torna tão atrativo.

- De maneira geral, quando a pureza do etileno é baixa, o processo a base de ar se torna mais atrativo. No entanto, o processo a base de ar pode requerer um sistema de purificação dessa corrente, caso contaminantes como enxofre, halogênios e hidrocarbonetos pesados estejam presentes, pois estes se comportam como venenos para 0 catalisador da reação, reduzindo sua atividade.

Enfim, o conjunto de itens listados anteriormente mostra a necessidade de uma avaliação macro de todo o processo, desde a aquisição de matérias primas até capacidade produtiva da unidade, para que seja possível definir qual o tipo de processo mais adequado a um dado projeto (KIRK-OTHMER, 2007).

Neste trabalho, o processo estudado é similar ao processo de oxidação direta à base de oxigênio, descrita em 3.2.3, sendo que maiores detalhes serão apresentados no item 4.2.1. 


\subsection{Mecanismos de Reação de Formação de Óxido de etileno}

O Etileno, na presença de oxigênio, possibilita a ocorrência de três diferentes tipos de reações, conforme mostrado na Figura 7.

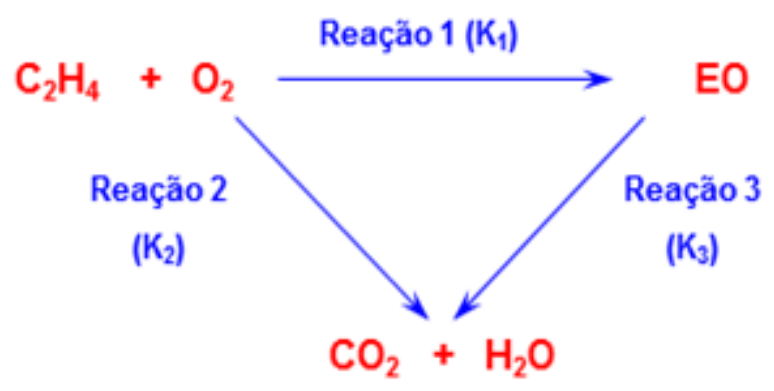

Figura 7 - Representação do triângulo das reações de oxidação de etileno (adaptado de Schouten, Borman, Westerterp, 1996)

- Reação Principal (reação 1 ou reação desejada): representa a oxidação parcial do óxido de etileno (EO) e libera cerca de $35 \mathrm{kcal} / \mathrm{mol}$ de etileno reagido (HALCON INTERNATIONAL, 1979).

- Reação Secundária (reação 2 ou reação indesejada): produzindo $\mathrm{CO}_{2} \mathrm{e}$ $\mathrm{H}_{2} \mathrm{O}$. A oxidação total do etileno a dióxido de carbono e água libera 337 $\mathrm{kcal} / \mathrm{mol}$ de etileno reagido (HALCON INTERNATIONAL, 1979).

- Reação de Oxidação do óxido de etileno (reação 3, também indesejada): produzindo $\mathrm{CO}_{2}$ e $\mathrm{H}_{2} \mathrm{O}$. A oxidação do óxido a dióxido de carbono e água produz $302 \mathrm{kcal} / \mathrm{mol}$ de óxido reagido (HALCON INTERNATIONAL, 1979).

O mecanismo de uma reação procura explicar a interações e transformações químicas ocorridas quando substâncias são colocadas em condições de reagir e gerar novos compostos. Mecanismo pode ser considerado como uma sequência plausível de passos para uma dada reação. Conhecer o mecanismo de uma reação permite ao pesquisador avaliar a consistência entre os dados obtidos em processo reais e a fundamentação teórica para explicar o fenômeno envolvido, além de possibilitar a realização de projetos robustos de reatores e a 
possibilidade de se realizar novos experimentos tomando como base os resultados oriundos do modelo (HULBURT, 1974)

Quagliano e Vallarino (1985) propõem que as pesquisas pela busca de um mecanismo, que explique uma dada reação, só devem ser iniciadas após o entendimento de como a velocidade de uma dada reação se comporta em função das concentrações dos reagentes envolvidos. Além disso, a relação entre velocidade e concentração indica apenas um mecanismo possível para explicação de uma reação, sendo que outras verificações experimentais, em especial a separação e identificação de intermediários, são fundamentais para confirmação do mecanismo proposto.

Reforçam também o fato de que um mecanismo não pode ser provado ao certo. Nesse caso, após realização de estudos e definição de um mecanismo, na verdade, está se explicitando o fenômeno de maior probabilidade de explicar o comportamento da reação em estudo. Um mecanismo é considerado consistente quando ele é coerente com todos os fatos conhecidos que se relacionam com a reação. Caso contrário, o mecanismo deve ser reestudado ou até mesmo descartado de futuros estudos.

Não existe um único mecanismo que explique totalmente o comportamento das reações listadas na Figura 7. Caminhos diferentes de reação até a obtenção dos produtos desejados são mostrados em estudos sobre o tema (os próximos parágrafos referenciam estes estudos), sendo que as principais divergências estão relacionadas a compreender quais espécies de oxigênio adsorvido interagem com o etileno durante o processo de formação do óxido de etileno.

Do ponto de vista da cinética e reatividade do processo, verifica-se que nenhum processo que trabalha com catálise homogênea é tido como eficiente. Porém, resultados satisfatórios são conseguidos através do uso de catálise heterogênea (CARVALHO, 2005). Catalisadores a base de prata têm sido utilizados para garantir a eficiência desse tipo de reação, uma vez que a prata, quando colocada em contato com oxigênio, induz à ocorrência de processos de adsorção não dissociativa do oxigênio que é termodinamicamente menos 
favorável sobre a prata quando em comparação com outros metais (exceto ouro). Dessa forma a taxa de oxidação do etileno por unidade de área de prata é significativamente maior que a adsorção não dissociativa do oxigênio (SACHTLER; BACKX; VAN SANTEN, 1981)

Ressalta-se também que, em sistemas de catálises heterogêneas, os quais envolvem interação entre um hidrocarboneto (no caso, o etileno) e espécies de oxigênios existentes na superfície do catalisador de prata, a velocidade das reações é determinada pela extensão do contato das moléculas reagentes, sendo também influenciadas diretamente pela temperatura e concentração dos reagentes (CARVALHO, 2005).

Além desses fatores (que são comuns a processos onde ocorrem reações homogêneas), outros relacionados ao grau de subdivisão dos reagentes e sua difusão também influenciam o processo, fazendo com que a determinação de mecanismos de reações heterogêneas seja mais complexa de se entender (QUAGLIANO; VALLARINO, 1985). Basicamente, a razão entre as taxas da reação 1 e da reação 2 (mostradas na Figura 7 ) é determinada pelo tipo de interação do etileno e oxigênio com a superfície da prata.

Existem pelo menos três tipos de espécies de oxigênio adsorvido em prata (KIRK-OTHMER, 2007):

- Oxigênio monoatômico quimissorvido (ou oxigênio atômico);

- Oxigênio diatômico ( ou molecular);

- Oxigênio de subsuperfície.

O fenômeno da adsorção do oxigênio em prata tem sido muito estudado ao longo dos últimos anos. Medições referentes à cinética e equilíbrio dessas reações têm sido realizadas e a quimissorção do oxigênio (em pelo menos duas formas diferentes: atômica e molecular) é reconhecida como o fenômeno relacionado a este processo.

Klugherz e Harriot (1971) indicam uma rota de formação de óxido de etileno, onde a reação ocorre entre etileno e oxigênio adsorvidos nos sítios formados 
pela adsorção dissociativa de uma camada de oxigênio sobre uma superfície metálica. Etileno, oxigênio e os produtos da reação competem pelos sítios de adsorção na superfície do catalisador, cuja composição é semelhante ao óxido de prata.

Nesse mecanismo, a primeira etapa consiste na formação de sítios ativos pela adsorção dissociativa do oxigênio em uma superfície de prata (Equação 4). A combinação do oxigênio adsorvido na prata pode ser representada por $S$, o sítio ativo.

$\mathrm{Ag}+\mathrm{O}_{2}<=>2 \mathrm{~S}$

Etileno e oxigênio podem ser adsorvidos nesses sítios ativos. O oxigênio, que participa da reação, pode ser tanto da espécie molecular quanto atômica (Equações 5 a 7 ).

$\mathrm{C}_{2} \mathrm{H}_{4}+\mathrm{S}<=>\mathrm{C}_{2} \mathrm{H}_{4} \cdot \mathrm{S}$

$\mathrm{O}_{2}+\mathrm{S}<=>\mathrm{O}_{2} \cdot \mathrm{S}$

$\mathrm{O}_{2}+2 \mathrm{~S}<=>20 \cdot \mathrm{S}$

A etapa limitante (controle da reação) é a reação entre o etileno e o oxigênio adsorvidos, representada pela equação 8 (onde $n=1$ ou 2 , dependendo se 0 oxigênio atuante é o atômico ou molecular).

$\mathrm{C}_{2} \mathrm{H}_{4} \cdot \mathrm{S}+\mathrm{O}_{\mathrm{n}} \cdot \mathrm{S} \rightarrow \mathrm{C}_{2} \mathrm{H}_{4} \mathrm{O}$

A formação de $\mathrm{CO}_{2}$ e $\mathrm{H}_{2} \mathrm{O}$ ocorre de forma similar. Acredita-se na existência de um conjunto de outras etapas que ainda necessitam ser executadas após o final da etapa limitante. É provável que moléculas de oxigênio subsuperficial participem da oxidação do etileno a $\mathrm{CO}_{2}$. 
Naturalmente, o mecanismo proposto não requer que os reagentes sejam adsorvidos no oxigênio adsorvido que cria os sítios ativos. Acredita-se que os átomos de prata possuem um papel fundamental no processo de adsorção do etileno e oxigênio reagentes.

Mecanismos estudados e propostos por Kilt e Sachtler (1974) defendem teorias fundamentadas em um processo onde ocorrem os fenômenos de adsorção e dessorção do oxigênio em superfícies de prata, obedecendo as seguintes etapas:

Inicialmente tem-se o processo denominado adsorção dissociativa de uma molécula de oxigênio (realizado em temperaturas elevadas) resultando na formação de quatro átomos de prata, como mostrado pelas equações 9 a 11 .

$\mathrm{O}_{2}+4 \mathrm{Ag}_{(\text {adj })} \rightarrow 2 \mathrm{O}_{(\text {ads })}^{2-}+4 \mathrm{Ag}_{(\text {adj })}^{+}$

A segunda etapa desse processo prevê um processo não dissociativo onde a obtenção de oxigênio molecular é representada pelas equações 10 e 11 .

$\mathrm{O}_{2}+\mathrm{Ag} \rightarrow \mathrm{O}_{\mathrm{ads}}^{2-}+\mathrm{Ag}^{+}$

$\mathrm{O}_{2}+4 \mathrm{Ag}_{(\text {nãoadj) }} \rightarrow 2 \mathrm{O}_{(\text {ads })}^{2-}+4 \mathrm{Ag}_{(\text {adj) }}^{+}$

Nesse mecanismo, pressupondo-se uma efetiva atuação dos compostos clorados presentes no meio, espera-se que a equação 10 seja totalmente bloqueada, havendo contribuições da equação 12, que decresce com a redução da temperatura. A próxima etapa prevê a reação seletiva do etileno com o oxigênio molecular.

$\mathrm{O}_{2(\mathrm{ads})}+\mathrm{C}_{2} \mathrm{H}_{4} \rightarrow \mathrm{C}_{2} \mathrm{H}_{4} \mathrm{O}+\mathrm{O}_{(\mathrm{ads})}$ 
Os átomos de oxigênio resultantes da equação anterior reagem com etileno, resultando nos produtos da oxidação. A máxima seletividade é alcançada quando uma molécula de oxigênio reage com seis átomos de oxigênio.

$$
\mathrm{O}(\mathrm{ads})+\mathrm{C}_{2} \mathrm{H}_{4} \rightarrow \mathrm{OC}_{2} \mathrm{H}_{4}(\mathrm{ads}) \stackrel{5 \mathrm{O}(\mathrm{ads})}{\longrightarrow} 2 \mathrm{CO}_{2}+2 \mathrm{H}_{2} \mathrm{O}
$$

$\mathrm{Na}$ última etapa desse processo o oxigênio atômico reage com etileno para formar dióxido de carbono e água. Uma vez que $\mathrm{O}_{\mathrm{ads}}^{2-}$ deve ser removido da superfície de prata antes da formação de uma nova quantidade de $\mathrm{O}_{\mathrm{ads}}^{2-}$, as duas reações (representadas pelas equações 12 e 13) devem ser combinadas. Dessa forma a estequiometria para a reação completa é:

$$
7 \mathrm{C}_{2} \mathrm{H}_{4}+6 \mathrm{O}_{2} \text { (ads) } \rightarrow 6 \mathrm{C}_{2} \mathrm{H}_{4} \mathrm{O}+2 \mathrm{CO}_{2}+2 \mathrm{H}_{2} \mathrm{O}
$$

O fato de a reação seletiva (equação 12) e de a reação secundária (equação 13) apresentarem a mesma ordem de reação e energias de ativação semelhantes, mostram que elas são realmente combinadas. Este mecanismo prevê que a seletividade máxima alcançada seja de $85,7 \%$ desde que algumas premissas sejam adotadas:

- O óxido de etileno formado não é oxidado;

- A reação 9 é bloqueada através da presença de uma concentração adequada de clorados.

- A taxa da reação 11 é pouco significativa quando comparada à reação 10.

- Recombinação de átomos de oxigênio (processo de dessorção) praticamente não ocorre.

Essas teorias também foram as primeiras a prever a isomerização do óxido de etileno a Acetaldeídos nas temperaturas de reação geralmente praticadas em processos industriais (KENSON; LAPKIN, 1970). 
Também é oriunda dessa teoria a explicação para limitação da máxima seletividade a ser obtida em uma reação de formação de óxido de etileno: $85,7 \%$. Valor este questionado em diversos estudos relatados em artigos de Van Santen e Kuipers (1987) e Nakatsuji et al. (1997) que mostram a possibilidade de se superar esse valor.

Pesquisas realizadas por Kagawa, Iwamoto e Seiyama (1981) também analisam o comportamento da cinética de reação em função do tipo de oxigênio presente no sistema e demonstram não existir um motivo exato para que a seletividade da reação seja limitada a $85,7 \%$. O mecanismo por eles proposto é apresentado pelo conjunto das equações 15 a 19.

$6 \mathrm{O}_{2}+6 \mathrm{Ag} \rightarrow 6 \mathrm{AgO}_{2}$

$2 \mathrm{Ag}+\mathrm{O}_{2} \rightarrow 2 \mathrm{AgO} \rightarrow \mathrm{AgO}_{2}+\mathrm{Ag}$

O mecanismo de formação de óxido de etileno é descrito por:

$6 \mathrm{C}_{2} \mathrm{H}_{4}+6 \mathrm{Ag} \rightarrow 6 \mathrm{C}_{2} \mathrm{H}_{4} \cdot \mathrm{Ag}$

$6 \mathrm{AgO}_{2}+6 \mathrm{C}_{2} \mathrm{H}_{4} \cdot \mathrm{Ag} \rightarrow 6 \mathrm{C}_{2} \mathrm{H}_{4} \mathrm{O} \cdot \mathrm{Ag}+6 \mathrm{AgO}$

$6 \mathrm{C}_{2} \mathrm{H}_{4} \mathrm{O} . \mathrm{Ag} \rightarrow 6 \mathrm{Ag}+6 \mathrm{C}_{2} \mathrm{H}_{4} \mathrm{O}$

Somando as equações 17,18 e 19, tem-se:

$6 \mathrm{C}_{2} \mathrm{H}_{4}+6 \mathrm{AgO}_{2} \rightarrow 6 \mathrm{C}_{2} \mathrm{H}_{4} \mathrm{O}+6 \mathrm{AgO}$

Já o mecanismo de formação de $\mathrm{CO}_{2}$ é descrito por:

$\mathrm{C}_{2} \mathrm{H}_{4}+\mathrm{Ag} \rightarrow \mathrm{C}_{2} \mathrm{H}_{4} \cdot \mathrm{Ag}$

$6 \mathrm{AgO}+\mathrm{C}_{2} \mathrm{H}_{4} \cdot \mathrm{Ag} \rightarrow 2 \mathrm{CO}_{2}+2 \mathrm{H}_{2} \mathrm{O}+6 \mathrm{Ag}$ 
Somando-se as equações 21 e 22 obtém-se:

$\mathrm{C}_{2} \mathrm{H}_{4}+6 \mathrm{AgO} \rightarrow 6 \mathrm{Ag}+2 \mathrm{CO}_{2}+2 \mathrm{H}_{2} \mathrm{O}$

E a reação global do processo torna-se

$6 \mathrm{O}_{2}+7 \mathrm{C}_{2} \mathrm{H}_{4} \rightarrow 6 \mathrm{C}_{2} \mathrm{H}_{4} \mathrm{O}+2 \mathrm{CO}_{2}+2 \mathrm{H}_{2} \mathrm{O}$

Nesse mecanismo a reação 16 é reversível e, dependendo do comportamento dessa reação, as etapas subsequentes poderão ser afetadas, possibilitando a obtenção de seletividades superiores a $85,7 \%$.

Estudos mais recentes, como os apresentados por Van Santen e Kuipers (1987), Grant, Lambert, 1985 apud Carvalho (2005), defendem a teoria do oxigênio de subsuperfície como a mais elucidativa para explicação do mecanismo e cinética dessas reações. Nesse cenário o oxigênio penetra para uma camada abaixo da superfície da prata modificando esses átomos de prata de modo a contribuir para um aumento da seletividade da reação.

O oxigênio de subsuperfície aparece em temperaturas superiores a $420 \mathrm{~K}$, quando o ponto de difusão do oxigênio atômico adsorvido da região da superfície até a subsuperfície se torna perceptível (CARVALHO, 2005).

Também é comprovado o aumento do rendimento da reação de formação de óxido de etileno, quando a superfície de prata do catalisador é amplamente coberta por moléculas de oxigênio, independente de qual seja seu tipo (VAN SANTEN; KUIPERS, 1987).

Van Santen e Groot (1986) também explicitam em seus estudos a existência de pelo menos dois tipos de oxigênio reativos na superfície de prata. Concluem que, sob determinadas faixas de pressão, o oxigênio pré-adsorvido em uma superfície de prata, a uma razão $O($ ads) $/ A g(s)=1$, reage mais rapidamente com o etileno que o oxigênio na fase gasosa. Outro ponto relevante está 
relacionado à reação do etileno com oxigênio atômico, tanto da forma direta quanto indireta, após a recombinação dos átomos de oxigênio.

O mecanismo de oxidação do etileno, proposto por Sachtler, Backx e Van Santen (1981), indica que a adsorção dissociativa do oxigênio (que necessita de dois sítios vagos) leva o processo à oxidação completa, enquanto que a adsorção não dissociativa (que necessita de apenas um sítio) resulta nas espécies indicadas na equação 25 , levando posteriormente à obtenção do óxido de etileno.

$\mathrm{C}_{2} \mathrm{H}_{4}+\mathrm{Ag}^{+} \mathrm{O}^{-} \rightarrow \mathrm{Ag}^{+} \mathrm{O}^{-} \mathrm{C}_{2} \mathrm{H}_{2} \mathrm{C}_{2} \mathrm{H}_{2} * \rightarrow \mathrm{Ag}+\mathrm{C}_{2} \mathrm{H}_{4} \mathrm{O}$

Em seus estudos, estes últimos autores, relatam também pesquisas referentes à oxidação do etileno na ausência de oxigênio gasoso, utilizando óxidos de prata $\left(\mathrm{Ag}_{2} \mathrm{O}\right.$ e $\left.\mathrm{Ag}_{2} \mathrm{O}_{2}\right)$ como oxidantes. A utilização de $\mathrm{Ag}_{2} \mathrm{O}_{2}$ resulta em um produto da oxidação, contendo quantidades significativas de óxido de etileno, enquanto que o uso de $\mathrm{Ag}_{2} \mathrm{O}$ mostra que, inicialmente não se forma óxido de etileno no processo reacional. Somente após a ocorrência do processo de redução, com a presença de prata metálica é que se inicia a formação do óxido de etileno.

\subsection{Conceitos para Gerenciamento de Unidades Produtivas de Óxido de etileno}

O gerenciamento de um processo, ou de variáveis de um processo, pode ser entendido como uma sequência de eventos, que envolve as seguintes etapas (RIBEIRO, 2003):

- Medição de um dado parâmetro ou variável;

- Avaliação do resultado medido;

- Verificação da necessidade de interferência no processo produtivo para se corrigir um resultado insatisfatório;

- Definição da estratégia ou da forma de atuação sobre o parâmetro ou variável, de modo a melhorar os resultados; 
- Atuação propriamente dita sobre o parâmetro ou variável;

- Realização de nova medição e reavaliação dos resultados obtidos.

Existem diversas formas de se avaliar o desempenho técnico e econômico de um catalisador utilizado em um processo de produção de óxido de etileno. Seletividade e Atividade são dois dos conceitos mais utilizados, mas devem sempre ser avaliados e gerenciados em conjunto com outros parâmetros e variáveis, listadas nos itens 3.4.3 a 3.4.8.

\subsubsection{Seletividade}

A seletividade da reação de produção de óxido de etileno é definida como o número de mols de óxido de etileno produzido, dividido pelo número de mols de etileno consumido, e mede a eficiência com que o etileno é usado pelo catalisador (HALCON INTERNATIONAL, 1979).

Em um processo químico, a reação principal (aquela que gera o produto desejado) é, de maneira geral, acompanhada por outras reações simultâneas que conduzem à formação de produtos considerados indesejáveis. Daí a importância em se medir a produção de produto desejado em relação à conversão de reagente.

Se todo o etileno reagido for transformado em óxido de etileno, a seletividade da reação seria 100\%, o que é impossível do ponto de vista prático em função dos mecanismos anteriormente explicados. Uma vez que o consumo de etileno representa o principal custo na produção de óxido de etileno, quanto maior a seletividade da reação, menores serão os custos de produção.

\subsubsection{Dedução das equações para o cálculo da Seletividade da reação de formação de óxido de etileno}

Existem seis equações utilizadas para a determinação da seletividade da reação (Tabela 5), as quais estão relacionadas com a variação da composição molar dos componentes na corrente de gás de reciclo, na entrada e saída do reator. Essas equações são conhecidas por $S_{1}, S_{2}, S_{3}, S_{4}, S_{5}$ e $S_{6}$. 
Tabela 5 - Equações para o cálculo das Seletividades $S_{1}$ a $S_{6}$ da reação de formação de óxido de etileno

\begin{tabular}{|c|c|c|}
\hline Seletividade & Fórmula para cálculo & $\begin{array}{l}\text { Avalia a relação entre os } \\
\text { seguintes componentes }\end{array}$ \\
\hline $\mathrm{S}_{1}=$ & $\begin{array}{l}\text { (Número de mols de óxido de etileno } \\
\text { produzido) / (número de mols de } \\
\text { etileno reagido) }\end{array}$ & $\begin{array}{l}\text { - óxido de etileno } \\
\text { produzido } \\
\text { - etileno } \\
\text { consumido }\end{array}$ \\
\hline $\mathrm{S}_{2}=$ & $\begin{array}{l}\qquad\left(\frac{1}{1+\frac{1}{2}\left(\frac{\mathrm{CO}_{2}}{\text { Óxido de etileno }}\right)}\right) \\
\mathrm{CO}_{2} \text { e óxido de etileno indicam a } \\
\text { variação no número de mols desses } \\
\text { componentes entre as correntes de } \\
\text { entrada e saída do reator. }\end{array}$ & $\begin{array}{l}\text { - óxido de etileno } \\
\text { produzido } \\
\text { - } \mathrm{CO}_{2} \text { produzido }\end{array}$ \\
\hline $\mathrm{S}_{3}=$ & $\begin{array}{l}\frac{6}{5+2\left(\frac{\mathrm{O}_{2}}{\text { Óxido de etileno }}\right)} \\
\mathrm{O}_{2} \text { e óxido de etileno indicam a } \\
\text { variação no número de mols desses } \\
\text { componentes entre as correntes de } \\
\text { entrada e saída do reator. }\end{array}$ & $\begin{array}{l}\text { - óxido de etileno } \\
\text { produzido } \\
\text { - oxigênio } \\
\text { consumido }\end{array}$ \\
\hline $\mathrm{S}_{4}=$ & $\begin{array}{l}\qquad 1,2-0,4 \frac{\mathrm{O}_{2}}{\mathrm{C}_{2} \mathrm{H}_{4}} \\
\mathrm{O}_{2} \text { e } \mathrm{C}_{2} \mathrm{H}_{4} \text { indicam a variação no } \\
\text { número de mols desses componentes } \\
\text { entre as correntes de entrada e saída } \\
\text { do reator }\end{array}$ & $\begin{array}{ll} & \text { oxigênio } \\
& \text { consumido } \\
- & \text { etileno } \\
\text { consumido }\end{array}$ \\
\hline $\mathrm{S}_{5}=$ & 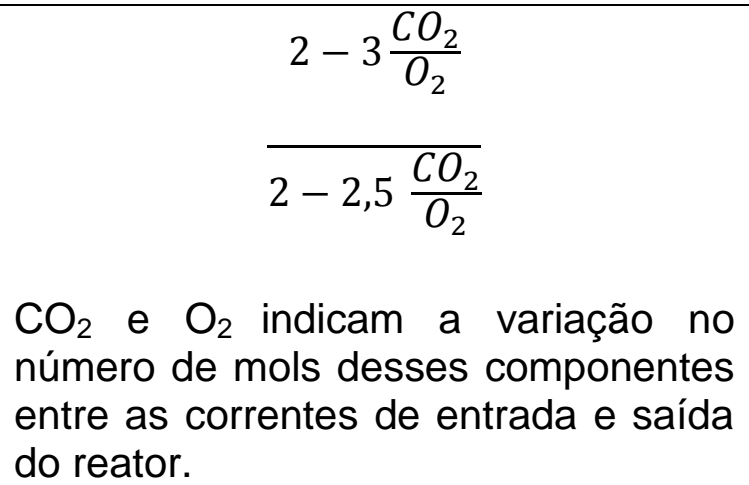 & $\begin{array}{ll}\text { - } & \text { oxigênio } \\
\text { consumido } \\
\text { - } \mathrm{CO}_{2} \text { produzido }\end{array}$ \\
\hline
\end{tabular}

(continua) 
(continuação)

\begin{tabular}{|c|c|c|}
\hline Seletividade & Fórmula para cálculo & $\begin{array}{c}\text { Avalia a relação entre } \\
\text { os seguintes } \\
\text { componentes }\end{array}$ \\
\hline $\mathrm{S}_{6}=$ & $1-0,5 \frac{\mathrm{CO}_{2}}{\mathrm{C}_{2} \mathrm{H}_{4}}$ & $\begin{array}{l}\bullet \mathrm{CO}_{2} \text { produzido } \\
\text { Etileno } \\
\text { consumido }\end{array}$ \\
& $\begin{array}{l}\mathrm{CO}_{2} \text { e } \mathrm{C}_{2} \mathrm{H}_{4} \text { indicam a variação no } \\
\text { número de mols desses componentes } \\
\text { entre as correntes de entrada e saída } \\
\text { do reator. }\end{array}$ & \\
\hline
\end{tabular}

A base teórica para a determinação dessas seletividades está relacionada às equações de oxidação total e parcial do etileno (equações 26 e 27) e foi demonstrada por Bulla (1979).

$$
\begin{aligned}
& \mathrm{C}_{2} \mathrm{H}_{4}+1 / 2 \mathrm{O}_{2} \rightarrow \mathrm{C}_{2} \mathrm{H}_{4} \mathrm{O} \\
& \mathrm{C}_{2} \mathrm{H}_{4}+3 \mathrm{O}_{2} \rightarrow 2 \mathrm{CO}_{2}+2 \mathrm{H}_{2} \mathrm{O}
\end{aligned}
$$

Conceitualmente, tomando como base as equações 26 e 27, pode-se definir como seletividade:

- Relação entre o número de mols de etileno consumido na reação 26 e o número total de mols de etileno consumido globalmente no processo (soma das reações representadas pelas equações 26 e 27).

- Relação entre o número de mols de óxido de etileno produzido na reação 26 e o número total de mols de etileno consumido neste processo (soma das reações representadas pelas equações 26 e 27).

$\mathrm{Na}$ equação 26, $1 \mathrm{~mol}$ de etileno reage com $1 / 2$ mol de oxigênio para produzir 1 mol de óxido de etileno. Já na equação 27, 1 mol de etileno reage com 3 mols de oxigênio para produzir 2 mols de $\mathrm{CO}_{2}$ e 2 mols de água.

Considerando que as duas reações juntas consomem 1 mol de etileno e que a seletividade da reação de produção de óxido de etileno seja dada por "S" (em 
fração molar), obtém-se os seguintes coeficientes estequiométricos para esse processo:

(S) $\mathrm{C}_{2} \mathrm{H}_{4}+\left(\frac{1}{2} S\right) \mathrm{O}_{2} \rightarrow(S) \mathrm{C}_{2} \mathrm{H}_{4} \mathrm{O}$

$(1-S) C_{2} H_{4}+3(1-S) O_{2} \rightarrow 2(1-S) C_{2}+2(1-S) H_{2} O$

A Tabela 6 mostra o total de número de mols de produtos e reagentes obtidos para o consumo de $1 \mathrm{~mol}$ de etileno a uma seletividade "S".

Tabela 6 - Estequiometria das reações de oxidação do Etileno

\begin{tabular}{|c|c|c|c|c|c|}
\hline & etileno & oxigênio & $\begin{array}{c}\text { óxido de } \\
\text { etileno }\end{array}$ & $\mathrm{CO}_{2}$ & água \\
\hline $\begin{array}{c}\text { Reação Principal } \\
\text { (equação 26) }\end{array}$ & $\mathrm{S}$ & $\left(\frac{1}{2}\right) \mathrm{S}$ & $\mathrm{S}$ & - & - \\
\hline $\begin{array}{c}\text { Reação Indesejada } \\
\text { (equação 27) }\end{array}$ & $(1-\mathrm{S})$ & $3(1-\mathrm{S})$ & - & $2(1-\mathrm{S})$ & $2(1-\mathrm{S})$ \\
\hline $\begin{array}{c}\text { Reação global do } \\
\text { processo (equação } \\
26+\text { equação 27) }\end{array}$ & 1 & $3-\left(\frac{5}{2}\right) \mathrm{S}$ & $\mathrm{S}$ & $2(1-\mathrm{S})$ & $2(1-\mathrm{S})$ \\
\hline
\end{tabular}

Utilizando-se os dados da Tabela 6, é possível escrever as relações $(\mathrm{mol} / \mathrm{mol})$ entre os diferentes produtos e reagentes presentes nesse processo, obtendose desta forma as equações $S_{1}$ a $S_{6}$ que representam a seletividade.

\subsubsection{Dedução da Seletividade $\mathrm{S}_{1}$}

Por definição, $S_{1}$ é dada como a relação entre o número de mols de óxido de etileno formado e o número de mols de etileno reagido no processo.

$$
\left(\frac{\text { Óxido de etileno }}{\text { Etileno }}\right)=\frac{S}{1}=S \rightarrow S_{1} \text { (Definição) }
$$




\subsubsection{Dedução da Seletividade $S_{2}$}

A seletividade $\mathrm{S}_{2}$ relaciona o número de mols de $\mathrm{CO}_{2}$ formado no processo em relação ao número de mols de óxido de etileno que também é obtido nesse processo.

$$
\begin{gathered}
\left(\frac{\mathrm{CO}_{2}}{\text { Óxido de etileno }}\right)=2 \frac{1-\mathrm{S}}{\mathrm{S}} \therefore\left(\frac{\mathrm{CO}_{2}}{\text { Óxido de etileno }}\right)=\frac{2}{\mathrm{~S}}-1 \therefore \\
\frac{\mathrm{CO}_{2}}{\text { Oxido de etileno }}+1=\frac{2}{\mathrm{~S}} \therefore \\
\left(\frac{1}{1+\frac{1}{2}\left(\frac{1 \mathrm{CO}_{2}}{\text { Oxido de etileno }}\right)}\right)=\mathrm{S}
\end{gathered}
$$

\subsubsection{Dedução da Seletividade $S_{3}$}

A seletividade $S_{3}$ relaciona o número de mols de oxigênio consumido no processo em relação ao número de mols de óxido de etileno obtido nesse processo.

$$
\begin{aligned}
& \left(\frac{\text { Oxigênio }}{\text { Óxido de etileno }}\right)-\frac{3-5 / 2 \mathrm{~S}}{\mathrm{~S}} \therefore\left(\frac{\text { Oxigênio }}{\text { Óxido de etileno }}\right)=\frac{3}{\mathrm{~S}}-\frac{5}{2} \\
& \left(\frac{\text { Oxigênio }}{\text { Óxido de etileno }}\right)+\frac{5}{2}=\frac{3}{\mathrm{~S}}: \frac{3}{5 / 2+\frac{\text { Oxigênio }}{\text { Óxido de etileno }}}= \\
& \frac{6}{5+2\left(\frac{\mathrm{O}_{2}}{\text { Oxido de etileno }}\right)}=\mathrm{S} \rightarrow \mathrm{S}_{3}
\end{aligned}
$$

\section{$\underline{\text { Dedução da Seletividade } S_{4}}$}

A seletividade $S_{4}$ relaciona o número de mols de oxigênio consumido no processo em relação ao número de mols de etileno também consumido nesse processo. 


$$
\begin{gathered}
\left(\frac{\text { Oxigênio }}{\text { Etileno }}\right)=\frac{3-5 / 2 \mathrm{~S}}{1} \therefore 5 / 2 \mathrm{~S}=3-\left(\frac{\mathrm{O}_{2}}{\mathrm{C}_{2} \mathrm{H}_{4}}\right) \\
\mathrm{S}=\frac{2 \mathrm{x} 3}{5}-\frac{2}{5} \frac{\mathrm{O}_{2}}{\mathrm{C}_{2} \mathrm{H}_{4}} \therefore \\
1,2-0,4 \frac{\mathrm{O}_{2}}{\mathrm{C}_{2} \mathrm{H}_{4}}=\mathrm{S} \rightarrow \mathrm{S}_{4}
\end{gathered}
$$

\subsubsection{Dedução da Seletividade $S_{5}$}

A seletividade $S_{5}$ relaciona o número de mols de $\mathrm{CO}_{2}$ obtido nesse processo em relação ao número de mols de oxigênio consumido no processo.

$$
\begin{gathered}
\left(\frac{\mathrm{CO}_{2}}{\text { Oxigênio }}\right)=\frac{2(1-\mathrm{S})}{3-5 / 2 \mathrm{~S}} \therefore 3\left(\frac{\mathrm{CO}_{2}}{\mathrm{O}_{2}}\right)-(5 / 2 \mathrm{~S}) \times \frac{\mathrm{CO}_{2}}{\mathrm{O}_{2}}=2-2 \mathrm{~S} \\
2 \mathrm{~S}-5 / 2 \mathrm{~S}\left(\frac{\mathrm{CO}_{2}}{\mathrm{O}_{2}}\right)=2-\frac{3 \mathrm{CO}_{2}}{\mathrm{O}_{2}} \therefore \\
\mathrm{S}=\frac{2-3 \frac{\mathrm{CO}_{2}}{\mathrm{O}_{2}}}{2-2,5 \frac{\mathrm{CO}_{2}}{\mathrm{O}_{2}}} \rightarrow \mathrm{S}_{5}
\end{gathered}
$$

\subsubsection{Dedução da Seletividade $\mathrm{S}_{6}$}

A seletividade $\mathrm{S}_{6}$ relaciona o número de mols de $\mathrm{CO}_{2}$ obtido nesse processo em relação ao número de mols de etileno consumido no processo.

$$
\begin{gathered}
\left(\frac{\mathrm{CO}_{2}}{\text { Etileno }}\right)=\frac{2(1-\mathrm{S})}{1} \therefore\left(\frac{\mathrm{CO}_{2}}{\text { Etileno }}\right)=2-2 \mathrm{~S} \\
2 \mathrm{~S}=2-\left(\frac{\mathrm{CO}_{2}}{\text { Etileno }}\right) \therefore \\
\mathrm{S}=1-0,5 \frac{\mathrm{CO}_{2}}{\mathrm{C}_{2} \mathrm{H}_{4}} \rightarrow \mathrm{S}_{6}
\end{gathered}
$$




\subsubsection{Atividade}

É a grandeza que mede o grau de reatividade do catalisador (capacidade de converter reagentes em produtos). Existem várias maneiras de se expressar a atividade catalítica (OXITENO, 2004):

- A taxa de uma reação por unidade de volume ou área do catalisador;

- O grau de conversão dos reagentes para um dado conjunto de condições operacionais;

- Temperatura requerida para se atingir um dado nível de conversão.

Quanto mais ativo é um catalisador menor será a temperatura necessária para alcançar as taxas de conversão desejadas no reator

O conceito de atividade está intimamente ligado ao conceito de cinética química, que trabalha o conhecimento das velocidades e mecanismos envolvidos durante uma reação química. Juntamente com a termodinâmica, que se preocupa em definir a condição de equilíbrio químico, a cinética tem por objetivo determinar o tempo em que as reações ocorrem, através de determinação da constante e da lei de velocidade de reação (SOUZA; FARIAS, 2008).

As reações químicas são classificadas em dois grupos principais:

- Reações homogêneas (quando todos os reagentes e produtos envolvidos estão em uma mesma fase);

- Reações heterogêneas (quando pelo menos um dos reagentes ou produtos envolvidos está em uma fase diferente).

Para reações homogêneas, a velocidade das reações depende apenas de dois fatores: a temperatura e a concentração dos reagentes. Já para o caso de reações heterogêneas, esses mesmos fatores possuem influência significativa na determinação da velocidade da reação, acrescidos ainda de fatores relacionados à eficiência com que os reagentes entram em contato ao longo do processo (QUAGLIANO; VALLARINO, 1985) 
Um catalisador é definido como uma substância que altera a velocidade de uma reação química. Ele participa do mecanismo da reação, levando a uma diminuição da energia de ativação e, consequentemente, a um aumento na constante de velocidade de reação. Ao final do processo o catalisador é regenerado, o que faz com o mesmo não seja considerado um reagente.

Assim como nas reações químicas, a catálise aplicada a um dado processo pode ser classificada em catálise homogênea (quando o catalisador e as espécies reagentes formam uma única fase) ou catálise heterogênea (quando catalisador e reagentes formam fases distintas). Nesse último caso, a reação química ocorre na interface entre as fases (SOUZA; FARIAS, 2008).

Considerando dois reagentes $\mathrm{A}$ e $\mathrm{B}$ colocados em um sistema onde o volume $\mathrm{e}$ a temperatura são constantes e no qual se processa a reação indicada pela equação 35.

$\mathrm{A}+\mathrm{B} \rightarrow \mathrm{C}+\mathrm{D}$

Após um determinado tempo, que varia de reação para reação, verifica-se que as concentrações de produtos e reagentes adquirem um valor constante, dizendo-se então que o sistema atingiu um estado de equilíbrio. O gráfico apresentado na Figura 8 mostra esse fenômeno, que também reforça 0 conceito de que o catalisador atua sobre o mecanismo de uma dada reação tornando-a mais rápida, mas não interfere no rendimento dessa reação. 


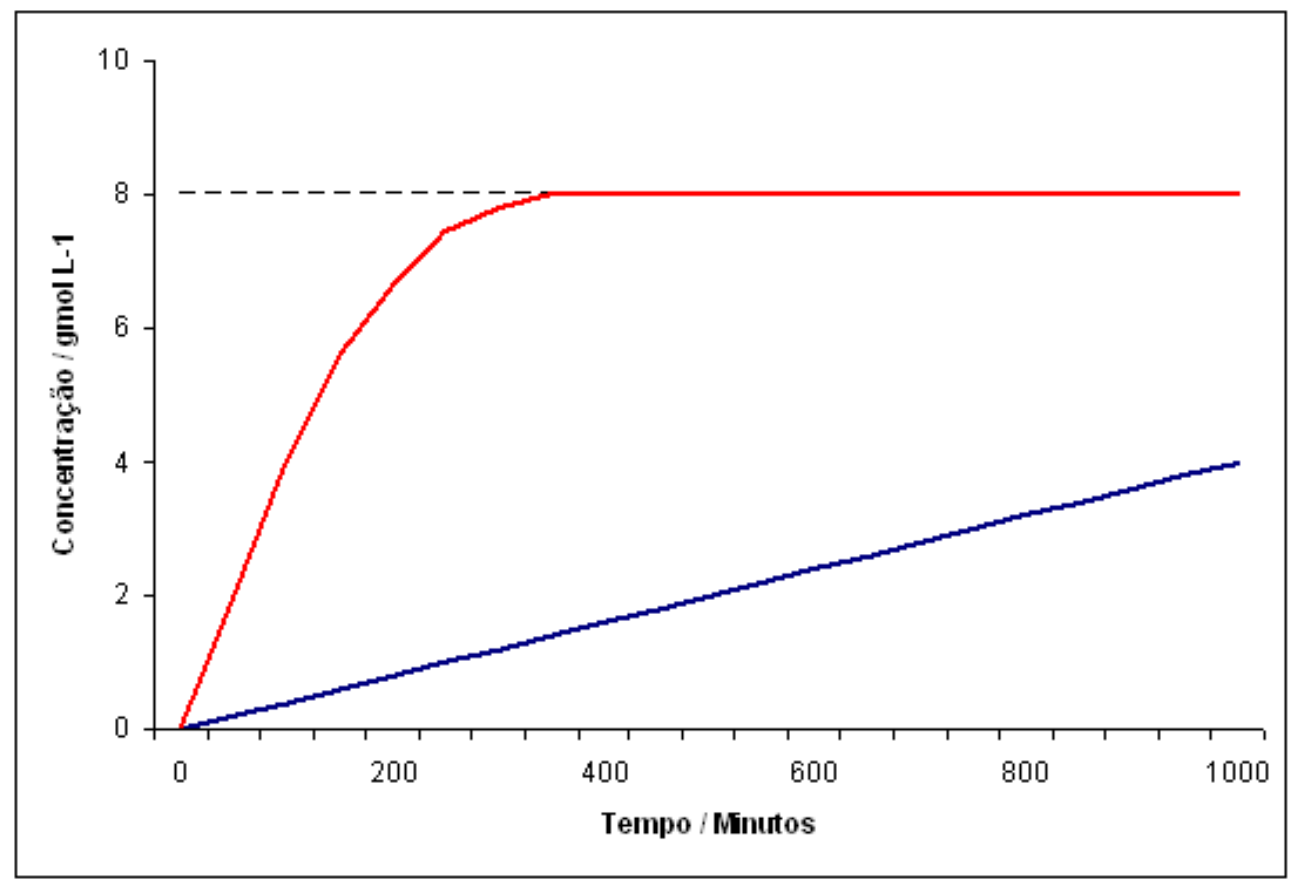

Figura 8 - Concentração de produtos obtida em reações catalíticas (linha vermelha) e não catalíticas (linha azul)

Pelo princípio de Le Chatelier, se um sistema em equilíbrio é submetido a qualquer perturbação exterior, o equilíbrio desloca-se no sentido contrário a essa perturbação. $O$ equilíbrio é afetado principalmente por dois parâmetros: temperatura e pressão.

Aumentando-se a temperatura do sistema em que uma dada reação ocorre, o processo endotérmico é favorecido. Diminuindo-se a temperatura desse mesmo sistema, o processo exotérmico é favorecido.

Aumentando a pressão do sistema, o processo é deslocado no sentido do estado de menor número de moléculas em estado gasoso. Reduzindo a pressão do sistema, o processo é deslocado no sentido do estado de maior número de moléculas em estado gasoso.

Qualquer sistema em que uma reação química possa ocorrer espontaneamente tende a se transformar de modo a se aproximar de um estado final de equilíbrio. Uma reação é dita espontânea, se e somente se a sua variação de energia livre entre o estado inicial e o estado final for menor 
que zero $(\Delta G<0$, e diz-se então que o sistema tem capacidade de realizar trabalho útil).

Seja a reação: a. A + b. B $\rightarrow$ c. C + d. D

A Lei da Ação de Massa diz que se um determinado sistema está em equilíbrio a uma determinada temperatura e pressão, então a razão $\left[\mathrm{C}_{C}\right]^{c}\left[\mathrm{C}_{D}\right]^{\mathrm{d} /}\left[\mathrm{C}_{A}\right]^{a}\left[\mathrm{C}_{B}\right]^{b}$ é constante e é chamada de constante de equilíbrio da reação, $\mathrm{K}$.

A Entalpia é uma propriedade termodinâmica extensiva (o valor da propriedade no sistema analisado é igual à soma dos valores da variável nas partes que compõem este sistema). É também uma função de estado (depende apenas da situação inicial e final que se encontra um dado sistema), sendo utilizada para determinação quantitativa da máxima energia presente, em um sistema termodinâmico e pode ser removida na forma de calor.

É definida como a soma da energia interna e o produto pressão-volume de um sistema $(\mathrm{H}=\mathrm{U}+\mathrm{P} . \mathrm{V})$, em que:

$\mathrm{U}=$ Energia interna do sistema;

$\mathrm{P}=$ Pressão absoluta do sistema;

$\mathrm{V}=$ Volume do sistema

A entalpia de uma reação química é entendida como o calor liberado ou absorvido em uma reação química e pode assumir valores positivos (reação endotérmica, ou que, absorve calor) ou negativos (reação exotérmica, ou que, libera calor).

A entalpia de reação está relacionada à constante de equilíbrio da reação através da equação de Van't Hoff:

$$
\frac{d \ln \mathrm{K}}{d T}=\frac{\Delta H^{\circ}}{R T^{2}}
$$


Entretanto, a entalpia de reação é uma função da temperatura. Assim, se a constante de equilíbrio da reação for conhecida pode-se determinar a entalpia de reação, como mostrado na Figura 9.

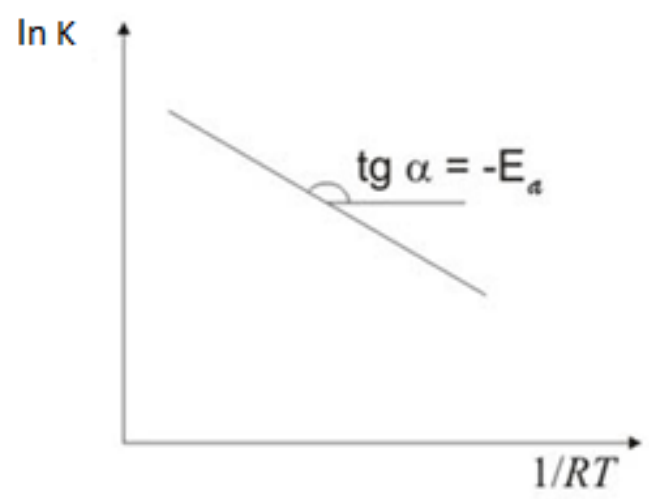

Figura 9 - Representação do cálculo da energia de ativação de uma reação (adaptado de OXITENO S/A INDÚSTRIA E COMÉRCIO, 2004)

\subsubsection{Produtividade}

É definida como a produção de óxido de etileno dividida pelo volume de catalisador utilizado no processo reacional.

A produtividade indica a quantidade de óxido de etileno que pode ser produzida por hora por unidade de volume de catalisador, sendo um parâmetro importante para se comparar desempenho de catalisadores e de diferentes unidades produtivas (SCIENTIFIC DESIGN COMPANY, 1998).

\subsubsection{Velocidade Espacial}

É definida como a vazão volumétrica de gás de reciclo que alimenta o reator, dividido pelo volume do leito de catalisador. Conceitualmente, representa o inverso do tempo de residência do gás no leito de catalisador. Quanto maior a velocidade espacial, menor é o tempo de residência do gás. É um parâmetro muito utilizado para comparar o desempenho de diferentes reatores e catalisadores em diferentes condições de operação (SCIENTIFIC DESIGN COMPANY, 1998). 
Este parâmetro está intimamente ligado ao desempenho do processo, uma vez que, a elevação do valor desse parâmetro contribui para o aumento do coeficiente de transmissão de calor nos tubos do reator e da seletividade do processo.

Do ponto de vista conceitual, quanto maior a vazão volumétrica de gás de reciclo escoando pelos tubos do reator, melhor será o desempenho da reação, ocorrendo, teoricamente um aumento da seletividade e um aumento na atividade (CRI CATALYSTS, 1996). Isso porque, nessas condições, obtém-se um menor tempo de residência para a corrente gasosa, levando a uma menor conversão de oxigênio, o que desfavorece a ocorrência da reação secundária e proporciona uma menor temperatura de operação para o processo. Por outro lado, quanto maior esta vazão, maior será concentração de oxigênio na saída, que necessita ser gerenciada continuamente para se evitar o atingimento das concentrações que levem a mistura gasosa a sua região de inflamabilidade.

Em condições normais de operação não são recomendadas variações na vazão volumétrica de gás de reciclo para o reator (obtida, na prática, através da variação da rotação do compressor de alimentação do gás de reciclo). Uma redução brusca da vazão de gás de reciclo aumenta o tempo de residência da corrente gasosa no reator e, eleva, rapidamente, a temperatura dos gases no leito catalítico e na saída do reator, pois, aumenta a conversão de oxigênio no processo. Como resultado, tem-se a ocorrência de reações de oxidação sem controle. Esse fenômeno é facilmente observado pelo aumento na temperatura de saída dos gases do reator, aumento do teor de subprodutos oriundos de reações de oxidação incompletas, como CO e propileno, além do aumento da composição dióxido de carbono. Em casos extremos, em que a redução dessa vazão é demasiadamente elevada, existe o risco da ocorrência de um descontrole da reação (capacidade de remoção de calor inferior à geração de calor oriunda das reações ocorridas no reator). 


\subsubsection{Temperatura da Reação}

O controle da temperatura da reação tem por objetivo principal garantir as taxas de conversão desejadas e manter o controle do fluxo de calor oriundo da energia liberada pelas reações que ocorrem no processo. Um aumento desnecessário da temperatura de reação eleva a taxa de combustão de etileno, o que resulta em um aumento da reação de oxidação do etileno, liberando mais energia, além de contribuir para uma queda da seletividade da reação.

\subsubsection{Pressão de Operação}

Este parâmetro também apresenta influência no comportamento do processo, uma vez que interfere nos valores da densidade do gás de reciclo, o que afeta diretamente todo o comportamento de velocidades no processo e 0 desempenho do sistema de compressão.

Teoricamente sua influência apresenta menor intensidade que as outras variáveis citadas. À medida que a pressão de operação é aumentada, esperase uma queda na seletividade e na temperatura da reação (CRI CATALYST, 1996)

\subsubsection{Qualidade das Matérias Primas}

O grau de pureza de matérias primas é essencial para se garantir a máxima eficiência nesse tipo de processo. $O$ efeito dos principais contaminantes da corrente de etileno sobre o desempenho da reação de formação de óxido de etileno foi discutido e relatado pelos detentores da tecnologia, como mostrado a seguir (SCIENTIFIC DESIGN COMPANY, 1998).

O Etileno, por exemplo, é um hidrocarboneto que apresenta traços de contaminantes críticos ao processo, tais como etano. A principal preocupação em relação à presença de etano na corrente de etileno está no fato de que existem interações entre as moléculas de etano e de inibidores da reação (a serem analisados no item 3.7), o que pode levar a uma queda do desempenho 
da reação. Daí a necessidade de se trabalhar com a máxima estabilidade possível para o teor de etano na corrente de gás de reciclo.

Outros hidrocarbonetos contaminantes que também merecem destaque são:

- Acetlieno, que reduz a atividade e a seletividade do catalisador, sendo que o efeito desse componente sobre o desempenho do catalisador é reversível, desde que sua concentração não ultrapasse 1000 ppm na composição do gás de reciclo, por um curto espaço de tempo;

- Propileno, que atua como agente oxidante no processo, aumentando a exotermia das reações.

Além disso, a presença desses compostos contribui para a formação de depósitos nos tubos do reator, impedindo a reação entre etileno e oxigênio.

Também é importante ressaltar a necessidade de minimizar o teor de enxofre na alimentação do processo, uma vez que esse componente atua como veneno para o catalisador, interferindo de forma irreversível no desempenho do catalisador. É possível eliminar o enxofre da corrente de alimentação de etileno através da passagem dessa corrente por um leito de absorção de enxofre à base de óxido de zinco.

No caso do oxigênio, o principal contaminante que interfere no desempenho da reação de formação do óxido de etileno é o Argônio.

O argônio é um inerte que ocupa espaço dentro do meio reacional sem trazer benefícios ao processo. Além disso, interfe na determinação do limite de flamabilidade do gás de reciclo (quanto maior o teor de argônio, menor o limite de flamabilidade). Para minimizar esse risco de segurança de processo, existe a necessidade da realização de uma purga períodica de parte da corrente de gás de reciclo visando reduzir a concentração de argônio no sistema. Uma vez que esta corrente é eliminada para a atmosfera e possui concentrações relevantes de etileno, naturalmente existe um impacto ambiental associado a esse processo de purga (além de queda de produtividade devido a perda de 
etileno para a atmosfera). Daí a necessidade de trabalhar com elevada pureza na corrente de oxigênio que alimenta o reator (KIRK-OTHMER, 2007).

\subsubsection{Segurança do Processo de produção de óxido de etileno}

A molécula de óxido de etileno é altamente reativa e o processo produtivo requer controles extremamente rígidos, de forma a minimizar riscos de reações descontroladas de combustão, as quais podem ocorrer em três pontos do processo, como relatado por Buffoni (2008):

- Antes da alimentação do reator, sendo conhecida como pré-ignição;

- Dentro dos tubos do reator, também conhecida como runaway;

- Na saída dos tubos do reator, a chamada pós-ignição.

\subsubsection{Pré-lgnição}

A pré-ignição é o nome dado à reação descontrolada de oxidação do etileno, quando esta ocorre em um ponto do processo localizado antes da entrada do gás de reciclo no reator.

Os pontos mais críticos para a ocorrência desse fenômeno são:

- Na estação de mistura, que é o primeiro ponto em que o oxigênio pode exceder a concentração limite de inflamabilidade do gás de reciclo, ou;

- Mais provavelmente, no trocador gás-gás, onde ocorre um aumento da temperatura do gás de reciclo antes de sua alimentação no reator.

A ocorrência do fenômeno de pré-ignição está normalmente associado a erros nas análises das concentrações dos componentes do gás de reciclo, falhas mecânicas ou de instrumentação, e erros de avaliação do operador em relação à gestão do processo produtivo (SHELL INTERNATIONAL CHEMICAL B.V, 2005). 
Quando esse fenômeno é evidenciado, a temperatura do ponto onde a préignição está ocorrendo sobe rapidamente até a faixa de 800 a $900^{\circ} \mathrm{C}$ e todo o oxigênio é consumido em um período de aproximadamente 3 minutos. Durante esse tempo, os equipamentos, tubulações e tubos do reator ficam submetidos a elevadas temperaturas, porém, uma vez que esse espaço de tempo é bastante curto, não são esperados danos que venham a comprometer as propriedades mecânicas e químicas desse conjunto.

Uma vez ocorrida uma pré-ignição, a alta temperatura do gás de reciclo na entrada do reator pode ser atenuada através da presença de um leito de inertes (que atua como uma seção de resfriamento dessa corrente), antes do efetivo contato da mistura reacional com o leito catalítico, o que é previsto nos projetos de reatores de produção de óxido de etileno (SHELL INTERNATIONAL CHEMICAL B.V, 2005).

Os itens mais sensíveis ao aumento de temperatura do gás de reciclo são as tubulações e o bocal de entrada do reator, principalmente nesse último ponto onde a velocidade de escoamento da corrente é a máxima. Nos demais equipamentos, localizados à montante do leito catalítico, em que as velocidades de escoamento são menores e os projetos mecânicos preveem paredes metálicas externas mais espessas, a criticidade é menor.

O controle da temperatura de todo o processo produtivo é, portanto, de extrema importância para se gerenciar a segurança operacional. Com esse objetivo, unidades produtoras de óxido de etileno contemplam sistemas de intertravamento que atuam sobre a vazão de alimentação de oxigênio para o processo, reduzindo-a a zero caso sejam percebidas elevações bruscas na temperatura do processo (CRI CATALYST, 1996). Esse sistema de intertravamento é gerenciado por termopares com sinais elétricos que precisam garantir respostas rápidas às variações do processo, para que o corte do suprimento de oxigênio após a detecção do fenômeno seja inferior a 20 segundos (OXITENO S/A INDÚSTRIA E COMÉRCIO, 2001). 


\subsubsection{Ignição no Tubo (runaway)}

O termo "runaway" é usado para descrever a situação em que o etileno é completamente oxidado a dióxido de carbono e água dentro do leito de catalisador, consumindo, desta forma, todo o oxigênio disponível, sem que ocorra a formação de óxido de etileno. A oxidação completa a $\mathrm{CO}_{2}$ e água produz muito mais calor que a oxidação parcial a óxido de etileno (SHELL INTERNATIONAL CHEMICAL B.V, 2005).

Numa situação de runway, verifica-se um aumento da temperatura da água que escoa pelo casco do reator e, é utilizada para resfriamento da reação. Em seguida, ocorre também um aumento da temperatura da corrente de gás de reciclo, e, consequentemente, das taxas de reação. Com o aumento das taxas de reação, a conversão do oxigênio também aumenta, resultando em uma maior produção de dióxido de carbono e menos óxido de etileno, pois uma elevada conversão de oxigênio favorece a ocorrência da reação secundária. Assim, mais calor é gerado no processo. Neste cenário, em que a área de troca térmica (ou capacidade de resfriamento do processo) permanece constante e a geração de calor cresce significativamente, não há como se controlar as reações (CRI CATALYST, 1996).

A ignição no interior dos tubos do reator está, normalmente, relacionada às seguintes situações:

- Perda de carga elevada nos tubos do reator, ocasionada por um mau processo de carregamento do catalisador no reator, gerando uma perda de carga acima do padrão desejado. Nesse caso, evidencia-se um maior tempo de residência da corrente de gás de reciclo escoamento pelo interior dos tubos, resultando numa maior conversão de oxigênio;

- Falhas no sistema de controle da temperatura da reação;

- Falha no controle da concentração de inibidores da reação na corrente de gás de reciclo, como descrito detalhadamente em 3.7, contribuindo para o incremento da taxa da reação secundária. 
A perda de controle da reação pode ser detectada pelo aumento da temperatura, pelo aumento na concentração de monóxido de carbono (CO) ou pela redução da concentração de oxigênio na corrente de gás de reciclo na saída do reator. Uma elevação na produção de vapor também pode indicar um início de perda de controle da reação. A geração de monóxido de carbono ocorre porque a concentração de oxigênio no gás de reciclo se torna muito pequena quando comparada a de etileno, resultando em um processo de oxidação incompleto.

O pico de geração de calor durante esse processo dura menos de 20 segundos, sendo esse o tempo requerido para se efetuar o corte de alimentação de oxigênio para o processo. Mesmo sem a alimentação de oxigênio, a reação continua em condições de oxidação completa, até que todo o oxigênio presente no gás de reciclo seja consumido.

O reator e seus tubos devem ser projetados de modo a prever esse tipo de ocorrência, sabendo-se que a exposição dos tubos do reator a elevadas temperaturas deve acontecer por um curto espaço de tempo, o que não deve comprometer suas propriedades mecânicas (OXITENO S/A INDÚSTRIA E COMÉRCIO, 2001).

\subsubsection{Pós-lgnição}

A oxidação completa do gás de reciclo na saída do reator, após o leito catalítico, é chamada pós-ignição.

Fenômenos de pós-ignição são observados com mais freqüência que as de pré-ignição e resultam em um aumento na temperatura de saída do gás de reciclo, podendo atingir valores da ordem de $700^{\circ} \mathrm{C}$, além da formação de depósitos de carbono nas paredes dos tubos do reator e elevação da concentração de monóxido de carbono na corrente de gás de reciclo (SHELL INTERNATIONAL CHEMICAL B.V, 2005). 
A pós-ignição normalmente está relacionada às seguintes situações:

- Temperatura de reação muito baixa, o que resulta em uma baixa conversão de oxigênio ao longo do leito catalítico, elevando a concentração desse componente na corrente de gás de reciclo na saída do reator. Esta situação é mais comum durante distúrbios operacionais;

- Pouca atividade na região inicial do leito de catalisador, ocasionada muitas vezes por falhas no trocador de calor que pré-aquece a corrente de gás de reciclo a ser alimentada no reator;

- Presença de pó de catalisador, oriundo do processo de carregamento do catalisador nos tubos, que pode se depositar nas tubulações de saída do reator, e acelerar a ocorrência de pós-ignições.

A pós-ignição pode ser detectada por alarmes de temperatura elevada na corrente de saída do reator, sendo necessário que o projeto do reator preveja a existência de instrumentos de detecção e transmissão que, garantam que o tempo de resposta desde o início desse processo até o bloqueio efetivo da vazão de oxigênio para o reator, não ultrapasse 20 segundos (OXITENO S/A INDÚSTRIA E COMÉRCIO, 2001).

\subsection{Reatores para produção de Óxido de etileno}

As reações de produção de óxido de etileno são realizadas em pressões da ordem de 20 atm e temperaturas entre 230 e $260^{\circ}$ C (só é possível trabalhar nessas condições de temperatura em função da utilização de um catalisador. $\mathrm{Na}$ ausência deste, a reação só ocorreria em temperaturas da ordem de 480 a $\left.590^{\circ} \mathrm{C}\right)$.

Reatores tubulares de leito fixo, no formato de trocadores de calor tipo casco tubos, como mostrado na Figura 10, têm sido utilizados para esse processo. No lado dos tubos circula a mistura reacional (denominada gás de reciclo) enquanto que no casco circula um fluido que tem por objetivo retirar calor do 
sistema (exotermia da reação). O reator é posicionado verticalmente com escoamento descendente dos fluidos (LIBANIO, 1995).

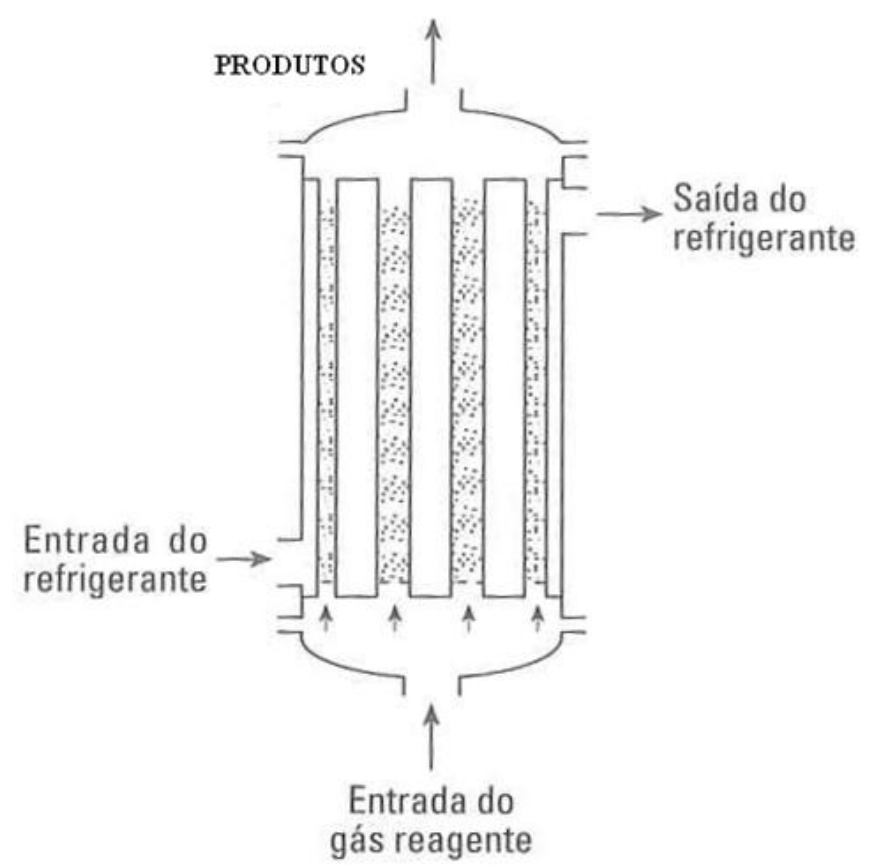

Figura 10 - Configuração típica de um reator tubular de leito fixo para produção de óxido de etileno

Estudos realizados por Coombs, Kim e Palombo (1997) reafirmam a opção por reatores tubulares por três razões principais:

- Primeiro, devido à possibilidade de alcançar maiores velocidades de escoamento, possibilitando a obtenção de coeficientes de transferência de calor mais elevados;

- Segundo, porque cinéticas similares à da oxidação do etileno são favorecidas neste tipo de reator, por requererem um menor volume;

- Finalmente, devido ao próprio histórico de sucesso operacional desses reatores em plantas mais antigas.

Em complemento a estes estudos, Levenspiel (1999) também aponta algumas características que direcionam para a escolha desse tipo de reator:

- O escoamento de gases através de leitos fixos se aproxima de um escoamento em um reator pistonado; 
- Os leitos fixos não podem usar partículas muito pequenas de catalisador devido a riscos de obstrução, o que acarretaria em uma alta perda de carga durante o escoamento dos gases;

- O catalisador utilizado nesse processo não é regenerado para uso posterior. Situações como esta, em que o catalisador é carregado no processo uma única vez e utilizado até o final de sua vida útil prevê a utilização de leitos fixos.

\subsubsection{Simulação de reatores de produção de óxido de etileno}

A modelagem de reatores multitubulares para a produção de óxido de etileno considera um fluxo sem dispersão axial, justificada por Libanio (1995), em função das condições de reação (altas temperaturas e condições geométricas de construção dos tubos que garantem um escoamento em alta velocidade), e requer a utilização de modelos termodinâmicos que permitam obter estimativas consistentes das propriedades dos componentes envolvidos no processo.

A seleção de um método de propriedades apropriado é fundamental na obtenção de resultados coerentes em um processo de simulação, uma vez que está diretamente relacionado à determinação de propriedades como coeficiente de fugacidade, entalpia, energia livre de Gibbs, viscosidade, condutividade térmica, coeficiente de difusão e tensão superficial (OPPE, 2012)

Um simulador de processos é uma ferramenta muito útil para representação de equipamentos de processo de unidades existentes ou para projetos de novas unidades. Neste trabalho foi utilizado o simulador de processo ASPEN PLUS para a avaliação fenomenológica do processo estudado. Porém, deve-se ter uma atenção especial na escolha dos modelos termodinâmicos e seus respectivos parâmetros, pois, quando não adequados, podem levar a resultados com grandes desvios em relação ao comportamento real de um processo.

Nesse simulador, cada método de cálculo de propriedades de equilíbrio é baseado em métodos das equações de estado e/ou métodos do coeficiente de 
atividade (este último é considerado a melhor maneira de representar misturas líquidas altamente não ideais a baixas pressões, quando são disponíveis dados experimentais).

Carlson (1996) descreve uma metodologia que direciona um pesquisador ou engenheiro à escolha de um modelo termodinâmico adequado às condições do processo em estudo. A principal etapa desse processo consiste na seleção de um método apropriado para o cálculo das propriedades físicas, o qual deve considerar quatro fatores:

- A natureza das propriedades de interesse: Muitas simulações de processos químicos incluem operações de destilação e evaporação, por exemplo. Desta forma, as relações de equilíbrio líquido vapor devem ser consideradas relevantes na escolha do método. Outro ponto crítico está relacionado à determinação das entalpias de componentes puros e de misturas de componentes. Além disso, propriedades como viscosidade, densidade, $\mathrm{pH}$ e condutividade térmica, muitas vezes são fundamentais para a realização de cálculos e dimensionamento de equipamentos.

- A composição da mistura: A composição influencia o cálculo de todas as propriedades e interfere no equilíbrio de fases, principalmente pelo fato de existirem interações entre os componentes da mistura. Normalmente, as interações na fase líquida são mais relevantes, pois, as moléculas estão mais próximas nesta fase.

- Os intervalos de pressão e temperatura para os quais se pretende modelar o processo: Esta definição é particularmente importante na escolha do método utilizado para modelagem do equilíbrio de fases de um sistema. Modelos cujos cálculos são fundamentados na lei de Raoult ou no uso de coeficientes de atividade não são precisos em condições de altas pressões, ou quando a temperatura do processo em estudo está acima da temperatura crítica de um componente. 
- A disponibilidade de parâmetros para a realização de simulações: Se parâmetros binários que representam interações entre componentes não estiverem disponíveis em literatura ou no banco de dados de um simulador, é impossível a realização dos cálculos das propriedades de uma mistura de componentes, ou mesmo, de um componente puro. Ao se utilizar um simulador, esses parâmetros precisam ser pesquisados em literatura, ou obtidos experimentalmente, de modo a se permitir a realização de cálculos consistentes.

Adotando como referência esta metodologia, Carlson (1996) também recomenda a utilização de uma árvore de decisões para a escolha do melhor modelo para o processo em estudo. Esta árvore de decisões pode ser aplicada ao processo descrito neste trabalho, em que se tem a presença de componentes polares, com pressões de operação acima de 10 bar e, cujos parâmetros binários de interação entre moléculas estão disponíveis no próprio banco de dados do simulador de processos.

Nessas condições, os modelos termodinâmicos de Peng-Robinson, RedlichKwong e Redlich-Kwong-Soave são identificados como adequados para a representação do processo.

Inicialmente desenvolvidas para representar as propriedades de uma fase gasosa, algumas equações de estado sofreram ajustes e modificações permitindo que também passassem a representar o comportamento de substâncias na fase líquida. De maneira geral, as equações de estado são classificadas em (TERRON, 1990):

- Equações teóricas: desenvolvidas segundo conceitos de Mecânica Estatística e Termodinâmica Estatística. Normalmente são equações de formas muito complexas envolvendo parâmetros de difícil avaliação. Essas equações permitem interpretações físicas do fenômeno que representam, mas, para serem empregadas na prática, requerem simplificações tais que, na maior parte dos casos, geram resultados apenas aproximados. 
- Equações Empíricas: Desenvolvidas por ajustes de dados experimentais a modelos puramente matemáticos, sem significado físico. Geralmente essas equações possuem muitos parâmetros, o que as tornam complexas e de difícil emprego.

- Equações Semi-Empíricas: São as equações mais utilizadas na prática, pois foram desenvolvidas por ajustes de dados experimentais a modelos matemáticos, apresentando também um significado físico baseado em uma dada teoria. São bastante utilizadas na indústria para o projeto de processos, simulação e otimização. Porém, são menos precisas para sistemas contendo moléculas polares e com fortes ligações de hidrogênio.

Sistemas constituídos por misturas gasosas onde estão presentes hidrocarbonetos de baixo peso molecular, gases que não pertencem à família dos hidrocarbonetos, e água (situação do estudo em questão) são bem representados pela equação de estado (equações 38 a 42) de Peng-Robinson (DAUBERT, 1985), reforçando o critério de escolha proposto por Carlson (1996).

$$
\begin{aligned}
& p=\frac{R T}{V_{m}-b}-\frac{a \alpha}{V_{m}^{2}+2 b V_{m}-b^{2}} \\
& a=\frac{0.45724 R^{2} T_{c}^{2}}{p_{c}} \\
& b=\frac{0.07780 R T_{c}}{p_{c}} \\
& \alpha=\left(1+\left(0.37464+1.54226 \omega-0.26992 \omega^{2}\right)\left(1-T_{r}^{0.5}\right)\right)^{2} \\
& T_{r}=\frac{T}{T_{c}}
\end{aligned}
$$


Nesse conjunto de equações, $\omega$ é o factor acêntrico das espécies, $R$ é a constante universal dos gases ideais, $Z=P V /(R T)$ é 0 fator de compressibilidade, Tc é a temperatura crítica do componente, Pc é a pressão crítica do componente e Tr é a temperatura reduzida do componente.

Recomendação similar é apresentada nos "guidelines for choosing a property method", sendo utilizado como critério para definição de propriedades de componentes e misturas quando se deseja avaliar o desempenho de um processo através do uso de simuladores (ASPEN PLUS, 1981).

Especificamente para misturas líquidas onde os componentes envolvidos são os listados nesse trabalho (óxido de etileno, etileno, oxigênio e demais produtos da reação), simulações de processo utilizando o modelo termodinâmico de Wilson fornecem resultados satisfatórios do ponto de vista de adequação entre dados teóricos e experimentais (MELLO, 2010). Ao se aplicar a metodologia da árvore de decisões proposta por Carlson (1996), as conclusões são similares: o modelo de Wilson, bem como NRTL e UNIQUAQ são boas escolhas para se representar adequadamente o comportamento do processo.

Essa adequação se deve principalmente ao fato do modelo de Wilson ser indicado para modelagem de soluções líquidas fortemente não ideais, porém miscíveis. Importante ressaltar que este modelo não é adequado para soluções em que pode ocorrer formação de duas fases líquidas (PRAUSNITZ; LICHTENTHALER; AZEVEDO, 1999).

O modelo de Wilson está baseado na estrutura molecular dos compostos da mistura, sendo a expressão para o cálculo da energia de excesso de Gibbs, válida para uma solução binária (tomando como referência uma solução ideal onde é aplicada a lei de Raoult), mostrada na equação 43. 
$\frac{g^{E}}{R T}=-x_{1} \ln \left(x_{1}+\mathrm{A}_{12} x_{2}\right)-x_{2} \ln \left(x_{2}+\mathrm{A}_{21} x_{1}\right)$

Dessa expressão são derivados os coeficientes de atividade $\left(\gamma_{\mathrm{i}}\right)$ de cada componente da mistura, os quais medem o grau de afastamento da mistura de sua condição de idealidade. Estes são representados pelas equações 44 e 45.

$$
\ln \gamma_{1}=-\ln \left(x_{1}+\mathrm{A}_{12} x_{2}\right)+x_{2}\left(\frac{\mathrm{A}_{12}}{x_{1}+\mathrm{A}_{12} x_{2}}-\frac{\mathrm{A}_{21}}{\mathrm{~A}_{21} x_{1}+x_{2}}\right)
$$

$$
\ln \gamma_{2}=-\ln \left(x_{2}+\mathrm{A}_{21} x_{1}\right)-x_{1}\left(\frac{\mathrm{A}_{12}}{x_{1}+\mathrm{A}_{12} x_{2}}-\frac{\mathrm{A}_{21}}{\mathrm{~A}_{21} x_{1}+x_{2}}\right)
$$

A equação de Wilson possui também dois parâmetros $\left(A_{12}, A_{21}\right)$, que estão relacionados ao volume molar dos componentes puros $\left(\mathrm{v}_{\mathrm{i}}\right)$ e a energia de interação entre os componentes da mistura (este conceito considera certa ordem na orientação das moléculas do líquido e não uma orientação aleatória). As equações 46 e 47, utilizadas para obtenção desses parâmetros são mostradas a seguir.

$$
\begin{aligned}
& \mathrm{A}_{12} \equiv \frac{v_{2}}{v_{1}} \exp \left(-\frac{\lambda_{12}-\lambda_{11}}{R T}\right) \\
& \mathrm{A}_{21} \equiv \frac{v_{1}}{v_{2}} \exp \left(-\frac{\lambda_{21}-\lambda_{22}}{R T}\right)
\end{aligned}
$$




\subsection{Catalisadores para os Processos de Produção de óxido de etileno}

Um catalisador pode acelerar significativamente a taxa de determinadas reações. A partir dessa premissa, um catalisador se torna mais adequado para o processo quanto mais seletivo ele for a favor da reação desejada para o processo.

De maneira geral, Levenspiel (1999) destaca algumas observações gerais em relação ao uso e seleção de catalisadores em processos industriais.

a) A seleção de um catalisador para promover uma dada reação não é $100 \%$ compreendida, podendo se necessitar de procedimentos de tentativa e erro, até que se encontre um catalisador que atenda as necessidades requeridas;

b) A explicação da ação de catalisadores está relacionada ao fato que estes modificam as moléculas de reagentes, de modo a formar intermediários nas regiões próximas à superfície do catalisador;

c) Em termos da teoria do estado de transição, o catalisador reduz a energia de ativação a ser vencida para que uma dada reação se inicie;

d) Embora o catalisador acelere a reação, ele nunca determina o equilíbrio ou o ponto final de uma reação. Essa característica é determinada somente pela termodinâmica do processo. Dessa forma, com ou sem catalisador, a constante de equilíbrio para a reação é sempre a mesma;

e) É importante que os catalisadores tenham grande superfície de contato uma vez que a superfície desse sólido é responsável pela atividade catalítica.

Sem a presença de um catalisador a energia de ativação da reação secundária é a menor de todas, fazendo com que as moléculas de etileno se direcionem para a busca dessa reação (nesse caso, diz-se que a seletividade da reação é 
próxima de zero). Além disso, sob essas condições de temperatura elevada, a maior parte das moléculas resultantes da reação de produção de óxido de etileno possui energia suficiente para romper a barreira da reação de formação de acetaldeído, que então reage muito facilmente para produzir $\mathrm{CO}_{2}$ e $\mathrm{H}_{2} \mathrm{O}$, como mostrado na Figura 11.

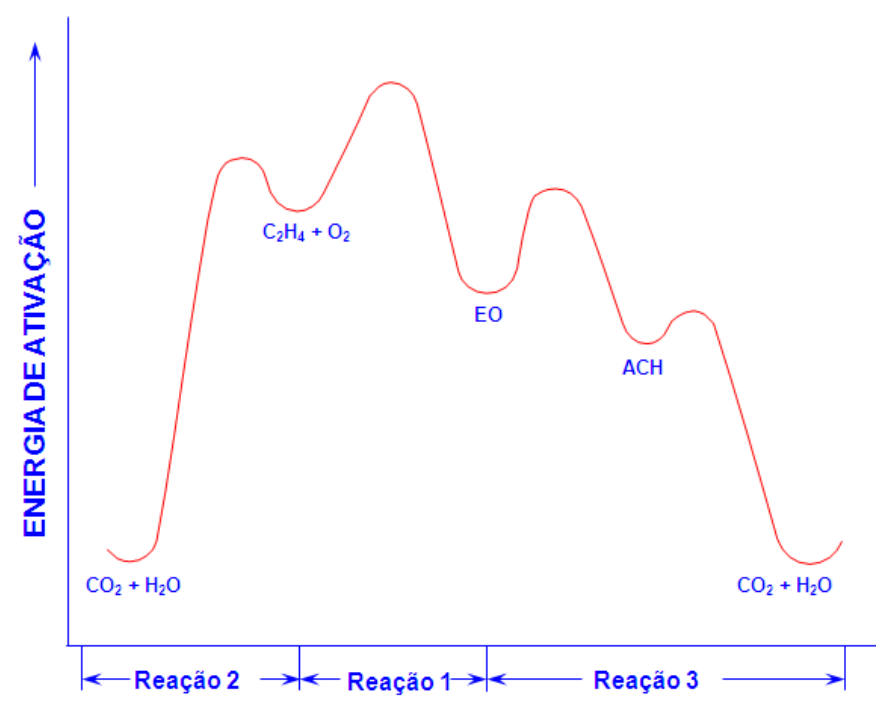

Figura 11 - Energias de ativação comparativas das reações de oxidação do etileno (adaptado de Buffoni, 2008)

A função do catalisador (à base de prata metálica) é baixar a energia de ativação de todas as reações, fazendo com que a energia de ativação necessária para a ocorrência da reação principal seja um pouco inferior à energia de ativação necessária para a ocorrência da reação secundária. Em resumo, o catalisador atua muito mais fortemente na redução da energia de ativação da reação principal. A Figura 12 exemplifica esse fenômeno. 


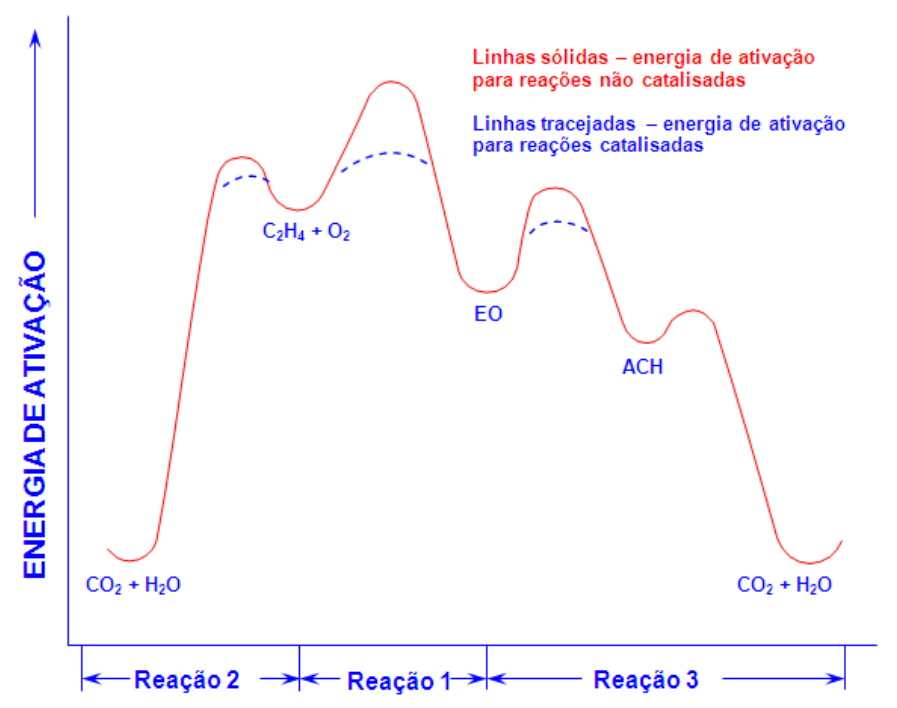

Figura 12 - Efeito do catalisador sobre as energias de ativação das reações de oxidação do etileno (adaptado de Buffoni, 2008)

O etileno e o oxigênio reagem mais facilmente sobre uma superfície de prata metálica do que se estivessem simplesmente misturados ao gás de reciclo. $O$ produto dessa reação (gases) deixa a superfície da prata novamente livre para que novas moléculas das matérias primas ocupem novamente esse espaço e promovam uma nova reação. Nessa nova condição, em que um catalisador está presente no meio reacional, a seletividade da reação se aproxima de 50\% - valor inaceitável do ponto de vista econômico - (OXITENO, 2004).

A geometria do catalisador (sua superfície e tamanho das partículas de prata depositadas no suporte) é um dos parâmetros de grande importância no desempenho da reação, pois, o etileno e o oxigênio reagem mais rapidamente quando se encontram sobre esta superfície de prata metálica do que se estivessem escoando livremente pelos tubos do reator.

Estudos relatados por Van Santen e Kuipers (1987) mostram que a eficiência na seletividade da reação de formação de óxido de etileno em uma superfície de prata cresce à medida que existe um maior contato entre a superfície da prata disponível para a realização do contato com o oxigênio 
A Figura 13 ilustra a disposição desejada de átomos de prata sobre a superfície de um suporte para o catalisador.

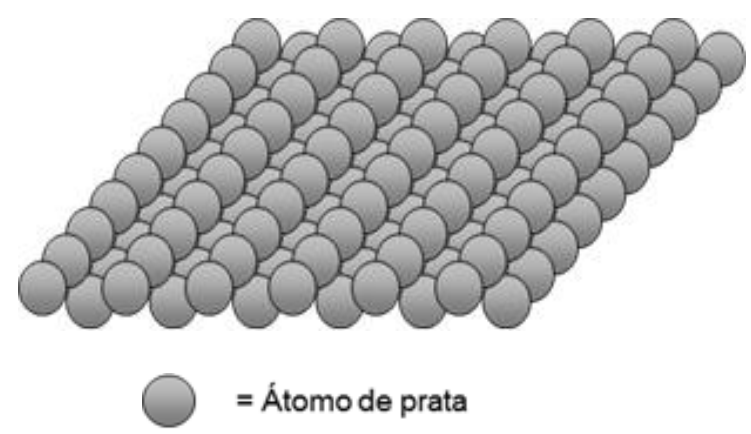

Figura 13 - Representação esquemática da superfície de um catalisador de prata (adaptado de Storey, 2007)

Após o contato dos reagentes na superfície metálica, os produtos obtidos em fase gasosa deixam a superfície livre para que novas moléculas de reagentes voltem a ocupar essas posições no catalisador (são os chamados sítios ativos do catalisador). Nault, Bolme e Johanson (1962) defendem em seus estudos que o processo de adsorção de reagentes e produtos ocorre de formas diferentes ao longo da superfície do catalisador e dos sítios ativos; sítios esses onde estaria evidenciada a maior atividade catalítica.

A distribuição da prata na superfície do catalisador é essencial para a obtenção de um número adequado de sítios ativos (locais na superfície da prata onde as moléculas de etileno e oxigênio reagem) nas partículas de catalisador. Quanto mais distribuídas pela superfície estiverem as partículas de prata, maior o número de sítios-ativos disponíveis e mais ativo o catalisador (STOREY, 2007).

A reação principal indica que a formação de óxido de etileno necessita da interação entre uma molécula de etileno com apenas um átomo de oxigênio. Como se tem uma quantidade significativa de oxigênio disponível na superfície do catalisador, é muito provável que o etileno reaja com mais de um átomo de oxigênio (Figura 14), o que favoreceria a ocorrência de reações não desejáveis. 


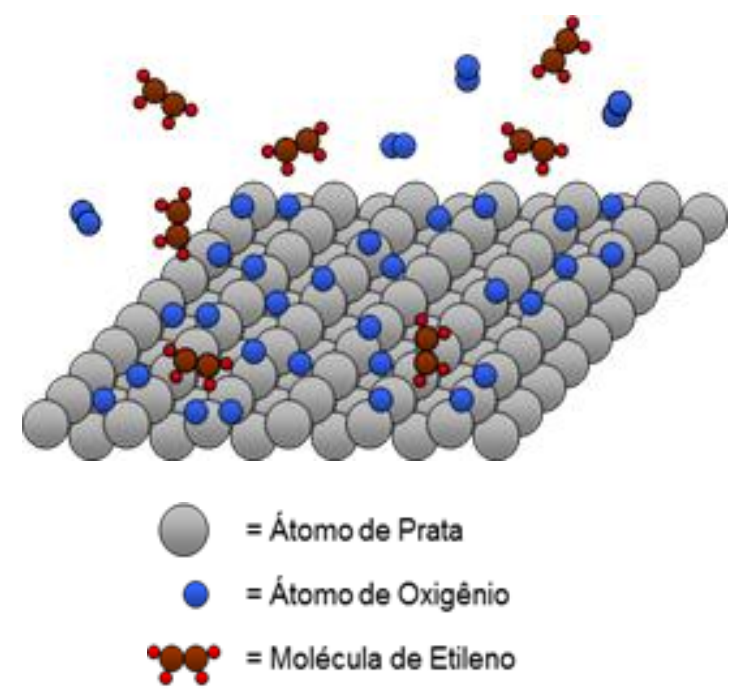

Figura 14 - Representação esquemática da área superficial de um catalisador de prata (adaptado de Storey, 2007)

\subsection{Inibidores da Reação Secundária (elevação da Seletividade da reação de formação de óxido de etileno)}

Os inibidores de reação são componentes fundamentais na obtenção da máxima seletividade de uma reação de formação de óxido de etileno. Aumentos consideráveis de seletividade são evidenciados, quando se adiciona à mistura reacional uma pequena quantidade de compostos contaminantes, que atuam de modo a direcionar a forma de adsorção dos átomos de oxigênio na superfície do catalisador. Essa condição reduz a probabilidade de uma molécula de etileno encontrar átomos de oxigênio adjacentes e posteriormente ser oxidada à $\mathrm{CO}_{2}$, como previsto nos mecanismos previamente apresentados (MURRAY, 1950).

Seletividades superiores a 90\% são relatadas por Van Santen e Kuipers (1987) e por Nakatsuji et al (1997), na presença de compostos clorados. Esses compostos têm por objetivo reduzir a probabilidade de ocorrência da reação do etileno com mais de uma molécula de oxigênio. A adição de um inibidor da reação secundária ao processo reduz o número de sítios ativos disponíveis para a reação e aumenta a seletividade, uma vez que favorece a reação do etileno com uma única molécula de oxigênio (Figura 15). 


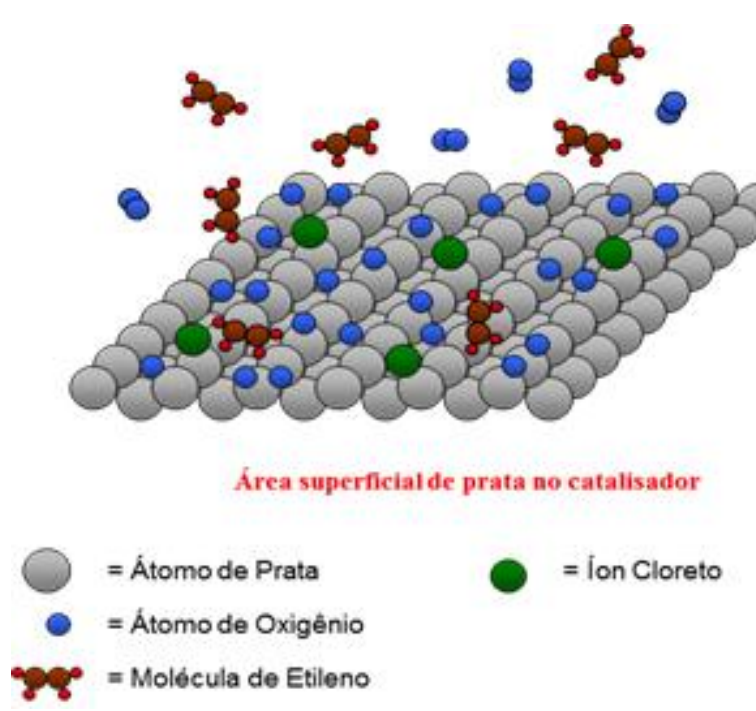

Figura 15 - Efeito da presença de clorados na superfície de um catalisador de prata (adaptado de Storey, 2007)

O principal inibidor de reação utilizado é o cloreto de etila (EC), cujas principais propriedades encontram-se listadas na Tabela 7. Outros compostos clorados presentes nesse processo são o cloreto de vinila (VC), cloreto de metila (MC) e o dicloroetano (DCE).

Tabela 7 - Principais Propriedades Físico Químicas do cloreto de etila (Inibidor da Reação)

\begin{tabular}{|l|l|}
\hline Estado Físico & Líquido (abaixo de $13^{\circ} \mathrm{C}$ ) \\
\hline Cor & Incolor \\
\hline Odor & Característico agradável \\
\hline Ponto de Ebulição & $12,2^{\circ} \mathrm{C}$ \\
\hline Ponto de Fusão & $-136,0^{\circ} \mathrm{C}$ \\
\hline Solubilidade em Água & $0,6 \mathrm{~g} / 100 \mathrm{ml}$ de água a $20^{\circ} \mathrm{C}$ \\
\hline
\end{tabular}

Quando o etileno se aproxima da superfície do catalisador, ao invés de reagir com uma molécula de oxigênio, ele pode reagir com um clorado (compostos que disputam com o oxigênio o sitio ativo da prata disponibilizado para reação), formando o composto cloreto de vinila. Quando isso acontece, o clorado é removido da superfície do catalisador. Pesquisas referentes ao efeito dos clorados sobre a seletividade concordam que a adsorção de clorados aumenta a concentração das espécies de oxigênio adsorvido de superfície - que também 
existe em superfícies com alta concentração de oxigênio (VAN SANTEN e KUIPERS, 1987).

O aumento da seletividade ocorre porque o clorado adicionado à superfície da prata atua de modo a direcionar a forma de entrada dos átomos de oxigênio para a realização do processo de adsorção. O oxigênio pode ser adsorvido na superfície da prata de duas formas: através de uma ligação tipo "ponte" ou através de uma ligação tipo "vertical" (Figura 16), sendo que, quando existe a ocorrência de ligações tipo "vertical", reduz-se a probabilidade de uma molécula de etileno encontrar átomos de oxigênio adjacentes e posteriormente ser oxidada à $\mathrm{CO}_{2}$, como previsto em mecanismos que buscam explicar o comportamento das reações (MURRAY, 1950).

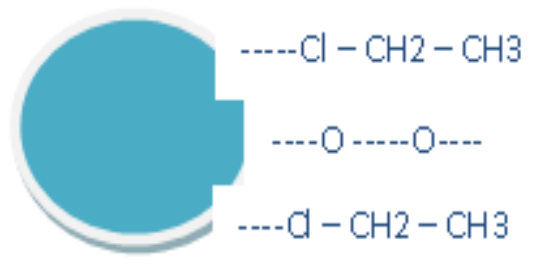

(a)

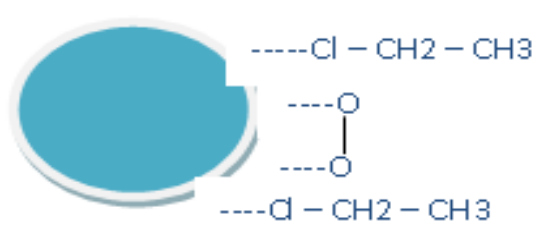

(b)

Figura 16 - Representação da adsorção do oxigênio em prata. (a) oxigênio adsorvido à prata por ligações tipo "vertical". (b) oxigênio adsorvido à prata por ligações tipo "ponte"

O processo de adsorção e remoção dos clorados na superfície do catalisador não é controlado por variáveis de processo que permitam sua gestão através de ações operacionais. Frente a isso, sugere-se a busca por mínimas variações em suas concentrações na corrente de gás de reciclo. Nota-se também a presença de substâncias conhecidas por dopantes ou promotoras. Nesse processo, as promotoras são substâncias como sódio, potássio, rênio e césio, que apresentam cargas elétricas opostas aos compostos clorados, atuando de modo a direcionar o encontro das moléculas de etileno com o oxigênio atômico, para favorecer o aumento da seletividade do processo. A presença dos dopantes também é mostrada na Figura 17. 
O mecanismo de atuação dessas promotoras sobre as reações envolvidas no processo ainda não é muito claro, porém Carvalho (2005) apresenta teorias sobre o papel dos promotores, relatando que o Césio tem a capacidade de aumentar a densidade eletrônica dos oxigênios adsorvidos, devido à interação da prata com oxiânions de Césio, beneficiando a oxidação total de etileno, mas, ao mesmo tempo, o Césio age inibindo a oxidação do óxido de etileno formado, aumentando dessa forma a seletividade do processo. Nesse cenário, o aumento da seletividade pela repressão da oxidação do óxido de etileno é maior que sua diminuição pelo aumento da densidade eletrônica dos oxigênios superficiais. Dessa forma, a seletividade é aumentada pela presença de Césio como promotor da reação.

Grant e Lambert (1985), apud Carvalho (2005) relatam resultados de experimentos onde catalisadores contaminados com moléculas de césio e rênio permitem a obtenção de valores mais elevados da seletividade da reação. Nessas condições, o césio bloqueia a oxidação do óxido de etileno, enquanto a densidade eletrônica dos oxigênios adsorvidos diminui pela adição de rênio. Essa combinação sobrepõe o efeito negativo da adição de césio para a oxidação completa, fazendo com que a seletividade seja mais elevada em função das combinações entre césio-rênio e prata.

Outros agentes importantes presentes nesse processo são os hidrocarbonetos presentes no gás de reciclo (etano e metano, em especial). Porém, existe uma competição na superfície do catalisador, onde átomos de clorados são removidos do processo por esses hidrocarbonetos. Um processo estável e que busca o ponto ótimo de operação, necessita manter a concentração de clorados o mais estável possível na superfície do catalisador (porém não é possível se medir e quantificar esse valor).

Hidrocarbonetos como o etano e o metano também podem remover os clorados da superfície do catalisador, formando cloreto de etila e cloreto de metila, respectivamente (Figura 17). Em suma, quanto maior a concentração de clorados no gás de reciclo, maior será sua concentração na superfície do catalisador. Porém, quanto maior a concentração de hidrocarbonetos no gás de 
reciclo, maior a remoção de clorados da superfície do catalisador (BUFONNI, 2008).

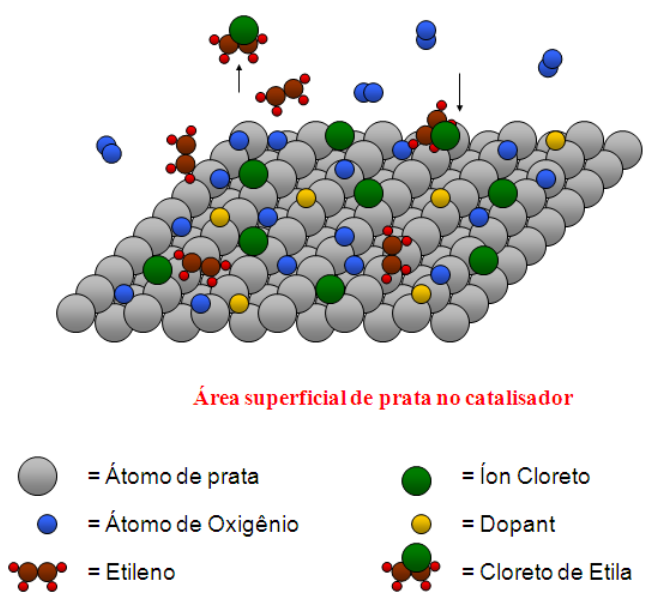

Figura 17 - Representação esquemática da influência de clorados na seletividade da reação de oxidação de etileno (adaptado de Storey, 2007)

Uma vez que não é possível realizar a medição do teor de clorados na superfície do catalisador, é necessário obter esse teor de uma forma indireta (o que é conseguido através do controle do teor de clorados na composição de gás de reciclo).

A existência de um analisador de clorados no gás de reciclo é, portanto, de vital importância para gerenciar o desempenho do processo [a concentração de clorados deve ser entendida como um somatório das concentrações de cloreto de etila (EC, ethyl chloride), cloreto de vinila (VC, vinyl chloride), dicloroetano (DCE) e cloreto de metila (MC, methyl chloride) neste gás]. Ou seja, quanto maior a concentração de clorados no gás de reciclo, maior será a concentração de clorados na superfície do catalisador.

Storey (2007) relata a importância da medição dessas concentrações, uma vez que elas permitem o cálculo de um fator (denominado fator $\mathrm{F}$ e calculado pela equação 48) que contabiliza matematicamente a distribuição dos clorados na superfície do catalisador. Ou seja, este fator mede a relação entre clorados que estão sendo adsorvidos na superfície da prata e os clorados que estão sendo adsorvidos pelos hidrocarbonetos presentes no gás de reciclo. 
Fator $\mathrm{F}=\frac{\mathrm{EC}+\mathrm{VC}+2 * \mathrm{EDC}+\left(\frac{\mathrm{MC}}{3}\right)}{\% \mathrm{C} 2 \mathrm{H} 4+85 *(\% \mathrm{C} 2 \mathrm{H} 6)}$

Uma dificuldade atrelada ao controle do Fator $F$ está no fato de que o comportamento do catalisador se altera com o passar do tempo em função do seu desgaste natural, devido envelhecimento, e do processo denominado sinterização (aglomeração de partículas de prata, formando partículas maiores na superfície do catalisador, reduzindo sua área ativa e, consequentemente, a presença de sítios ativos no processo). Em função dessas características, o Fator $\mathrm{F}$ necessita ser periodicamente ajustado.

\subsection{Métodos estatísticos: análise de um conjunto de dados multivariados}

A crescente competitividade mundial tem orientado muitas empresas para a busca da excelência operacional, motivada muitas vezes pelo alto desenvolvimento da automação e facilidade de monitoramento de grande número de variáveis dos processos produtivos. O monitoramento individual de cada uma dessas variáveis, apesar de ser trabalhoso e necessitar de um cuidadoso gerenciamento, pode ser realizado (MANZI; CALID, 1997).

Porém, os resultados obtidos para esse tipo de abordagem geralmente não são os melhores, uma vez que deixam de considerar os efeitos de interação entre as variáveis analisadas. Quando os efeitos de interações não podem ser desprezados (devido sua importância no processo), recomenda-se a adoção de métodos estatísticos multivariados, classificados em:

- Métodos de Dependência: buscam avaliar o grau de correlação existente entre variáveis dependentes e independentes (método utilizado neste estudo).

- Métodos de Interdependência: são utilizados quando, em um conjunto de variáveis, não são conhecidas quais são as variáveis dependentes e independentes. Nesses casos, os métodos buscam identificar como e porque determinadas variáveis estão correlacionadas. 


\subsubsection{Avaliação Estatística de Dados}

A avaliação estatística de um conjunto de dados pode seguir diferentes critérios. Neste trabalho, empregou-se uma sequência de métodos estatísticos, que ajudaram na visualização, seleção de variáveis, refinamento e validação dos modelos estatísticos de predição obtidos através de regressão.

\subsubsection{Construção de um Modelo de Regressão}

Kutner et al (2004) apresenta uma estratégia de construção de um modelo de regressão como mostrado na Figura 18, onde argumenta que esta estratégia envolve três e, às vezes, quatro fases, a saber:

1. Coleta e preparação dos dados;

2. Redução do número de variáveis exploratórias;

3. Refinamento e seleção do modelo;

4. Validação do modelo.

A etapa 1 deste trabalho, coleta e preparação de dados, está devidamente detalhada nos itens 4.5.3.1 e 4.5.3.2, do capítulo Materiais e Métodos, levando sempre em conta a estatística descritiva apresentada no item 3.8.2.1.

A etapa 2 deste trabalho, redução das variáveis exploratórias, está descrita no item 4.5.3.3, do capítulo Materiais e Métodos. A base desta seleção foi o uso da matriz de correlações empregando o teste de correlação de Pearson, apresentado no item 3.8.2.3.

A etapa 3, refinamento e seleção dos modelos, foi realizada através do uso do algoritmo Best Subsets do software MINITAB 15.0. Foi utilizado o critério do Cp de Mallows, descrito no item 3.8.2.4, para a escolha do número de variáveis que melhor representa um modelo de regressão. Em seguida foi realizado 0 diagnóstico de qual o modelo que melhor representa o processo em estudo, como descrito no item 3.8.6 e 3.8.7. 
Finalmente, a etapa 4, validação do modelo foi realizada como descrito nos itens 5.3.1, 5.3.2 e 5.3.3 do capítulo Resultados e Discussão.

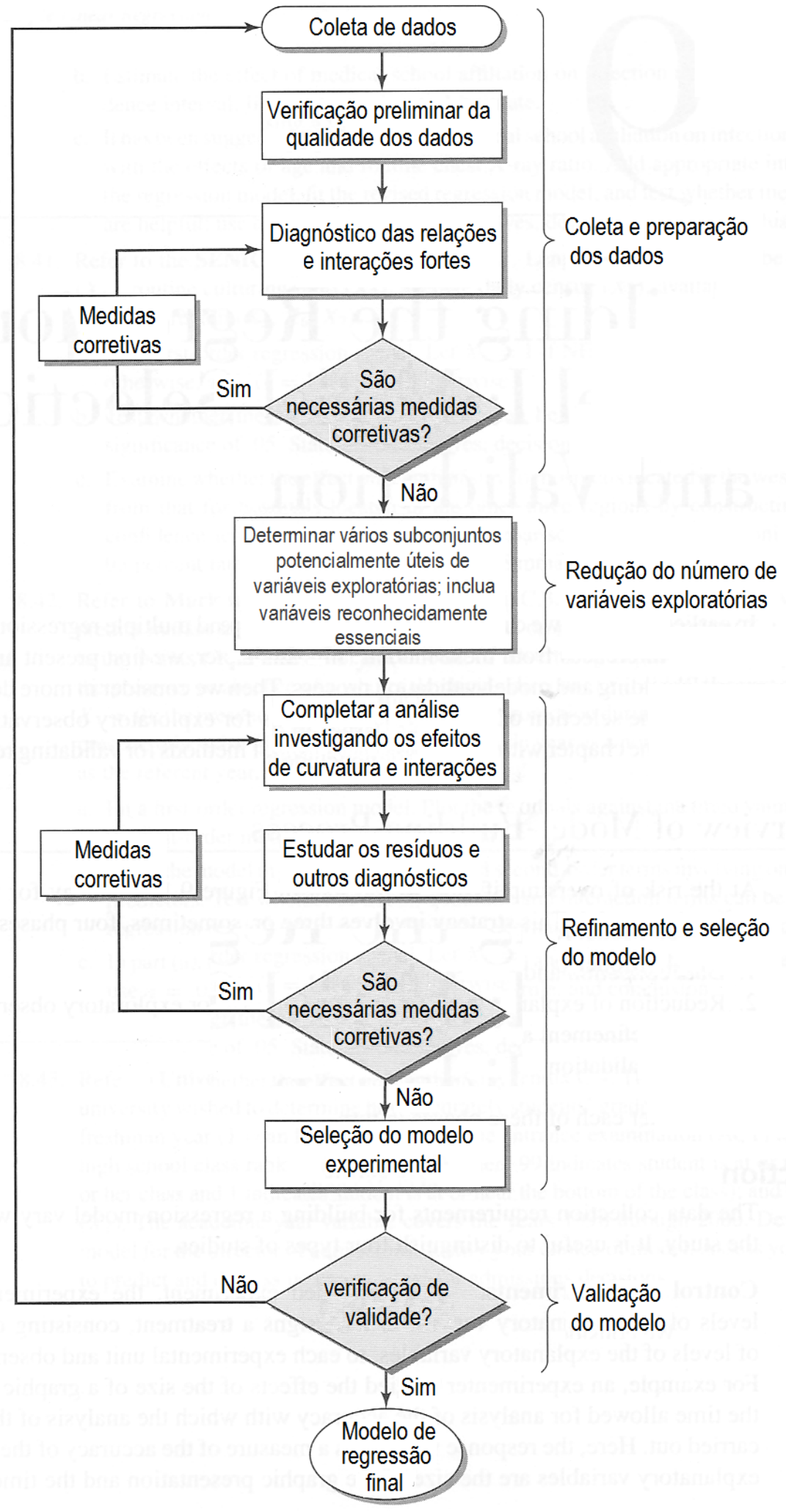

Figura 18 - Estratégia para construção de um modelo de regressão. Fonte: Kutner et al, 2004. 


\subsubsection{Medidas Estatísticas de dados}

As principais medidas de avaliação estatística de um conjunto de dados são (CAMARGO,1996):

- Medidas de tendência central.

- Medidas de dispersão.

A média é a principal ferramenta de avaliação da tendência central de um conjunto de dados, sendo calculada por:

$\mathrm{x}_{\mathrm{m}}=\frac{\left(\mathrm{x}_{1}+\mathrm{x}_{2}+\mathrm{x}_{3}+\cdots+\mathrm{x}_{\mathrm{n}}\right)}{\mathrm{n}}$

Onde $x_{1}, x_{2}, x_{3}, \ldots, x_{n}$ representam cada um dos dados do conjunto estudado e $n$ representa o número total de dados analisados

Normalmente representadas pela variância, medidas de dispersão avaliam quão distantes os dados se encontram do valor médio.

A variância está diretamente relacionada às variações observadas em um determinado conjunto de dados, sendo calculada pelo quociente entre 0 somatório dos quadrados da diferença entre cada valor individual $\left(\mathrm{x}_{\mathrm{i}}\right)$ e a média dos valores do conjunto em estudo $\left(x_{m}\right)$, também chamado de soma de quadrados (SS), e o número de graus de liberdade do sistema, GL.

$\operatorname{Var} \mathrm{x}_{\mathrm{i}}=\frac{\sum\left[\left(\left(\mathrm{x}_{\mathrm{i}}-\mathrm{x}_{\mathrm{m}}\right)\right)^{2}\right]}{\mathrm{n}-1}=\frac{(\mathrm{SS})}{\mathrm{GL}}$

\subsubsection{Visualização de dados}

A visualização de dados por meio de gráficos proporciona muitas ideias sobre o comportamento de um conjunto de variáveis (se existem diferenças entre amostras, como duas ou mais variáveis se correlacionam, etc). Isso ajuda o pesquisador a tomar decisões e formular hipóteses. A seguir são mostrados 
alguns gráficos típicos utilizados para a visualização de um conjunto de dados de variáveis distintas.

O primeiro deles mostra as características da distribuição dos dados (box-andwhiskers plots) e o outro indica como as variáveis, duas a duas, podem se correlacionar (Matriz de correlações).

Complementando a matriz de correlações, acrescenta-se 0 teste de correlações de Pearson que, além da visualização, quantifica a correlação, mostrando o valor do coeficiente e a probabilidade de significância do mesmo (MONTGOMERY, 2005).

\subsection{Box and whisker plots}

Box-and-Whisker plots ou simplesmente box-plots são simples representações diagramáticas dos cinco números sumários [valor mínimo, 1ำ quartil (quartil inferior), $2^{\circ}$ quartil (mediana), 3ำ quartil (quartil superior), valor máximo], sendo úteis para mostrar as características de distribuição de um conjunto de dados.

Um box-plot consiste de uma caixa (box), bigodes (whiskers) e outliers, como mostra o esquema da Figura 19. Eles podem ser representados vertical ou horizontalmente (MONTGOMERY, 2005).

A linha que divide a caixa é a mediana, as linhas a partir da caixa são os bigodes (whiskers). Estes limitam a distribuição e os pontos indicados pelos asteriscos são os pontos fora da curva (outliers). O fundo da caixa é o primeiro quartil e o topo da caixa é o terceiro quartil. Os limites dos bigodes são estimados, segundo Manual do software MINITAB 15.0, pelas equações 51 e 52.

Limite inferior:

$$
\text { L.I. }=Q_{1}-1,5\left(Q_{3}-Q_{1}\right)
$$


Limite superior:

$$
\text { L.S. }=Q_{3}+1,5\left(Q_{3}-Q_{1}\right)
$$

Os pontos que ficarem fora desses dois limites são os pontos considerados fora da distribuição padrão, também conhecidos como "outliers".

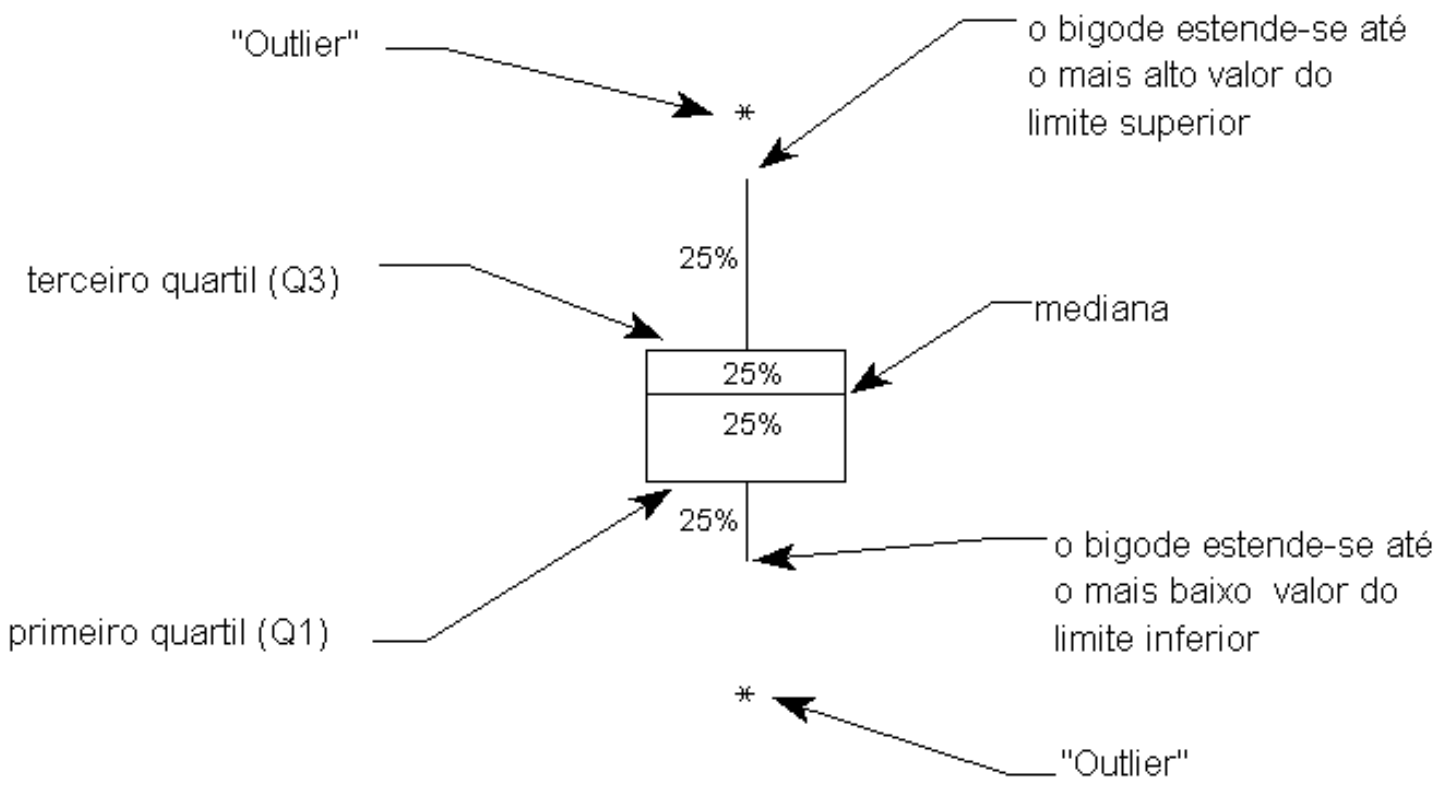

Figura 19 - Esquema ilustrativo apresentando as principais partes do Box-and-Wisker plots (ou simplesmente boxplot).

\subsection{Matriz de Correlações}

É uma matriz bidimensional e simétrica, composta por gráficos que correlacionam as variáveis de um processo (duas a duas), sendo útil para visualizar de forma imediata e qualitativa as potenciais correlações entre todas as variáveis envolvidas neste processo, como mostra a Figura 20 (MONTGOMERY, 2005). 


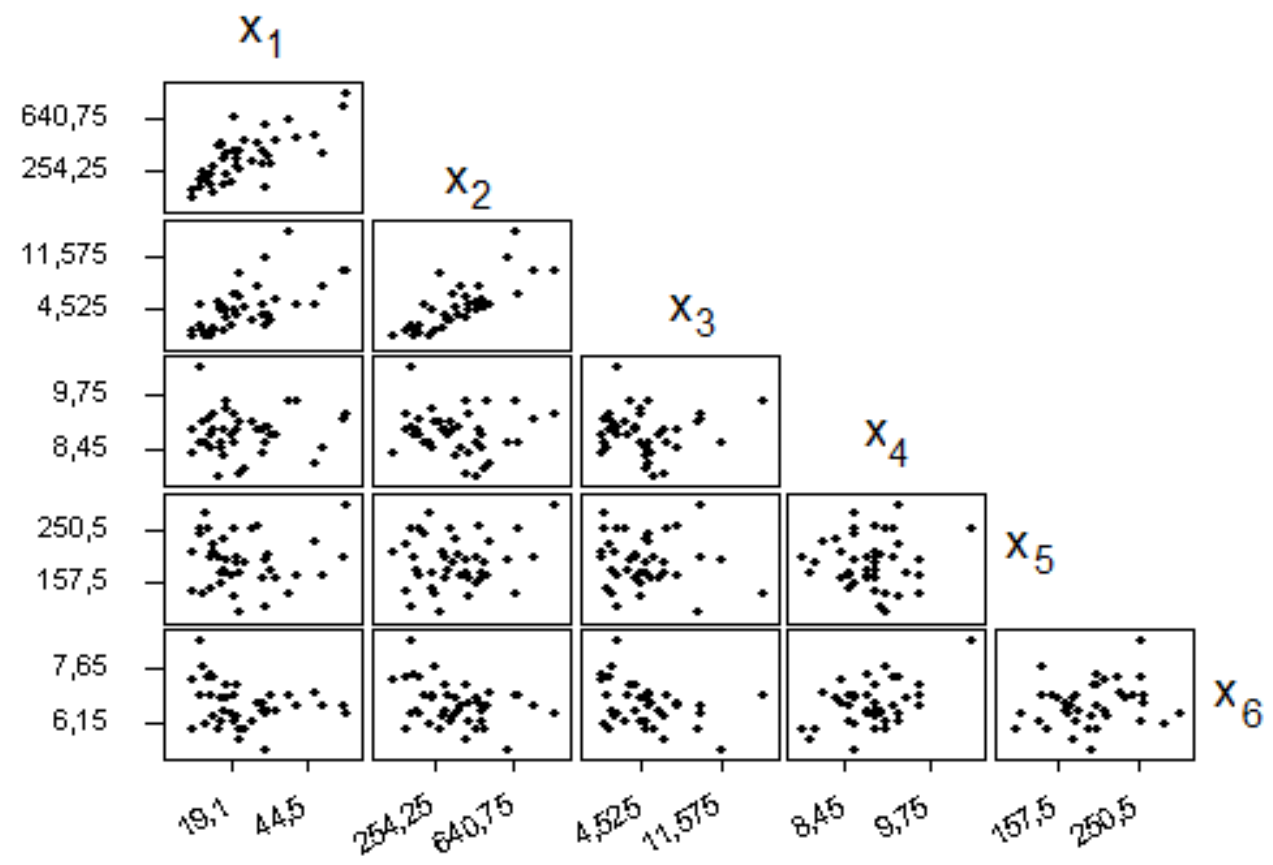

Figura 20 - Ilustração da matriz correlação com algumas variáveis genéricas

Apesar de ser considerada uma maneira grosseira de verificar a existência de correlação entre duas variáveis, Nasser (2009) discute a viabilidade de utilização dessa ferramenta estatística para se iniciar a análise de um conjunto de dados, indicando visualmente a potencial relação entre as variáveis avaliadas.

\subsubsection{Teste de Correlação de Pearson}

Outra maneira de visualizar, agora quantitativamente, as correlações entre duas ou mais variáveis de interesse é por meio do teste de correlação de Pearson.

Este coeficiente de correlação expressa o grau de dependência linear entre duas variáveis, sendo representado normalmente pela letra $r$ e podendo variar entre -1 e 1 (LIRA, 2004).

Além disso:

- O valor zero indica que não há relação linear entre as variáveis; 
- Valores positivos indicam uma correlação positiva entre as variáveis (situação em que uma variável aumenta com o aumento da outra);

- Valores negativos indicam uma correlação negativa entre as variáveis (situação em que uma variável diminui com o aumento da outra).

Para duas variáveis quaisquer sendo testadas, $x$ e $y$, calcula-se o coeficiente de correlação de Pearson, $r$, como mostrado na equação 53.

$$
r=\frac{\sum\left(x_{i}-\bar{x}\right)\left(y_{i}-\bar{y}\right)}{\sqrt{\left(\sum\left(x_{i}-\bar{x}\right)^{2}\right)\left(\sum\left(y_{i}-\bar{y}\right)^{2}\right)}}
$$

Supondo uma distribuição normal dos dados, a significância do coeficiente de correlação entre as variáveis é avaliada mediante um teste de hipótese, onde a declaração de hipóteses é dada por:

$H_{0}$ : a regressão não é significativa $(r=0)$ e

$H_{1}$ : a regressão é significativa $(r \neq 0)$

A interpretação do teste é feita através da avaliação do nível de significância apresentado no teste de hipóteses (o valor da probabilidade $p$ é utilizado para avaliar se um modelo de regressão proposto é ou não significativo para explicar um determinado processo, sendo utilizado no julgamento de qualquer teste de hipóteses).

O valor da probabilidade $p$ é o menor nível de significância que levaria à rejeição da hipótese nula (ou seja, ele mede a probabilidade de aceitação ou rejeição de uma hipótese analisada).

Pode-se entender o valor da probabilidade $\mathrm{p}$ como o julgamento das hipóteses pré-estabelecidas. A hipótese $\mathrm{H}_{1}$ é aceita como verdadeira, caso o valor $\mathrm{p}$ seja inferior a 0,05 , considerando um nível de significância $\alpha=5 \%$. Isso significa 
que podemos afirmar com 95\% de confiança que a regressão estudada é significativa (RODRIGUES; IEMMA, 2005).

A Tabela 8 mostra, a título de exemplo, uma matriz com os resultados quantitativos das correlações apresentadas na matriz de correlações da Figura 20.

Tabela 8 - Teste de Pearson para a verificação das correlações entre as variáveis duas a duas mostradas na matriz de correlação.

\begin{tabular}{|c|c|c|c|c|c|}
\hline & $X_{2}$ & $X_{3}$ & $X_{4}$ & $X_{5}$ & $X_{6}$ \\
\hline \multirow{2}{*}{$X_{1}$} & 0,725 & & & & \\
\hline & 0,000 & & & & \\
\hline \multirow{2}{*}{$X_{2}$} & 0,634 & 0,779 & & & \\
\hline & 0,000 & 0,000 & & & \\
\hline \multirow{2}{*}{$x_{3}$} & 0,053 & $-0,080$ & 0,020 & & \\
\hline & 0,744 & 0,618 & 0,901 & & \\
\hline \multirow{2}{*}{$X_{4}$} & 0,012 & 0,143 & $-0,080$ & 0,020 & \\
\hline & 0,942 & 0,373 & 0,620 & 0,900 & \\
\hline \multirow{2}{*}{$X_{5}$} & $-0,225$ & $-0,330$ & $-0,355$ & 0,460 & 0,209 \\
\hline & 0,158 & 0,035 & 0,023 & 0,003 & 0,190 \\
\hline \multicolumn{3}{|c|}{$\begin{array}{l}\text { Teste de Pearson: Conteúdo } \\
\text { da Célula }\end{array}$} & \multicolumn{3}{|c|}{$\begin{array}{l}\text { - Coeficiente de correlação de Pearson } \\
\text { - Valor da probabilidade para julgar a } \\
\text { hipótese nula, } \mathrm{H}_{0}\end{array}$} \\
\hline
\end{tabular}

\subsubsection{Algorítmo best subsets}

Se $p$ é o número de variáveis regressoras de um modelo, então o número de modelos possíveis para representar este fenômeno seria $2^{p-1}$ (este número cresce geometricamente com o número de variáveis preditoras). Avaliar todas as alternativas (ou modelos) possíveis para representar um determinado fenômeno é uma tarefa difícil. 
A simplificação desta tarefa pode ser feita por meio de vários procedimentos computacionais. Um destes procedimentos é o best subsets regression que emprega o critério do $C_{p}$ de Mallows (Kutner et al, 2004), o qual está baseado no conceito do erro quadrático médio dos valores ajustados do modelo.

Este procedimento permite economizar tempo, porque o melhor subconjunto de variáveis é identificado, sem requerer o ajuste de todos os possíveis modelos de regressão.

O algoritmo também identifica bons subconjuntos para cada número possível de variáveis $X$ a serem empregadas na elaboração de um modelo de regressão. Se o número de variáveis regressoras é superior a 30 ou 40, esta técnica pode requerer um tempo computacional excessivo. Neste caso, é conveniente escolher outro procedimento de seleção de variáveis, por exemplo, stepwise regression (Kutner et al, 2004).

O $C_{p}$ de Mallows é estimado levando em conta a Tabela ANOVA (análise de variância) da regressão para o conjunto de variáveis testadas na seleção do modelo.

Dessa forma,

$C_{p}=\frac{S E_{p}}{\operatorname{MSE}_{m}}-(n-2 p)$

Onde:

$\mathrm{SSE}_{\mathrm{p}}$ é a soma de desvios quadráticos considerando p parâmetros, e $n$ observações, incluindo o intercepto;

$\mathrm{MSE}_{\mathrm{m}}$ é a média de desvios quadráticos do erro para um modelo com $\mathrm{m}$ preditores.

A escolha do subconjunto de variáveis regressoras, empregando o citério do $\mathrm{Cp}$ de Mallows, inclui a análise dos valores de $\mathrm{Cp}$ estimado para cada subconjunto. Este critério está relacionado com a média dos desvios 
quadráticos do erro residual de cada subconjunto de variáveis, ajustados a um modelo a partir de n observações como mostrado na equação 54.

Se não há viés na regressão de um modelo com $p-1$ variáveis, o valor esperado para $\mathrm{Cp}$ é igual a $\mathrm{p}$. Assim, quando se analisa graficamente os valores de $\mathrm{Cp}$ em relação a $\mathrm{p}$, verifica-se que modelos com pequeno viés tendem a cair na linha de $\mathrm{Cp}=\mathrm{p}$. Nos modelos com alto viés, o valor de $\mathrm{Cp}$ tende a cair consideravelmente acima desta linha. Valores de $\mathrm{Cp}$ abaixo da linha de $\mathrm{Cp}=\mathrm{p}$ são interpretados como apresentando nenhum viés (KUTNER el al, 2004).

Para ilustrar a seleção de variáveis usando o critério do Cp, Kutner et al (2004) ilustra um exemplo de busca dos melhores subconjuntos de regressão para um processo cirúrgico, com 8 variáveis regressoras.

As Figuras 21 e 22 mostram os gráficos para os critérios de seleção de variáveis com 8 preditores e a saída do programa Minitab, para o exemplo citado.

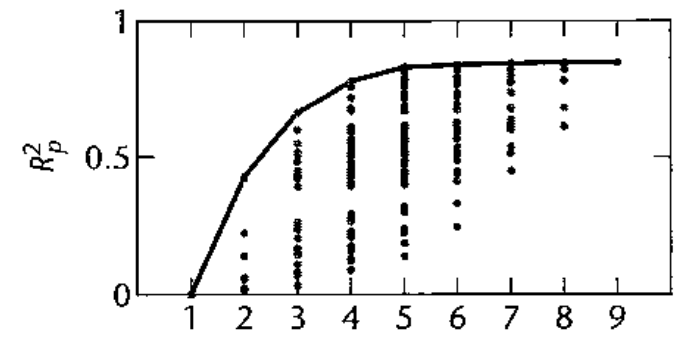

(a)

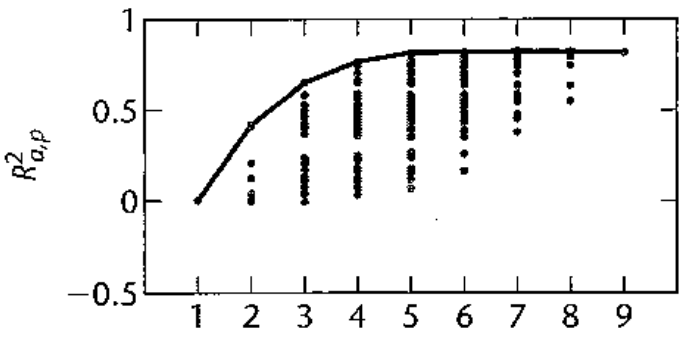

(b)

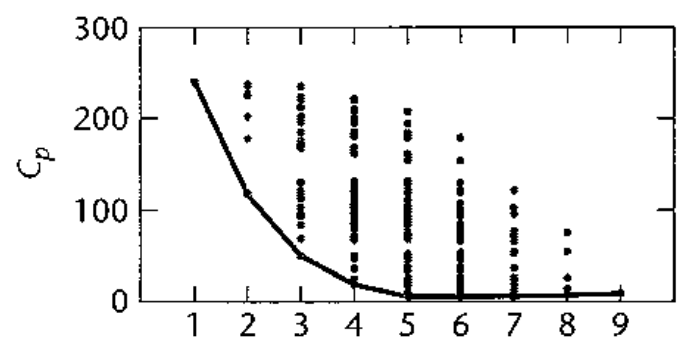

(c)

Figura 21 - Diagramas dos critérios de seleção do exemplo citado com 8 preditores. (a) é o coeficiente de determinação $R_{p}^{2}$ em função do número de regressores; (b) é o coeficiente de determinação ajustado, $R_{a, p}^{2}$, em função do número de regressores e (c) é o $\mathrm{Cp}$ de Mallows em função do número de regressores. 
Response is InSurviv

\begin{tabular}{|c|c|c|c|c|c|c|c|c|c|}
\hline Vars & $\mathrm{R}-\mathrm{Sq}$ & $R-S q(\operatorname{adj})$ & $C-p$ & $\mathrm{~S}$ & $\begin{array}{ll}B & F \\
1 & r \\
0 & 0 \\
0 & g \\
d & i \\
c & n \\
I & 0 \\
0 & \epsilon\end{array}$ & 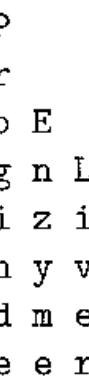 & $\begin{array}{l}\text { L } \\
i \\
\text { v A } \\
\text { e } \\
\text { r }\end{array}$ & 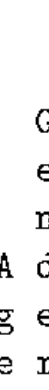 & $\begin{array}{ll} & \mathrm{H} \\
\mathrm{G} & \mathrm{i} \\
\mathrm{e} & \mathrm{s} \\
\mathrm{n} & \mathrm{t} \\
\mathrm{d} & \mathrm{m} \\
\mathrm{e} & 0 \\
\mathrm{r} & \mathrm{d}\end{array}$ \\
\hline 1 & 42.8 & 41.7 & 117.4 & 0.37549 & & $\mathrm{X}$ & & & \\
\hline 1 & 42.2 & 41.0 & 119.2 & 0.37746 & & & $\mathrm{x}$ & & \\
\hline 2 & 66.3 & 65.0 & 50.5 & 0.29079 & & $x \quad x$ & & & \\
\hline 2 & 59.9 & 58.4 & 69.1 & 0.31715 & & & $\mathrm{X}$ & & \\
\hline 3 & 77.8 & 76.5 & 18.9 & 0.23845 & & $x \quad x$ & & & \\
\hline 3 & 75.7 & 74.3 & 25.0 & 0.24934 & 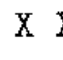 & $X X$ & & & \\
\hline 4 & 83.0 & 81.6 & 5.8 & 0.21087 & $\mathrm{X} 7$ & 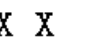 & & & \\
\hline 4 & 81.4 & 79.9 & 10.3 & 0.22023 & & $\begin{array}{l}x \times r \\
X\end{array}$ & $x$ & & \\
\hline 5 & 83.7 & 82.1 & 5.5 & 0.20827 & $\mathrm{X}$ & $\mathrm{x} x$ & & & $\mathrm{X}$ \\
\hline 5 & 83.6 & 81.9 & 6.0 & 0.20931 & $\mathrm{X}$ & $X X$ & $x$ & $X$ & \\
\hline 6 & 84.3 & 82.3 & 5.8 & 0.20655 & $\mathrm{x}$ & $\mathrm{XX}$ & $x$ & & $\mathrm{x}$ \\
\hline 6 & 83.9 & 81.9 & 7.0 & 0.20934 & $x$ & $X X$ & & & $X X$ \\
\hline 7 & 84.6 & 82.3 & 7.0 & 0.20705 & $X$ & $\mathrm{X} X$ & $x$ & & $X X$ \\
\hline 7 & 84.4 & 82.0 & 7.7 & 0.20867 & $\mathrm{x}$ & $x \quad x$ & $x \quad x$ & & $\mathrm{x}$ \\
\hline 8 & 84.6 & 81.9 & 9.0 & 0.20927 & $\mathrm{X}$ & $\mathrm{X} X$ & $X X$ & & $x x$ \\
\hline
\end{tabular}

Figura 22 - Resposta do software Minitab, para os melhores subconjuntos do exemplo do processo cirúrgico.

Observa-se, pela Figura 21, que cada critério, para cada p parâmetros estão conectados com linhas sólidas. Os melhores valores globais referem-se às condições que direcionam aos máximos valores de $R_{p}^{2}, R_{a, p}^{2}$ e o mínimo para o $\mathrm{C}_{\mathrm{p}}$. Já a saída do software MINITAB 15.0, mostrada na Figura 22, permite a escolha dos melhores subconjuntos através da análise númérica dos resulados para cada um desses critérios.

A escolha do melhor subconjunto deve estar pautada na obtenção de um modelo que resulte no menor esforço em termos de análise e controle do processo. Em geral, procura-se um número de regressores com menores $\mathrm{C}_{\mathrm{P}} \mathrm{e}$ coeficientes de determinação mais elevados. Vale a pena lembrar que esta seleção é válida para modelos lineares e que, uma vez selecionadas as 
variáveis regressoras mais significativas para o processo, os passos seguintes são o refinamento do modelo e a sua validação.

\subsection{3 $\quad$ Regressão Linear}

Quando um processo qualquer é representado por mais de uma variável, a análise de regressão é uma ferramenta bastante utilizada para se obter uma relação funcional entre essas variáveis (CAMARGO,1996). Nesse cenário, uma delas é conhecida por variável dependente ou resposta (normalmente representada por y) e as outras por variáveis independentes (normalmente representadas por $\mathrm{x}_{1}, \mathrm{x}_{2}, \mathrm{x}_{3} \ldots, \mathrm{x}_{n}$ ).

A análise de regressão visa estudar um conjunto de dados de uma amostra, para determinar se duas ou mais variáveis estão de alguma forma relacionadas dentro da população a que pertencem e permite a obtenção de uma equação matemática que mostra essa relação.

Os modelos mais comumente utilizados para a obtenção de relações entre as variáveis são a regressão linear simples (aplicada a processos constituídos por uma única variável independente, onde a relação entre variáveis se dá através de uma equação do $1^{\circ}$ grau) e a regressão multilinear, a qual é aplicada a processos constituídos por mais de uma variável independente, onde a relação entre variáveis se dá através de uma equação polinomial diferente de uma equação de 1ํgrau (CLARK; DOWNING, 1999).

Nesse contexto, variáveis independentes são aquelas utilizadas para explicar o comportamento (ou resposta) de um dado fenômeno. Na equação $y=a \cdot x+b, x$ representa a variável independente e y a variável que representa a resposta desse processo (variável dependente).

Porém, alguns cuidados devem ser considerados no equacionamento de um modelo de regressão (CLARK; DOWNING, 1999): 
- Uma predição baseada em um modelo de regressão é sempre condicional, ou seja, só se pode predizer um valor futuro da variável dependente, se forem conhecidos os valores das variáveis independentes;

- Todo modelo de regressão é elaborado a partir de dados passados e só será válido se não houver alteração no tipo de relação entre as variáveis;

- Um modelo de regressão é determinado para uma faixa de estudo das variáveis (valores fora desse intervalo representam extrapolações que estão sujeitas a maiores incertezas).

A ferramenta regressão multilinear foi utilizada neste trabalho, para a obtenção de um modelo de predição dos resultados de um processo em função de variáveis independentes classificadas como significativas para o processo.

\subsubsection{Regressão Multilinear}

Inicialmente, pode-se admitir que a verdadeira relação entre diversas variáveis é dada por:

$\mathrm{Y}=\mathrm{B}_{0}+\mathrm{B}_{1} \cdot \mathrm{x}_{1}+\mathrm{B}_{2} \cdot \mathrm{x}_{2}+\cdots+\mathrm{B}_{\mathrm{k}} \cdot \mathrm{x}_{\mathrm{k}}$

Partindo-se de um conjunto qualquer de dados, um modelo de regressão pode ser equacionado para se representar o processo anterior. A elaboração deste modelo consiste basicamente na determinação da relação abaixo:

$$
y=\beta_{0}+\beta_{1}{ }^{*} x_{1}+\beta_{2}{ }^{*} x_{2}+\ldots+\beta_{k}{ }^{*} x_{k}+\varepsilon
$$

Onde $\varepsilon$ representa o erro experimental e $\beta_{1}, \beta_{2}, \beta_{k}$ representam estimativas dos coeficientes $B_{1}, B_{2}, B_{k}$ através de um conjunto de dados $\left(y_{1}, x_{i 1}\right),\left(y_{2}, x_{i 2}\right), \ldots,\left(y_{p}\right.$, $\mathrm{X}_{\mathrm{ip}}$ ), com i pertencente ao intervalo $1 \leq i \leq n$ 
Um dos métodos normalmente utilizados para estimativa dos coeficientes $B_{1}$, $B_{2}, B_{k}$ é o dos mínimos quadrados, onde uma função que representa a soma dos quadrados dos desvios verificados entre o valor estimado pelo modelo e 0 valor real da variável dependente, é minimizada (CLARK ; DOWNING, 1999).

\subsubsection{Equacionamento do Modelo de Regressão}

As equações do modelo de regressão multilinear podem ser escritas para as $n$ observações realizadas em um processo, como mostrado na equação 57 (SUGAHARA, 2000).

$$
\begin{aligned}
& Y 1=\beta_{0}+\beta_{1}{ }^{*} \mathrm{X}_{11}+\beta_{2}{ }^{*} \mathrm{X}_{12}+\ldots+\beta_{k}{ }^{*} \mathrm{X}_{1 \mathrm{k}}+\varepsilon_{1} \\
& \mathrm{Y} 2=\beta_{0}+\beta_{1}{ }^{*} \mathrm{X}_{21}+\beta_{2}{ }^{*} \mathrm{X}_{22}+\ldots+\beta_{\mathrm{k}}{ }^{*} \mathrm{X}_{2 \mathrm{k}}+\varepsilon_{2} \\
& \mathrm{Yn}=\beta_{0}+\beta_{1}{ }^{*} \mathrm{X}_{\mathrm{n} 1}+\beta_{2}{ }^{*} \mathrm{X}_{\mathrm{n} 2}+\ldots+\beta_{\mathrm{k}}{ }^{*} \mathrm{X}_{\mathrm{nk}}+\varepsilon_{\mathrm{k}}
\end{aligned}
$$

Em uma notação compacta, temos $Y=X \beta_{M}+\varepsilon_{M}$

Onde:

$\mathrm{Y}=\left|\begin{array}{llll}y_{1} & y_{2} & y_{3} \ldots & y_{n}\end{array}\right|^{\top}$

$\mathrm{X}=\left|\begin{array}{ccc}\mathrm{X}_{11} & \mathrm{x}_{12} & \mathrm{x}_{13} \\ \mathrm{X}_{21} & \mathrm{x}_{22} & \mathrm{x}_{23} \\ : & : & : \\ \mathrm{X}_{\mathrm{n} 1} & \mathrm{X}_{\mathrm{n} 2} & \mathrm{X}_{\mathrm{nk}}\end{array}\right|$

$\mathrm{Y}, \mathrm{X}$ são as matrizes de observações das variáveis dependentes e independentes.

$$
\beta_{\mathrm{M}}=\left|\begin{array}{llll}
\beta_{0} & \beta_{1} & \beta_{2} \ldots & \beta_{k}
\end{array}\right|^{\top}
$$


$\varepsilon_{\mathrm{M}}=\left|\begin{array}{llll}\varepsilon_{0} & \varepsilon_{1} & \varepsilon_{2} \ldots & \varepsilon_{n}\end{array}\right|^{\top}$

$\beta_{\mathrm{M}, \varepsilon_{\mathrm{M}}}$ são, respectivamente: a matriz dos coeficientes e a matriz dos erros.

A soma dos quadrados dos desvios é dada por:

$S^{2}=\varepsilon^{\top} \varepsilon$

\subsubsection{Diagnóstico da melhor adequação dos dados ao modelo}

De uma maneira geral, o desempenho de um modelo de regressão pode ser avaliado através de um conjunto de testes decorrentes da ANOVA da regressão.

A soma de desvios quadráticos total $\left(\mathrm{SS}_{\text {modelo }}\right)$, a soma de desvios quadráticos individuais $\left(\mathrm{SS}_{\mathrm{fator}}\right)$ e a soma de desvios quadráticos devido ao erro residual, ou mesmo devido ao erro puro (quando existem repetições genuínas), são informações importantes na construção dos testes e estimativas dos coeficientes de ajuste dos dados ao modelo.

Enfim, a análise da regressão não finaliza quando um modelo qualquer é ajustado. Um exame detalhado dos coeficientes de regressão, determinação e dos resíduos complementam a análise.

\subsubsection{Coeficiente de Determinação}

O coeficiente de determinação, $\mathrm{R}^{2}$, é uma estatística que pode ser interpretada como a proporção da variabilidade dos dados, explicada pelo modelo de regressão.

Sugahara (2000) comenta que o coeficiente representa a contribuição à variabilidade de uma resposta $\mathrm{y}$, dada pelas variáveis $\mathrm{x}_{1}, \mathrm{x}_{2}, \mathrm{x}_{3} \ldots, \mathrm{x}_{\mathrm{k}}$, de tal forma que, quanto maior o valor de $\mathrm{R}^{2}$, maior a é capacidade do modelo de regressão predizer adequadamente o valor da variável de resposta Y. 
$\mathrm{R}^{2}$ pode ser estimado com base nas somas de quadrados estimadas na ANOVA da regressão. Várias estatísticas $R^{2}$ podem ser apresentadas. $A$ mais comum, é estimada como:

$\mathrm{R}^{2}=\frac{\mathrm{SS}_{\text {modelo }}}{\mathrm{SS}_{\text {total }}}$

Onde:

$\mathrm{SS}_{\text {modelo }}=$ soma de desvios quadráticos devido à regressão; e,

$\mathrm{SS}_{\text {total }}=$ soma de desvios quadráticos totais.

O problema potencial desta estatística é que ela sempre aumenta com o aumento de fatores que representam o modelo, mesmo que estes fatores não sejam significantes ao processo.

Com o intuito de corrigir este problema, pode-se empregar o $\mathrm{R}^{2}$ ajustado, que é uma estatística ajustada ao tamanho do modelo, ou seja, ao número de fatores. O $\mathrm{R}^{2}$ ajustado, $R_{a j}^{2}$, pode realmente decrescer, caso termos não significantes forem adicionados ao modelo. $O R_{a j}^{2}$ também pode ser estimado por meio das somas de quadrados advindas da ANOVA da regressão, como:

$$
\mathrm{R}_{\mathrm{aj}}^{2}=1-\frac{\mathrm{SS}_{\mathrm{E}} / \mathrm{gl}_{\mathrm{E}}}{\mathrm{SS}_{\mathrm{total}} / \mathrm{gl}_{\mathrm{total}}}
$$

Onde:

$\mathrm{SS}_{\mathrm{E}}=$ soma de desvios quadráticos devido ao erro;

$\mathrm{gl}_{\mathrm{E}}=$ número de graus de liberdade com o qual o erro é estimado;

$\mathrm{SS}_{\text {total }}=$ soma de desvios quadráticos totais; $\mathrm{e}$,

$\mathrm{gl}_{\text {total }}=$ número total de graus de liberdade (tamanho da amostra)

Finalmente, ainda existe uma predição para $\circ \mathrm{R}^{2}$ que é uma estatística estimada como: 


$$
\mathrm{R}_{\text {Pred }}^{2}=1-\frac{\text { PRESS }}{\text { SS }_{\text {total }}}
$$

A estatística PRESS é uma medida da capacidade de um modelo predizer novos dados coletados de um processo em estudo. A palavra PRESS é um acrônimo de Prediction Error Sum of Squares.

O PRESS pode ser computado como a soma de quadrados de erros preditos, obtida por predição do i-ésimo ponto dos dados com um modelo que inclui todas as observações exceto o i-ésimo ponto. Um baixo valor de PRESS indica que o modelo é possível de ser um bom preditor.

Todas as estatísticas mencionadas são empregadas como parâmetro para se avaliar quão próximo de um processo real se encontra um modelo calculado com os dados disponíveis. Na prática, o $\mathrm{R}_{\mathrm{aj}}^{2}$ é o valor mais representativo do modelo em questão.

Três classificações são sugeridas para avaliação de um coeficiente de determinação (KUME, 1993):

- $\mathrm{R}^{2}$ acima de 0,90 representa um modelo de regressão com forte correlação;

- $0,60<\mathrm{R}^{2}<0,90$ representa um modelo de regressão com boa correlação;

- $\mathrm{R}^{2}$ próximo de zero representa um modelo em que a correlação é praticamente inexistente.

\subsection{Síntese da Revisão Bibliográfica e Hipóteses Derivadas}

Baseada na pesquisa bibliográfica apresentada, pode-se concluir que a base teórica relacionada à otimização da seletividade das reações de produção de óxido de etileno mostra a influência de um conjunto de variáveis como: tipo de catalisador, teor de prata metálica contida no catalisador, interação dos clorados junto à superfície do catalisador, temperatura de reação, pressão de 
operação do reator, vazão de alimentação e recirculação de gás pelo interior do reator.

A prática operacional de uma unidade produtiva mostra que, na grande maioria dos eventos, em que é necessária a intervenção humana na busca de uma melhoria de desempenho da seletividade, a atuação é realizada em uma única variável de processo, sendo que variações na concentração de clorados no teor de gás de reciclo têm sido a mais requisitada pelos operadores de processo, muito em função da facilidade de se alterar essa concentração e também da rápida resposta obtida quando se atua nesse parâmetro.

Uma vez que existem vários parâmetros que interferem no desempenho da seletividade da reação, é de se esperar que a seletividade possa ser interpretada como uma variável dependente de um conjunto de outras variáveis, podendo ser escrita, de forma genérica como:

$S=f\left(x_{1}, x_{2}, x_{3}, x_{4}, \ldots x_{n}\right)$

Evidenciada a dependência de um conjunto de variáveis, é possível definir um modelo matemático que demonstre a influência de cada variável no desempenho da seletividade, bem como o possível efeito de interações dessas variáveis no resultado do processo.

Caso a influência dessas variáveis e das interações sejam estatisticamente significativas, é de se esperar que a atuação conjunta em mais de uma variável resulte em uma melhoria mais rápida e mais efetiva da seletividade da reação. 


\section{MATERIAIS E MÉTODOS}

\subsection{Introdução}

O objetivo deste capítulo é apresentar a metodologia para coleta e análise dos dados de processo utilizada neste estudo, bem como descrever o processo de produção de óxido de etileno utilizado atualmente na Oxiteno S.A Indústria e Comércio e apresentar os detalhes técnicos do reator utilizado nesse processo.

Inicialmente, é apresentado um descritivo detalhado do processo de produção de óxido de etileno, focando o detalhamento da etapa de reação, em que também são listados os dados técnicos de construção e operação do reator de produção de óxido de etileno.

Posteriormente, são apresentadas as metodologias e recursos utilizados para a coleta dos dados de processo e aquisição de dados analíticos referentes à composição do gás de reciclo.

Finalizando o capítulo, é apresentada a metodologia utilizada para o tratamento desses dados (e hipóteses adotadas), de modo a se definir o conjunto de variáveis relevantes para a gestão eficiente da seletividade do processo.

\subsection{Descritivo do processo de Produção de óxido de etileno (Oxiteno S/A Indústria e Comércio)}

A unidade produtiva em estudo teve sua partida em outubro/2008, sendo que 0 processo é considerado moderno do ponto de vista tecnológico, apresentando diversas melhorias em relação ao processo padrão, previamente apresentado nesse trabalho nos itens 3.2.1, 3.2.2 e 3.2.3.

A Figura 23 indica um fluxograma resumido desse processo, sendo que os números e letras indicados entre parênteses representam os equipamentos utilizados no processo, e que são citados ao longo do texto a seguir. 


\subsubsection{Reação e Absorção de óxido de etileno}

Definições:

- Gás diluente: componente inerte que deve ser adicionado à mistura etileno e oxigênio, para que a mesma não atinja concentrações dentro do limite de explosividade da mistura.

- Corrente de Gás de Reciclo Pobre: é o nome dado à corrente de reagentes e gás inerte diluente (metano ou nitrogênio), que alimenta o reator e que se encontra praticamente isenta de óxido de etileno

- Corrente de Gás de Reciclo Rica: é o nome dado à corrente gasosa efluente do reator e que apresenta elevada concentração de óxido de etileno.

Nessa etapa do processo, a mistura reacional, constituída por etileno (1), oxigênio (2) e gás diluente é pré-aquecida em um trocador de calor tipo cascotubos (A) e alimenta os tubos do reator catalítico (B) de produção de óxido de etileno, que opera em elevada pressão (o reator pode ser aproximado por um trocador de calor casco-tubos vertical com fluxo de escoamento descendente).

As matérias primas principais (etileno e oxigênio) passam por "tratamentos" específicos antes de alimentar o reator:

- O etileno, proveniente da empresa Braskem, é pré-aquecido em um trocador de calor $(\mathrm{C})$, para minimizar o risco de formação de hidratos (contaminantes que reduzem a atividade do catalisador), e, posteriormente, alimenta um leito de absorção (D), que tem por objetivo reduzir o teor de enxofre presente no etileno. Segue então em direção a um dispositivo de contato e distribuição de gases (similar a um distribuidor de refluxo de uma coluna de destilação), denominado Estação de Mistura ( $E)$, onde é misturado com o oxigênio e com o gás de reciclo, tornando a mistura a mais homogênea possível, antes de alimentar o reator $(\mathrm{B})$. 
- O oxigênio, proveniente da empresa Oxicap, é filtrado (F), com o objetivo de reter partículas contaminantes, antes de alimentar a Estação de Mistura, juntamente com o Etileno e o gás de reciclo.

No casco desse reator ocorre o escoamento de água (4), que tem por objetivo remover o calor gerado na reação de formação de óxido de etileno. Essa água é aquecida até a geração de uma corrente em flash, que é enviada para um vaso separador de fases $(G)$, onde a fase líquida e a fase gasosa são separadas e reaproveitadas em outras etapas do processo produtivo (o vapor gerado é enviado para um sistema de distribuição de vapor de alta pressão)

No reator, sob determinadas condições de pressão, temperatura e velocidade de escoamento da mistura, os reagentes são convertidos parcialmente a óxido de etileno. Ressalta-se a ocorrência de reações secundárias, onde ocorre a formação de $\mathrm{CO}_{2}$ e $\mathrm{H}_{2} \mathrm{O}$.

Uma pequena vazão de cloreto de etila (4), armazenado em cilindros no estado líquido, que age como um "inibidor" da reação e contribui para a melhoria da seletividade da reação, é injetada na corrente de gás de reciclo através de um conjunto de bombas dosadoras.

A corrente efluente do reator é resfriada no trocador de calor (A) e o processo de separação do óxido de etileno dos demais componentes inicia-se com uma etapa de absorção gasosa, onde uma coluna de absorção gasosa $(H)$, que opera com alimentação de água (5) em contra-corrente à alimentação gasosa, é alimentada (em sua base) pela corrente efluente do reator.

As condições de operação da coluna absorvedora são pré-estabelecidas, de modo a se garantir a máxima solubilização do óxido de etileno em água e a mínima solubilização dos demais componentes na água. Esta corrente é posteriormente enviada para a seção de purificação de óxido de etileno. 
Geram-se, portanto, duas novas correntes no processo de absorção gasosa:

- Uma solução aquosa de óxido de etileno (6), chamada corrente de água de reciclo rica;

- Uma corrente, constituída pelos demais gases não absorvidos (7) pela água (rica em etileno, por exemplo). Essa corrente é retornada para o processo reacional após sua compressão.

Antes de ser comprimida, uma pequena parte da corrente gasosa (7) é purgada (8) para uma das caldeiras de geração de vapor da área de utilidades. Esta purga tem por objetivo controlar os teores de argônio e nitrogênio, que entram no processo como contaminantes do oxigênio, evitando uma superconcentração desses componentes na corrente de gás de reciclo. Após a compressão, uma parte dessa corrente é destinada ao Sistema de Remoção de $\mathrm{CO}_{2}$ (9), que tem por objetivo eliminar o $\mathrm{CO}_{2}$ gerado na reação e a outra parte retorna para o processo produtivo (10), alimentando a Estação de Mistura, onde esta corrente irá se juntar á alimentação de etileno e oxigênio. 


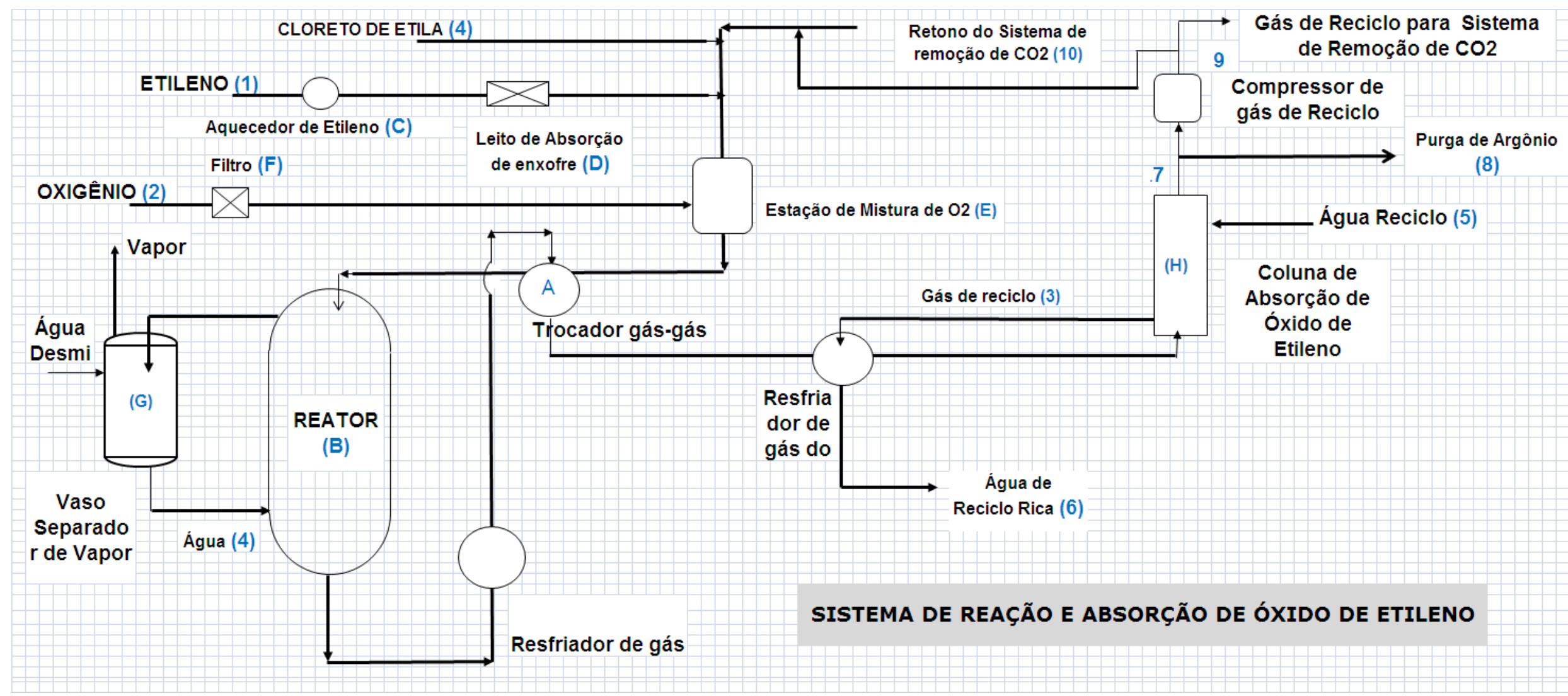

Figura 23 - Fluxograma de Processo Produtivo de óxido de etileno (Sistema de Reação e Absorção de óxido de etileno) - Oxiteno S/A Indústria e Comércio. 


\subsection{Dados do Reator de produção de óxido de etileno}

O trabalho foi desenvolvido através da coleta de dados realizadas em um reator de produção de óxido de etileno, atualmente em operação na Oxiteno S/A Indústria e Comércio, cujas principais características estão descritas na Tabela 9.

Tabela 9 - Dados técnicos do reator de produção de óxido de etileno.

\begin{tabular}{|c|c|c|}
\hline Dado de Projeto & Lado do Casco & Lado dos Tubos \\
\hline Fluido & Vapor / água & Gás de reciclo \\
\hline Densidade $\left(\mathrm{kg} / \mathrm{m}^{3}\right)$ & 1000 & 13,8 \\
\hline Pressão de projeto $\left(\mathrm{kgf} / \mathrm{cm}^{2}\right)$ & 57,4 & 24,2 \\
\hline Temperatura de Projeto $\left({ }^{\circ} \mathrm{C}\right)$ & 275 & 280 \\
\hline $\begin{array}{l}\text { Diâmetro interno do casco } \\
\qquad(\mathrm{mm})\end{array}$ & 4160 & - \\
\hline Tampo superior do reator & \multicolumn{2}{|c|}{ Elíptico $(2: 1)$} \\
\hline Tampo inferior do reator & \multicolumn{2}{|c|}{ Toricônico } \\
\hline $\begin{array}{c}\text { Corrosão admissível (mm / } \\
\text { ao longo da vida útil do } \\
\text { equipamento) }\end{array}$ & 3 & 1,5 \\
\hline Tratamento térmico & Realizado & Realizado \\
\hline $\begin{array}{c}\text { Diâmetro dos tubos (externo } \\
\text { e interno), } \mathrm{mm}\end{array}$ & - & $50,8 / 46,0$ \\
\hline $\begin{array}{l}\text { Comprimento dos tubos } \\
\qquad(\mathrm{mm})\end{array}$ & - & 12200 \\
\hline Passo dos Tubos (mm) & - & Triangular $(59,0)$ \\
\hline Número de tubos & - & 3787 \\
\hline Material de construção & SA-533-GrB Cl2 & AS-789-UNS S31803 \\
\hline
\end{tabular}




\subsection{Seleção de variáveis para o estudo}

As variáveis de processo selecionadas para o estudo foram obtidas através de visitas ao Centro de Operações da unidade produtora de óxido de etileno, onde foi possível identificar um conjunto de variáveis relacionadas ao monitoramento do desempenho da reação de produção de óxido de etileno e que apresentam medição on-line no SDCD existente na unidade.

\subsubsection{SDCD - Sistema Digital de Controle Distribuído}

O Sistema Digital de Controle Distribuído (SDCD) é um equipamento de automação industrial, que tem por objetivo controlar processos e permitir uma otimização da produtividade industrial, focando a diminuição de custos de produção, melhoria na qualidade dos produtos, precisão das operações e segurança operacional.

Ele é composto basicamente por um conjunto integrado de dispositivos que garantem o controle e a supervisão do processo produtivo em uma unidade industrial. O sistema é dotado de processadores e redes redundantes que permitem uma descentralização do processamento de dados e decisões, através do uso de unidades remotas na planta. É através das Unidades de processamento, distribuídas nas áreas produtivas, que os sinais dos equipamentos de campo são processados, transformados em informação de processo e atualizados em tempo real nas telas de operação da Sala de Controle (JUNIOR, 2012).

O SDCD é composto basicamente de quatro subsistemas:

- Subsistema de Aquisição de Dados e Controle.

- Subsistema de Comunicação.

- Subsistema de Monitoração e Operação.

- Subsistema de Supervisão e Otimização. 


\subsubsection{1 $\quad \underline{\text { SDCD - Subsistema de Aquisição de Dados e Controle }}$}

O objetivo deste grupo de elementos é promover a interface direta com o processo e realizar as funções de controle no local em que uma dada variável é medida.

Desse subsistema fazem parte os cartões de interface de entrada e saída com o processo, tais como: entradas e saídas analógicas, entradas e saídas digitais, multiplexadores, Conversores Analógico/Digital e Digital/Analógico.

Este subsistema possui placas de memória que armazenam os microprogramas das funções executáveis, das rotinas de diagnósticos de falha, as placas de módulos para redundância parcial ou total e os circuitos necessários à segurança intrínseca do processo.
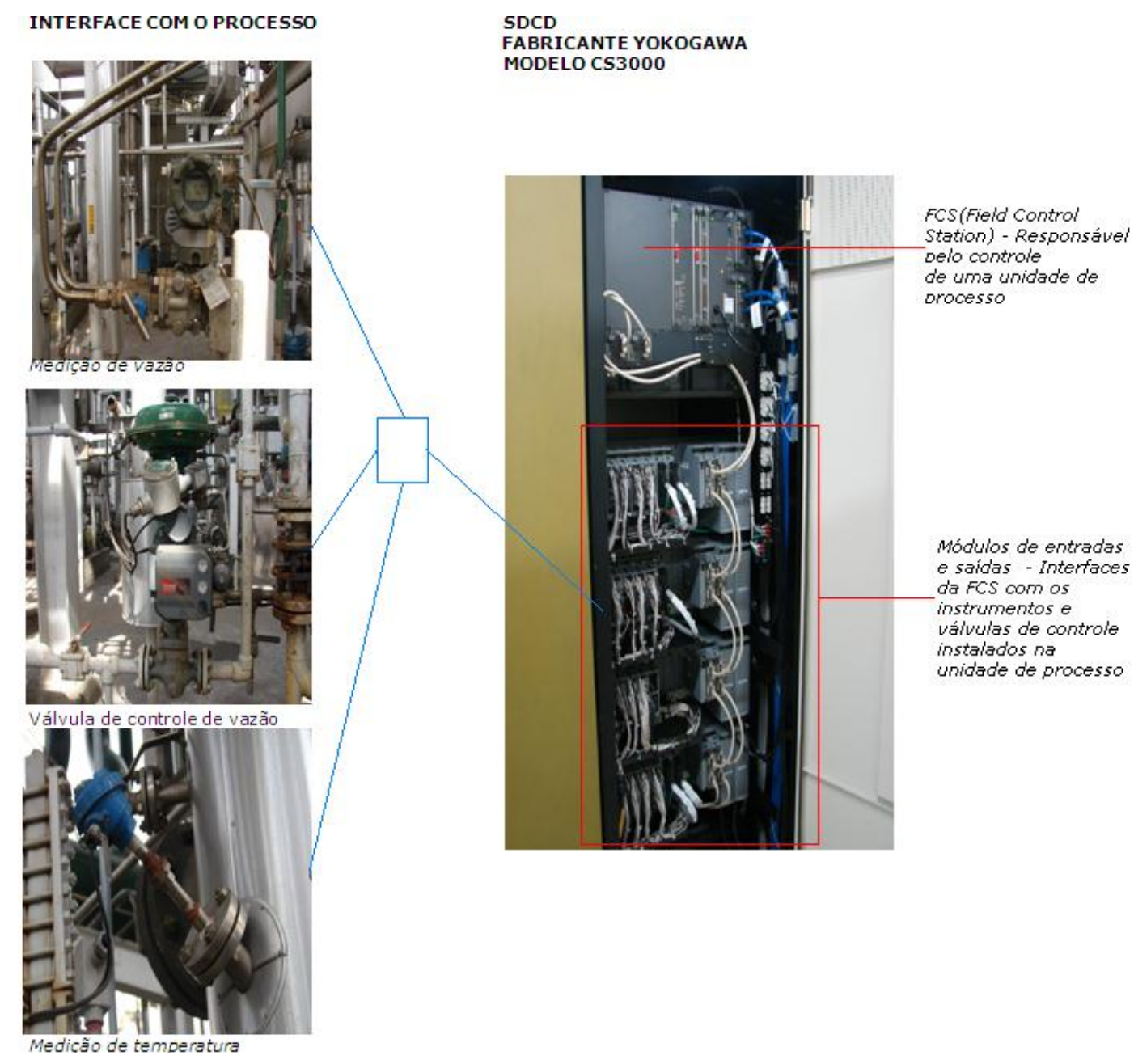

Figura 24 - Representação de uma interface SDCD / Processo produtivo 


\subsubsection{Subsistema de Comunicação}

O Subsistema de Comunicação é uma rede local de comunicações (RL), necessária para estabelecer a intercomunicação com os demais subsistemas. Considera-se que uma rede é "local" em função de dois parâmetros: a distância máxima entre os seus nós e a sua velocidade de transmissão.

O SDCD utilizado no monitoramento do processo em estudo (modelo CS3000, fornecido pela empresa Yokogawa) é composto por (JUNIOR, 2012):

- 5 FCS's (Field Control Station) e 3 HIS's (Human Interface Station), destinados ao controle de processo das Unidades Quimicas;

- 7 FCS's com 5 HIS's, para o controle das Unidades Petroquimicas (onde está localizada a unidade produtora de óxido de etileno);

- 2 HIS's dedicadas à operação das estações de carregamento (cativa e multipropósto).

Do ponto de vista da gestão técnica do processo, os itens mais relevantes e que compõe esse SDCD são:

- Número máximo de instrumentos a serem monitorados por cada HIS = 100.000.

- Número total de estações em múltiplos domínios = até 256/sistema.

- Número total de estações na rede = até $64 /$ domínio.

- Número total de domínios de rede = até $16 /$ sistema .

- $\mathrm{CPU}=$ Pentium $300 \mathrm{MHz}$ (para Windows 2000) ou mais e Pentium 800 $\mathrm{MHz}$ ou mais (para Windows XP).

- Memória RAM = 96 MB ou mais (para Windows 2000) ou $256 \mathrm{MB}$ ou mais (para Windows XP).

- Disco rígido $=4 \mathrm{~GB}$ ou mais.

- Vídeo $=1024 \times 768$ ou acima; 256 cores ou mais. 
Existem 3 tipos de varredura possíveis para a aquisição dos dados:

- "Basic Scan": onde a varredura é de 1 segundo (este é o tipo de varredura vigente no processo).

- "Médium Speed Scan": onde a varredura média é definida entre $200 \mathrm{~ms}$ ou $500 \mathrm{~ms}$.

- "High Speed Scan": varredura rápida podendo ser selecionadas as opções de $50 \mathrm{~ms}$ ou $100 \mathrm{~ms}$.

\subsubsection{Subsistema de Monitoração e Operação}

Este subsistema trata especificamente da interface homem-máquina (HISHuman Interface Station). Interface homem-máquina pode ser entendida como os dispositivos de "Hardware", que fornecem ao operador um maior controle e um melhor nível de informação sobre a condição de operação da planta, reduzindo o seu esforço através da simplificação dos procedimentos operacionais.

O processo de aquisição dos dados consiste na leitura de campo (transmissor primário) de uma variável pré-definida. Quando a variável faz parte de uma malha de controle, esse sinal é transmitido para o respectivo controlador da malha, para posteriormente ocorrer uma ação sobre o processo. Se a variável não faz parte de uma malha de controle, o transmissor primário faz a leitura e ocorre uma transmissão direta do sinal para o painel de controle do CS3000.

O comportamento do processo é monitorado continuamente por operadores localizados no Centro de Operações da unidade, através de telas gráficas, que permitem uma visualização detalhada do processo.

São características normalmente existentes em um subsistema de operação e monitoração:

- Fornecer ao operador um conjunto de informações sobre o estado de operação da planta; 
- Fornecer ao operador, em tempo hábil, informações em um formato que evidencie a ocorrência de condições excepcionais de operação, para que providências imediatas possam ser tomadas;

- Permitir que variáveis de processo sejam agrupadas de maneira que o operador possa realizar uma análise comparativa entre variáveis constituintes de cada grupo;

- Possibilitar o uso simultâneo de várias estações de operação, para que todas as funções disponíveis possam ser utilizadas em todas as estações de operação e estas possam ser instaladas em locais diferentes.

\subsubsection{Subsistema de Supervisão e Otimização}

O Subsistema de Supervisão e Otimização consiste de computadores destinados a execução de funções específicas, tais como supervisão total do sistema, otimização do processo, geração de relatórios gerenciais.

São exemplos de integrantes deste subsistema os computadores conectados na base de dados do SDCD através da rede e que executam as seguintes funções: Gerenciamento de alarmes, gerenciamento do desempenho de malhas de controle, aquisição de dados do processo para serem trabalhados posteriormente em planilhas Excel.

\subsection{Metodologia para coleta e análise de dados do processo produtivo}

\subsubsection{Coleta de dados relacionados às Variáveis de Processo}

Uma vez selecionadas as variáveis de influência no processo produtivo, foi então realizada a aquisição de um conjunto de dados dessas variáveis no período de 01/11/2008 a 10/02/2011. As principais variáveis do processo produtivo são monitoradas continuamente através de um sistema de controle de aquisição de dados, modelo CS3000, fornecido pela empresa Yokogawa, com as características operacionais anteriormente descritas. 
A lista de variáveis de processo para as quais foram coletados dados (e a nomenclatura pelas quais são identificadas no processo) encontra-se na Tabela 10.

Tabela 10 - Variáveis de processo coletadas no estudo.

\begin{tabular}{|c|c|}
\hline Variável & Descrição da Variável \\
\hline FC 101 & Vazão de etileno \\
\hline FC 103 & Vazão de Oxigênio \\
\hline FR121A & Vazão de Gás de reciclo \\
\hline TR124B & Temperatura da Reação \\
\hline FR121C & Vazão de alimentação do sistema de remoção de $\mathrm{CO}_{2}$ \\
\hline FR126 & Pressão da Reação \\
\hline PR121 & Teor de Clorados na corrente de gás de reciclo \\
\hline Fator F & \\
\hline
\end{tabular}

\subsubsection{Descrição das medições realizadas no processo produtivo}

\subsection{Medição da vazão de Alimentação de etileno para o Reator}

A vazão de alimentação de etileno para o reator de produção de óxido de etileno é realizada via um medidor mássico com as seguintes características técnicas:

- Fabricante: Micro Motion;

- Modelo dos tubos sensores: F100SI128SZ;

- Modelo do Conversor: IFT9701/1N2Z;

- Faixa de medição de vazão: 0-9000 kg/h 
A Figura 25 mostra o detalhe do tubo sensor onde se realiza a medição, bem como detalhes do transmissor e conversor do sinal eletrônico da medição.

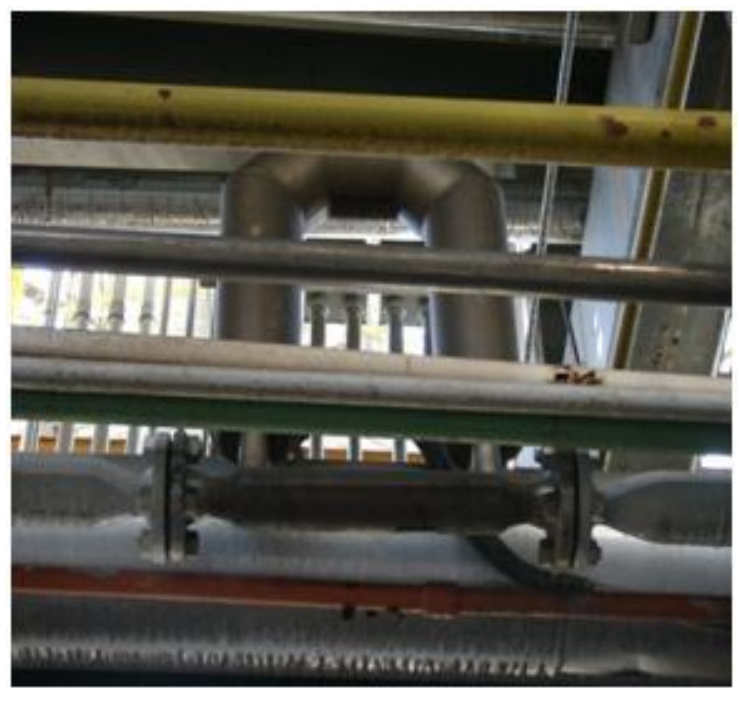

(a)

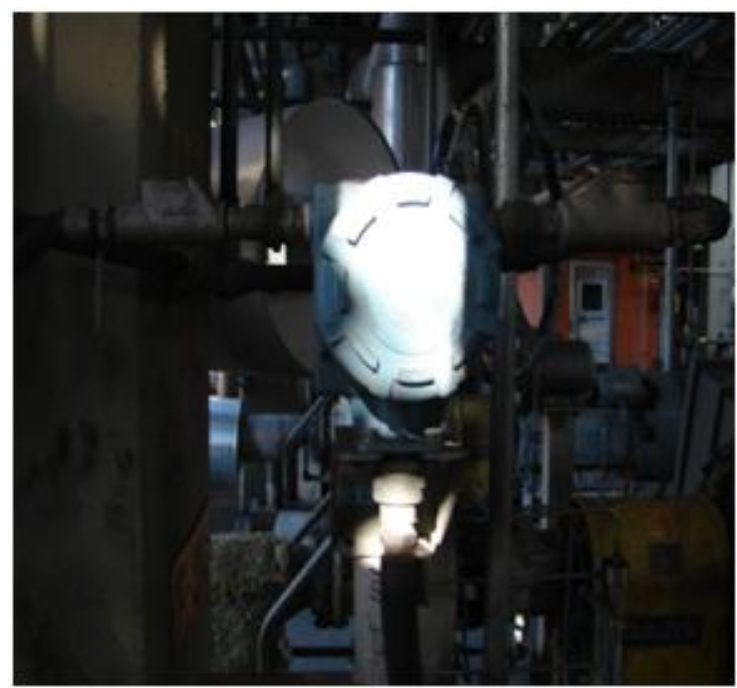

(b)

Figura 25 - Detalhe do sistema de medição de vazão de etileno. (a) Tubos sensores; (b) Conversor / transmissor

\subsection{Medição da vazão de Alimentação de oxigênio para o Reator}

A vazão de alimentação de oxigênio para o reator de produção de óxido de etileno é realizada via um medidor mássico com as seguintes características técnicas:

- Fabricante: Yokogawa;

- Modelo dos tubos sensores: RCCS39/IR-A10A e 2SL/BG/GA/H1/P6/P8;

- Modelo do Conversor: RCCF31-AH2A/BG/GA/UF1;

- Faixa de medição de vazão: 0-10000 kg/h

A Figura 26 mostra o detalhe dos tubos sensores onde se realiza a medição, bem como detalhes do transmissor e conversor do sinal eletrônico da medição. 


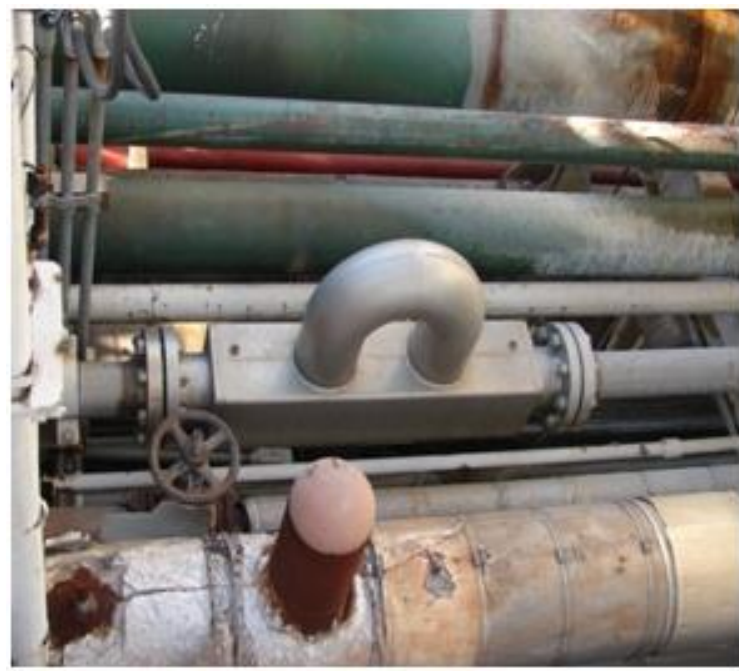

(a)

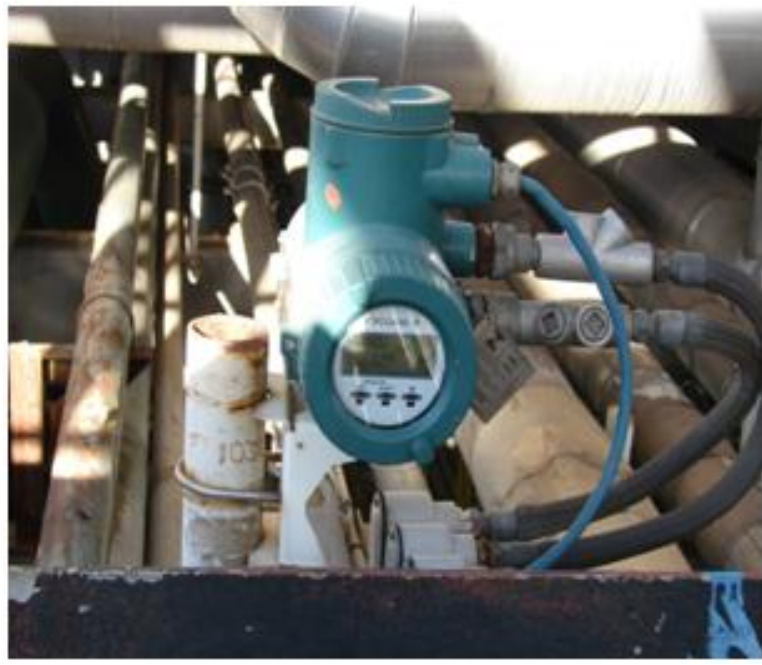

(b)

Figura 26 - Detalhe do sistema de medição de vazão de oxigênio. (a) Tubos sensores; (b) Conversor / transmissor

As medições das vazões de etileno (FC101) e oxigênio (FC103) são realizadas por medidores de vazão mássica do tipo Coriolis, que pode ser utilizado para medições de fluxo de líquidos e gases.

O medidor de vazão Coriolis é constituído basicamente por tubos sensores de medição e por um módulo conversor/transmissor. Nesse tipo de instrumento, os tubos de medição são submetidos a uma oscilação gerada por uma bobina de excitação e, por esse motivo, ficam vibrando em uma frequência de baixa amplitude, imperceptível visualmente. Quando um fluido qualquer é introduzido no tubo de medição em vibração, o efeito Coriolis se manifesta, causando uma torção, que é captada por meio de sensores magnéticos, que geram tensões em formato de ondas senoidais. A simulação do efeito Coriolis é mostrada nas Figuras 27 a 29. 


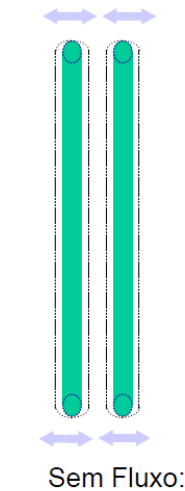

Vibração Paralela

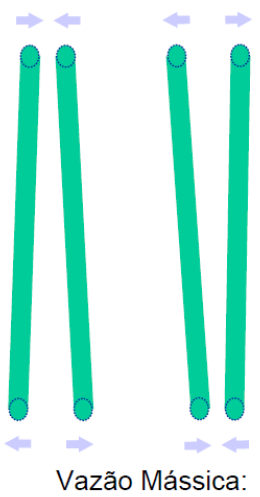

Efeito Coriolis

Figura 27 - Simulação do Efeito Coriolis em um medidor de vazão

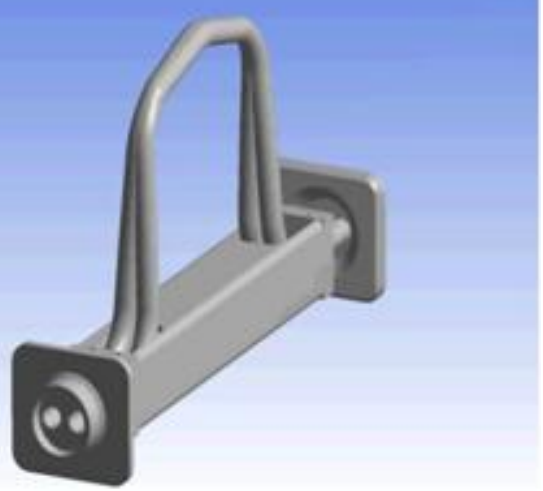

(a)

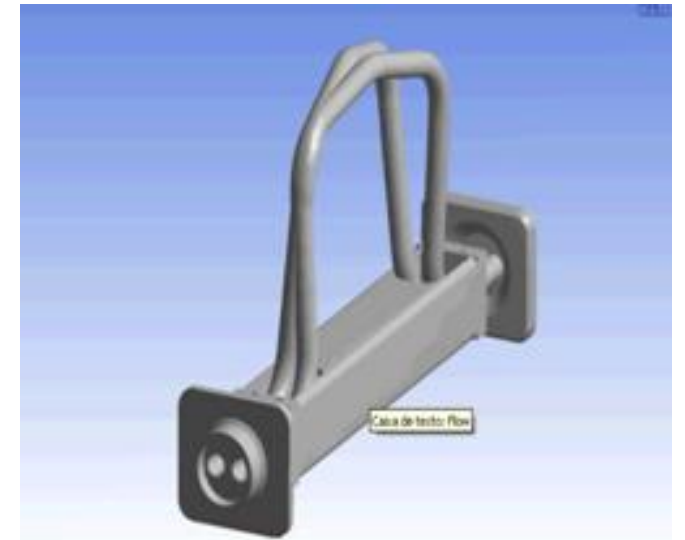

(b)

Figura 28 - Simulação do Efeito Coriolis em um medidor de vazão. (a) Situação em que não ocorre o fluxo de fluidos pelo medidor; (b) Situação em que ocorre o fluxo de fluidos pelo medidor.

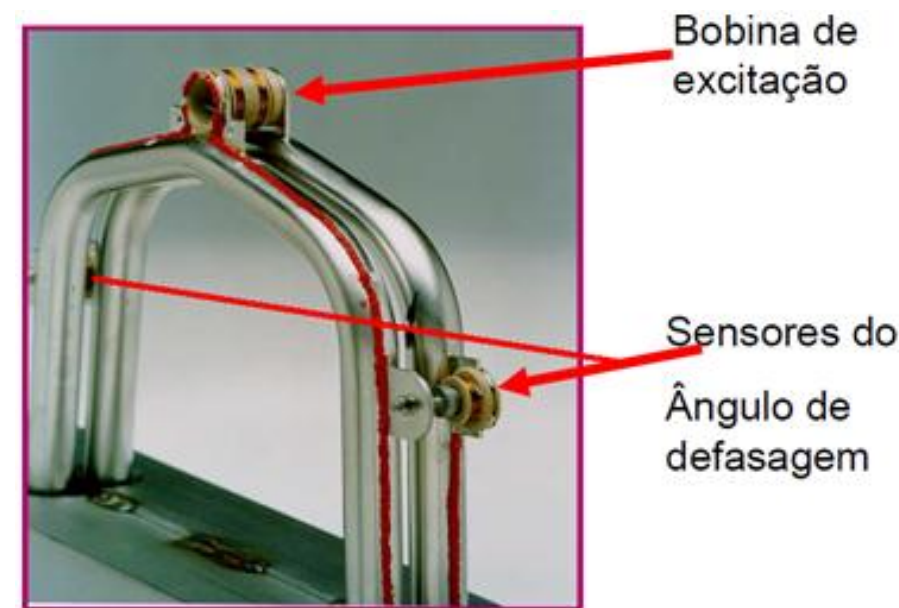

Figura 29 - Detalhamento da bobina de excitação de um medidor de vazão com efeito Coriolis.

O movimento dos tubos sensores de medição é detectado por dois sensores magnéticos, sendo que, cada sensor gera um sinal de tensão senoidal (Figura 30). Portanto, quanto maior for a vazão mássica, maior o efeito Coriolis, maior 
a torção dos tubos de medição que se encontram vibrando e maior a defasagem dos sinais senoidais oriundos dos sensores magnéticos.

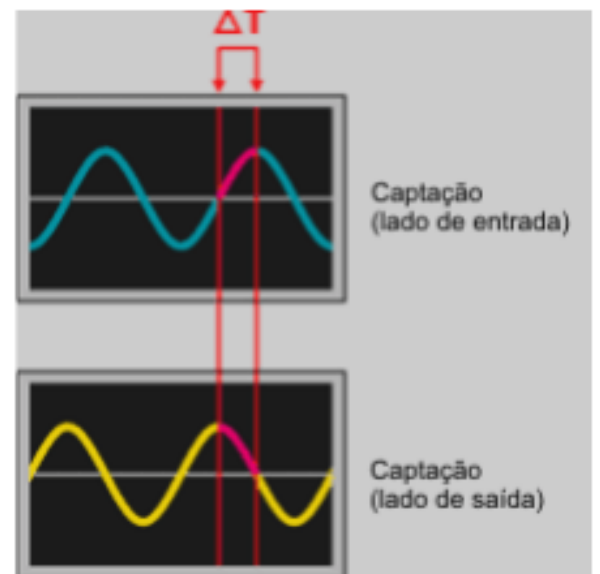

Figura 30 - Tensão senoidal gerada em um medidor de vazão tipo Coriolis

Um sensor de temperatura é montado no tubo, monitorando a temperatura com o objetivo de compensar as interferências das deformações elásticas sofridas com a oscilação da temperatura. A medição da densidade do fluido é obtida pela frequência do sinal senoidal dos sensores magnéticos. Quanto maior for a densidade do fluído, maior a frequência do sinal senoidal.

O módulo conversor/transmissor do medidor mássico Coriolis tem como função processar os sinais de tensões senoidais e relacionar a defasagem entre os mesmos com valores de vazão mássica. O valor de vazão mássica medida é escalonado em um sinal elétrico padronizado (4-20 mA), que é enviado ao SDCD, que faz seu processamento e relaciona com a faixa de vazão mássica configurada para a aplicação a que se destina.

\subsection{Medição da vazão de Gás de Reciclo para o Reator}

A medição de vazão de Gás de Reciclo é realizada por um medidor tipo Tubo Venturi como mostrado na Figura 31. 


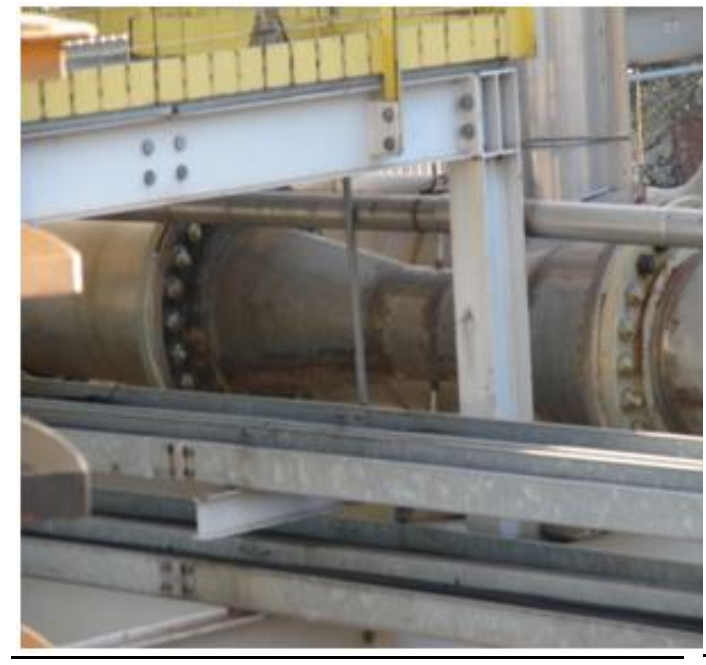

(a)

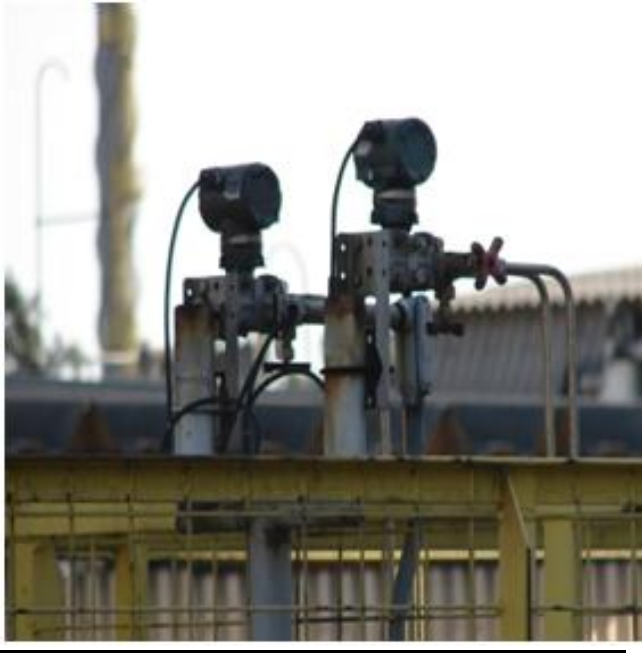

(b)

Figura 31 - Detalhe do sistema de medição de vazão de gás de reciclo para o reator. (a) tubo Venturi; (b) Instrumentos de medição da pressão diferencial

O medidor Venturi é constituído de um tubo que sofre uma redução (através de um "estrangulamento" da área de seção de escoamento do fluido), e posterior expansão da área de escoamento, voltando a escoar por uma tubulação com diâmetro similar à tubulação onde inicialmente estava escoando.

Nesse processo, o fluido inicialmente tem um grande aumento da velocidade de escoamento e, à medida que escoa pelas restrições e expansões, tem sua pressão e velocidades alteradas, até o momento de saída do Venturi, onde a velocidade se iguala à velocidade de entrada no medidor. A medição de vazão é obtida através da medição da diferença de pressão que existe entre diferentes seções de escoamento.

\subsection{Medição da Temperatura da Reação}

A medição da temperatura da reação é realizada por termopares, como os mostrados na Figura 32, e que apresentam as seguintes características técnicas:

- Modelo: Termopar Tipo T;

- Faixa de Medição: 0-300ㄷ 


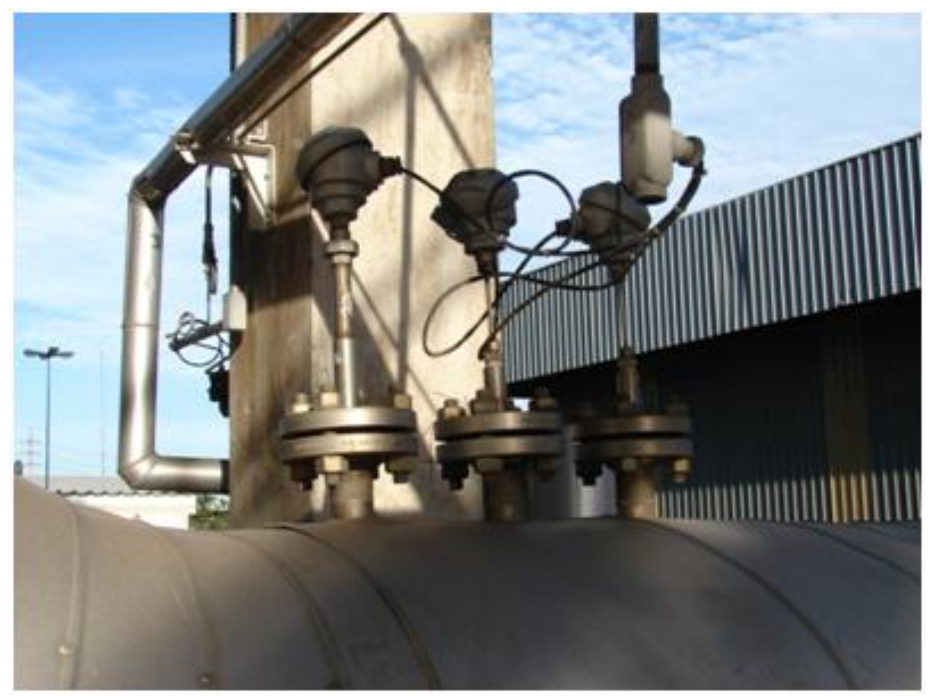

Figura 32 - Detalhe do sistema de medição de temperatura da reação

O tipo de termopar utilizado nesse processo de medição consiste de dois condutores metálicos de naturezas distintas, na forma de metais puros ou ligas homogêneas. Os fios são soldados em uma extremidade ao qual se dá o nome de junta de medição, enquanto que a outra extremidade dos fios é levada ao instrumento de medição da força eletromotriz (ou ddp - diferença de potencial) fechando um circuito elétrico (junta de referência). O aquecimento da junção dos dois metais gera o aparecimento de uma ddp.

Nesse sistema, as medições de temperatura são realizadas em conjunto com um conversor, que tem por função enviar um sinal elétrico padronizado (4-20 $\mathrm{mA}$ ) ao SDCD, referente ao valor de temperatura obtido através da medição do ddp, gerado pelo termopar (quanto maior a temperatura, maior o ddp).

\subsection{Medição da Vazão de Gás para o Sistema de Remoção de $\mathrm{CO}_{2}$}

A medição da vazão de gás para o sistema de remoção de $\mathrm{CO}_{2}$ é realizada por um dispositivo denominado "annubar" (Figura 33). 


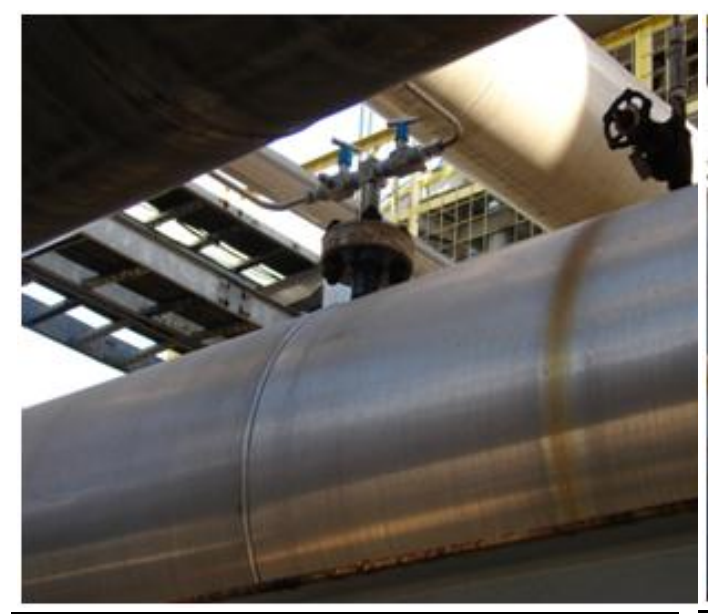

(a)

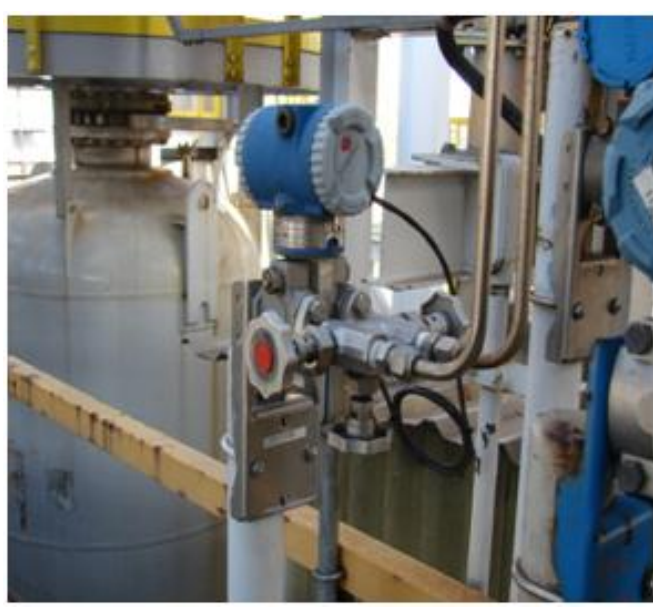

(b)

Figura 33 - Detalhe do sistema de medição da vazão de gás para o sistema de remoção de $\mathrm{CO}_{2}$. (a) Annubar; (b) Instrumento de medição da pressão diferencial

Nesse tipo de medição, o dispositivo responsável pela geração de uma pressão diferencial ocupa todo o diâmetro do tubo. A parte de alta pressão do sinal de $\Delta \mathrm{P}$ é produzida pelo impacto do fluido nos furos do sensor, sendo então separado e fluindo em volta do annubar. Os furos sensores na parte frontal sentem a pressão de impacto causada pelo fluido.

Após o fluido separar-se em torno do sensor annubar, uma zona de baixa pressão (abaixo da pressão estática no tubo) é criada, devido ao formato do sensor. $\mathrm{O}$ lado de baixa pressão do sinal de $\Delta \mathrm{P}$ é percebido pelos furos localizados à jusante do medidor annubar.

A diferença de pressão é proporcional à raiz quadrada da vazão. Quando são medidas vazões de gases, a densidade do fluido varia dependendo da pressão e da temperatura, sendo necessário efetuar a correção do valor medido, compensando essa variação.

\subsection{Medição da Vazão de Clorados}

A medição da vazão de clorados é realizada por um orifício integral como o mostrado na Figura 34. 


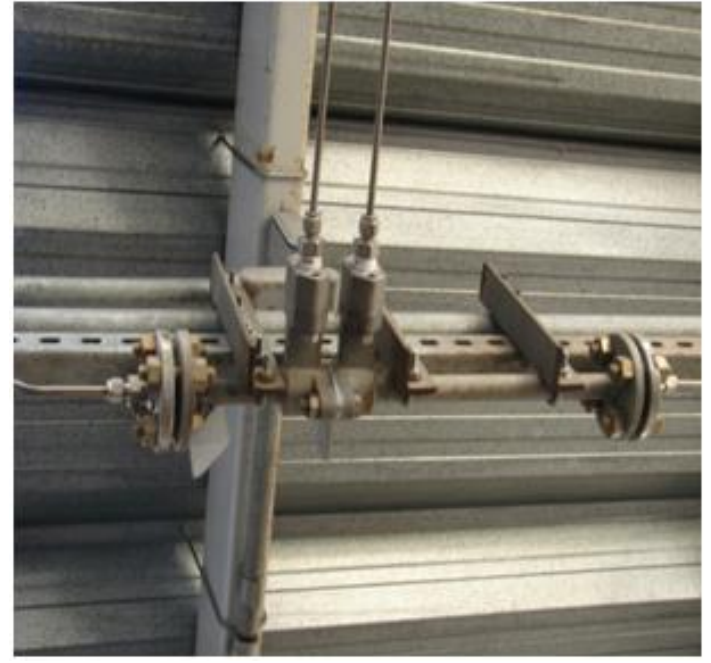

(a)

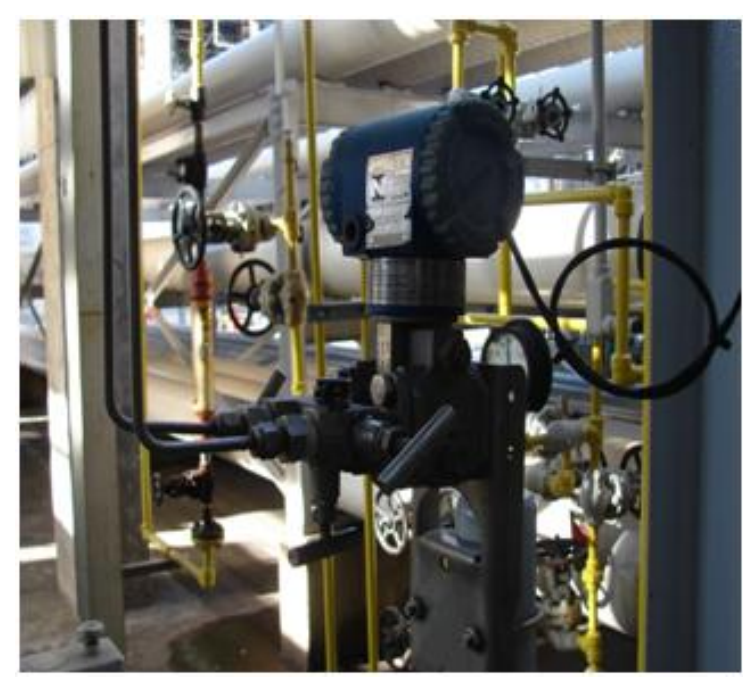

(b)

Figura 34 - Sistema de medição da vazão de clorados para o sistema de gás de reciclo. (a) Orifício integral; (b) Instrumento de medição da pressão diferencial

A função do orifício integral (restrição utilizada para medição de baixas vazões em tubulações de pequeno diâmetro) é gerar um diferencial de pressão, relacionado com a vazão de cloreto de etila. Após medição deste diferencial de pressão, um sinal elétrico padronizado (4-20 mA) é enviado ao SDCD, representando a vazão medida $(0-1,7 \mathrm{~kg} / \mathrm{h})$.

Sua instalação é incorporada à câmara de medição de pressão diferencial, sendo que o fluido passa obrigatoriamente pela câmara de alta pressão do medidor e, a queda de pressão, provocada pela restrição, é transmitida imediatamente para câmara de baixa pressão.

\subsection{Medição da Pressão de Reação}

A medição da pressão da reação é realizada por um instrumento, mostrado na Figura 35, que apresenta as seguintes características técnicas:

- Fabricante: Foxboro;

- Modelo: IGP20-T22E21E-M2

- Faixa de Medição: 0-40 kgf/cm² 


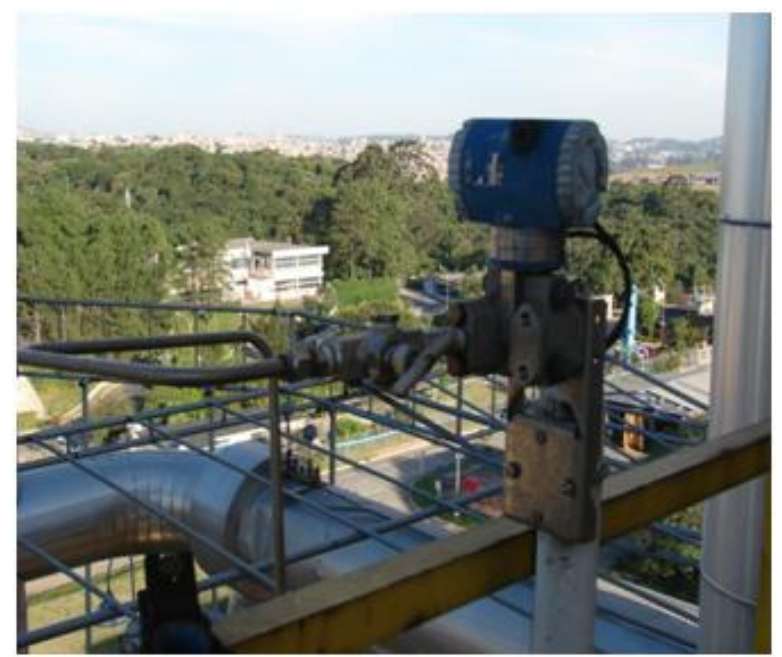

Figura 35 - Detalhe do instrumento de medição da pressão da reação

O funcionamento do sensor, utilizado nesse processo de medição, parte do princípio da deformação de uma estrutura quando esta está sujeita a uma dada força. A pressão à qual uma estrutura está sujeita poderá ser determinada pela variação da resistência de um sensor. Neste tipo de medição, quatro resistores são integrados, de modo que dois resistores aumentam sua resistência e dois diminuem com o aumento ou decréscimo da pressão aplicada.

Portanto, este tipo de instrumento recebe a pressão de processo em sua cápsula de medição através de um diafragma isolador. Este diafragma transmite a pressão que irá deformar elasticamente os resistores, alterando seus valores de resistência proporcionalmente à pressão aplicada. A eletrônica deste medidor processa esta medição de resistência associando com o valor de pressão da aplicação (0-40 kgf/ $\left./ \mathrm{cm}^{2}\right)$, um sinal elétrico padronizado (4-20 $\mathrm{mA}$ ), representativo da pressão medida, que é transmitida pelo instrumento ao SDCD.

\subsection{Medição da Concentração de Clorados no gás de reciclo}

A medição da concentração de clorados, que é alimentado na corrente de recirculação de gás de reciclo, é realizada por um analisador de processo, mostrado na Figura 36, que apresenta as seguintes características técnicas: 
- Fabricante: ABB;

- Modelo: Vista II;

- Tipo de detector: FID (Ionização de chamas)

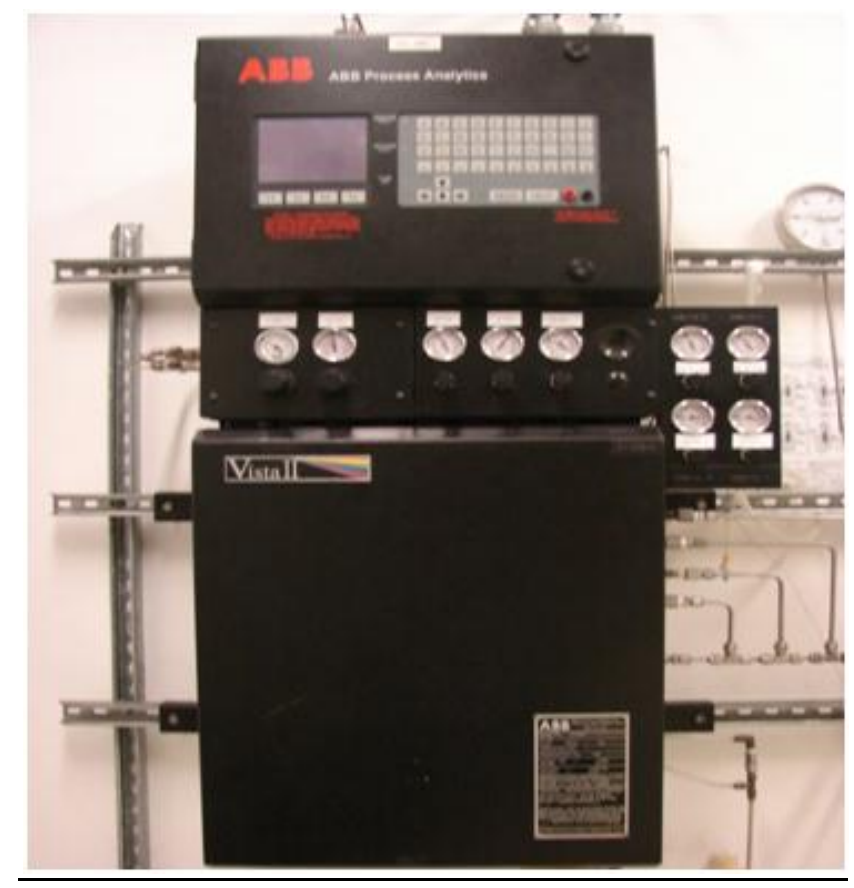

Figura 36 - Analisador de vazão de clorados para o sistema de gás de reciclo

O funcionamento do detector por ionização de chamas está baseado no princípio de que a condutividade elétrica de um gás é diretamente proporcional à concentração de partículas eletricamente carregadas existentes nesta concentração.

O circuito de medição é constituído por um detector por ionização de chama, uma fonte de tensão e um circuito de amplificação. O detector possui no seu interior um queimador (que queima o gás de saída da coluna em uma chama de hidrogênio e ar). A ponta do queimador constitui um eletrodo (cátodo), enquanto que outro eletrodo (ânodo) é colocado na periferia da chama. Entre os dois elétrodos estabelece-se um campo elétrico, cujo potencial é fornecido pela fonte. Os íons formados na combustão são atraídos pelos eletrodos, estabelecendo uma corrente diretamente proporcional à quantidade de átomos de carbono no gás de saída da coluna. O detector necessita de um suprimento 
de ar e hidrogênio para assegurar a constância da chama. A combustão é iniciada através de um filamento aquecido por corrente elétrica.

Quando da coluna provém somente o gás de transporte, ocorre apenas a combustão entre o ar e o hidrogênio. Neste caso, a condutividade elétrica do gás queimado entre os eletrodos é baixa, uma vez que a quantidade de íns formados é muito pequena. Estabelece-se pelo circuito uma corrente constante, denominada corrente de fundo, que é cancelada eletronicamente pelo amplificador. Quando o gás de transporte sai da coluna com um componente separado (hidrocarboneto), esse último se queima, provocando um aumento de íons na mesma proporção que a concentração do componente separado. Então, a condutividade elétrica do gás que se queima entre os eletrodos cresce, aumentando a corrente no circuito. Portanto, para cada componente separado na coluna (exemplo: cloreto de etila, cloreto de metila e cloreto de vinila) haverá uma queima.

Quanto maior for a concentração do componente, maior a condutividade elétrica do gás e maior será o sinal de corrente no circuito do detector, esse sinal de corrente é processado e enviado ao SDCD.

\subsubsection{Coleta de dados relacionados às Análises do Processo (Composição do Gás de Reciclo)}

A composição do gás de reciclo também é obtida continuamente através de medições realizadas por analisadores on-line de processo.

As análises da composição do gás de reciclo na entrada e saída do reator são de vital importância, pois a seletividade do processo é calculada através de equações que envolvem essas medições, como apresentadas no item 3.4.1.1. Cromatografia gasosa é a metodologia utilizada para a avaliação da composição do gás de reciclo e que serve como base para o cálculo da seletividade da reação. As concentrações de óxido de etileno são medidas por um analisador dedicado ao gerenciamento desse componente, conforme 
orientação da empresa detentora da tecnologia utilizada no processo em estudo.

\subsubsection{Medição da composição da corrente de gás de reciclo via Cromatografia gasosa}

O equipamento utilizado para realização dessas amostragens é um cromatógrafo fabricado pela empresa Yokogawa, modelo CG1000 MarK II, como mostrado na Figura 37.

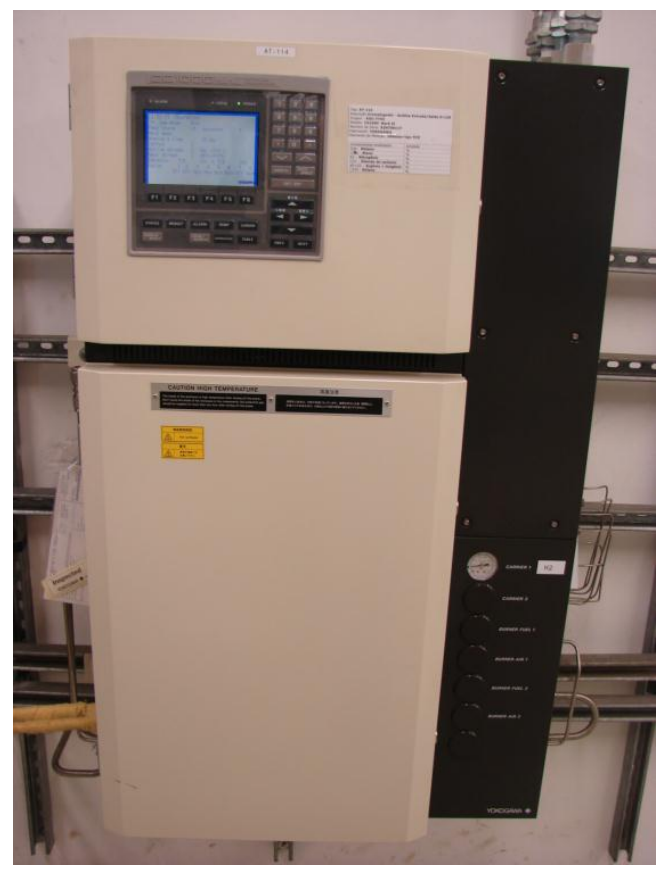

Figura 37 - Cromatógrafo de Processo, modelo CG1000 MarK II

Este cromatógrafo é adequado para medir quantitativamente os componentes presentes no gás de entrada e saída do reator de produção de óxido de etileno, que estão mostrados na Tabela 11. 
Tabela 11 - Variáveis Analíticas Coletadas no estudo.

\begin{tabular}{|c|c|}
\hline Variável & Descrição da Variável \\
\hline AR101 & Concentração de oxigênio: gás de reciclo alimentando o reator \\
\hline AR105 & Concentração de oxigênio: gás de reciclo efluente do reator \\
\hline AR114a & Concentração de Etileno: gás de reciclo que alimenta o reator \\
\hline AR114b & Concentração de $\mathrm{CO}_{2}$ : gás de reciclo que alimenta o reator \\
\hline AR114c & Concentração de Etileno: gás de reciclo efluente do reator \\
\hline AR114d & Concentração de $\mathrm{CO}_{2}:$ gás de reciclo efluente do reator \\
\hline
\end{tabular}

O cromatógrafo de processo CG1000 MarK II é um instrumento analítico que permite determinar o tipo e a quantidade dos componentes de uma amostra, sendo constituído basicamente por três elementos acoplados em série, que formam o circuito cromatográfico, mostrado na Figura 38.

- Introdutor: tem como função introduzir um determinado volume de amostra no fluxo do fluido de transporte.

- Coluna cromatográfica: tem como função separar os diversos componentes da amostra, de acordo com as diferentes velocidades em que cada componente se desloca no interior da coluna.

- Detector: tem como função gerar um sinal proporcional à concentração ou à massa, conforme o tipo de detector, do componente separado. 


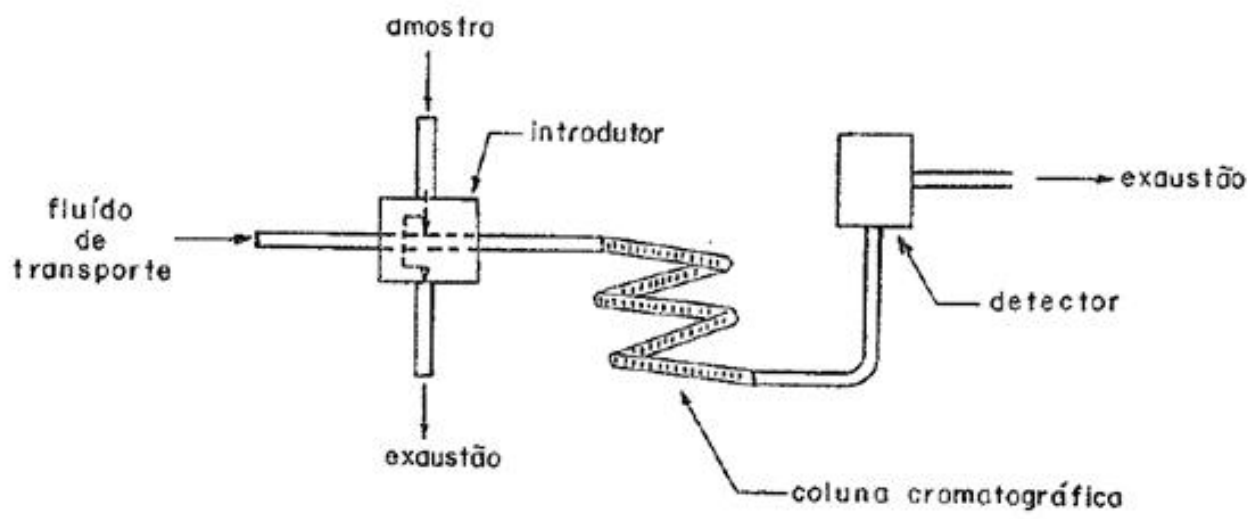

Figura 38 - Detalhe dos elementos de medição do cromatógrafo de processo

Em cada ciclo de análise do cromatógrafo (que, para o equipamento em questão, é de 300 segundos), são observadas as seguintes etapas de processo:

1ํ - O fluido de transporte flui continuamente pelo circuito cromatográfico.

2 - A amostra é introduzida no fluxo do fluído de transporte.

$3^{0}$ - A amostra é levada pelo fluído de transporte até a coluna cromatográfica.

4 ํ - Os componentes são separados pela coluna cromatográfica.

5o - Os componentes separados são levados pelo fluido de transporte até o detector.

6ำ - O sinal gerado pelo detector, em função do componente separado, é tratado eletronicamente e enviado a um sistema de aquisição de dados (exemplo: SDCD). O cromatógrafo CG1000 Mark II utiliza o detector do tipo condutibilidade térmica, como mostrado na Figura 39. 


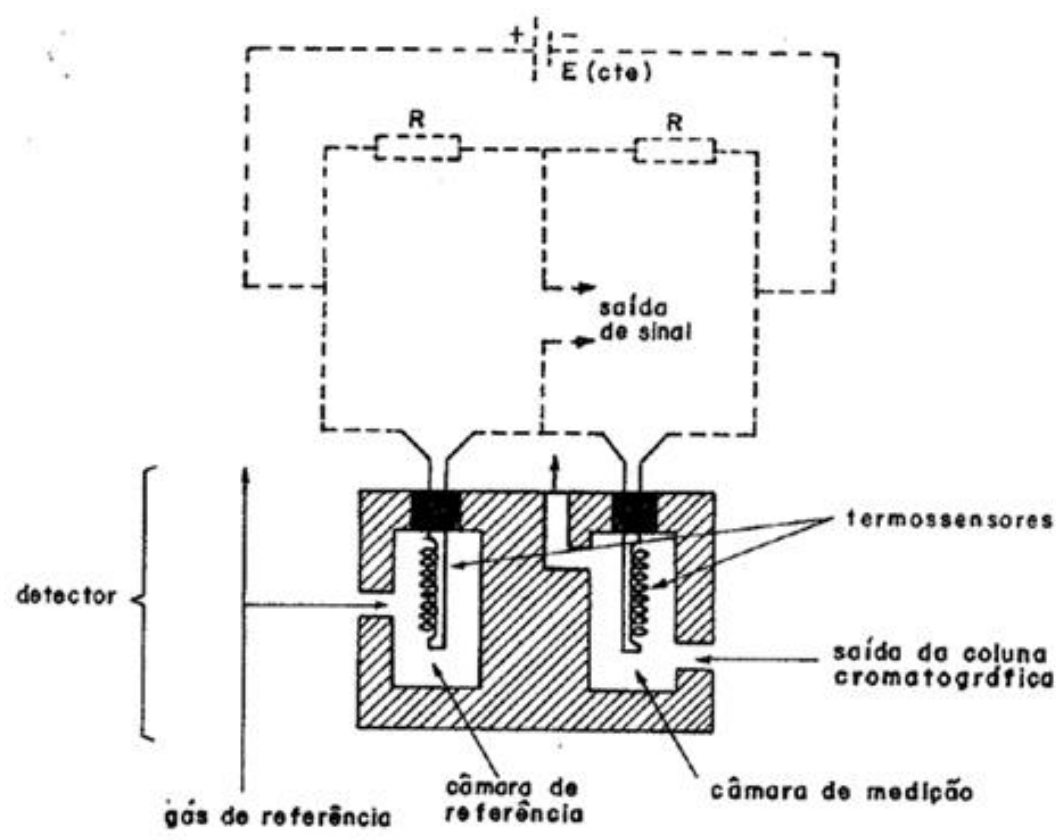

Figura 39 - Detalhe do detector do cromatógrafo de processo

O detector por condutibilidade térmica, acoplado a um circuito eletrônico, forma um sistema de medição que gera um sinal elétrico. Este sinal é proporcional à diferença de condutibilidade térmica entre o gás na saída da coluna e o gás de referência. Os gases hélio e hidrogênio são os mais utilizados, pois apresentam boa condutividade térmica, propriedade exigida pelo detector, e baixa densidade, o que resulta em alta velocidade de escoamento, reduzindo assim o tempo necessário para a sua separação.

A câmara de medição permite que o gás de saída da coluna cromatográfica entre em contato contínuo com o termosensor, instalado no seu interior, e a sua geometria possibilita a renovação permanente do gás (essa característica garante ao detector um tempo de resposta pequeno, porém o torna sensível a variações do fluxo de gás de transporte, requerendo um controle perfeito dessa variável).

A câmara de referência permite que o gás de referência entre em contato com o termosensor instalado no seu interior (o gás de referência é o mesmo utilizado para o transporte da amostra). 
4.5.2.2 Medição da composição da corrente de gás de reciclo via Espectômetro de Massa

Em função da importância das medições da composição do gás de reciclo para a gestão e tomadas de decisão no processo produtivo, o monitoramento das composições é realizado de forma redundante, através de outro equipamento o espectrômetro de massa, modelo Questor IV fabricado pela empresa AAB Extrel, mostrado na Figura 40.

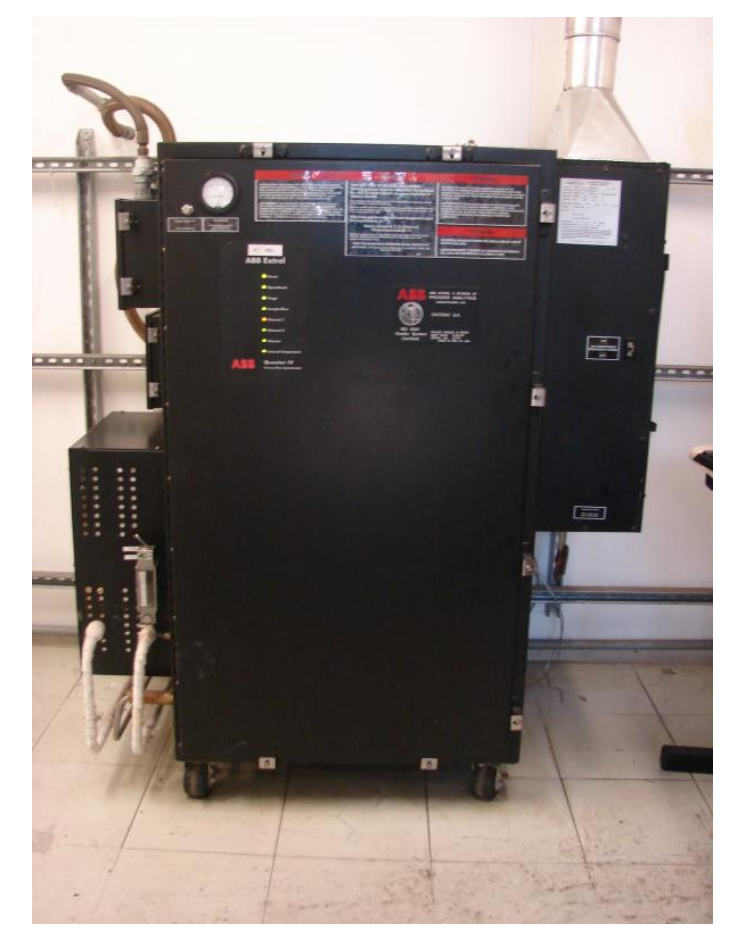

Figura 40 - Espectômetro de massa, modelo Questor IV

Nesse equipamento são realizadas medições quantitativas (\%) dos mesmos componentes listados na Tabela 11.

As análises dos componentes da mistura gasosa são realizadas através da seguinte metodologia: um espectômetro de massa bombardeia uma mistura gasosa com elétrons em sua câmara de medição, para produzir íons eletricamente carregados. Os íons atravessam um campo magnético, que direciona suas trajetórias de modos diferentes, dependendo de suas massas. $O$ campo magnético separa os íons em um padrão chamado espectro de massa. 
A massa e a carga dos íons podem ser medidas por sua posição no espectro através do detector deste analisador.

Quando uma molécula é ionizada, gera-se uma massa espectral identificada por uma relação "massa/carga" (m/z) e com uma característica daquela molécula em particular. Obtém-se, portanto, a intensidade relativa de cada íon fragmentado, chamando-se "pico base". Este "pico base" de espectro iônico é muito intenso e é normalizado em $100 \%$.

Para analisar componentes de uma amostra deve-se executar primeiramente uma correção de eventuais "ruídos de fundo", nos sinais detectados. Estes ruídos são principalmente provenientes do sistema de vácuo da câmera de medição.

Cada tipo de gás possui uma tabela de fragmentação dos componentes existentes nesta amostra e suas massas de interferências. $O$ ajuste de fragmentação tem por objetivo anular as interferências dos componentes, a serem quantificados na massa base de medição. A calibração final é executada com uma composição gasosa padrão, próxima ao do processo a ser analisado.

O espectrômetro de massa deve passar por um processo de manutenção preventiva obrigatória em intervalos de seis meses a um ano, requerendo um tempo de parada da unidade produtiva de aproximadamente 36 horas. Caso, durante esse período, não seja possível programar uma parada geral da unidade, o gerenciamento é realizado exclusivamente pelo cromatógrafo CG1000 MarK II (cromatografia gasosa), apresentado em 4.5.2.1.

\subsubsection{Medição da composição de óxido de etileno na corrente de gás de reciclo}

Em função das baixas concentrações de óxido de etileno no processo reacional, e, pelo fato de ser a molécula chave a ser gerenciada no processo, utiliza-se um analisador de processo específico para o monitoramento das 
concentrações de óxido de etileno nas correntes de entrada e saída do reator (cromatógrafo a gás, intitulado AT120 D, como mostrado na Figura 41).

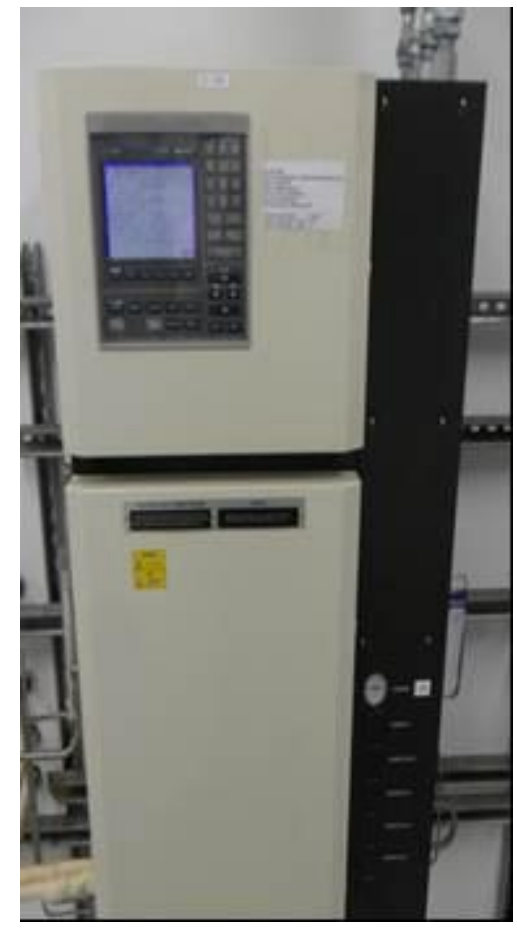

(a)

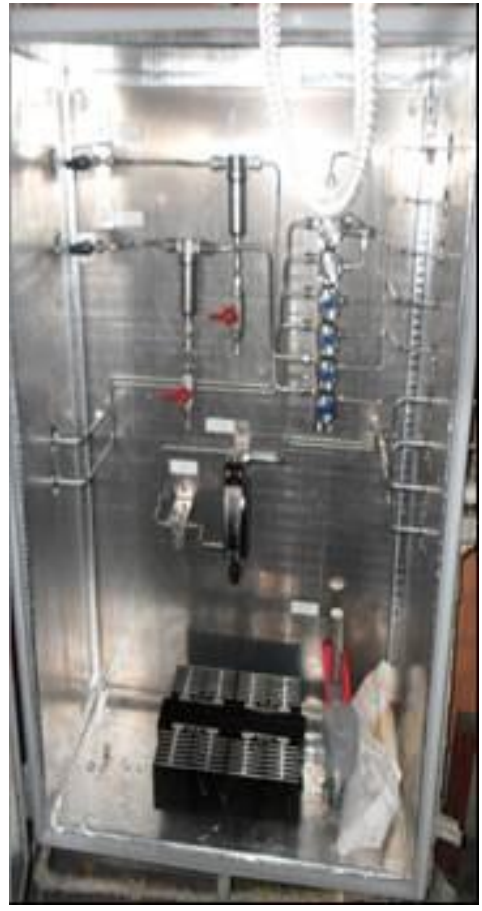

(b)

Figura 41 - (a) Analisador para óxido de etileno (cromatógrafo AT120D - modelo CG1000 Mark II); (b) Caixa quente para condicionamento da amostra.

As principais características técnicas desse equipamento são listadas a seguir:

- Fabricante: Yokogawa

- Modelo: CG1000 MarK II

- Tempo do ciclo de medição: 300 segundos

- Tipo de detector: TCD (detector por condutibilidade térmica)

- Gás de referência do detector: Hidrogênio

- Quantidade de colunas de separação: 2

- Gás de transporte da amostra: Hidrogênio

- Gás de calibração para análise do gás de entrada: 501 ppm de óxido de etileno com balanço em Nitrogênio.

- Gás de calibração para análise do gás de saída: 1,99\% de óxido de etileno com balanço em Nitrogênio.

- Repetibilidade: $1 \%$ em relação ao fundo de escala 
Este cromatógrafo de processo está dedicado à medição da concentração de óxido de etileno, na entrada e saída do reator. A medição da concentração de óxido de etileno no gás de entrada do reator é realizada em ppm, devido ao seu baixo valor, e a medição da concentração de óxido de etileno no gás de reciclo, na saída do reator, é medida em \%.

A faixa de operação recomendada pelo fabricante está entre 0 a $5 \%$ molar de óxido de etileno, na corrente de gás de reciclo, e a incerteza dessa medição é de apenas $2 \%$ em relação ao valor medido, o que confere uma elevada precisão nos resultados avaliados para esse componente. Além disso, a leitura das concentrações é rápida, ocorrendo atualizações das medições a cada 5 minutos, no máximo.

Seu princípio de funcionamento é idêntico ao do cromatógrafo utilizado para medição das demais concentrações dos componentes da corrente de gás de reciclo, como descrito em 4.5.2.1.

A resposta obtida para a análise do óxido de etileno é um cromatograma, como o mostrado na Figura 42, onde o valor de concentração de óxido de etileno é diretamente proporcional à área do pico. O cromatograma pode ser considerado como ideal uma vez que não possui interferências de outros gases (ou seja, a separação é perfeita e permite uma baixa incerteza e alta repetibilidade nas medições). 


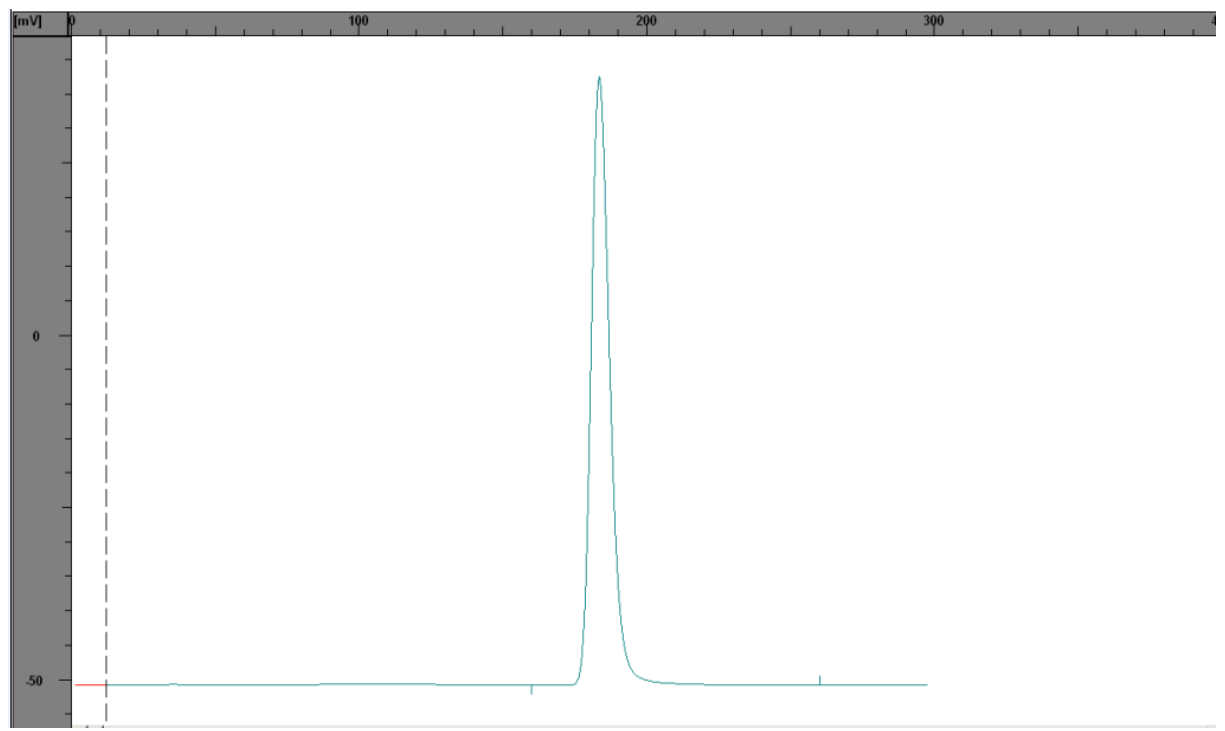

Figura 42 - Cromatograma típico das análises realizadas no cromatógrafo AT120D

Como resultado desse processo de medição, as concentrações de óxido de etileno na corrente de gás de reciclo são monitoradas pelas variáveis mostradas na Tabela 12.

Tabela 12 - Variáveis Analíticas que Monitoram a Concentração de óxido de etileno

\begin{tabular}{|l|l|}
\hline AR120D & Concentração de óxido de etileno: gás de reciclo alimentando reator \\
\hline AR120E & Concentração de óxido de etileno: gás de reciclo efluente do reator \\
\hline
\end{tabular}

\subsubsection{Metodologia para Análise Estatística dos Dados e Tratamento dos} Resultados Obtidos

Os dados, obtidos conforme metodologia apresentada em 4.5.1 e 4.5.2, foram analisados e trabalhados, com o objetivo de se interpretar o processo, comparando os resultados com a fenomenologia que representa o processo de produção de óxido de etileno. Quatro abordagens foram realizadas:

a) O tratamento dos dados de forma estatística, visando obter um conjunto de dados adequados para a análise do processo, além de proporcionar uma visão de como as variáveis independentes influenciam no resultado da seletividade da reação e como estas 
variáveis estão correlacionadas entre si. Essa etapa se subdividiu em:

- Eliminação dos dados inconsistentes;

- Eliminação de outliers;

- Avaliação de correlações entre variáveis;

- Codificação de dados;

b) Determinação de um modelo matemático que representa 0 comportamento da seletividade da reação, empregando o conceito de regressão multilinear. Complementa-se a abordagem, através da realização de análises exploratórias nos modelos matemáticos obtidos, os quais permitiram o estabelecimento das melhores condições de operação da unidade na busca pela máxima seletividade do processo. Essa etapa se subdividiu em:

- Estabelecimento de modelos de regressão, para representar o fenômeno;

- Definição do melhor modelo de regressão, que representa o processo.

c) A simulação termodinâmica do processo, visando analisar se o comportamento observado está condizente com os modelos teóricos previstos pela engenharia (balanços de massa, balanços de entalpia, cinética das reações químicas). Essa etapa se subdividiu em:

- Simulação do processo através da utilização de um simulador, cujo objetivo é a análise do comportamento fenomenológico do processo. Esse tipo de simulador é utilizado comercialmente para geração de propriedades de componentes, simulação de operações unitárias, projeto de processos e verificação / comparação entre dados reais de um processo e dados teóricos previstos para este mesmo processo;

- Interpretação dos resultados obtidos, comparando-os com os dados reais de processo. 
d) Análise exploratória do modelo, onde determinadas variáveis foram fixadas em uma dada condição de operação e variaram-se as demais variáveis ao longo das faixas de operação aplicáveis ao processo. Posteriormente, foi realizada a interpretação dos resultados obtidos, comparando-os com a fenomenologia que representa o processo em estudo.

Detalhamento da metodologia utilizada para execução efetiva de cada uma dessas etapas está descrita nos itens 4.5.3.1 a 4.5.3.7.

A coleta dos dados de processo e a realização do tratamento estatístico descrito anteriormente permitiram o conhecimento das condições padrão típicas de operação da unidade em estudo. Essas situações aproximam-se do conceito de fotografia de um evento, apresentado em trabalhos como os de Nasser (2009) e apresentado também como uma das principais contribuições da engenharia de processos para avaliação da competitividade de uma unidade produtiva (SARAIVA, 2010). De maneira simplificada essas fotografias reproduzem com fidelidade o comportamento esperado de um dado processo.

O estabelecimento de situações que representam as condições padrão de operação, bem como a análise do ajuste desses dados ao modelo estatístico desenvolvido empiricamente, permite definir com significativa relevância o grau de influência de cada variável de operação no comportamento do processo.

O ajuste dos dados de processo ao modelo estatístico pode ser avaliado através da alimentação deste modelo com dados reais de processo, sendo obtida como resposta a seletividade da reação. A comparação entre a seletividade prevista pelo modelo e a seletividade real do processo (obtida através dos cálculos que utilizam a medição das concentrações dos componentes do gás de reciclo) determina o quão próximo está o modelo proposto do fenômeno estudado. Em caso de um bom ajuste, pode-se dizer que o modelo empírico e as variáveis estudadas representam de forma satisfatória os fenômenos envolvidos no processo. 
A validação do modelo estatístico proposto perante a fenomenologia envolvida no processo também pode ser realizada através da comparação do mesmo conjunto de dados com os resultados esperados, quando se estuda 0 fenômeno através de um simulador de processo. Aplica-se, nessa situação, o mesmo critério de aderência de resultados utilizado para validação do modelo estatístico.

\subsubsection{Eliminação de Dados Inconsistentes}

Os dados adquiridos junto ao analisador on-line e CS3000 foram exportados para uma planilha excel, utilizada como base para elaboração de cálculos, e gráficos apresentados no capítulo 5 deste trabalho. O processo de análise estatística dos dados inicia-se com a eliminação de dados inconsistentes existentes no conjunto adquirido. Esse processo foi realizado através da adoção das premissas listadas a seguir:

- Foram excluídos os dados referentes a períodos em que a unidade produtiva estava parada (por qualquer que fosse o motivo causador dessa parada);

- Foram excluídos dados onde foram evidenciadas falhas no sistema de medição.

- 1 caso: uma vazão de processo indicando zero quando sabidamente a planta estava operando.

- 2 caso: resultados anormais em função do comportamento do processo (nesse caso, o critério utilizado é o conhecimento conceitual do processo em estudo, tomando como base a revisão bibliográfica apresentada no capítulo 3 deste trabalho)

Alguns exemplos de medições inconsistentes:

- Valores concentrações do gás de reciclo que resultaram em seletividades inferiores a $60 \%$ ou superiores a $93 \%$

- Vazão de alimentação de etileno para a unidade inferior a $3400 \mathrm{~kg} / \mathrm{h}$ 
- Temperatura de reação inferior a $200^{\circ} \mathrm{C}$

- Controle do teor de clorados inferior a $0,01 \%$ ou superior a $0,12 \%$

Nesses casos, todo conjunto de dados (de processo e analíticos) foi eliminado do estudo, pois a utilização destes poderia resultar em correlações e conclusões equivocadas.

Também é importante ressaltar que todos os dados foram adquiridos durante 0 período de uma dada campanha (entende-se por campanha o processo de produção que ocorre dentro do tempo de vida útil de um catalisador - nesse caso, o fabricante do catalisador prevê um intervalo de 2,5 a 4,0 anos, em média). Para efeitos de estudos de desempenho de uma unidade, não se recomenda a utilização de dados de campanhas diferentes (uma vez que os dados seriam obtidos de processos operados com catalisadores diferentes).

\subsubsection{Eliminação de Outliers}

De posse deste novo conjunto de dados de processo, excluídos os dados inconsistentes, a próxima etapa foi a realização dos cálculos das médias e desvios-padrão de cada variável, com o objetivo de identificar e eliminar os outliers (ou dados anômalos do processo). Um dado anômalo é definido como uma observação que não é condizente com o restante da massa de dados em estudo (WERKEMA, 1995).

Outra visão em relação a esse tipo de dados está relacionada ao conceito de causas comuns e causas especiais. O conceito de causas comuns prevê que os processos variem dentro de uma faixa, uma vez que máquinas, mão de obra, qualidade da matéria prima e métodos de trabalho não podem ser iguais $100 \%$ do tempo. Nesse caso, as variações são permanentes e fazem parte do processo. São as chamadas causas crônicas. Quando um processo apresentar uma medição fora desses limites, diz-se que algo diferente do esperado ocorreu (nesse caso, uma causa especial ou um dado anômalo ou outlier foi 
evidenciado), Um estudo específico em relação ao evento, que motivou a geração desse dado, merece ser realizado (KENETT; ZACKS, 1998)

Nesse trabalho, o critério estatístico utilizado para a eliminação dos outilers é o apresentado por Breyfogle, Cupello e Meadows (2001): a probabilidade de uma determinada variável de processo estar localizada fora de um intervalo corresponde ao seu valor médio, mais ou menos três vezes o desvio padrão, é muito baixa. Nessa situação, podemos considerar que o dado observado foge ao comportamento padrão do processo, sendo considerado um outiler (sua exclusão do conjunto de dados não compromete a qualidade da análise a ser realizada no processo).

\subsubsection{Avaliação de Correlações entre Variáveis}

Excluídos os outilers, a próxima etapa consistiu na análise estatística dos dados buscando evidenciar correlações entre as variáveis inicialmente estudadas e uma possível redução no número de variáveis a serem avaliadas.

Os estudos de correlações entre variáveis foram realizados através do software MINITAB 15.0, em duas etapas distintas:

a) Avaliação de correlações entre os resultados obtidos para as diversas formas de cálculo de seletividade;

b) Avaliação de correlações entre as concentrações dos componentes medidos no gás de reciclo via analisadores;

c) Avaliação de correlações entre as variáveis de processo.

\subsubsection{Codificação de Dados}

O número de variáveis críticas para o gerenciamento da seletividade da reação de produção de óxido de etileno foi reduzido a quatro, após a avaliação das correlações entre as variáveis de processo. 
Uma vez que a ordem de grandeza dessas variáveis é muito diferente, houve necessidade de se normalizar as variáveis conforme procedimento descrito a seguir:

Valor normalizado $=\frac{\text { (valor lido da variável-R })}{\mathrm{R}^{*}}$

Onde:

$\mathrm{R}=\frac{\text { (valor máx.da variável no conjunto de dados }+ \text { valor mín da variável no conjunto de dados) }}{2}$

$\mathrm{R}^{*}=\frac{\text { (valor máx.da variável no conjunto de dados- valor mín da variável no conjunto de dados) }}{2}$

A codificação dos dados também é bastante importante para a manutenção do sigilo dos dados utilizados no estudo, sem que ocorra perda de qualidade das informações que estão sendo trabalhadas.

\subsubsection{Modelos de Regressão Multilinear}

Utilizando-se o software MINITAB 15.0, foram elaborados modelos de regressão multilinear para o conjunto de dados normalizados, com o objetivo de analisar o grau de influência de cada variável e das interações entre variáveis no comportamento da seletividade do processo.

A utilização de um software específico permite uma simulação do processo (determinação da seletividade da reação) em função de diversas análises, em relação às suas variáveis independentes.

Os modelos que apresentam a melhor aderência à explicação do processo em estudo são aqueles que resultam nos menores valores do $\mathrm{Cp}$ de Mallows (item 3.8.2.4), juntamente com os maiores coeficientes de determinação (item 3.8.7). 


\subsubsection{Simulação do Processo}

Um processo industrial pode ser estudado detalhadamete através do uso dos chamados simuladores de processo, os quais permitem ao engenheiro uma série de funcionalidades como:

- Prever o comportamento de um dado processo;

- Determinar as condições ótimas para os quais um novo processo será projetado;

- Realizar análises de sensibilidade do processo (isto é, entender o comportamento do processo, em função da alteração de determinadas variáveis);

- Otimizar processos já existentes.

Para que seja possível atender a esses objetivos, o simulador permite que cada equipamento ou corrente que constitui o processo seja estudado individualmente, sendo possível conhecer detalhes como composições, temperaturas, pressões, propriedades físico químicas, dimensionamento de equipamentos, etc.

A realização desses estudos só é possível pelo fato de que os simuladores apresentam em seu banco de dados um conjunto de modelos matemáticos (balanços de massa, balanços de entalpia, dados de equilíbrio termodinâmico e cinética de equações), dados de correlações e métodos matemáticos iterativos, que permitem a solução de problemas em alto grau de complexidade matemática em curto espaço de tempo.

Neste trabalho, a modelagem da reação de produção de óxido de etileno, tomando como base as correntes de alimentação de oxigênio e temperatura da reação, foi efetuada no simulador de processos ASPEN PLUS, utilizando como dados de entrada do simulador as faixas reais de operação das variáveis de processo significativas, definidas conforme metodologia apresentada em 4.5.3.3 e 4.5.3.4. 


\subsubsection{Análise exploratória do modelo empregando a metodologia de superfície de resposta}

Definidas as variáveis e interações significativas para o processo, foi realizada uma análise exploratória do modelo, relacionando o comportamento da seletividade da reação em função de alterações nessas variáveis (analisadas duas a duas, mantendo as demais variáveis fixas em determinadas condições de processo).

Nesta etapa do processo, a partir do modelo estatístico geral, foram construídos os chamados modelos desdobrados, cuja resposta foi obtida em função da variação de duas variáveis, fixando-se as outras duas, em níveis préestabelecidos. Desta forma, foram construídas as superfícies de respostas, que dão uma indicação do direcionamento a ser seguido na busca pelas melhores condições de operação em cada situação estudada. 


\section{$5 \quad$ RESULTADOS E DISCUSSÃO}

\subsection{Introdução}

O principal objetivo deste capítulo foi a identificação das variáveis de processo, que influenciam significativamente a seletividade da oxidação de etileno, e a posterior elaboração de um modelo de regressão, para quantificar a influência dessas variáveis no desempenho do processo.

Também foi realizada uma análise exploratória do modelo em função de alterações nessas variáveis. Esse procedimento teve por objetivo analisar 0 comportamento do processo em função de faixas de operação combinadas dessas variáveis, procurando desta forma, simular todos os casos possíveis de operação da unidade em estudo. As análises permitiram avaliar a direção a ser adotada para a busca da melhor seletividade possível para o processo, abrindo-se a possibilidade para aplicações práticas e sugestões para melhorias no processo.

\subsection{Análise Estatística dos Dados Analíticos e de Processo}

Esta seção foi subdivida em duas partes:

- Análise dos dados analíticos (composição do gás de reciclo) e;

- Análise de dados de processo (variáveis típicas de controle de processo, como vazões, temperaturas e pressões).

\subsubsection{Análises da Composição do Gás de Reciclo}

As composições de todos os componentes do gás de reciclo de interesse para o cálculo da seletividade foram medidas e estão representadas (parcialmente) na Tabela 13 (ressalta-se que os dados apresentados já excluem dados relacionados a medições inconsistentes e outliers, como descrito em 4.5.3.1 e 4.5.3.2 e totalizam cerca de 9 mil dados analisados). 
Tabela 13 - Representação (parcial) de dados analíticos coletados no processo (em concentrações mássicas)

\begin{tabular}{|c|c|c|c|c|c|c|c|c|}
\hline Data & $\begin{array}{c}\text { AR101 } \\
\text { (ENT - } \\
\text { O2) }\end{array}$ & $\begin{array}{r}\text { AR105 } \\
(\text { SAI-O2) } \\
-\end{array}$ & $\begin{array}{c}\text { AR114 } \\
\text { (ENT- } \\
\text { C2H4) }\end{array}$ & $\begin{array}{c}\text { AR114 } \\
\text { (ENT- } \\
\text { CO2) }\end{array}$ & $\begin{array}{c}\text { AR114 } \\
\text { (SAl- } \\
\text { C2H4) }\end{array}$ & $\begin{array}{c}\text { AR114 } \\
\text { (SAI- } \\
\text { CO2) }\end{array}$ & $\begin{array}{c}\text { AR120D } \\
\text { (ENT - } \\
\text { EO) }\end{array}$ & $\begin{array}{c}\text { AR120E } \\
\text { (SAI - } \\
\text { EO) }\end{array}$ \\
\hline 2008-11-19 00:00:00 & 4,90 & 2,89 & 20,42 & 0,68 & 18,27 & 1,28 & 0,01 & 1,90 \\
\hline 2008-11-19 01:00:00 & 4,88 & 2,92 & 19,69 & 0,66 & 17,60 & 1,25 & 0,01 & 1,90 \\
\hline 2008-11-19 02:00:00 & 4,88 & 2,94 & 19,35 & 0,65 & 17,27 & 1,23 & 0,01 & 1,90 \\
\hline 2008-11-19 03:00:00 & 4,76 & 2,82 & 19,44 & 0,63 & 17,36 & 1,21 & 0,01 & 1,90 \\
\hline 2008-11-19 04:00:00 & 4,71 & 2,78 & 19,42 & 0,61 & 17,35 & 1,18 & 0,01 & 1,90 \\
\hline 2008-11-19 22:00:00 & 4,64 & 2,74 & 20,10 & 0,63 & 18,01 & 1,20 & 0,01 & 1,90 \\
\hline 2008-11-19 23:00:00 & 4,67 & 2,78 & 20,09 & 0,63 & 18,02 & 1,20 & 0,01 & 1,90 \\
\hline 2008-11-20 00:00:00 & 4,74 & 2,86 & 19,97 & 0,63 & 17,90 & 1,20 & 0,01 & 1,90 \\
\hline 2008-11-20 01:00:00 & 4,67 & 2,81 & 19,92 & 0,63 & 17,88 & 1,19 & 0,01 & 2,05 \\
\hline 2008-11-20 02:00:00 & 4,64 & 2,80 & 20,05 & 0,62 & 18,04 & 1,18 & 0,01 & 2,05 \\
\hline 2008-11-20 03:00:00 & 4,68 & 2,82 & 19,89 & 0,62 & 17,89 & 1,18 & 0,01 & 2,05 \\
\hline 2008-11-20 04:00:00 & 4,66 & 2,84 & 19,74 & 0,62 & 17,74 & 1,17 & 0,01 & 2,05 \\
\hline $2008-11-2005: 00: 00$ & 4,58 & 2,77 & 20,09 & 0,61 & 18,11 & 1,16 & 0,01 & 2,05 \\
\hline 2008-11-20 06:00:00 & 4,63 & 2,81 & 20,40 & 0,61 & 18,41 & 1,17 & 0,01 & 2,05 \\
\hline 2008-11-20 07:00:00 & 4,67 & 2,82 & 20,46 & 0,62 & 18,44 & 1,18 & 0,01 & 2,05 \\
\hline 2008-11-20 08:00:00 & 4,77 & 2,90 & 19,91 & 0,63 & 17,87 & 1,20 & 0,01 & 2,10 \\
\hline 2008-11-20 09:00:00 & 4,73 & 2,86 & 19,34 & 0,63 & 17,27 & 1,20 & 0,01 & 2,10 \\
\hline $2008-11-20$ 10:00:00 & 4,73 & 2,85 & 19,02 & 0,63 & 16,94 & 1,20 & 0,01 & 2,10 \\
\hline 2008-11-20 11:00:00 & 4,69 & 2,81 & 18,79 & 0,63 & 16,72 & 1,19 & 0,01 & 2,10 \\
\hline
\end{tabular}

\subsubsection{Análise da Seletividade da Reação}

As seletividades do processo $\left(S_{1}\right.$ a $\left.S_{6}\right)$ foram calculadas conforme as equações apresentadas na Tabela 5.

Os cálculos utilizaram como variáveis independentes as concentrações mássicas dos componentes presentes no gás de reciclo na entrada e na saída do reator (dados obtidos através dos analisadores on-line, descritos em 4.5.2) mostrados nas Tabelas 11 e 12. Já os resultados dos cálculos das seletividades do processo estão mostrados na Figura 43. 


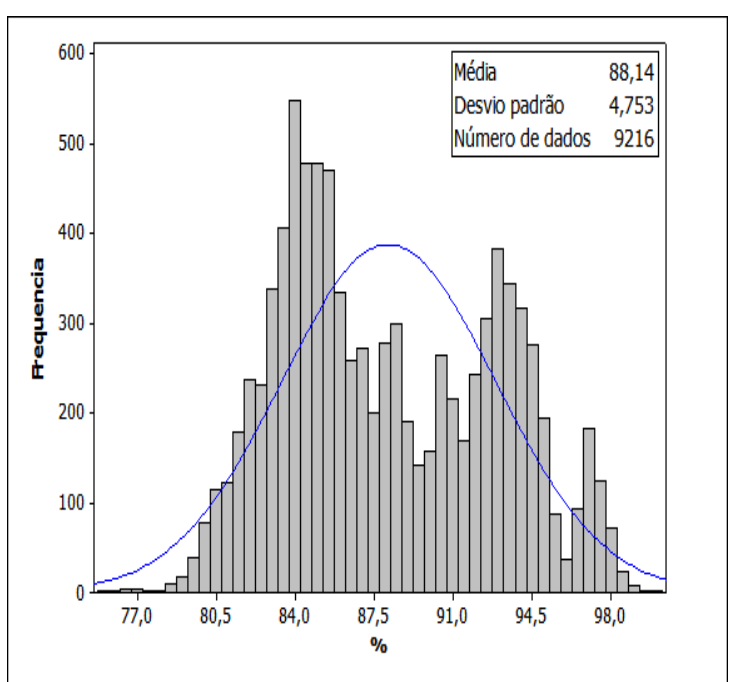

(a)

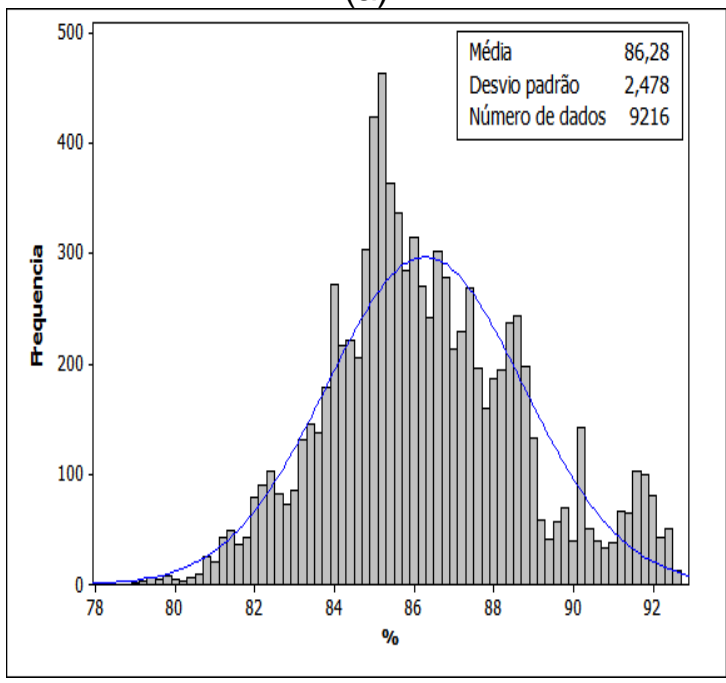

(c)

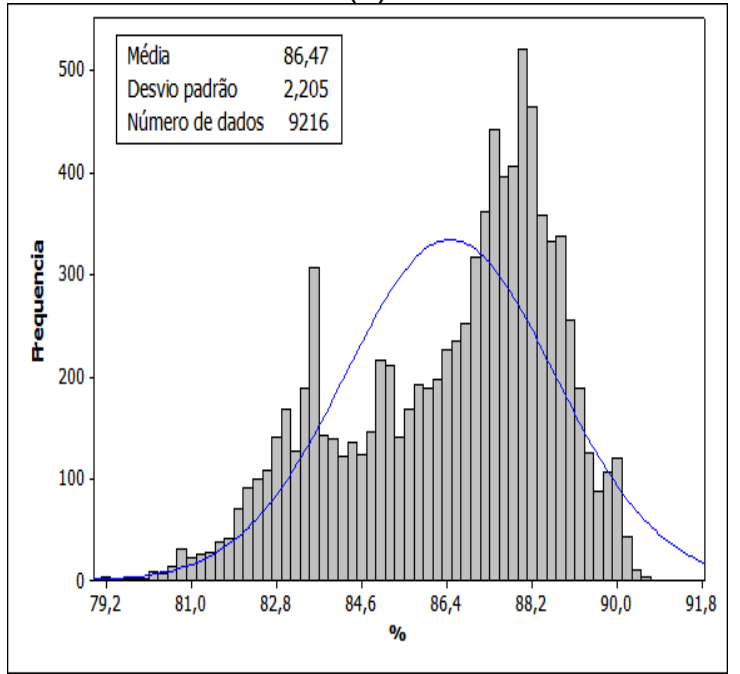

(e)

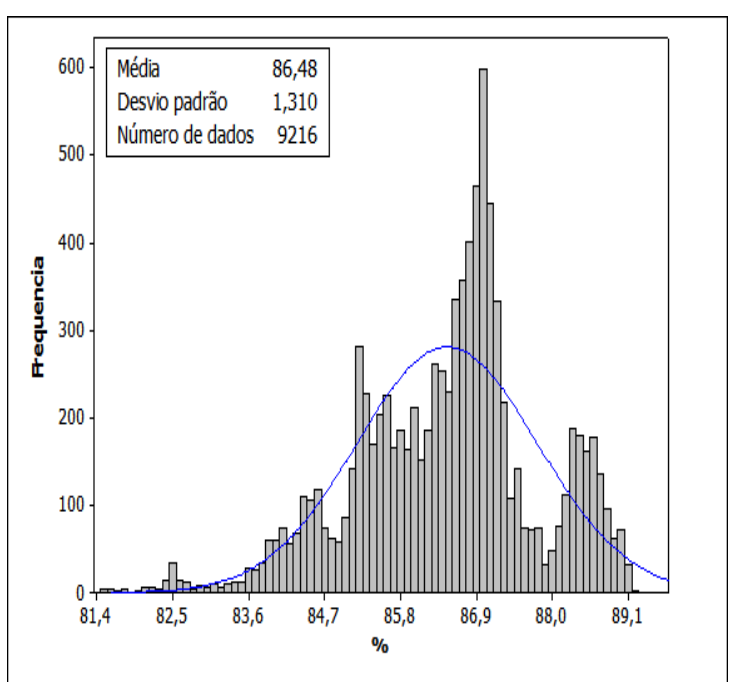

(b)

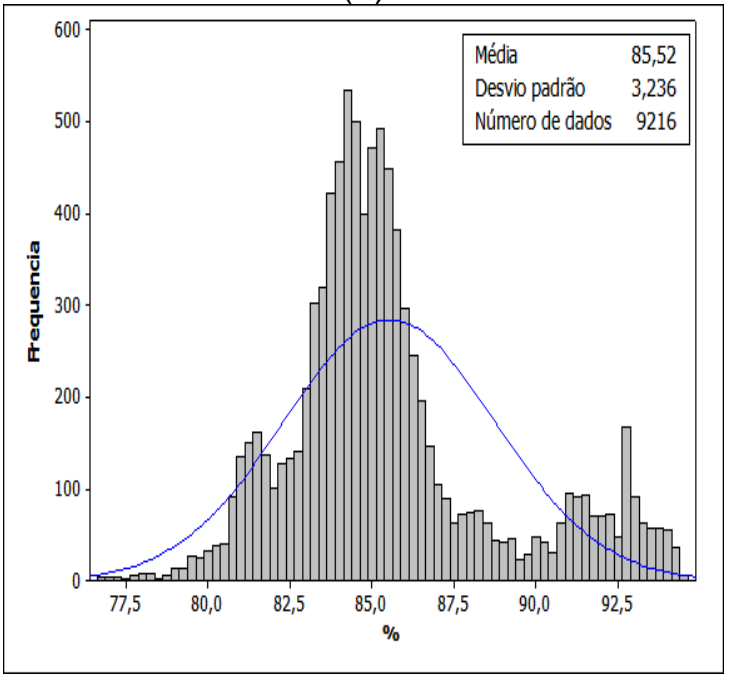

(d)

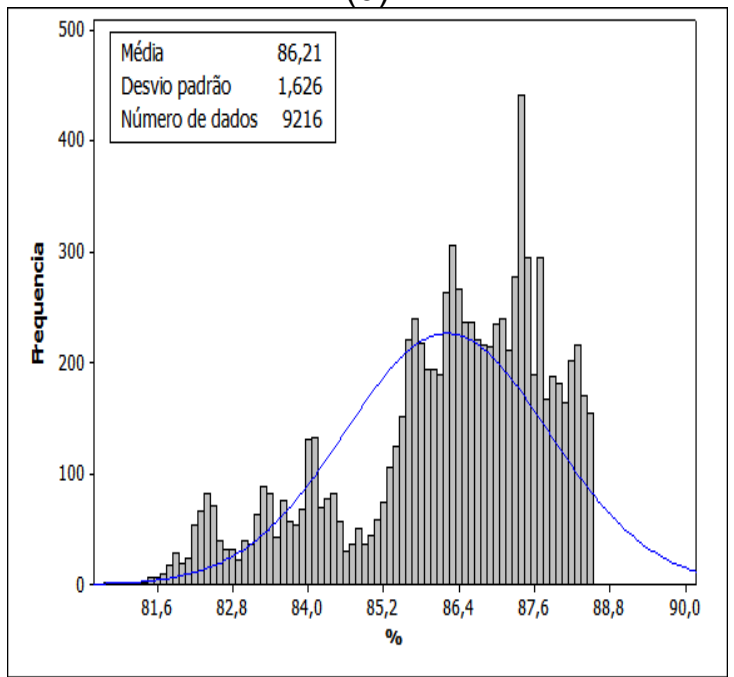

(f)

Figura 43 - Histograma (média e desvio-padrão) das Seletividades de processo $\left(\mathrm{S}_{1}\right.$ a $S_{6}$, em \%) calculadas em função das concentrações dos componentes no gás de reciclo. (a) $\mathrm{S}_{1}$; (b) $\mathrm{S}_{2}$; (c) $\mathrm{S}_{3}$; (d) $\mathrm{S}_{4}$; (e) $\mathrm{S}_{5}$; (f) $\mathrm{S}_{6}$ 
Uma análise dos resultados calculados para esse parâmetro (utilizando as equações e conceitos apresentados em 3.4.1.1) indicou que os resultados estão altamente correlacionados (como indicam os valores do coeficiente de Pearson e valor da probabilidade $p$, mostrados na Tabela 14). A relevância da correlação permitiu escolher apenas uma das medições de seletividade e adotá-la como parâmetro de gestão do processo.

Tabela 14 - Correlação entre os valores de Seletividade obtidos via medições em Analisadores de Processo.

\begin{tabular}{|c|c|c|c|c|c|}
\hline & $\mathrm{S}_{1}$ & $\mathrm{~S}_{2}$ & $\mathrm{~S}_{3}$ & $\mathrm{~S}_{4}$ & $\mathrm{~S}_{5}$ \\
\hline $\mathrm{S}_{2}$ & 0,071 & & & & \\
& 0,000 & & & & \\
\hline \multirow{2}{*}{$\mathrm{S}_{3}$} & 0,186 & 0,722 & & & \\
& 0,000 & 0,000 & & & \\
\hline \multirow{2}{*}{$\mathrm{S}_{4}$} & $-0,249$ & 0,690 & 0,904 & & \\
& 0,000 & 0,000 & 0,000 & & \\
\hline $\mathrm{S}_{5}$ & $-0,116$ & 0,463 & $-0,273$ & $-0,205$ & \\
& 0,000 & 0,000 & 0,000 & 0,000 & \\
\hline $\mathrm{S}_{6}$ & $-0,319$ & 0,921 & 0,597 & 0,737 & 0,504 \\
& 0,000 & 0,000 & 0,000 & 0,000 & 0,000 \\
\hline
\end{tabular}

Observação: para cada célula, $01^{\underline{0}}$ valor representa o coeficiente de correlação de Pearson e $02^{\circ}$ valor representa o valor da probabilidade $p$.

Conforme exposto em 4.5.2, a análise da concentração de óxido de etileno na corrente de gás de reciclo é realizada em um equipamento de alta precisão, dedicado exclusivamente a realização dessa análise, o que eleva o grau de confiança no cálculo das seletividades, cuja fórmula de calculo engloba este componente (no caso, as seletividades $S_{1}, S_{2}$ e $S_{3}$ ). Já os componentes: etileno, $\mathrm{CO}_{2}$ e oxigênio, cujas concentrações são medidas através de um equipamento de cromatografia gasosa, possuem a mesma incerteza de medição, segundo fabricante do equipamento, independentemente de suas concentrações. Nesse caso, a menor incerteza está relacionada ao componente de menor concentração na corrente de gás de reciclo, o $\mathrm{CO}_{2}$.

Analisando ainda as características relacionadas às incertezas de medição, a seletividade, que combina esses dois componentes (óxido de etileno e $\mathrm{CO}_{2}$ ), 
tende a apresentar resultados mais confiáveis, do ponto de vista de precisão, sendo a mais adequada para se representar o comportamento do processo. Em função dessas observações, a seletividade $S_{2}$ foi definida como a mais adequada para o gerenciamento do desempenho do processo.

\subsubsection{Análise das Variáveis de Processo}

Os resultados de todas as variáveis de processo, medidas ao longo do estudo, estão representados pelas cartas de valores individuais mostrados na Figura 44 (ressalta-se que os dados apresentados já excluem dados relacionados a medições inconsistentes e outliers, como descrito em 4.5.3.1 e 4.5.3.2).

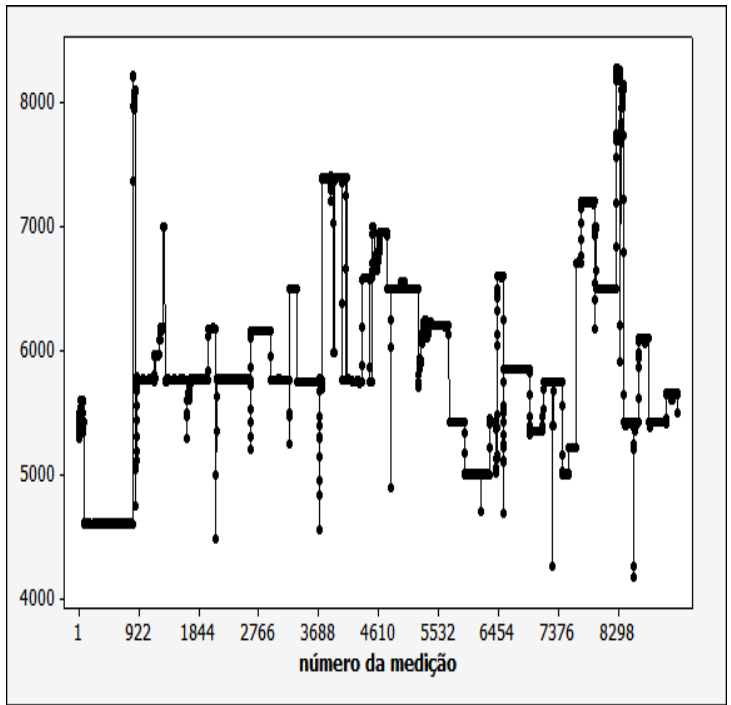

(a)

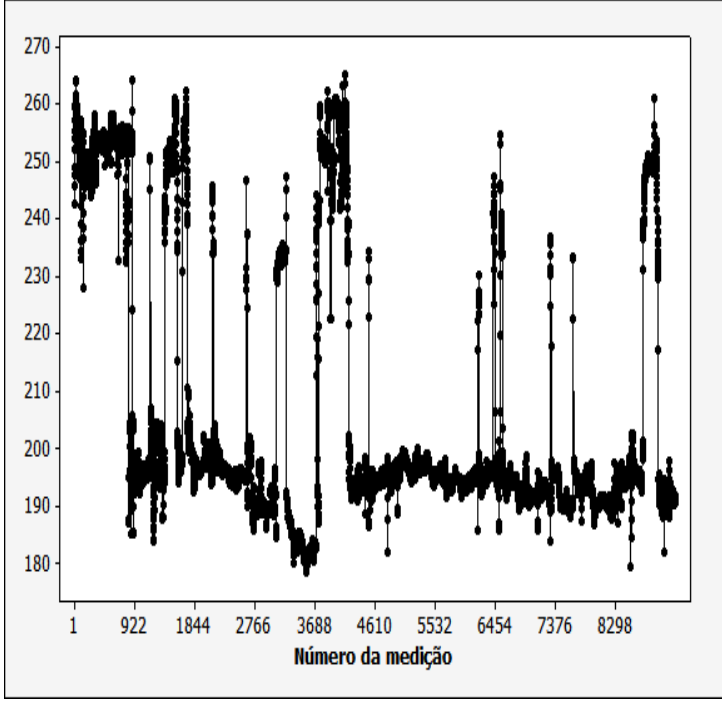

(c)

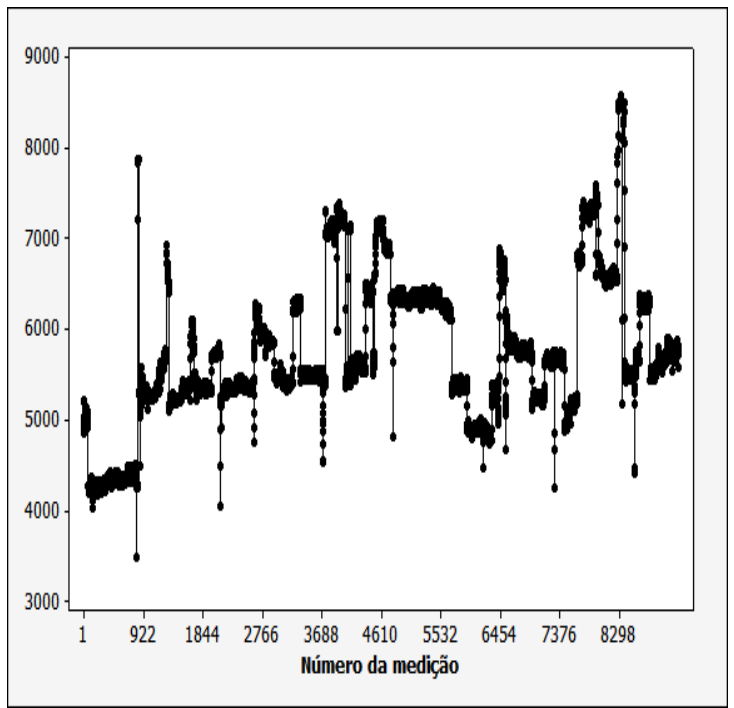

(b)

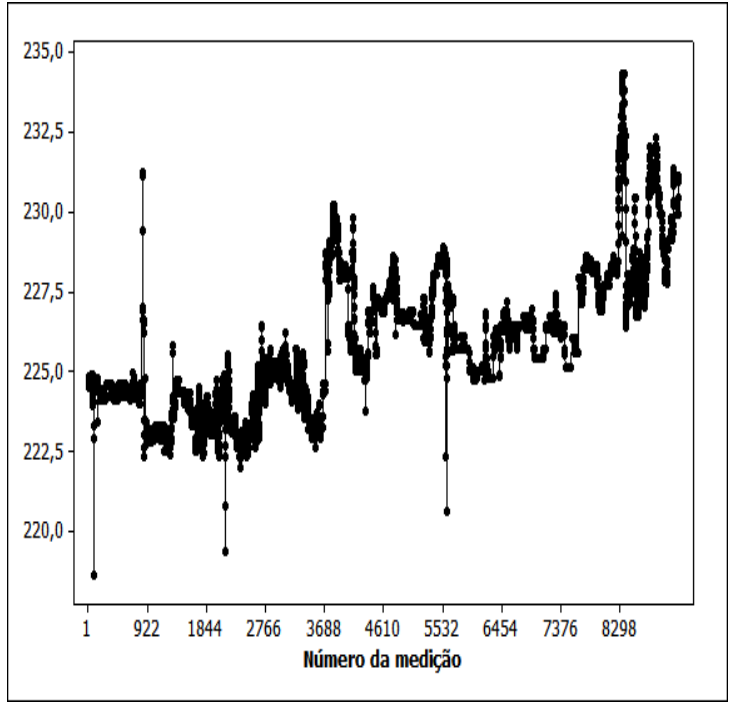

(d)

(continua) 
(continuação)

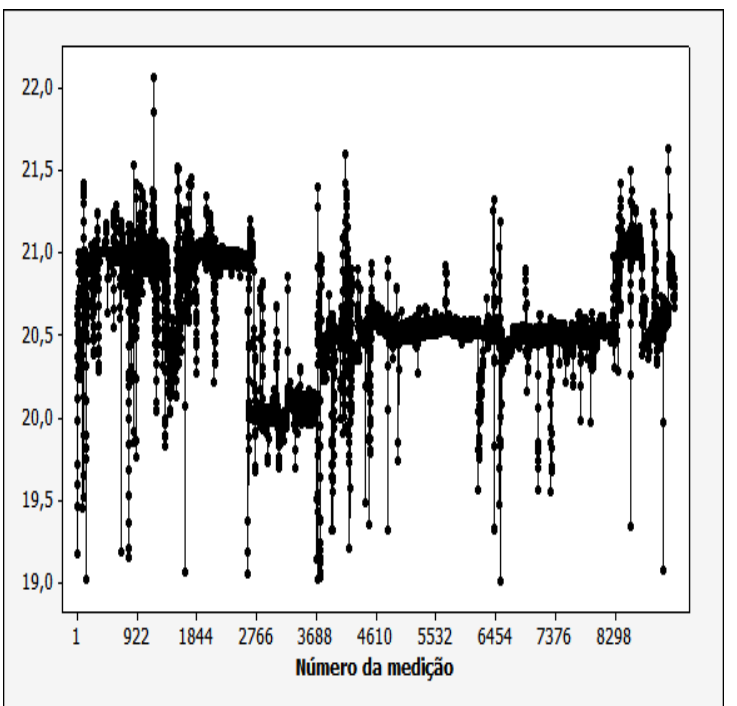

(e)

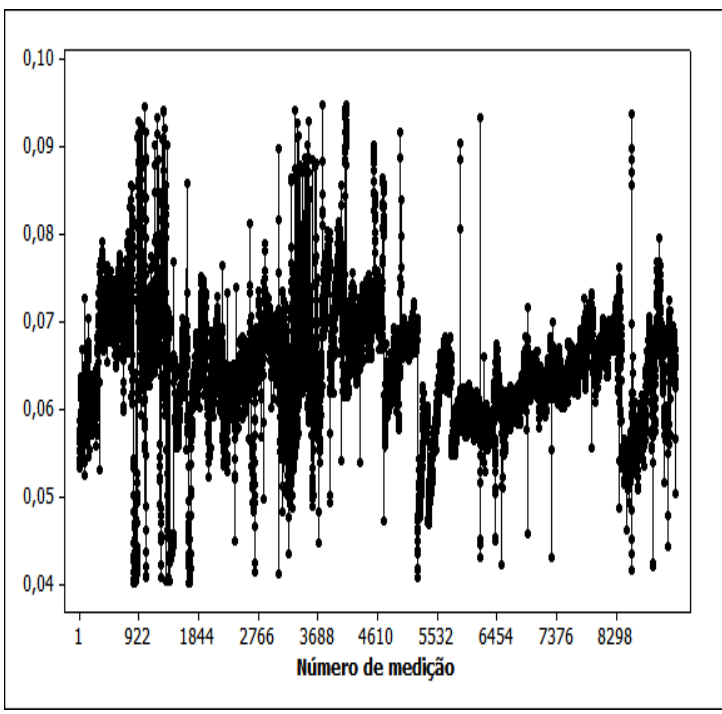

(g)

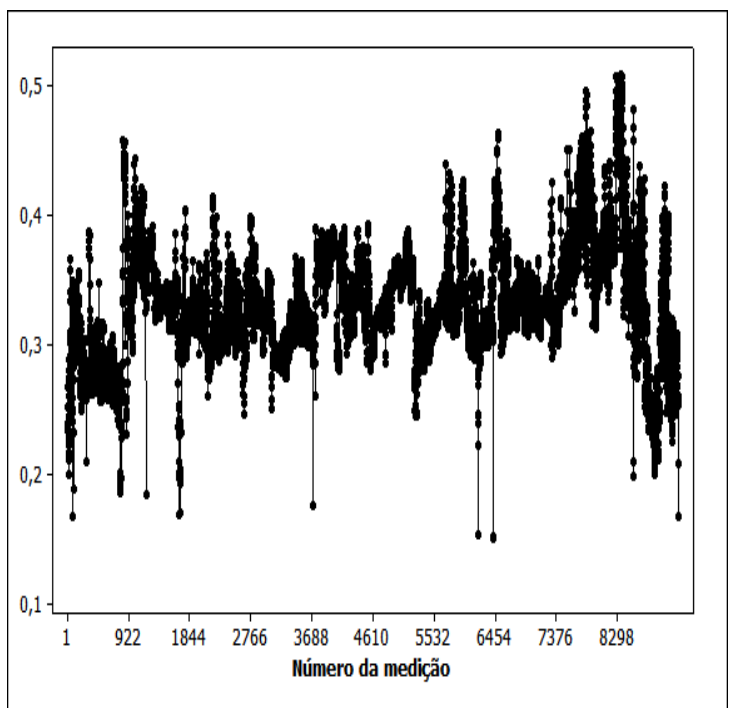

(f)

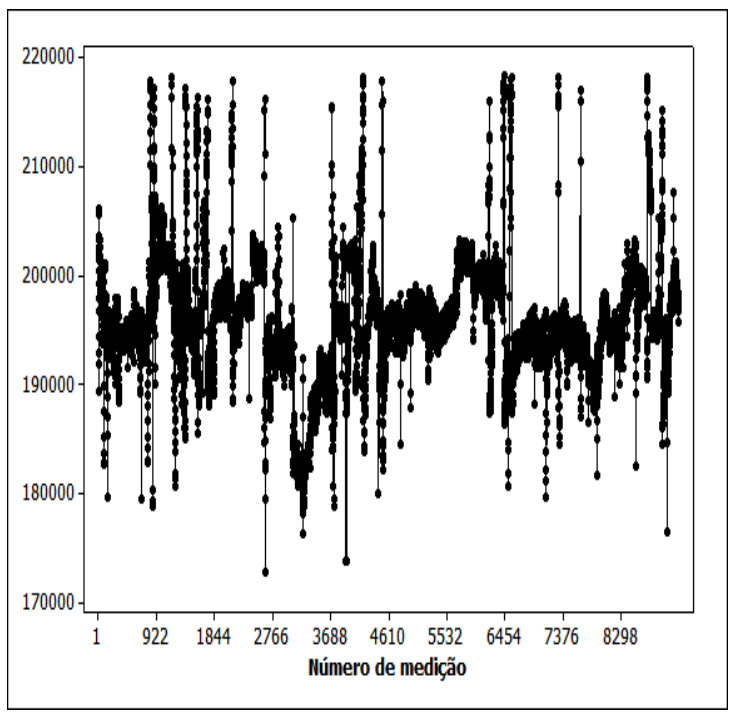

(h)

Figura 44 - Cartas de Valores Individuais das Variáveis de Processo medidas nesse estudo. (a) vazão de etileno (FC101) em kg/h; (b) vazão de oxigênio (FC103) em kg/h; (c) vazão de gás de reciclo (FR121) em t/h; (d) temperatura da reação (TR124B) em ${ }^{\circ} \mathrm{C}$; (e) pressão da reação (PR121) em $\mathrm{kg} / \mathrm{cm}^{2} \mathrm{~g}$; (f) vazão de clorados (FR126) em t/h; (g) teor de clorados (Fator F) em \%; (h) vazão de alimentação do sistema de remoção de $\mathrm{CO}_{2}$ (FR121C) em kg/h

A análise das variáveis de processo, medidas pelo SDCD, indicou a existência de variáveis correlacionadas (avaliação realizada através da análise do coeficiente de correlação de Pearson). Em função dessas correlações foi possível reduzir o número de variáveis a se estudar nesse processo, sem que ocorresse perda significativa na qualidade da análise desses dados. 
Os resultados do coeficiente de Pearson para avaliação das correlações entre as variáveis estudadas estão listadas na Tabela 15.

Tabela 15 - Correlações (coeficiente de Pearson) para as variáveis de processo

\begin{tabular}{|c|c|c|c|c|c|c|c|}
\hline & FC101 & FC103 & FR121A & TR124B. & PC121 & FR126 & Fator F \\
\hline FC103 & 0,959 & & & & & & \\
& 0,000 & & & & & & \\
\hline FR121A & $-0,234$ & $-0,269$ & & & & & \\
& 0,000 & 0,000 & & & & & \\
\hline TR124B & 0,466 & 0,616 & 0,022 & & & & \\
& 0,000 & 0,000 & 0,038 & & & & \\
& & & & & & & \\
\hline PC121 & $-0,195$ & $-0,198$ & 0,200 & $-0,153$ & & & \\
& 0,000 & 0,000 & 0,000 & 0,000 & & & \\
& & & & & & & \\
\hline FR126 & 0,535 & 0,518 & $-0,352$ & 0,230 & $-0,042$ & & \\
& 0,000 & 0,000 & 0,000 & 0,000 & 0,000 & & \\
& & & & & & & \\
\hline Fator F & 0,178 & 0,125 & 0,117 & 0,050 & $-0,035$ & 0,123 & \\
& 0,000 & 0,000 & 0,000 & 0,000 & 0,000 & 0,000 & \\
& & & & & & & \\
\hline FR121C & $-0,088$ & $-0,087$ & 0,231 & 0,017 & 0,481 & 0,012 & $-0,079$ \\
& 0,000 & 0,000 & 0,000 & 0,097 & 0,000 & 0,251 & 0,000 \\
\hline
\end{tabular}

Observação: para cada célula, o $1^{\circ}$ valor representa o coeficiente de Pearson e ○ $2^{\circ}$ valor representa o valor da probabilidade $p$.

Os valores do coeficiente de correlação de Pearson e da probabilidade $p$, mostrados na Tabela 15, indicam respectivamente, o grau de correlação entre duas variáveis e a confirmação estatística dessa correlação.

Nota-se, portanto, a existência de um grande número de correlações relevantes entre variáveis, o que permite um conhecimento bastante robusto do processo através da análise de um número mais restrito de variáveis, facilitando dessa forma o processo de gestão.

Adotando a premissa descrita no parágrafo anterior, foram analisadas as variáveis listadas na Tabela 10, tomando como base, inicialmente, as 
literaturas pesquisadas e descritas na revisão bibliográfica (capítulo 3) deste trabalho (SCIENTIFIC DESIGN COMPANY, 1998; CRI CATALYST, 1996; KIRK-OTHMER, 2007).

Do ponto de vista teórico, as variáveis de menor relevância para este processo são: pressão da reação (PC121), vazão de clorados (FR126) e vazão de alimentação do sistema de remoção de $\mathrm{CO}_{2}$ (FR121C). Desta forma, a eliminação dessas variáveis do conjunto de dados em estudo, teoricamente, não afeta significativamente a qualidade das informações referentes ao processo, o que permitiu a exclusão dessas variáveis do estudo.

Das cinco variáveis restantes, nota-se que a variável vazão de etileno (FC101) apresenta uma correlação praticamente perfeita, quando analisada junto à variável vazão de oxigênio (FC103), e, ambas apresentam uma correlação significativamente forte com a variável temperatura da reação (TR124). Em função desse grau de correlação, a rigor, apenas uma dessas variáveis poderia ser escolhida para o estudo do processo.

Porém, por questões operacionais e gestão de aspectos comerciais da unidade produtiva, é recomendável que uma variável relacionada à vazão de alimentação de uma matéria prima seja sempre monitorada e controlada. Isso porque esta vazão define a carga de operação da unidade, elemento utilizado para decisões importantes do ponto de vista de gestão (é interessante se manter o monitoramento sobre a variável vazão de oxigênio, uma vez que a malha de controle que atua sobre essa vazão é mais instável que a malha de controle que atua sobre a vazão de etileno).

A temperatura da reação também é uma variável importante de se monitorar continuamente, uma vez que está associada ao gerenciamento do processo de envelhecimento do catalisador, sendo também muito importante em processos de partida, parada e alterações da carga de operação, pois permite ao operador a sensação exata da velocidade com que as manobras são realizadas na unidade produtiva e se o processo está operando em condições seguras. 
Os dois comentários anteriores permitem concluir que a temperatura da reação e a vazão de alimentação de oxigênio, mesmo sendo variáveis correlacionadas, precisam ser monitoradas durante a operação da unidade.

Como conclusão dessas afirmações, foi possível analisar o comportamento do processo, tomando como base apenas quatro variáveis, sem que ocorressem perdas na qualidade das informações e dados coletados. São elas:

- FC103 (vazão de Oxigênio);

- FR121A (vazão de gás de reciclo);

- TR124B (temperatura da reação);

- Fator F (teor de clorados).

Observação: Com o objetivo de facilitar a escrita do modelo matemático em estudo, as variáveis de processo foram codificadas conforme descrito na Tabela 16.

Tabela 16 - Codificação das Variáveis de processo

\begin{tabular}{|c|c|}
\hline Variável de Processo & Simbologia da Variável \\
\hline Vazão de Oxigênio (FC103) & $\mathbf{x}_{\mathbf{1}}$ \\
\hline Vazão de Gás de Reciclo (FR121A) & $\mathbf{x}_{2}$ \\
\hline Temperatura da Reação (TR124B) & $\mathbf{x}_{3}$ \\
\hline Teor de Clorados (Fator F) & $\mathbf{x}_{4}$ \\
\hline
\end{tabular}

\subsection{Modelos de Regressão Multilnear}

Calculadas as seletividades (variável dependente) para o conjunto de dados definido, e selecionadas as variáveis de processo que representam os fenômenos que o descrevem (variáveis independentes), foi possível analisar a existência de uma relação de dependência entre essas variáveis. 
Preliminarmente, a esta análise fez-se necessária a normalização e codificação dos dados, uma vez que a ordem de grandeza destes era bastante diferente, o que poderia levar à obtenção de modelos com coeficientes que dificultariam a interpretação dos resultados. Essa transformação matemática foi realizada conforme descrito em 4.5.3.4, sendo obtidos os resultados mostrados na Figura 45.

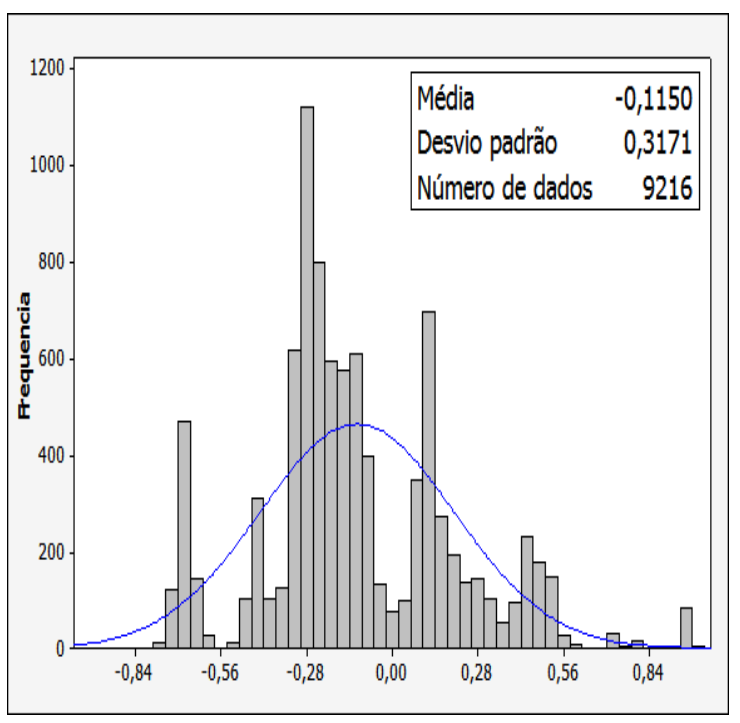

(a)

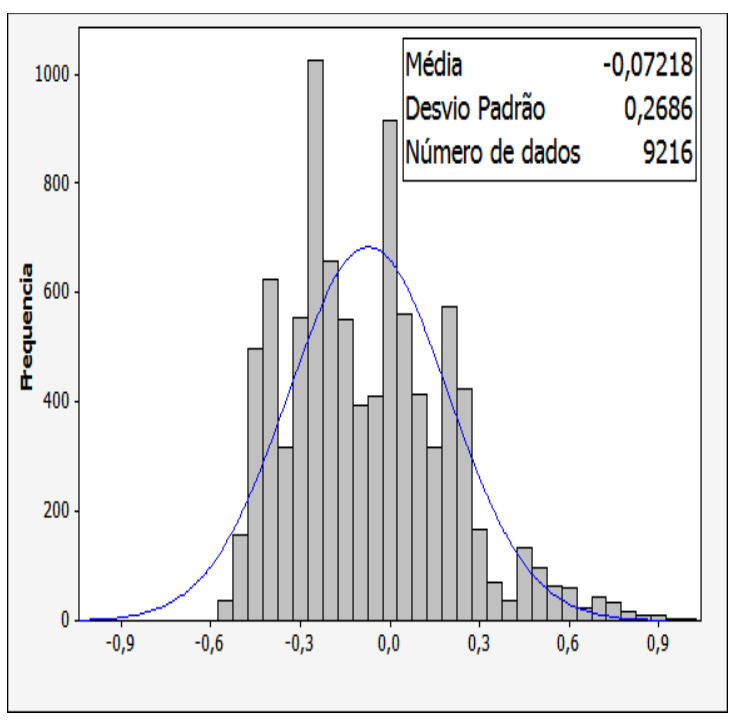

(c)

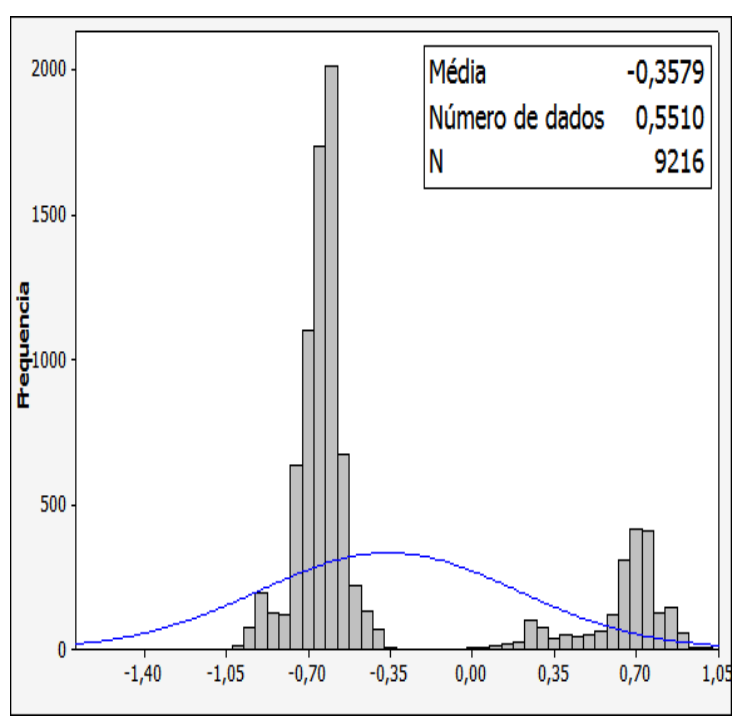

(b)

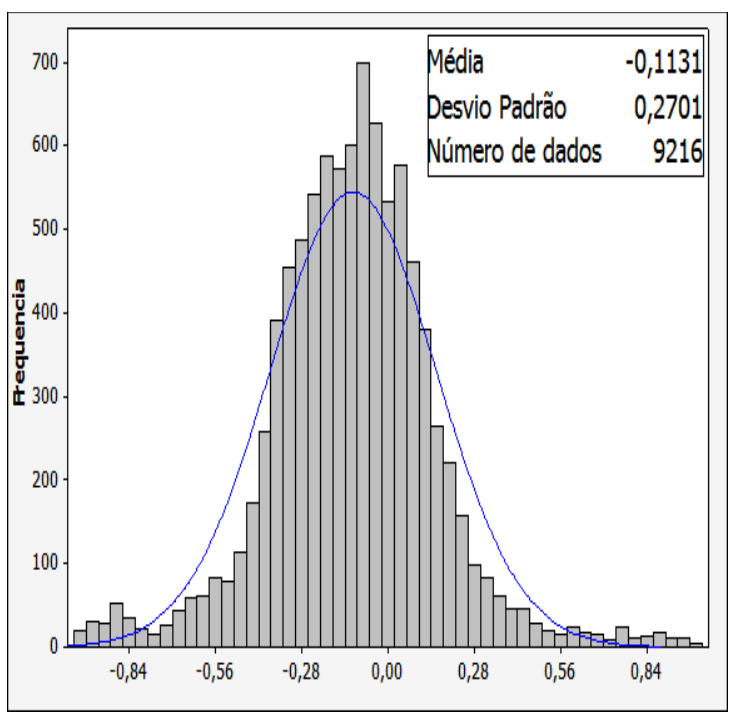

(d)

Figura 45 - Variáveis de Processo Codificadas. (a) vazão de oxigênio, $\mathrm{x}_{1}$; (b) vazão de gás de reciclo, $\mathrm{x}_{2}$; (c) temperatura da reação, $\mathrm{x}_{3}$; (d) teor de clorados, $\mathrm{x}_{4}$. 
Utilizando-se os dados das variáveis codificadas, foram analisados inicialmente, 7 modelos de regressão multilinear (sem efeitos de interação entre variáveis) que pudessem explicar o comportamento da seletividade da reação em função das 4 variáveis independentes selecionadas. Os resultados obtidos são mostrados na Tabela 17.

Tabela 17 - Análise de Modelos de Regressão Linear Múltipla para o Processo

\begin{tabular}{|c|c|c|c|c|c|c|c|}
\hline Var & $\mathrm{R}-\mathrm{Sq}$ & $R-S q(\operatorname{adj})$ & Mallows Cp & $\mathbf{S}$ & $x_{1} x_{2}$ & $x_{3}$ & $\mathrm{x}_{4}$ \\
\hline 1 & 45,0 & 45,0 & 1532,8 & 1,0849 & & $\mathrm{X}$ & \\
\hline 1 & 34,5 & 34,5 & 3583,4 & 1,1839 & $X$ & & \\
\hline 2 & 49,9 & 49,9 & 581,4 & 1,0357 & $\mathrm{X}$ & X & \\
\hline 2 & 48,0 & 48,0 & 939,0 & 1,0544 & X & $\mathrm{X}$ & \\
\hline 3 & 52,3 & 52,2 & 118,4 & 1,0108 & $\mathrm{x}$ & $\mathrm{x}$ & $\mathrm{X}$ \\
\hline 3 & 50,9 & 50,9 & 379,6 & 1,0249 & $\mathrm{X} X$ & $\mathrm{X}$ & \\
\hline 4 & 52,8 & 52,8 & 5,0 & 1,0046 & $\mathrm{x} x$ & $\mathrm{x}$ & $x$ \\
\hline
\end{tabular}

Os dados obtidos mostraram que:

- A variável temperatura da reação $\left(\mathrm{x}_{3}\right)$ explica $45,0 \%$ das variações do processo;

- A variável vazão de oxigênio $\left(x_{1}\right)$ explica $34,5 \%$ das variações do processo;

- Ao analisarmos as duas variáveis conjuntamente $\left(\mathrm{x}_{1}\right.$ e $\left.\mathrm{x}_{3}\right)$, a explicação do modelo chega a $49,9 \%$;

- O modelo que considera a influência de todas as variáveis de processo explica $52,8 \%$ das variações do processo.

- O modelo que considera a influência apenas da vazão de oxigênio $\left(\mathrm{x}_{1}\right)$, temperatura $\left(\mathrm{x}_{3}\right)$ e teor de clorados $\left(\mathrm{x}_{4}\right)$ explica $52,2 \%$ das variações do processo (ou seja, a influência da variável vazão de gás de reciclo no resultado do modelo é muito pequena).

Admitindo que o modelo com maior valor de coeficiente de determinação $\left(R^{2}=\right.$ $52,8 \%$ e o menor $\mathrm{Cp}$ de Mallows é o que melhor representa o processo, foi possível desenvolver, através da utilização do software MINITAB 15.0, uma equação (regressão multilinear) que demonstra matematicamente o nível de importância de cada variável na determinação da seletividade, bem como a 
direção ideal de atuação sobre cada variável, como mostrado na equação 70 e nas Tabelas 18 e 19.

Seletividade $=0,036-0,241 \cdot x_{1}+0.044 \cdot x_{2}-0.558 \cdot x_{3}+0.153 \cdot x_{4}$

Tabela 18 - Coeficientes do modelo de regressão multilinear

\begin{tabular}{|c|c|c|c|c|}
\hline Variável & $\frac{\text { Coeficiente }}{}$ & Erro padrão & Estatística t & $\frac{\text { Probabilidade }}{\underline{\mathrm{p}}}$ \\
\hline Constante & 0,036 & 0,002794 & 12,75 & 0,000 \\
\hline $\mathbf{x}_{\mathbf{1}}$ & $-0,241$ & 0,009036 & $-26,70$ & 0,000 \\
\hline $\mathbf{x}_{\mathbf{2}}$ & 0,044 & 0,004096 & 10,74 & 0,000 \\
\hline $\mathbf{x}_{\mathbf{3}}$ & $-0,558$ & 0,01015 & $-54,98$ & 0,000 \\
\hline $\mathbf{x}_{\mathbf{4}}$ & 0,153 & 0,007862 & 19,41 & 0,000 \\
\hline
\end{tabular}

Tabela 19 - Análise de variância do modelo de regressão multilinear

\begin{tabular}{|c|c|c|c|c|c|}
\hline Fonte & $\frac{\text { Graus de }}{\text { Liberdade }}$ & $\frac{\underline{\text { Soma dos }}}{\underline{\text { Quadrados }}}$ & $\frac{\underline{\text { Média dos }}}{\underline{\text { Quadrados }}}$ & $\underline{\text { Razão F }}$ & $\frac{\text { Probabilidade }}{\underline{\mathrm{p}}}$ \\
\hline Regressão & 4 & 409,39 & 102,35 & 2580,43 & 0,000 \\
\hline $\begin{array}{c}\text { Erro } \\
\text { Residual }\end{array}$ & 9211 & 365,34 & 0,04 & & \\
\hline Total & 9215 & 774,73 & & & \\
\hline
\end{tabular}

A análise estatística dos dados obtidos (valor da probabilidade $p<0,001$ ) demonstrou que o modelo de regressão proposto e todas as variáveis que 0 compõe apresentavam significância estatística, permitindo que o modelo fosse usado para explicar satisfatoriamente 0 comportamento do processo (reforçando que este modelo explica $52,8 \%$ das variações do processo). 
O maior coeficiente de determinação $\left(R^{2}=52,8 \%\right)$, obtido para o modelo de regressão multilinear, indicou a possibilidade de se explorar mais os dados na busca do incremento desse valor, o que pode ser obtido através da inclusão dos efeitos de interação entre variáveis e coeficientes quadráticos na avaliação do desempenho do processo.

As variáveis utilizadas na elaboração desse novo modelo, bem como as interações e coeficientes quadráticos avaliados, são mostradas na Tabela 20.

Tabela 20 - Codificação das Variáveis de processo (modelo de regressão com interações)

\begin{tabular}{|c|c|}
\hline $\begin{array}{c}\text { Variável de } \\
\text { Processo }\end{array}$ & $\begin{array}{c}\text { Codificação da } \\
\text { Variável }\end{array}$ \\
\hline Vazão de Oxigênio & $\mathrm{x}_{1}$ \\
\hline Vempão de Gás de Reciclo & $\mathrm{x}_{2}$ \\
\hline Teor de Clorados & $\mathrm{x}_{3}$ \\
\hline Vazão de Oxigênio * Vazão de Gás de Reciclo & $\mathrm{x}_{4}$ \\
\hline Vazão de Oxigênio * Temperatura da Reação & $\mathrm{x}_{1} \cdot \mathrm{x}_{2}$ \\
\hline Vazão de Oxigênio * Teor de Clorados & $\mathrm{x}_{1} \cdot \mathrm{x}_{3}$ \\
\hline Vazão de Gás de Reciclo * Temperatura da Reação & $\mathrm{x}_{1} \cdot \mathrm{x}_{4}$ \\
\hline Vazão de Gás de Reciclo * Teor de Clorados & $\mathrm{x}_{2} \cdot \mathrm{x}_{3}$ \\
\hline Temperatura da Reação * Teor de Clorados & $\mathrm{x}_{2} \cdot \mathrm{x}_{4}$ \\
\hline Vazão de Oxigênio * Vazão de Oxigênio & $\mathrm{x}_{3} \cdot \mathrm{x}_{4}$ \\
\hline Vazão de Gás de Reciclo * Vazão de Gás de Reciclo & $\mathrm{x}_{1}{ }^{2}$ \\
\hline Temperatura da Reação * Temperatura da Reação & $\mathrm{x}_{2}{ }^{2}$ \\
\hline Teor de Clorados * Teor de Clorados & $\mathrm{x}_{3}{ }^{2}$ \\
\hline
\end{tabular}


Tomando como base a mesma metodologia utilizada para a avaliação dos modelos lineares, foram desenvolvidos novos modelos de regressão linear (considerando agora os efeitos de interação entre duas variáveis e os coeficientes quadráticos) para estimar a seletividade da reação, como mostrado na Tabela 21. A relevância de cada modelo foi avaliada através da análise do coeficiente de determinação $\left(R^{2}\right)$. Os resultados mostrados na Tabela 21 explicam a variabilidade do processo, a qual tende a aumentar à medida que analisamos um conjunto maior de variáveis conjuntamente.

$\mathrm{Na}$ Tabela 21 foi analisado o comportamento do processo em diversas situações: desde quando o processo busca ser explicado por uma única variável até situações em que todas as interações entre pares de variáveis são utilizadas para a análise do modelo.

Tabela 21 - Análise de Modelos de Regressão (considerando efeitos de interação entre variáveis e coeficientes quadráticos) possíveis para o Processo

\begin{tabular}{|c|c|c|c|c|c|c|c|c|c|c|c|c|c|c|c|c|}
\hline Var & $\mathrm{R}-\mathrm{Sq}$ & R-Sq (adj) & Mallows Cp & $\mathrm{S}$ & $\begin{array}{l}x \\
1 \\
\end{array}$ & & $\begin{array}{l}x \\
3 \\
\end{array}$ & $\begin{array}{l}X \\
4 \\
\end{array}$ & $\begin{array}{l}x \\
3\end{array}$ & $\begin{array}{l}X \\
1 \\
\star \\
X \\
4\end{array}$ & $\begin{array}{l}x \\
2 \\
\star \\
x \\
3 \\
\end{array}$ & $\begin{array}{ll}X & X \\
2 & 3 \\
\star & \star \\
X & X \\
4 & 4 \\
\end{array}$ & $\begin{array}{ll}X & X \\
3 & 1 \\
\text { * } & \text { } \\
X & X \\
4 & 1 \\
\end{array}$ & $\begin{array}{l}X \\
2 \\
\star \\
X \\
2 \\
\end{array}$ & & $\begin{array}{l}X \\
4 \\
\star \\
X \\
4 \\
\end{array}$ \\
\hline 1 & 45,0 & 45,0 & 3500,9 & 0,21506 & & & $\bar{X}$ & & & & & & & & & \\
\hline 1 & 34,5 & 34,5 & 5927,1 & 0,23469 & $\mathrm{X}$ & & & & & & & & & & & \\
\hline 2 & 50,2 & 50,2 & 2296,5 & 0,20462 & & & $\mathrm{X}$ & & & & & & $\mathrm{X}$ & & & \\
\hline 2 & 49,9 & 49,9 & 2374,9 & 0,20531 & $\mathrm{x}$ & & $\mathrm{X}$ & & & & & & & & & \\
\hline 3 & 55,6 & 55,6 & 1056,0 & 0,19326 & $\mathrm{X}$ & & $\mathrm{X}$ & & 2 & & & & & & & \\
\hline 3 & 53,5 & 53,5 & 1538,9 & 0,19776 & $\mathrm{X}$ & & X & & & & & & $\mathrm{X}$ & & & \\
\hline 4 & 56,9 & 56,8 & 762,2 & 0,19047 & $\mathrm{X}$ & & X & X & 2 & & & & & & & \\
\hline 4 & 56,3 & 56,3 & 889,5 & 0,19168 & $\mathrm{X}$ & & X & & 2 & & & & & $\mathrm{X}$ & & \\
\hline 5 & 57,9 & 57,9 & 525,5 & 0,18819 & $\mathrm{X}$ & & X & $\mathrm{X}$ & 2 & & & & & $\mathrm{X}$ & & \\
\hline 5 & 57,2 & 57,1 & 694,3 & 0,18981 & $\mathrm{X}$ & & X & $\mathrm{X}$ & 2 & & $\mathrm{x}$ & & & & & \\
\hline 6 & 58,3 & 58,3 & 438,4 & 0,18733 & $\mathrm{X}$ & & X & $\mathrm{X}$ & 2 & & $\mathrm{x}$ & & & $\mathrm{X}$ & & \\
\hline 6 & 58,1 & 58,1 & 485,7 & 0,18779 & $\mathrm{X}$ & & X & $X$ & 2 & & & & & $\mathrm{X}$ & & $\mathrm{X}$ \\
\hline 7 & 58,8 & 58,8 & 313,3 & 0,18610 & $\mathrm{X}$ & & X & $\mathrm{X}$ & & & $\mathrm{x}$ & & & $\mathrm{X}$ & & \\
\hline 7 & 58,6 & 58,5 & 377,2 & 0,18673 & $\mathrm{X}$ & & X & $\mathrm{X}$ & 2 & & $\mathrm{x}$ & & & $\mathrm{X}$ & $\mathrm{X}$ & \\
\hline 8 & 59,3 & 59,2 & 215,7 & 0,18514 & $\mathrm{X}$ & & X & $\mathrm{X}$ & $x_{2}$ & & $\mathrm{x}$ & & & $\mathrm{X}$ & $\mathrm{X}$ & \\
\hline 8 & 59,1 & 59,1 & 251,1 & 0,18548 & $\mathrm{X}$ & & X & $\mathrm{X}$ & $x_{2}$ & & $\mathrm{x}$ & & $\mathrm{X}$ & $x$ & & \\
\hline 9 & 60,0 & 60,0 & 48,9 & 0,18348 & $\mathrm{x}$ & & $x$ & $\mathrm{x}$ & & & $\mathrm{x}$ & & $\mathrm{x}$ & $x$ & $\mathrm{X}$ & \\
\hline 9 & 59,4 & 59,3 & 189,6 & 0,18487 & $\mathrm{X}$ & & $\mathrm{X}$ & $\mathrm{X}$ & & & $\mathrm{X}$ & & & X & $\mathrm{X}$ & $\mathrm{x}$ \\
\hline 10 & 60,1 & 60,0 & 37,0 & 0,18335 & $\mathrm{X}$ & & X & $\mathrm{x}$ & & & $\mathrm{X}$ & $\mathrm{X}$ & $\mathrm{X}$ & $x \mathrm{x}$ & $\mathrm{X}$ & \\
\hline 10 & 60,0 & 60,0 & 42,6 & 0,18341 & $\mathrm{X}$ & & $\mathrm{X}$ & $\mathrm{X}$ & & & $\mathrm{X}$ & & $\mathrm{X}$ & $x$ & X & $x$ \\
\hline 11 & 60,1 & 60,1 & 28,4 & 0,18326 & $\mathrm{x}$ & & $\mathrm{X}$ & $\mathrm{x}$ & & $\mathrm{x}$ & $\mathrm{X}$ & $x$ & $\mathrm{X}$ & $x$ & $\mathrm{X}$ & $x$ \\
\hline 11 & 60,1 & 60,0 & 34,3 & 0,18331 & X & $\mathrm{X}$ & $\mathrm{X}$ & $\mathrm{X}$ & $\mathrm{x}$ & & $\mathrm{X}$ & & $\mathrm{X}$ & $x$ & $\mathrm{X}$ & $x$ \\
\hline 12 & 60,1 & 60,1 & 23,8 & 0,18320 & X & $\mathrm{X}$ & $\mathrm{X}$ & $\mathrm{X}$ & $\mathrm{x}$ & $\mathrm{K}$ & $\mathrm{X}$ & $x$ & $\mathrm{X}$ & $x$ & $\mathrm{X}$ & $x$ \\
\hline 12 & 60,1 & 60,1 & 27,4 & 0,18324 & $\mathrm{x}$ & & $\mathrm{x}$ & $\mathrm{x}$ & & $x$ & $\mathrm{X}$ & $x$ & $\mathrm{x}$ & $x$ & $\mathrm{X}$ & $x$ \\
\hline 13 & 60,2 & 60,1 & 18,9 & 0,18314 & X & $\mathrm{X}$ & $\mathrm{X}$ & $\mathrm{X}$ & & $x \mathrm{X}$ & $\mathrm{X}$ & & $x \quad x$ & $x$ & $\mathrm{X}$ & $\mathrm{x}$ \\
\hline 13 & 60,1 & 60,1 & 22,5 & 0,18318 & $\mathrm{x}$ & & $\mathrm{x}$ & $\mathrm{x}$ & & & $\mathrm{X}$ & $x y$ & $x \quad x$ & $x$ & $\mathrm{X}$ & $x$ \\
\hline 14 & 60,2 & 60,1 & 15,0 & 0,18309 & $\mathrm{x} 2$ & $\mathbf{x}$ & $\mathrm{x}$ & $\mathrm{x}$ & & & $x$ & $x 2$ & $\mathrm{x} x$ & $x$ & $\mathrm{x}$ & $x$ \\
\hline
\end{tabular}


Os resultados obtidos mostraram que o efeito das interações entre variáveis é relevante e que, se estas forem consideradas na elaboração de modelos de regressão, temos um incremento da explicação da variabilidade do processo de $52,8 \%$ para $60,1 \%$, tornando o modelo matemático mais robusto e mais preciso. Esse novo modelo de regressão multilinear é representado pela equação 71 .

Seletividade $=86.90-1.89 \cdot x_{1}+0.07 \cdot x_{2}-1.73 \cdot x_{3}+0.44 \cdot x_{4}-1.18 \cdot$ $x_{1} \cdot x_{2}+7.02 \cdot x_{1} \cdot x_{3}+0.44 \cdot x_{1} \cdot x_{4}+1.82 \cdot x_{2} \cdot x_{3}-0.16 \cdot x_{2} \cdot x_{4}-0.57 \cdot x_{3} \cdot$ $x_{4}-1.94 \cdot x_{1}^{2}-1.03 \cdot x_{2}^{2}-2.05 \cdot x_{3}^{2}-0.29 \cdot x_{4}^{2}$

Assim como para o modelo de regressão multilinear, a análise estatística dos dados obtidos (valor da probabilidade $p<0,001$ nas Tabelas 22 e 23) demonstra que o novo modelo de regressão proposto e todas as variáveis que o compõe apresentam significância estatística, permitindo que o modelo fosse usado para explicar satisfatoriamente o comportamento do processo.

Tabela 22 - Coeficientes do modelo de regressão multilinear (considerando interações entre variáveis e coeficientes quadráticos)

\begin{tabular}{|c|c|c|c|c|}
\hline Variável & Coeficiente & Erro padrão & Estatística t & $\begin{array}{c}\text { Probabilidade } \\
\mathrm{p}\end{array}$ \\
\hline Constante & 86,9 & & & \\
\hline $\mathrm{x}_{1}$ & $-1,89$ & 0,05602 & $-33,67$ & 0,000 \\
\hline $\mathrm{x}_{2}$ & 0,07 & 0,02358 & 3,18 & 0,001 \\
\hline $\mathrm{x}_{3}$ & $-1,73$ & 0,07445 & $-23,28$ & 0,000 \\
\hline $\mathrm{x}_{4}$ & 0,44 & 0,04662 & 9,37 & 0,000 \\
\hline $\mathrm{x}_{1} \cdot \mathrm{x}_{2}$ & $-1,18$ & 0,08037 & $-14,69$ & 0,000 \\
\hline $\mathrm{x}_{1} \cdot \mathrm{x}_{3}$ & 7,02 & 0,2639 & 26,61 & 0,000 \\
\hline
\end{tabular}

(continua) 
(continuação)

\begin{tabular}{|c|c|c|c|c|}
\hline Variável & Coeficiente & Erro padrão & Estatística t & $\begin{array}{c}\text { Probabilidade } \\
p\end{array}$ \\
\hline $\mathrm{x}_{1} \cdot \mathrm{x}_{4}$ & 0,44 & 0,1450 & 3,07 & 0,002 \\
\hline $\mathrm{x}_{2} \cdot \mathrm{x}_{3}$ & 1,82 & 0,09652 & 18,91 & 0,000 \\
\hline $\mathrm{x}_{2} \cdot \mathrm{x}_{4}$ & $-0,16$ & 0,06634 & $-2,43$ & 0,015 \\
\hline $\mathrm{x}_{3} \cdot \mathrm{x}_{4}$ & $-0,57$ & 0,1736 & $-3,26$ & 0,001 \\
\hline $\mathrm{x}_{1}{ }^{2}$ & $-1,94$ & 0,1631 & $-11,88$ & 0,000 \\
\hline $\mathrm{x}_{2}{ }^{2}$ & $-1,03$ & 0,06651 & $-15,47$ & 0,000 \\
\hline $\mathrm{x}_{3}{ }^{2}$ & $-2,05$ & 0,1504 & $-13,66$ & 0,000 \\
\hline $\mathrm{x}_{4}{ }^{2}$ & $-0,29$ & 0,07107 & $-4,04$ & 0,000 \\
\hline & & & & \\
\hline
\end{tabular}

Tabela 23 - Análise de variância do modelo de regressão multilinear (considerando interações entre variáveis e coeficientes quadráticos)

\begin{tabular}{|c|c|c|c|c|c|}
\hline Fonte & $\begin{array}{l}\text { Graus de } \\
\text { Liberdade }\end{array}$ & $\begin{array}{l}\text { Soma dos } \\
\text { Quadrados }\end{array}$ & $\begin{array}{l}\text { Média dos } \\
\text { Quadrados }\end{array}$ & Razão F & $\frac{\text { Probabilidade }}{\underline{\mathrm{p}}}$ \\
\hline Regressão & 14 & 11864,77 & 847,48 & 993,53 & 0,000 \\
\hline $\begin{array}{c}\text { Erro } \\
\text { Residual }\end{array}$ & 9201 & 7848,44 & 0,85 & & \\
\hline Total & 9215 & 19713,21 & & & \\
\hline
\end{tabular}

\subsubsection{Validação do Modelo Matemático Proposto}

Uma vez definido o modelo matemático empírico que representa o processo em estudo (para os intervalos pré-estabelecidos para as variáveis de processo), existia a necessidade de se verificar o quão robusto era este 
modelo, o que é feito através de duas formas distintas de validação: estatística e fenomenológica.

\subsubsection{Validação Estatística do Modelo Matemático Proposto}

Nessa metodologia de validação, um novo conjunto de dados de processo (independentes dos dados inicialmente utilizados) foi coletado e foram utilizados para alimentar o modelo matemático. Três mil e oitocentos novos dados foram coletados ao longo do ano de 2012, os quais foram utilizados para cálculo da seletividade do processo e comparação com o modelo proposto.

A resposta obtida através do modelo matemático foi comparada com o valor real da seletividade observada no processo. Quanto menor forem os desvios observados entre esses valores, mais robusto é o modelo proposto.

A Tabela 24 mostra (parcialmente) os dados coletados, o resultado da seletividade obtida via modelo matemático e o desvio percentual observado entre o valor da seletividade real do processo e o valor obtido via modelo. Esse desvio foi calculado como mostrado na equação 72 .

Desvio $(\%)=100^{*}[($ Seletividade calculada via modelo $)-($ Seletividade real do processo)] / (Seletividade calculada via modelo) 
Tabela 24 - Parte dos dados para validação estatística do modelo matemático proposto

\begin{tabular}{|c|c|c|c|c|c|c|c|}
\hline Data & S2 (\%) & FC103 & FR1121A & TR-124B & $\begin{array}{l}\text { Teor de } \\
\text { Clorados }\end{array}$ & $\begin{array}{c}\text { S (calculado via } \\
\text { modelo } \\
\text { empírico) }\end{array}$ & $\begin{array}{c}\text { Desvio (\%), } \\
\text { (Scalc-Sreal) / } \\
\text { (Scalc) }\end{array}$ \\
\hline $2012-01-0100: 00: 00$ & 84,5 & 5675,9 & 194,7 & 232,4 & 0,0656 & 82,5 & $-2,4$ \\
\hline 2012-01-01 01:00:00 & 84,5 & 5660,0 & 194,5 & 232,2 & 0,0653 & 82,6 & $-2,3$ \\
\hline $2012-01-0102: 00: 00$ & 84,5 & 5659,9 & 194,1 & 232,1 & 0,0653 & 82,7 & $-2,2$ \\
\hline 2012-01-01 03:00:00 & 84,5 & 5660,1 & 194,2 & 232,1 & 0,0650 & 82,7 & $-2,2$ \\
\hline 2012-01-01 04:00:00 & 84,5 & 5660,1 & 194,8 & 232,1 & 0,0649 & 82,7 & $-2,2$ \\
\hline 2012-01-01 05:00:00 & 84,5 & 5645,8 & 195,1 & 232,1 & 0,0645 & 82,7 & $-2,2$ \\
\hline 2012-01-01 06:00:00 & 84,5 & 5394,9 & 193,6 & 231,6 & 0,0656 & 82,6 & $-2,3$ \\
\hline 2012-01-01 07:00:00 & 84,7 & 5293,7 & 193,4 & 231,4 & 0,0656 & 82,6 & $-2,6$ \\
\hline 2012-01-01 08:00:00 & 84,7 & 5275,2 & 194,6 & 231,1 & 0,0702 & 82,9 & $-2,1$ \\
\hline 2012-01-01 09:00:00 & 84,7 & 5298,5 & 195,0 & 231,1 & 0,0669 & 83,0 & $-2,0$ \\
\hline $2012-01-0110: 00: 00$ & 84,7 & 5300,3 & 194,5 & 230,9 & 0,0654 & 83,1 & $-1,9$ \\
\hline 2012-01-01 11:00:00 & 84,7 & 5298,4 & 194,6 & 230,6 & 0,0656 & 83,4 & $-1,5$ \\
\hline $2012-01-0112: 00: 00$ & 84,8 & 5289,5 & 194,2 & 230,3 & 0,0672 & 83,7 & $-1,3$ \\
\hline 2012-01-01 13:00:00 & 84,7 & 5271,7 & 193,4 & 230,2 & 0,0667 & 83,7 & $-1,3$ \\
\hline $2012-01-0114: 00: 00$ & 84,7 & 5273,5 & 194,1 & 230,0 & 0,0649 & 83,9 & $-1,0$ \\
\hline 2012-01-01 15:00:00 & 84,8 & 5275,7 & 193,6 & 230,0 & 0,0663 & 83,9 & $-1,1$ \\
\hline 2012-01-01 16:00:00 & 84,7 & 5279,9 & 193,2 & 230,0 & 0,0691 & 83,9 & $-1,0$ \\
\hline $2012-01-0117: 00: 00$ & 84,7 & 5298,0 & 193,9 & 230,0 & 0,0696 & 83,9 & $-0,9$ \\
\hline 2012-01-01 18:00:00 & 84,7 & 5312,3 & 193,5 & 230,0 & 0,0686 & 83,9 & $-0,9$ \\
\hline 2012-01-01 19:00:00 & 84,7 & 5320,0 & 193,3 & 230,0 & 0,0688 & 83,9 & $-0,9$ \\
\hline $2012-01-0120: 00: 00$ & 84,7 & 5320,1 & 193,7 & 230,0 & 0,0690 & 84,0 & $-0,9$ \\
\hline 2012-01-01 21:00:00 & 84,8 & 5307,1 & 194,0 & 229,8 & 0,0696 & 84,1 & $-0,9$ \\
\hline 2012-01-01 22:00:00 & 84,9 & 5276,8 & 194,0 & 229,7 & 0,0698 & 84,2 & $-0,8$ \\
\hline $2012-01-0123: 00: 00$ & 84,8 & 5270,2 & 194,6 & 229,7 & 0,0690 & 84,2 & $-0,7$ \\
\hline
\end{tabular}

A análise de um histograma dos valores dos desvios calculados permite uma visualização mais clara dos resultados, como mostrado na Figura 46. 


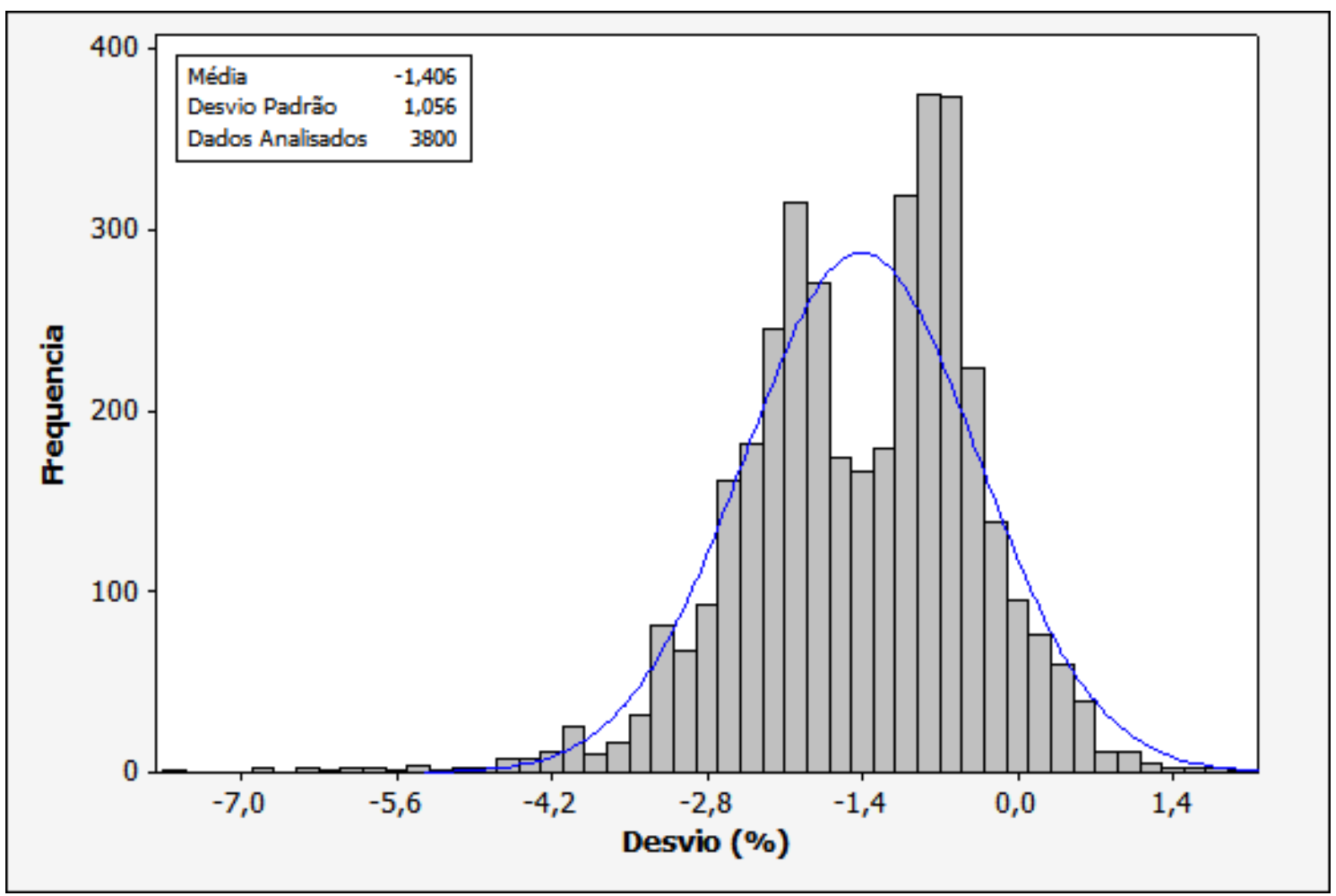

Figura 46 - Validação estatística do modelo matemático proposto - Comparação da seletividade calculada via modelo e seletividade real do processo. Desvio (\%) = (Seletividade calculada - seletividade real) / Seletividade calculada.

Os resultados mostraram que os desvios observados são relativamente baixos (apresentam um valor médio de $-1,406 \%$ ), o que indicou um alto grau de ajuste do modelo proposto aos dados reais de processo. Mesmo com os bons resultados obtidos com este modelo, o mesmo ainda pode ser trabalhado para atenuar o efeito da perda natural de seletividade ao longo do tempo, em função do envelhecimento do catalisador, explicado em 3.7.

O processo de validação do modelo desenvolvido, considerando a aquisição de novos dados de processo e o efeito do processo de envelhecimento do catalisador é descrito a seguir.

Os dados originalmente coletados para elaboração do modelo estatístico foram obtidos ao longo de 36 meses, sendo que a tendência de queda da seletividade neste período pode ser observada na Figura 47. 


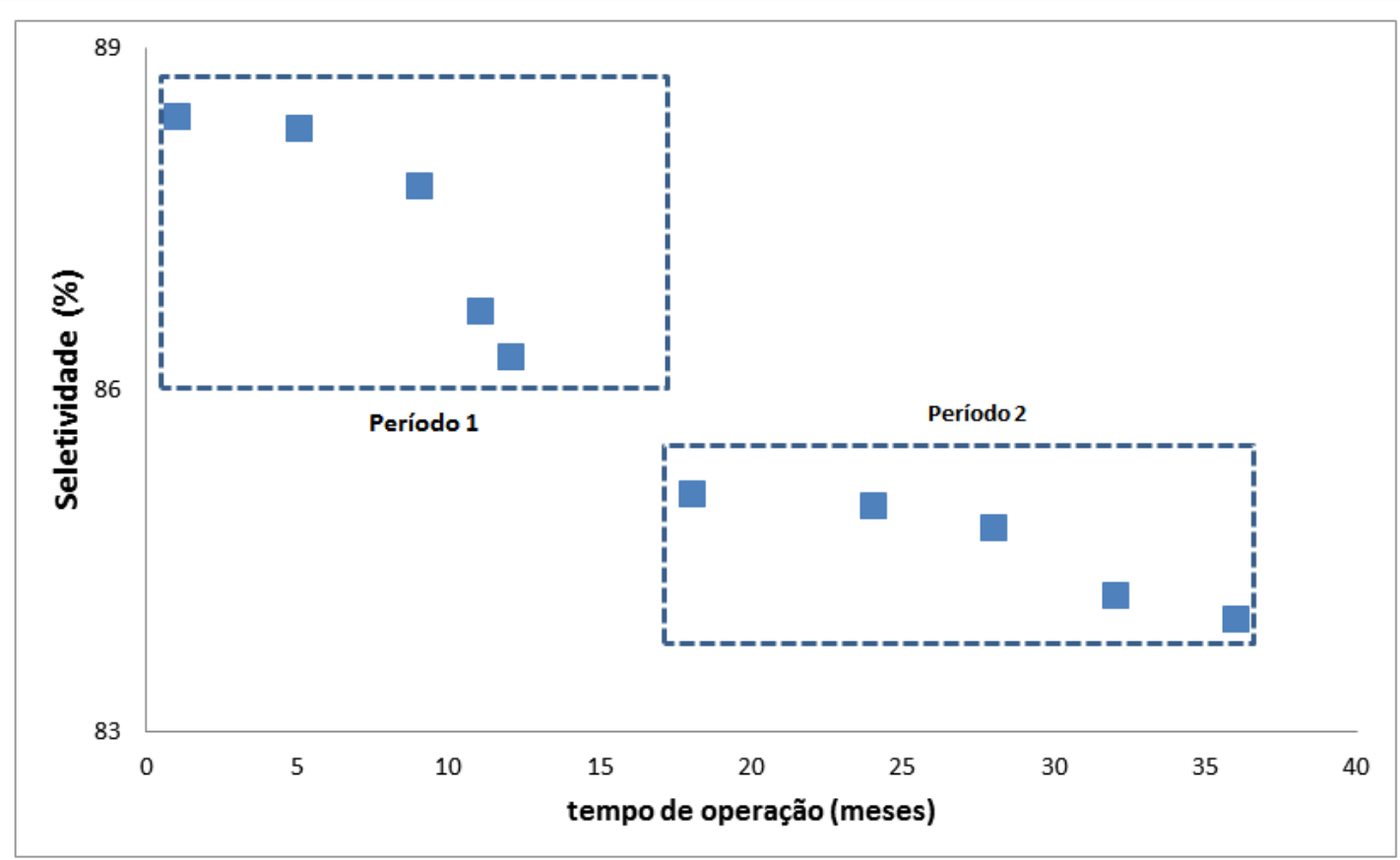

Figura 47 - Evolução da Seletividade média mensal do catalisador em função do seu tempo de operação (envelhecimento).

Nota-se que a perda de seletividade é mais relevante no início de vida do catalisador (indicado na Figura 47 como período 1), sendo que a partir de então, a perda de seletividade é menos relevante e segue praticamente uma tendência linear. Esta tendência está coerente com as teorias relacionadas ao processo de sinterização, que prevê uma maior perda de seletividade no início de vida do catalisador (STOREY, 2007). Em média, a queda de seletividade no $1^{\circ}$ período de operação do catalisador foi de $0,11 \%$ ao mês. Já para o $2^{\circ}$ período de operação, a perda média de seletividade foi da ordem de 0,068 \% ao mês.

O modelo estatístico desenvolvido é válido para o intervalo de tempo de vida do catalisador, para o qual foram coletados os dados que permitiram a geração desse modelo, ou seja, 36 meses de operação. A aplicação desse modelo para um tempo de operação acima de 36 meses pode ser realizada, desde que o modelo seja corrigido pelo efeito do envelhecimento do catalisador. É esta correção que, aplicada ao conjunto de dados mostrados na Tabela 24, permitiu uma validação mais consistente do modelo. 
A validação do modelo, considerando o efeito do envelhecimento do catalisador, foi realizada, conforme as etapas descritas abaixo:

- Para os três mil e oitocentos novos dados de processo coletados, foi calculada a seletividade da reação via modelo empírico, sendo os resultados mostrados na Tabela 24;

- A seletividade calculada via modelo foi corrigida em função do envelhecimento do catalisador ao longo dos 36 meses de operação (valor este obtido da análise dos dados originalmente coletados para 0 desenvolvimento do modelo). Para os novos dados, os valores da seletividade, calculada via modelo, foram subtraídos da perda total de seletividade ocorrida nos 36 meses, onde os dados foram coletados, eliminando-se desta forma, os efeitos do envelhecimento do catalisador no resultado matemático do modelo.

- Uma nova correção foi realizada em função do mês de coleta dos novos dados. Dados coletados no $1^{\circ}$ mês de análise foram corrigidos pelo efeito da perda de seletividade mensal, devido envelhecimento do catalisador (no caso, a seletividade calculada via modelo ainda foi subtraída de um valor médio de $0,11 \%$ ao mês - valor este obtido da análise dos dados da Figura 47). Para dados coletados no $2^{-}$mês, a correção aplicada foi a subtração de um valor de $2^{*} 0,11 \%$. No $3^{\circ}$ mês, a correção aplicada foi a subtração de $3^{*} 0,11 \%$, e assim sucessivamente.

Considerando a aplicação das correções descritas anteriormente aos dados apresentados na Tabela 24, foi realizada uma nova avaliação do ajuste do modelo aos dados utilizados para sua validação, obtendo-se novos valores dos desvios. O histograma que representa o desvio médio dos resultados do modelo corrigido, em relação aos novos dados coletados no processo, é apresentado na Figura 48. 


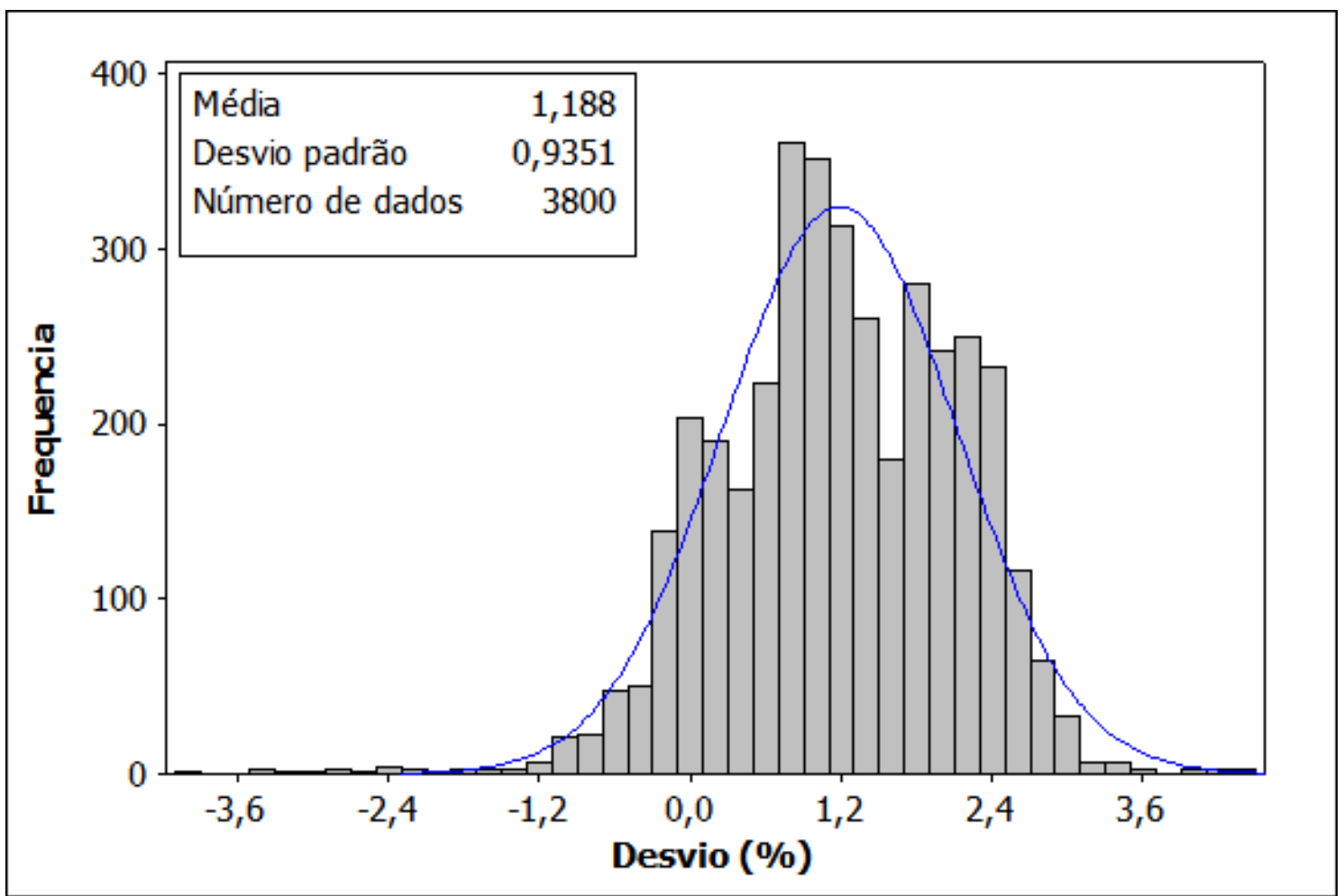

Figura 48 - Validação estatística do modelo matemático proposto, corrigido pelos efeitos do envelhecimento do catalisador - Comparação da seletividade calculada via modelo e seletividade real do processo. Desvio $(\%)=($ Seletividade calculada - seletividade real) / Seletividade calculada.

Observou-se que o desvio entre os resultados reais da seletividade do processo em relação ao modelo matemático proposto e corrigido, conforme critério anteriormente explicado, é bastante baixo (da ordem de 1,18\%), mostrando que o modelo é adequado, do ponto de vista estatístico, para representar o processo em estudo.

Esses resultados também permitem afirmar que o modelo pode ser utilizado para tomada de decisões na forma de atuação sobre as variáveis de processo, sabendo-se que os resultados obtidos deverão ser continuamente gerenciados pelos operadores de processo e engenheiros, uma vez que nem todos os fatores de influência no processo estão sendo considerados no modelo utilizado para a tomada de decisão. 


\subsubsection{Validação Fenomenológica do Modelo Matemático Proposto}

O processo de validação fenomenológica do modelo proposto consistiu basicamente na comparação entre os resultados da seletividade da reação, obtida através do modelo matemático desenvolvido, e da seletividade prevista por simulações realizadas em um simulador de processo.

Para realização de simulações do processo, foi estabelecido que as reações envolvidas no processo são catalisadas por sólidos e seguem o mecanismo de Langmuir-Hinshelwood, o qual se mostra consistente com os resultados experimentais, obtidos em estudos como os realizados por Lafarga,et al. (2000).

O mecanismo reacional proposto por Langmuir-Hinshelwood visa explicar 0 comportamento de reações catalisadas por sólidos, onde moléculas diferentes competem pela adsorção em um mesmo sítio. Essa competição pode ser visualizada no esquema mostrado na Figura 49, em que A e B representam moléculas de dois reagentes quaisquer na fase gasosa, $\mathrm{P}$ representa o produto desta reação (também na fase gasosa) e os índices $k_{i}$ representam as constantes cinéticas de cada uma das reações envolvidas no processo.

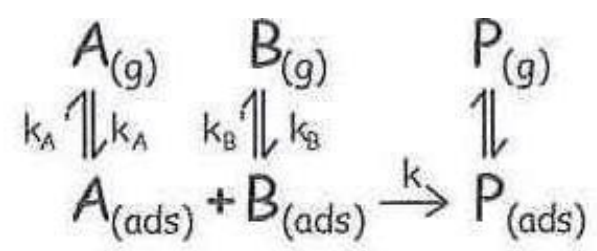

Figura 49 - Esquema simplificado do processo de competição entre moléculas por um mesmo sítio ativo.

Lafarga, et al. (2000) focavam em seus estudos a determinação dos parâmetros cinéticos da reação de oxidação do etileno, mas também confirmaram variações do comportamento cinético das reações em função de parâmetros operacionais como faixa de temperatura de operação, concentrações e vazões das correntes de alimentação, além da influência do tipo de reator utilizado no processo. Além disso, estudaram simplificações no mecanismo de Langmuir-Hinshelwood, tornando o mecanismo mais aplicável 
do ponto de vista experimental, sem perder a qualidade nos resultados e conclusões obtidas.

Os dados cinéticos obtidos nesses estudos foram utilizados como dados de entrada para o simulador de processo e encontram-se listados na Tabela 25.

Tabela 25 - Parâmetros cinéticos das equações de oxidação do etileno

\begin{tabular}{|c|c|c|}
\hline Parâmetro & $\begin{array}{l}\text { Reação Principal ( } \mathrm{r} 1 \text { ) } \\
\mathrm{C}_{2} \mathrm{H}_{4}+\frac{1}{2} \mathrm{O}_{2} \stackrel{\mathrm{Ag}}{\rightarrow} \mathrm{C}_{2} \mathrm{H}_{4} \mathrm{O}\end{array}$ & $\begin{array}{c}\text { Reação Secundária (r2) } \\
\mathrm{C}_{2} \mathrm{H}_{4}+3 \mathrm{O}_{2} \rightarrow 2 \mathrm{CO}_{2}+2 \mathrm{H}_{2} \mathrm{O}\end{array}$ \\
\hline \multirow[t]{2}{*}{ ki } & $1,33 \times 10^{5} \mathrm{mmol} / \mathrm{g}_{\text {cat }} . \mathrm{s}$ bar $^{1+n}$ & $1,80 \times 10^{6} \mathrm{mmol} / \mathrm{g}_{\text {cat }} . \mathrm{s} \mathrm{bar}^{1+n}$ \\
\hline & $1,33 \times 10^{-3} \mathrm{~mol} / \mathrm{g}_{\text {cat }} . \mathrm{s} \mathrm{Pa}^{1+n}$ & $1,80 \times 10^{-2} \mathrm{~mol} / \mathrm{g}_{\text {cat }} . \mathrm{s} \mathrm{Pa}^{1+n}$ \\
\hline $\mathrm{Ea}$ & $60,7 \mathrm{~kJ} / \mathrm{mol}$ & $73,2 \mathrm{~kJ} / \mathrm{mol}$ \\
\hline \multirow[t]{2}{*}{$\mathrm{K}_{\mathrm{E}}$} & $6,5 \mathrm{bar}^{-1}$ & 4,33 bar $^{-1}$ \\
\hline & $6,5 \times 10^{-5} \mathrm{~Pa}^{-1}$ & $4,33 \times 10^{-5} \mathrm{~Pa}^{-1}$ \\
\hline $\mathrm{n}$ & 0,58 & 0,30 \\
\hline
\end{tabular}

Onde:

$\mathrm{ki}=$ taxa da reação i ;

$\mathrm{Ea}=$ Energia de ativação da reação;

$\mathrm{K}_{\mathrm{E}}=$ constante de adsorção para o componente etileno;

$\mathrm{n}=$ ordem da reação do componente oxigênio.

A simulação do processo passou pela definição de uma sequência de etapas, que contemplaram a definição dos componentes que fazem parte do processo, o método utilizado para o cálculo de propriedades, a elaboração de um fluxograma simplificado de processo, a definição das características dos equipamentos a serem utilizados e a cinética das reações envolvidas no processo. Esses itens são detalhadamente apresentados a seguir: 
1) Definição dos componentes que fazem parte do sistema a ser estudado (Figura 50).

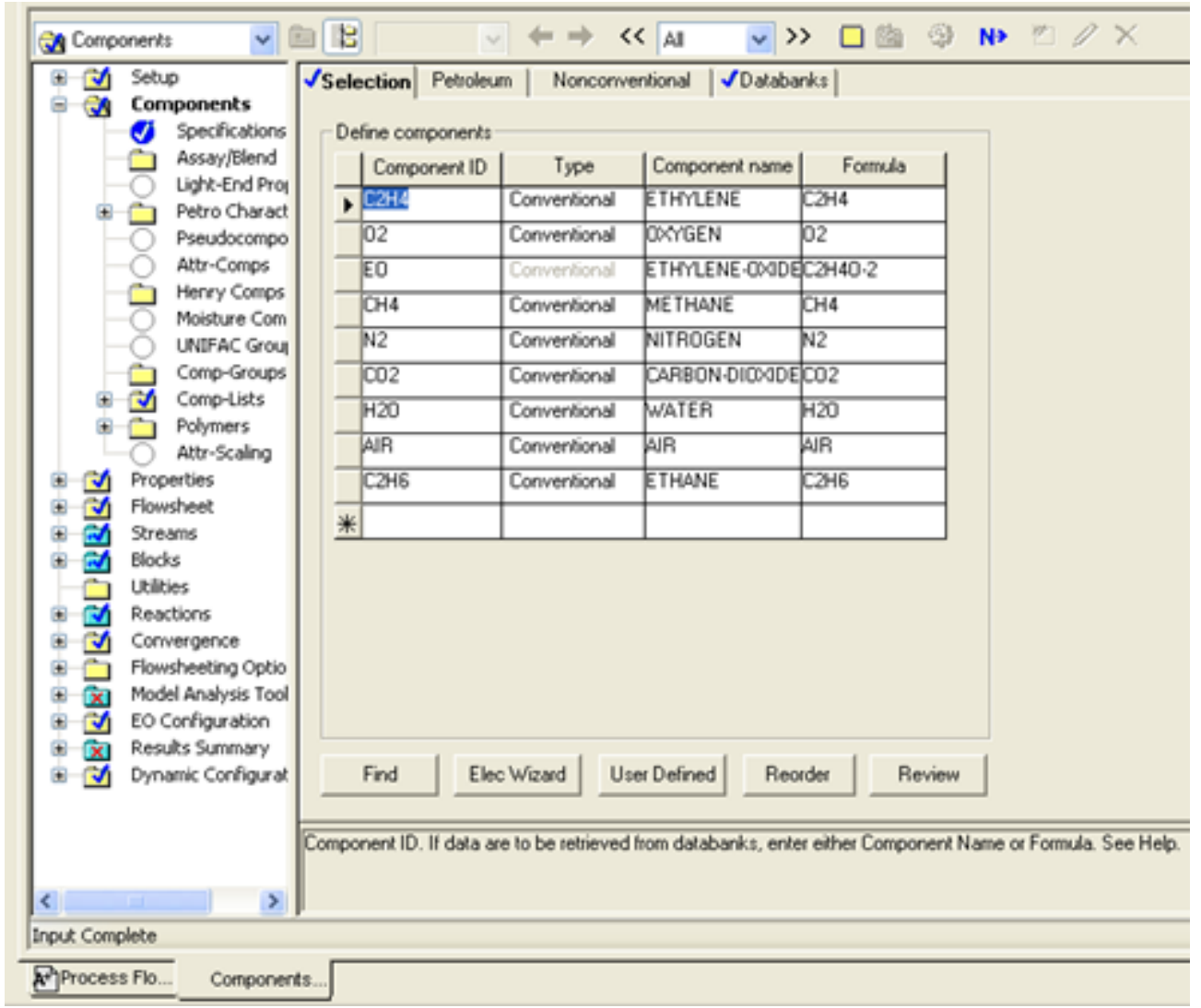

Figura 50 - Simulação do processo - Definição dos componentes que fazem parte do sistema.

Na simulação do processo foram consideradas as composições dos principais componentes do gás de reciclo que circula pelo reator: etileno, oxigênio, óxido de etileno, metano, nitrogênio, gás carbônico, água, etano. 
2) Definição do modelo de propriedades termodinâmicas utilizadas para os cálculos de entalpias e energia livre de Gibbs de misturas (Figura 51)

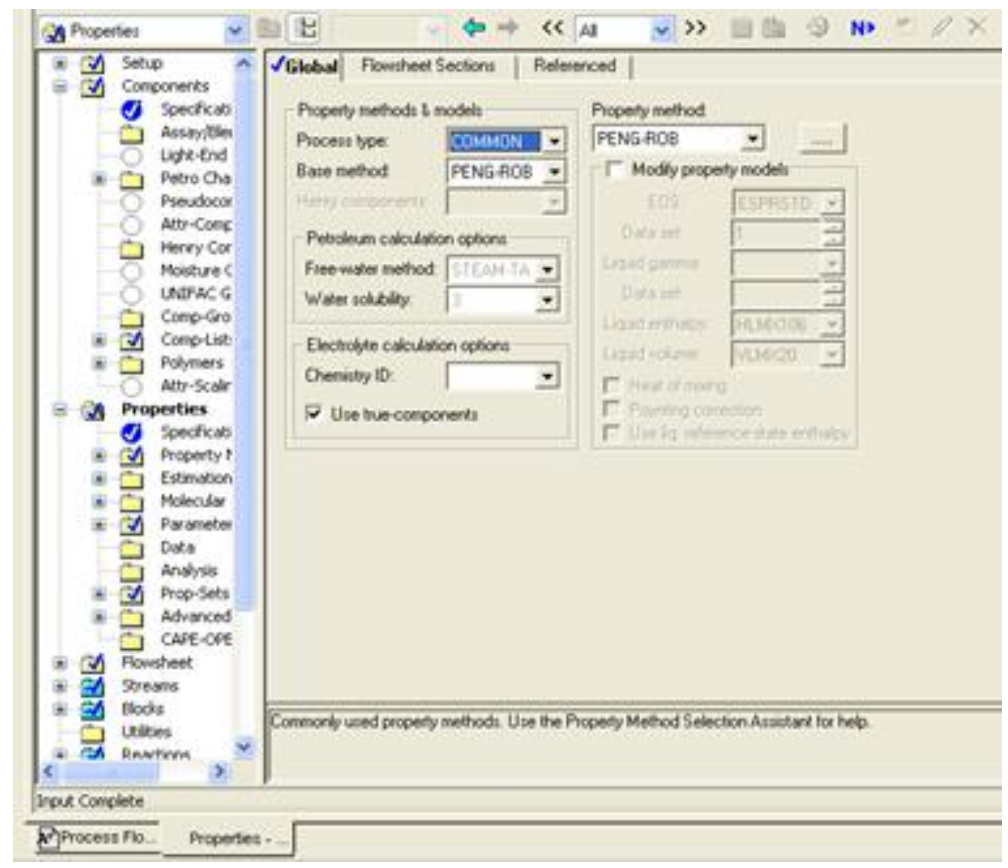

Figura 51 - Simulação do processo - Definição do modelo de propriedades termodinâmicas.

As propriedades dos componentes foram calculadas, utilizando como base 0 modelo termodinâmico de Peng-Robinson (o qual faz parte do banco de dados do simulador), em função das considerações já estabelecidas em 3.5.1.

3) Definição do fluxograma simplificado do processo (utilizando os chamados "blocos de simulação" e correntes materiais). Especificamente para este processo foi definido que o bloco é um misturador simples e que o reator segue o modelo Plug and Flow 'RPlug' (Figura 52).

Especificamente para este estudo, a definição desse item é a mais importante, uma vez que o simulador permite a escolha de diferentes tipos de reatores, cada qual com suas características específicas como listado a seguir (ASPEN PLUS, 1981):

a) Reatores de Balanço: subdivididos em duas categorias:

- RYield - Nesse tipo de simulação, observa-se apenas o balanço de massa do sistema e não se observa o balanço 
atômico. É utilizado para modelar reações de estequiometria complexa.

- RStoic - Nesse tipo de simulação, os balanços de massa e atômico são tratados simultaneamente. É utilizado para modelar reações estequiométricas, quando a cinética é desconhecida ou irrelevante.

b) Reatores de Equilíbrio: subdivididos em quatro categorias

- Geral - Nesse tipo de simulação, a cinética da reação não é levada em consideração. São similares aos de reatores de balanço, porém com especificações distintas.

- REquil - Nesse tipo de simulação são calculados simultaneamente o equilíbrio químico e de fases. É aplicado somente para 2 fases (líquido e vapor), sendo aplicável quando estão envolvidos no processo muitos componentes e poucas reações.

- RGibbs - Nesse tipo de simulação, as reações são desconhecidas, sendo que os cálculos realizados visam a minimização da Energia Livre de Gibbs (estão baseados na proposição de composições que minimizam a energia livre de Gibbs da mistura produto, aplicando o conceito de equilíbrio termodinâmico).

- Reatores Cinéticos - Nesse tipo de simulação, que engloba os modelos de reator CSTR (RCSTR), Plug Flow (RPlug) e Bateladas (RBatch), as cinéticas das reações são consideradas e devem, portanto, ser especificadas no processo. 
A cinética pode ser especificada através de modelos pré-fabricados ou subrotinas do usuário (Fortran). Os modelos pré-fabricados são:

- Lei de Potências (Arrenhius).

- LHHW - Langmuir, Hinshelwood, Hougen \&.Watson.

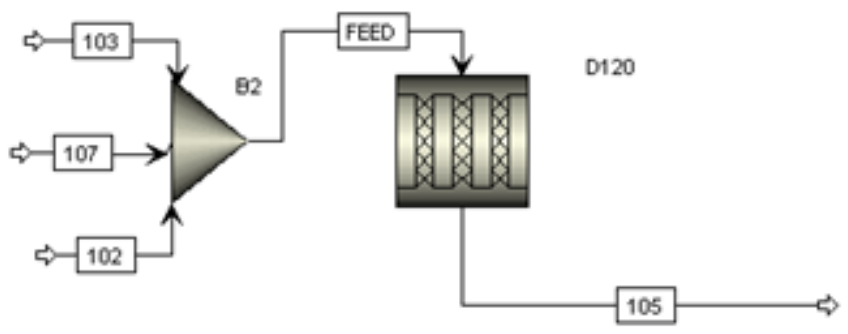

Figura 52 - Simulação do processo - Definição dos blocos e tipo de reator.

Além desses pontos listados, alguns itens específicos foram pré- estabelecidos para simulação do desempenho do reator:

- Coeficiente de troca térmica no processo de resfriamento das reações: adotado o valor de projeto fornecido pela empresa licenciadora da tecnologia utilizada $\left(200 \mathrm{kcal} / \mathrm{hm}^{2}{ }^{\circ} \mathrm{C}\right)$;

- Considerada apenas a presença de fase vapor no meio reacional;

- Perda de carga ao longo do leito fixo de catalisador foi considerada desprezível;

- Perdas térmicas no processo são consideradas desprezíveis. 
4) Definição das reações envolvidas, bem como dos parâmetros cinéticos obtidos em literatura, listados na Tabela 25 e apresentados na Figura 53.

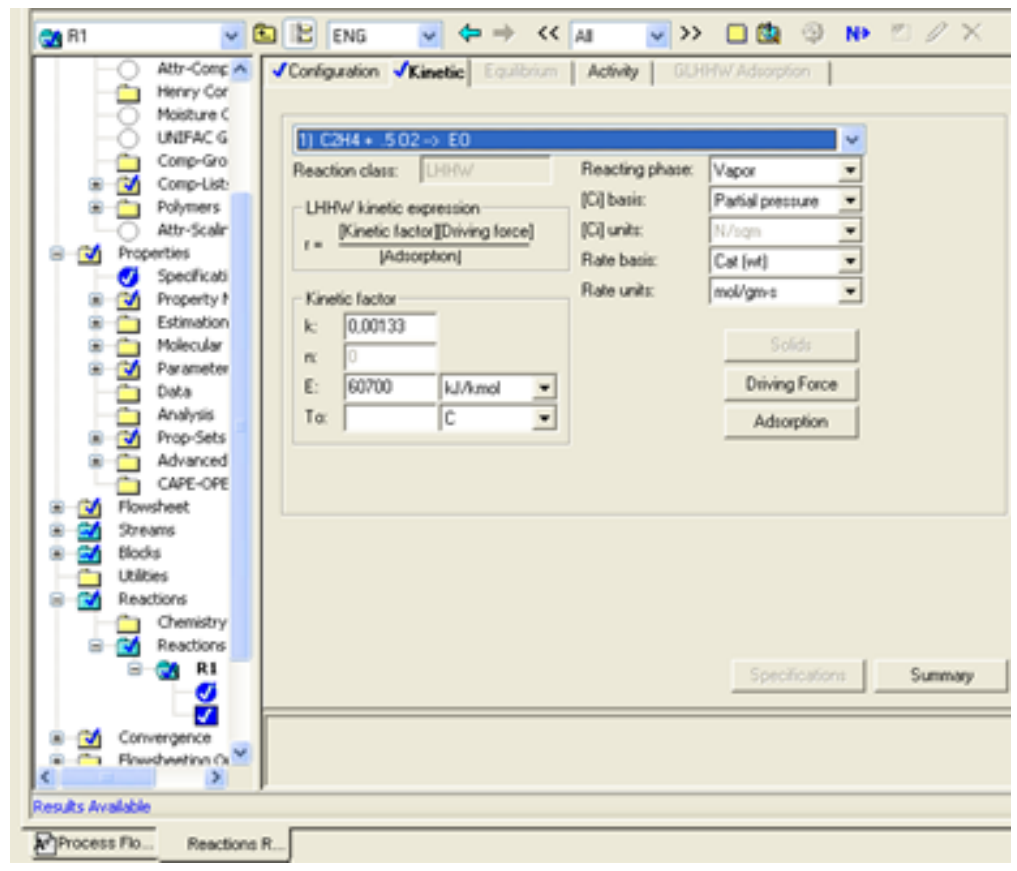

Figura 53 - Simulação do processo - Definição das reações e parâmetros cinéticos que representam o processo.

Os dados cinéticos utilizados para simulação do processo são aqueles apresentados inicialmente na Tabela 25.

5) Definição dos dados de entrada para os blocos usados no fluxograma simplificado de simulação e nas correntes pertinentes. Nesse caso, o próprio simulador analisa os graus de liberdade e indica quais correntes deverão ser especificadas e quais dados de projeto de equipamento devem ser preenchidos (Figura 54 e Figura 55). 


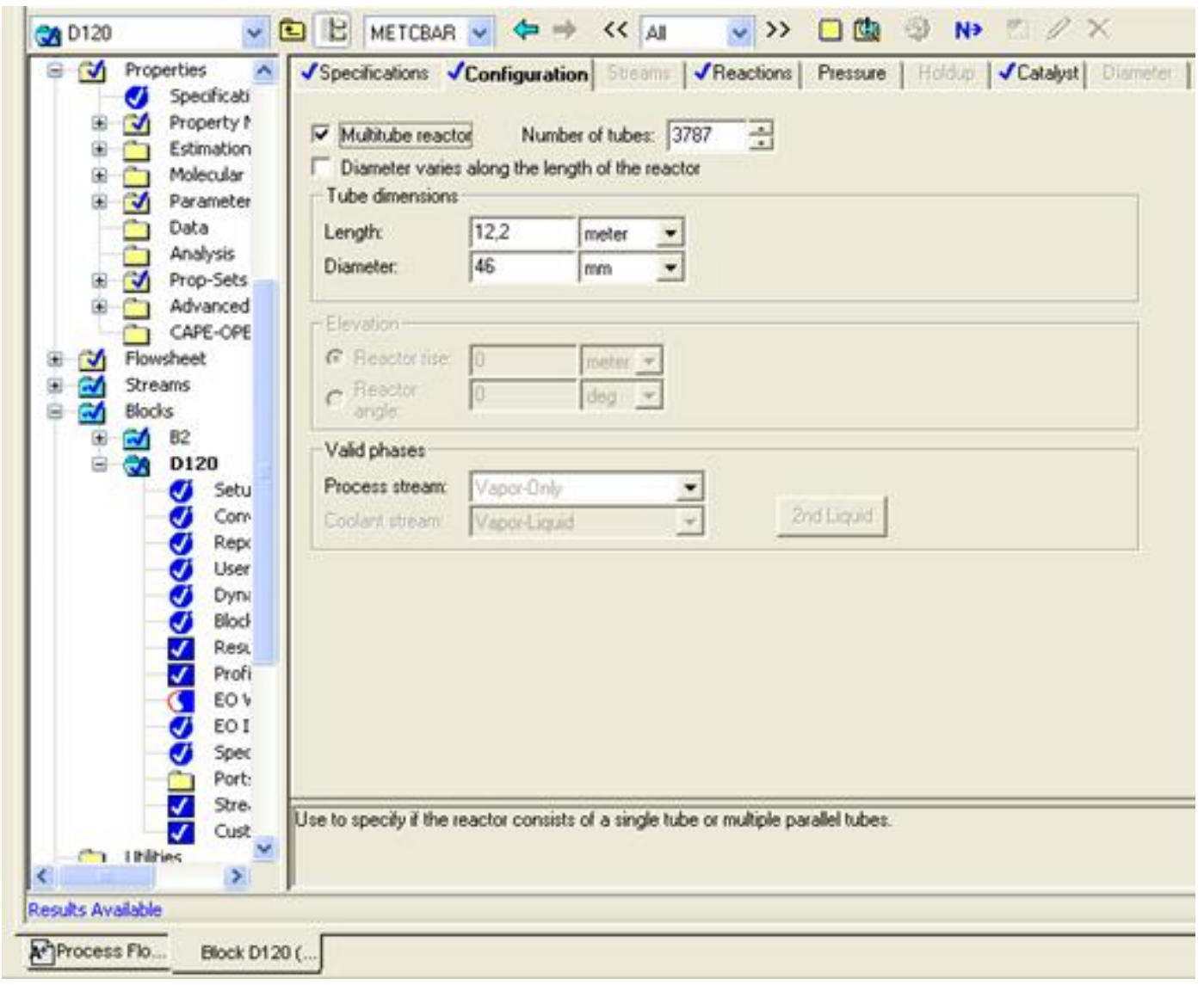

Figura 54 - Simulação do processo - Definição das especificações do processo.

Nessa etapa da simulação, foram estabelecidos os parâmetros geométricos do reator (número de tubos, comprimento dos tubos e seu diâmetro), utilizando-se os dados reais de projeto, listados anteriormente na Tabela 9. 


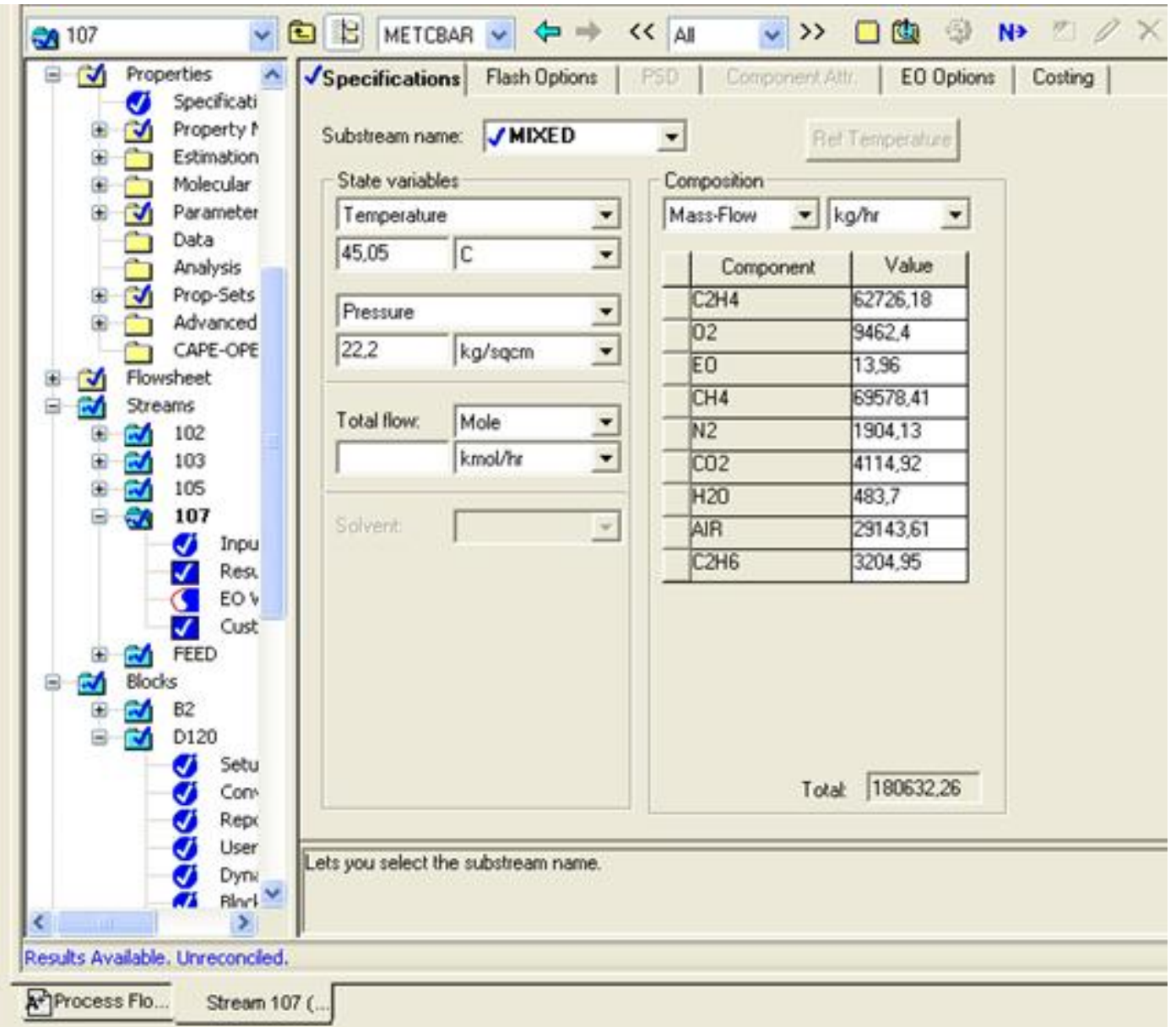

Figura 55 - Simulação do processo - Definição das especificações do processo.

Também foram estabelecidas condições de pressão de reação, temperatura do processo e vazões de alimentação dos reagentes, de modo a se obter a simulação efetiva do processo (conversão de reagentes e cálculo das respectivas seletividades obtidas)

6) Com os dados fornecidos nos itens anteriores, o simulador realiza uma análise preliminar e, se estiverem corretamente preenchidos e na sua totalidade, permite realizar a simulação do processo. Neste caso, o resultado é a completa especificação da corrente de saída do reator (Figura 56). 


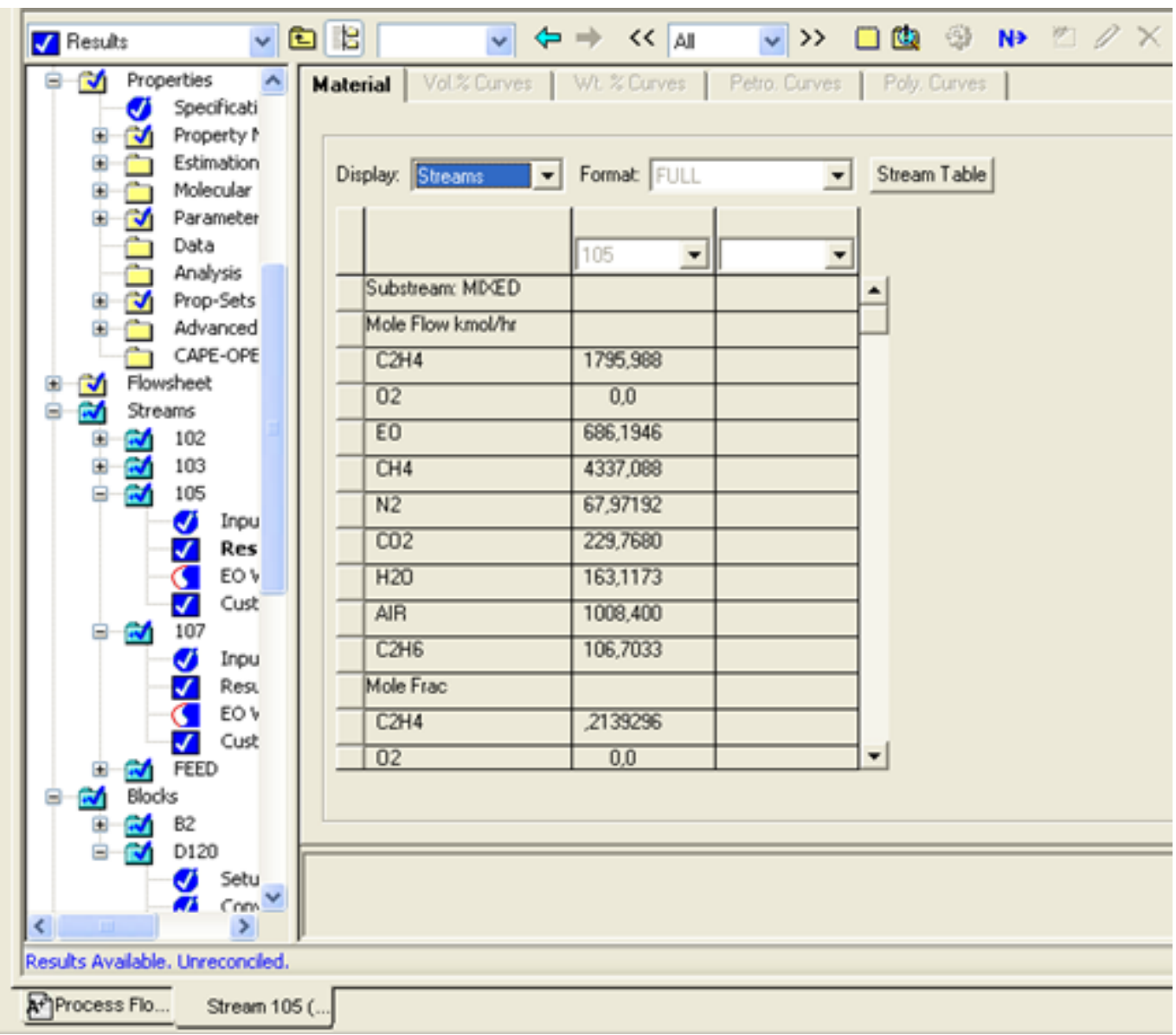

Figura 56 - Simulação do processo - Resultados da simulação preliminar do processo.

7) Análise de sensibilidade do modelo em estudo: É possível variar os dados da simulação de forma automática e Tabelar os resultados obtidos para cada uma dessas simulações. Para tanto, utiliza-se a ferramenta "Sensitivity" da Guia "Tools/Model Analysis Tools", onde se define quais variáveis serão manipuladas, qual a faixa dessa manipulação e quais variáveis deverão ser Tabeladas como resultado da análise de sensibilidade (Figura 57 e Figura 58). 


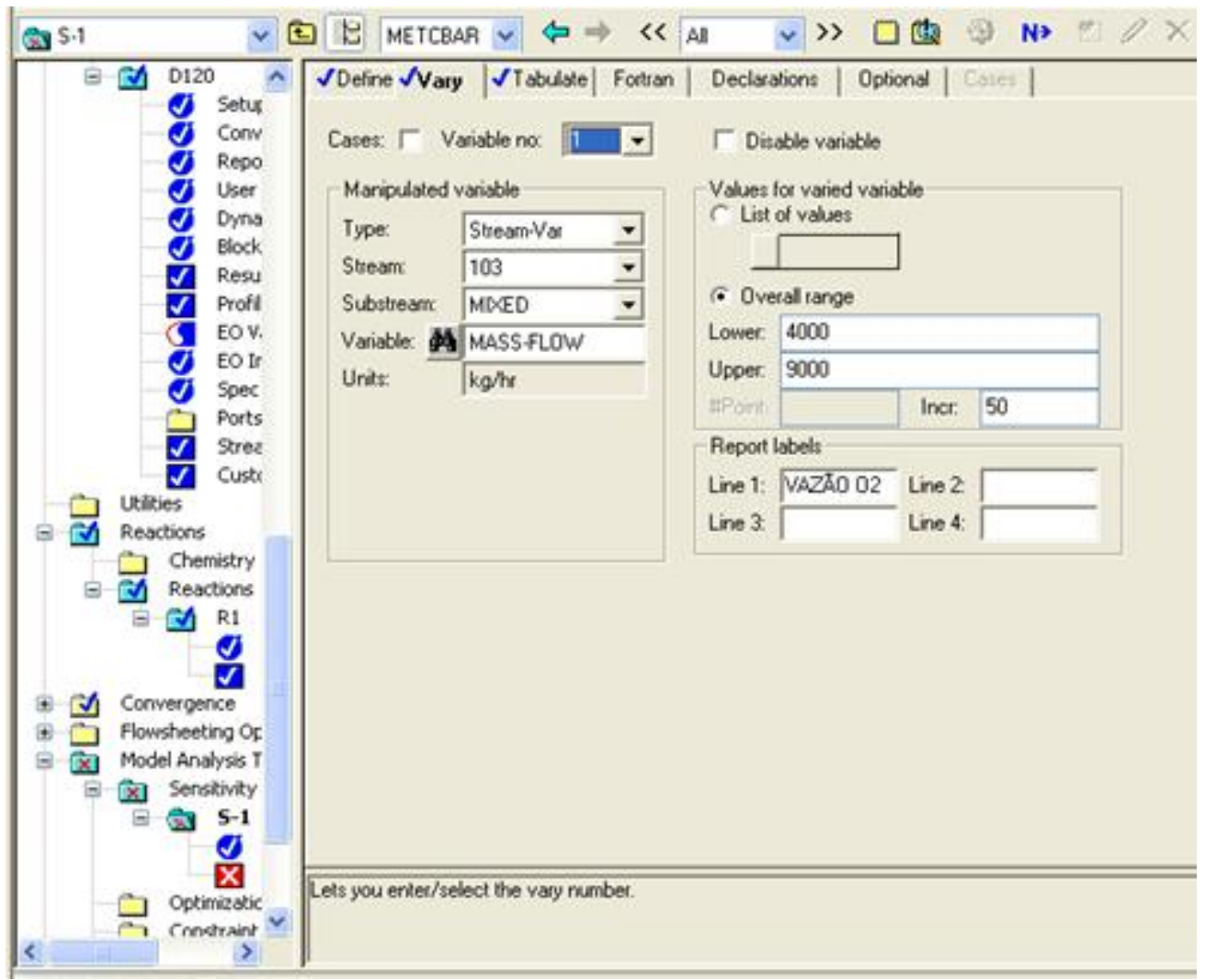

Figura 57 - Simulação do processo - Análise de sensibilidade do modelo às variações de vazão de alimentação de oxigênio no processo e temperatura da reação

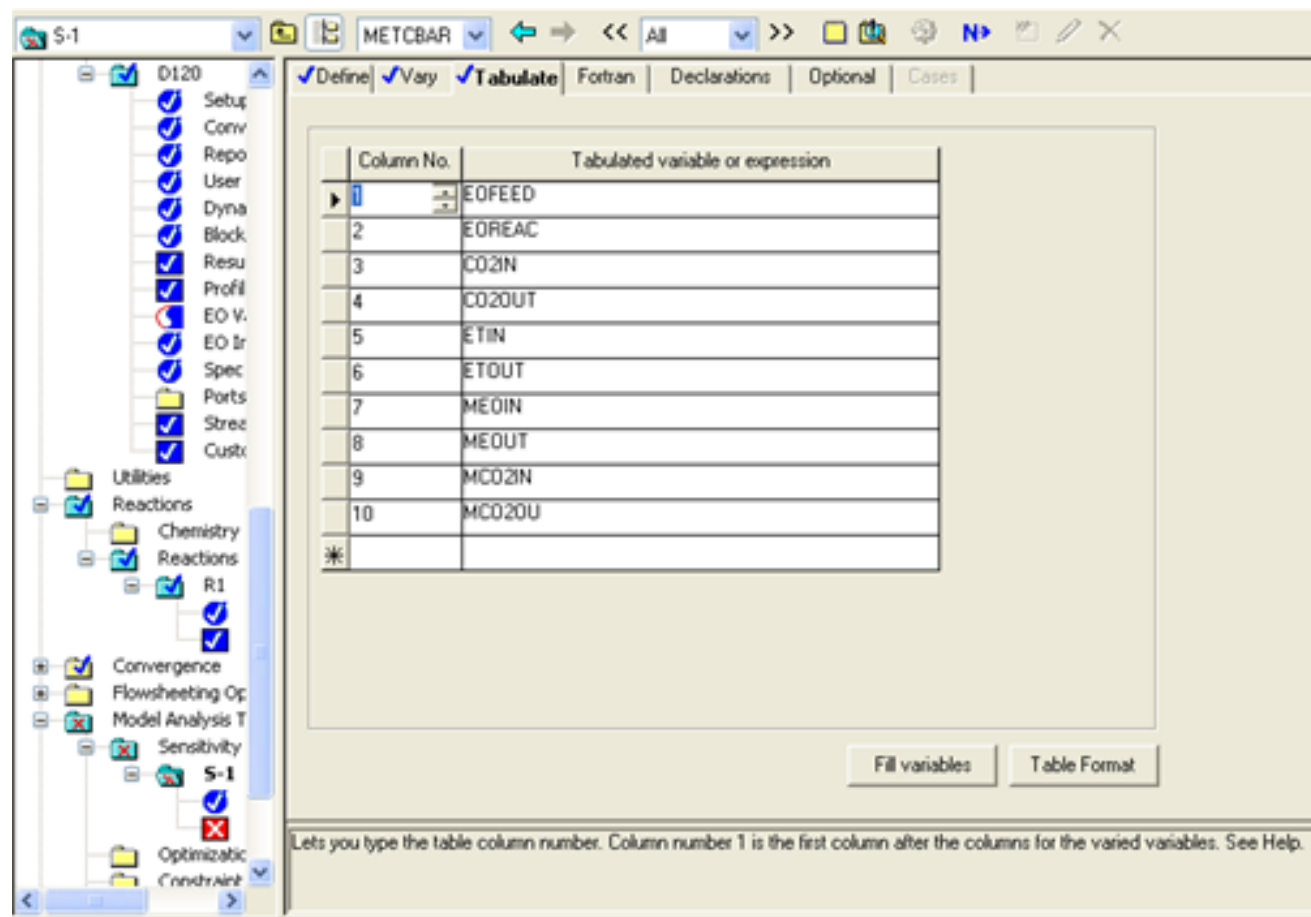

Figura 58 - Simulação do processo - Análise de sensibilidade do modelo às variações de vazão de alimentação de oxigênio no processo e temperatura da reação 
8) Os resultados obtidos são apresentados na forma de uma Tabela (Figura 59), que pode ser facilmente transferida para uma planilha do Excel.

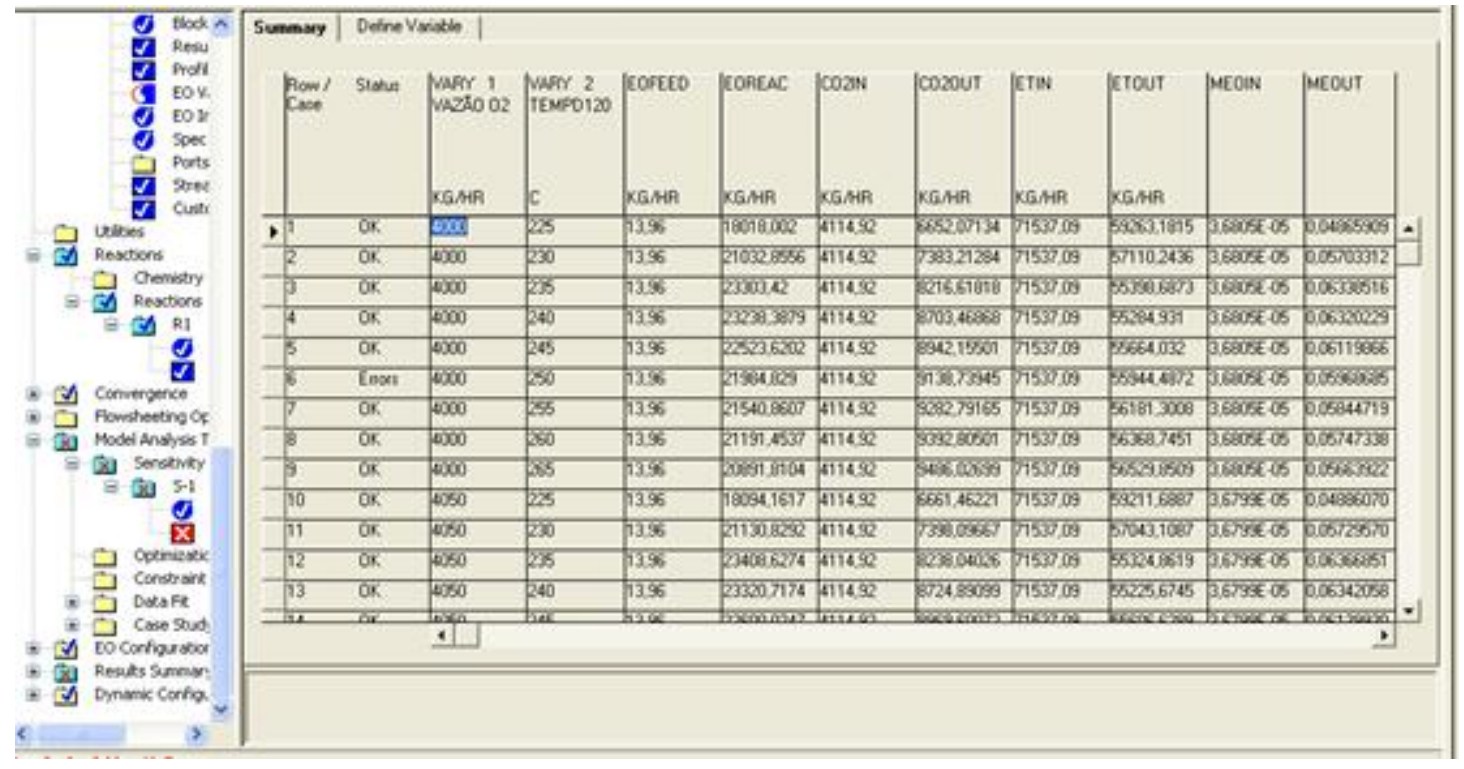

Figura 59 - Simulação do processo - Resultado de uma simulação de processo

Neste estudo em particular, os resultados obtidos via simulador estão mostrados (parcialmente) na Tabela 26.

Tabela 26 - Resultados da Simulação do Processo de oxidação de etileno

\begin{tabular}{|c|c|c|c|c|c|c|c|c|}
\hline $\begin{array}{l}\text { Vazão de } \\
\text { Oxigênio }\end{array}$ & Temperatura & $\begin{array}{c}\text { Vazão de EO na } \\
\text { entrada do } \\
\text { reator }\end{array}$ & $\begin{array}{l}\text { Vazão de EO } \\
\text { na saída do } \\
\text { reator }\end{array}$ & $\begin{array}{c}\text { Vazão de } \mathrm{CO} 2 \\
\text { na entrada do } \\
\text { reator }\end{array}$ & $\begin{array}{c}\text { Vazão de } \mathrm{CO} 2 \\
\text { na saída do } \\
\text { reator }\end{array}$ & $\begin{array}{c}\text { Vazão de etileno } \\
\text { na entrada do } \\
\text { reator }\end{array}$ & $\begin{array}{c}\text { Vazão de etileno } \\
\text { na saída do } \\
\text { reator }\end{array}$ & Seletividade \\
\hline $\mathrm{kg} / \mathrm{h}$ & $\mathrm{C}$ & $\mathrm{kg} / \mathrm{h}$ & $\mathrm{kg} / \mathrm{h}$ & $\mathrm{kg} / \mathrm{h}$ & $\mathrm{kg} / \mathrm{h}$ & $\mathrm{kg} / \mathrm{h}$ & $\mathrm{kg} / \mathrm{h}$ & $\% \mathrm{~mol}$ \\
\hline 4000 & 235 & 13,96 & 22.155 & 4.115 & 9.074 & 71.537 & 55.857 & 89,86 \\
\hline 4000 & 240 & 13,96 & 22.086 & 4.115 & 9.091 & 71.537 & 55.895 & 89,80 \\
\hline 4000 & 245 & 13,96 & 22.039 & 4.115 & 9.119 & 71.537 & 55.916 & 89,73 \\
\hline 4000 & 255 & 13,96 & 21.910 & 4.115 & 9.149 & 71.537 & 55.989 & 89,62 \\
\hline 4000 & 260 & 13,96 & 21.845 & 4.115 & 9.178 & 71.537 & 56.021 & 89,53 \\
\hline 4050 & 230 & 13,96 & 22.294 & 4.115 & 9.065 & 71.537 & 55.771 & 89,93 \\
\hline 4050 & 235 & 13,96 & 22.222 & 4.115 & 9.091 & 71.537 & 55.809 & 89,85 \\
\hline 4050 & 240 & 13,96 & 22.160 & 4.115 & 9.109 & 71.537 & 55.842 & 89,79 \\
\hline 4050 & 245 & 13,96 & 22.098 & 4.115 & 9.131 & 71.537 & 55.875 & 89,73 \\
\hline 4050 & 250 & 13,96 & 22.045 & 4.115 & 9.158 & 71.537 & 55.900 & 89,66 \\
\hline 4050 & 255 & 13,96 & 21.985 & 4.115 & 9.169 & 71.537 & 55.935 & 89,61 \\
\hline 4050 & 260 & 13,96 & 21.925 & 4.115 & 9.188 & 71.537 & 55.967 & 89,55 \\
\hline 4100 & 230 & 13,96 & 22.372 & 4.115 & 9.090 & 71.537 & 55.714 & 89,91 \\
\hline 4100 & 235 & 13,96 & 22.297 & 4.115 & 9.110 & 71.537 & 55.755 & 89,85 \\
\hline 4100 & 240 & 13,96 & 22.236 & 4.115 & 9.132 & 71.537 & 55.786 & 89,78 \\
\hline 4100 & 250 & 13,96 & 22.114 & 4.115 & 9.170 & 71.537 & 55.853 & 89,66 \\
\hline 4100 & 255 & 13,96 & 22.060 & 4.115 & 9.188 & 71.537 & 55.881 & 89,61 \\
\hline 4100 & 260 & 13,96 & 21.999 & 4.115 & 9.212 & 71.537 & 55.912 & 89,54 \\
\hline 4150 & 230 & 13,96 & 22.443 & 4.115 & 9.106 & 71.537 & 55.663 & 89,91 \\
\hline 4150 & 235 & 13,96 & 22.369 & 4.115 & 9.128 & 71.537 & 55.703 & 89,84 \\
\hline 4150 & 240 & 13,96 & 22.317 & 4.115 & 9.148 & 71.537 & 55.730 & 89,79 \\
\hline
\end{tabular}


Os resultados da Tabela 26 foram trabalhados de modo a se obter uma superfície de resposta que proporcionasse uma visão global do comportamento teórico da seletividade em função das variações da temperatura da reação e vazão de oxigênio. Essa visualização é mostrada na Figura 60.

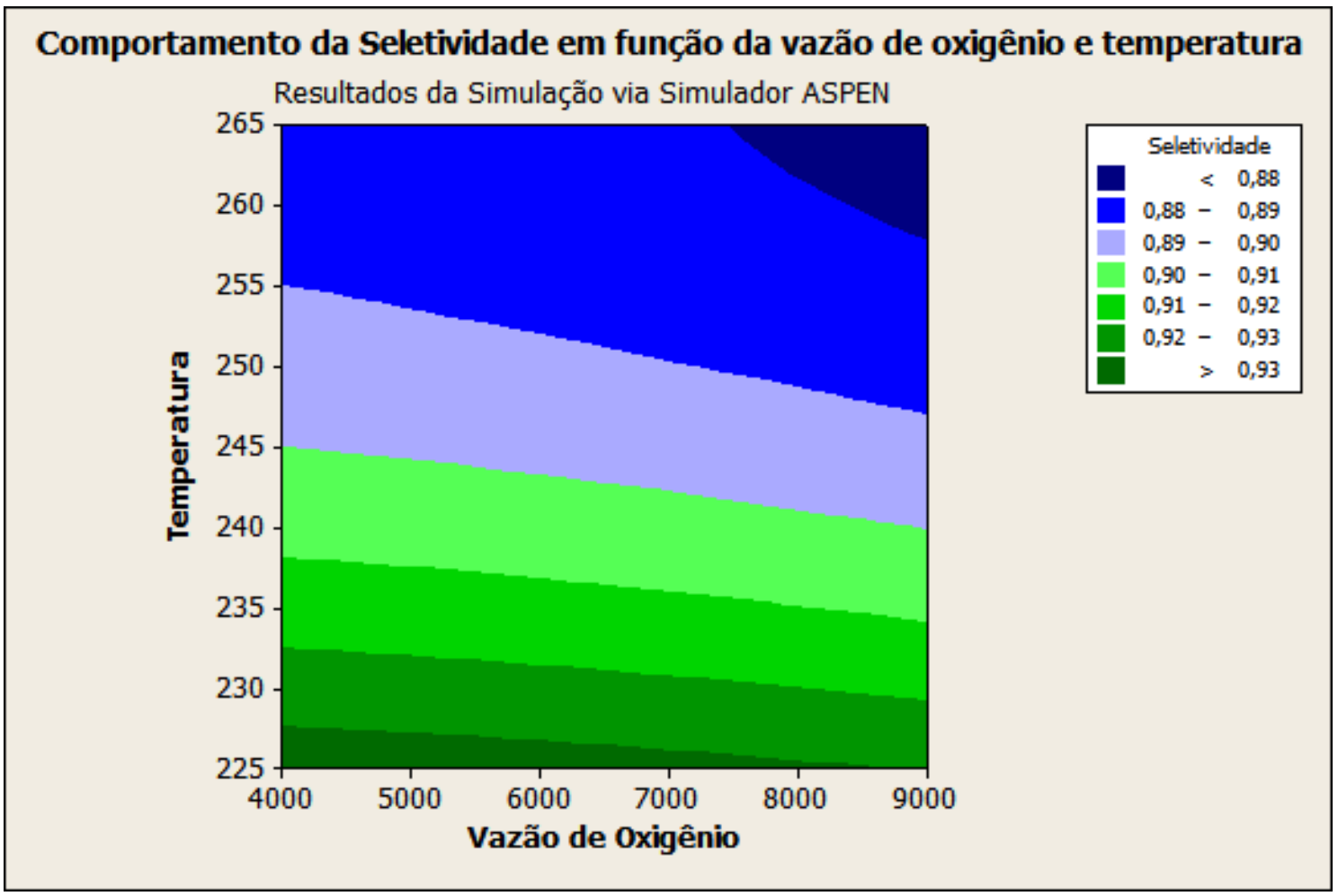

Figura 60 - Comportamento da seletividade da reação obtida via simulação de processo

Os resultados da simulação fenomenológica apresentados na Figura 60 mostraram-se coerentes com os resultados obtidos através do modelo estatístico desenvolvido (equação 71), pois demonstraram que a melhoria da seletividade está associada à redução da vazão de oxigênio e temperatura da reação (mesma conclusão obtida via modelo estatístico), quando se busca uma otimização do processo.

Do ponto de vista da magnitude dos resultados, existe uma variação de aproximadamente $6 \%$ no resultado da seletividade obtida através do modelo fenomenológico em relação ao modelo estatístico, estando a maior em favor do modelo fenomenológico. Parte dessa diferença está relacionada ao fato de a simulação fenomenológica não considerar o efeito de perda de seletividade devido o envelhecimento do catalisador. 
Considerando que o objetivo da avaliação fenomenológica está na validação dos resultados obtidos via modelo estatístico, através da análise do comportamento da seletividade em função de alterações nas variáveis mais relevantes do processo, pode-se dizer, com base nos resultados da Figura $60 \mathrm{e}$ equação 71 que ambos representaram satisfatoriamente o comportamento real da seletividade da reação.

\subsection{Análise Global do Modelo de Regressão}

Uma vez validado o modelo matemático proposto, tanto via base estatística, como via base fenomenológica, o mesmo pode ser avaliado em relação à consistência e coerência, em relação aos aspectos abordados na revisão bibliográfica apresentada neste trabalho.

O valor dos coeficientes de cada variável dos modelos de regressão propostos (equações 70 e 71) indicam o grau de influência de cada uma dessas variáveis sobre o resultado da seletividade do processo. Já o sinal positivo ou negativo indica que incrementos na variável influenciam de forma a aumentar ou diminuir a seletividade da reação respectivamente.

Das quatro variáveis selecionadas como importantes para a elaboração do modelo da equação 70 , segundo metodologia estabelecida em 5.2.3, verificase a vazão de oxigênio e a temperatura da reação como sendo as mais importantes para o gerenciamento do processo, seguidas do teor de clorados, que apresenta uma significativa importância, e por último, a vazão de gás de reciclo, que, perante essas outras três variáveis, mostra-se pouco relevante.

- O sinal negativo da temperatura demonstra que atuações no processo produtivo em favor do aumento da seletividade devem ser realizadas focando reduções na temperatura da reação.

Conforme mostrado nas equações 26 e 27 e na Figura 12, a reação principal do processo (formação de uma molécula de óxido de etileno) consome $1 / 2 \mathrm{~mol}$ de oxigênio e apresenta menor energia de ativação 
que a reação de formação dos subprodutos $\mathrm{CO}_{2}$ e água (esta, por sua vez, consome 3 mols de oxigênio). Dessa forma, temperaturas mais baixas favorecem a ocorrência da reação principal, resultando em um menor consumo de moléculas de oxigênio, o que contribui para redução da vazão de oxigênio no processo.

Temperaturas mais baixas contribuem também para reduzir os efeitos do processo de sinterização da prata, resultando no melhor aproveitamento possível dos sítios-ativos do catalisador, uma vez que favorece a orientação das moléculas de oxigênio em seu processo de adsorção na prata, como mostrado na Figura 16.

- O sinal negativo da vazão de oxigênio também demonstra que o aumento da seletividade está atrelado a alterações de processo que visem reduções na vazão de alimentação desse reagente no processo. À medida que se verifica um aumento da seletividade da reação, é de se esperar um menor consumo de moléculas de oxigênio no processo, resultando em um incremento da concentração desse componente na corrente de gás de reciclo.

De acordo com a cinética desse processo, esse tipo de atuação também contribui para o aumento da seletividade, pois a influência da concentração de oxigênio é mais significativa para a cinética da reação principal, como mostrado nos valores de ordem de reação da Tabela 25. $O$ aumento dessa concentração necessita ser gerenciado rigorosamente, uma vez que elevadas concentrações de oxigênio nessa corrente podem resultar em uma mistura que venha atingir os seus limites de inflamabilidade. Portanto, a atuação sobre a vazão de oxigênio é fundamental para garantir que a mistura reacional esteja sempre dentro dos limites de segurança operacional.

- O sinal positivo da variável teor de clorados demonstra que a seletividade da reação cresce se aumentarmos a concentração de clorados na corrente de gás de reciclo. 
Os resultados também mostram que a variável teor de clorados exerce sim uma influência no resultado do processo, mas não com intensidade relatada nas literaturas pesquisadas (STOREY, 2007).

A seletividade da reação é sensível a variações no teor de clorados no gás de reciclo, existindo um ponto ótimo que, maximiza o resultado da seletividade e necessita ser ajustado periodicamente, em função dos efeitos de sinterização da prata ao longo do tempo de vida do catalisador (SHELL OIL COMPANY, 1997). Isto pode ser observado pela análise da equação 71 , que representa 0 modelo matemático mais completo.

O etileno, principal matéria prima utilizada nesse processo, está acompanhado de hidrocarbonetos contaminantes como etano e metano, cujas concentrações não são controladas e, portanto, não se mantém constantes na composição da corrente de gás de reciclo. Em contrapartida, as literaturas pesquisadas indicam forte influência desses contaminantes sobre a atuação dos compostos clorados, recomendando que a composição desses compostos permaneça constante no processo.

Portanto, o processo estudado demanda constantes intervenções operacionais sobre a variável teor de clorados, de modo a minimizar o efeito da variação da concentração dos hidrocarbonetos contaminantes. Como resultado há uma natural dificuldade de se obter a concentração ideal de clorados, bem como um aumento da variabilidade dos resultados sobre essa variável. Essa alta variabilidade influencia no desenvolvimento do modelo matemático, podendo explicar o porquê dessa variável não ter se destacado como a mais relevante para o modelo proposto.

O modelo matemático também mostra que a variável teor de clorados não pode ser analisada isoladamente, uma vez que o efeito de sua interação com outras variáveis (em especial a temperatura) é bastante relevante, como indica a equação 71 .

Nessa situação, a utilização mais efetiva dos sítios-ativos do catalisador, motivada pela redução das temperaturas, permite que mais moléculas de compostos clorados possam atuar sobre esses sítios, favorecendo 0 
incremento da concentração desses componentes, o que vai ao encontro do previsto pelo modelo estatístico.

Do ponto de vista de precisão do modelo desenvolvido, as diferenças entre os valores da seletividade real do processo (e aqueles obtidos via equação 71 e via simulação fenomenológica) estão relacionadas a fatores como:

- O modelo fenomenológico apresenta sempre valores de seletividade superiores aos valores reais de processo (em geral da ordem de 6\%). Não é possível definir no modelo fenomenológico o nível de atividade do catalisador, sendo provável que, ao adotarmos os parâmetros cinéticos da reação, definidos na Tabela 25, o modelo de reator previsto assume a existência de um tipo de catalisador com uma atividade maior que o catalisador efetivamente usado no processo (pode-se dizer que o catalisador utilizado no processo de simulação apresenta um teor de prata mais elevado que o catalisador existente no processo).

Além disso, os parâmetros cinéticos adotados não apresentam 100\% de aderência aos resultados reais da seletividade do processo estudado por Lafarga, et al. (2000), o que por si só já traz uma incerteza ao modelo analisado.

Outro ponto relevante está no fato de que a simulação fenomenológica não considera o efeito do teor de clorados, variável que, no processo real, mostra ser relevante no resultado da seletividade da reação, podendo contribuir de forma negativa no resultado da seletividade, caso não esteja trabalhando em faixas próximas dos valores ótimos. 0 modelo fenomenológico também é estático e representa a avaliação de um processo em uma dada condição, que não se perpetua ao longo do tempo de vida útil do catalisador. Na prática, à medida que o catalisador é utilizado, ele perde seletividade, não sendo possível reproduzir esse efeito na simulação fenomenológica. Como consequência, naturalmente os resultados dessa simulação tendem a valores maiores que os resultados reais do processo. 
- O modelo estatístico, por sua vez, apresenta uma seletividade cerca de $1,18 \%$ superior, na média, que os resultados reais obtidos no processo estudado.

Evidentemente, parte dessa discrepância está relacionada ao fato do modelo explicar $60,1 \%$ das variações do processo, como apresentado na Tabela 21. As demais variações não estão contempladas no modelo e agregam incertezas nos resultados obtidos. 


\subsection{Análise Exploratória do Modelo de Regressão}

A influência de um conjunto de variáveis no desempenho de um processo pode ser representada através de superfícies de resposta, onde é possível avaliar a resposta em função de diferentes níveis adotados para as variáveis independentes desse processo (BOX; HUNTER; HUNTER, 2005). A avaliação da influência dessas variáveis sobre a seletividade da reação, denominada neste trabalho "análise exploratória" do modelo, teve por objetivo avaliar as condições de processo que direcionam os resultados a uma melhoria da seletividade.

A análise exploratória do modelo visa entender o comportamento do processo em situações consideradas mais comuns do ponto de vista operacional. Essas situações preveem que apenas duas variáveis de processo sejam alteradas simultaneamente na busca pela melhoria dos resultados de um determinado processo (as outras duas variáveis se mantém fixas em valores pré-definidos).

Seis diferentes análises exploratórias do modelo foram realizadas de acordo com o descrito nas Tabelas 27 a 38.

A variável de resposta, para cada uma das análises experimentais e seus respectivos modelos desdobrados, foi a seletividade da reação de produção de óxido de etileno, sendo que a análise estatística dos dados foi realizada com auxílio do software MINITAB 15.0.

Para cada uma das simulações é mostrado inicialmente o modelo de regressão generalizado obtido ao longo do estudo (equação 71), seguido dos modelos desdobrados. Modelos desdobrados são aqueles em que são fixados os valores de duas variáveis em quatro situações diferentes $\left(1^{\underline{a}}\right.$ e $2^{\underline{a}}$ variável na faixa mínima de operação, $1^{\underline{a}}$ e $2^{\underline{a}}$ variável na faixa máxima de operação, $1^{\underline{a}}$ variável na faixa mínima de operação e $2^{\underline{a}}$ variável na faixa máxima de operação, $1^{\underline{a}}$ variável na faixa máxima de operação e $2^{\underline{a}}$ variável na faixa mínima de operação), explorando-se os intervalos -1 a 1 de operação das outras duas variáveis de processo. 
Tabela 27 - 1ํㅡ Análise exploratória do modelo e seus objetivos

\begin{tabular}{|c|c|}
\hline Objetivo & Descrição \\
\hline $\begin{array}{l}\text { Estudar os efeitos das } \\
\text { variáveis - vazão de } \\
\text { oxigênio e vazão de gás } \\
\text { de reciclo - sobre o } \\
\text { resultado da seletividade } \\
\text { da reação, mantendo-se } \\
\text { as demais variáveis } \\
\text { selecionadas no modelo } \\
\text { empírico (temperatura da } \\
\text { reação e teor de } \\
\text { clorados) em faixas de } \\
\text { operação pré-fixadas. }\end{array}$ & $\begin{array}{l}\text { Realização de quatro análises diferentes que } \\
\text { resultam na obtenção de } 4 \text { novos modelos, os } \\
\text { chamados modelos desdobrados: } \\
\text { Situação 1: } \\
\text { - Temperatura da reação na faixa mínima de } \\
\text { operação; } \\
\text { - Teor de clorados na faixa mínima de } \\
\text { operação } \\
\text { Situação } 2 \text { : } \\
\text { - Temperatura da reação na faixa máxima de } \\
\text { operação; } \\
\text { - Teor de clorados na faixa mínima de } \\
\text { operação } \\
\text { Situação } 3 \text { : } \\
\text { - Temperatura da reação na faixa mínima de } \\
\text { operação; } \\
\text { - Teor de clorados na faixa máxima de } \\
\text { operação } \\
\text { Situação } 4 \text { : } \\
\text { - Temperatura da reação na faixa máxima de } \\
\text { operação; } \\
\text { operação }\end{array}$ \\
\hline
\end{tabular}

A faixa mínima e a faixa máxima de operação das variáveis descritas na Tabela anterior foram codificadas, respectivamente com os níveis -1 e +1 , como mostrado na Tabela 28. 
Tabela 28 - Níveis das variáveis de processo em unidades codificadas e valores reais de processo ( $1^{\mathrm{a}}$ análise exploratória do modelo)

\begin{tabular}{|c|c|c|c|c|c|c|}
\hline \multirow{3}{*}{$\begin{array}{c}\text { Situação } \\
1\end{array}$} & \multirow{2}{*}{\multicolumn{2}{|c|}{ Variáveis Independentes }} & \multicolumn{4}{|c|}{ Variáveis Fixas } \\
\hline & & & \multirow{2}{*}{$\frac{\text { 1a Variável }}{x_{3}}$} & \multirow{2}{*}{$\begin{array}{c}\begin{array}{c}\text { Valor codificado } \\
\text { Valor real }\end{array} \\
-1 ; 218,6\end{array}$} & \multirow{2}{*}{$\frac{\text { 2a Variável }}{\mathrm{x}_{4}}$} & \multirow{2}{*}{$\begin{array}{c}\text { Valor codificado; } \\
\text { Valor real } \\
-1 ; 0,04\end{array}$} \\
\hline & $x_{1}$ & $x_{2}$ & & & & \\
\hline 2 & $x_{1}$ & $x_{2}$ & $x_{3}$ & $1 ; 234,3$ & $x_{4}$ & $-1 ; 0,04$ \\
\hline 3 & $x_{1}$ & $x_{2}$ & $x_{3}$ & $-1 ; 218,6$ & $x_{4}$ & $1 ; 0,09$ \\
\hline 4 & $x_{1}$ & $x_{2}$ & $x_{3}$ & $1 ; 234,3$ & $x_{4}$ & $1 ; 0,09$ \\
\hline
\end{tabular}

Onde:

$x_{1}=$ vazão de oxigênio

$x_{2}=$ vazão de gás de reciclo

$x_{3}=$ temperatura da reação

$\mathrm{x}_{4}=$ teor de clorados 
Modelo Geral: $\mathrm{S}=86.90-1.89 \cdot \mathrm{x}_{1}+0.07 \cdot \mathrm{x}_{2}-1.73 \cdot \mathrm{x}_{3}+0.44 \cdot \mathrm{x}_{4}-1.18 \cdot \mathrm{x}_{1} \cdot \mathrm{x}_{2}+7.02 \cdot \mathrm{x}_{1} \cdot \mathrm{x}_{3}+0.44 \cdot \mathrm{x}_{1} \cdot \mathrm{x}_{4}+1.82 \cdot \mathrm{x}_{2} \cdot \mathrm{x}_{3}-0.16 \cdot \mathrm{x}_{2} \cdot \mathrm{x}_{4}-$ $0.57 \cdot \mathrm{x}_{3} \cdot \mathrm{x}_{4}-1.94 \cdot \mathrm{x}_{1}^{2}-1.03 \cdot \mathrm{x}_{2}^{2}-2.05 \cdot \mathrm{x}_{3}^{2}-0.29 \cdot \mathrm{x}_{4}^{2}$

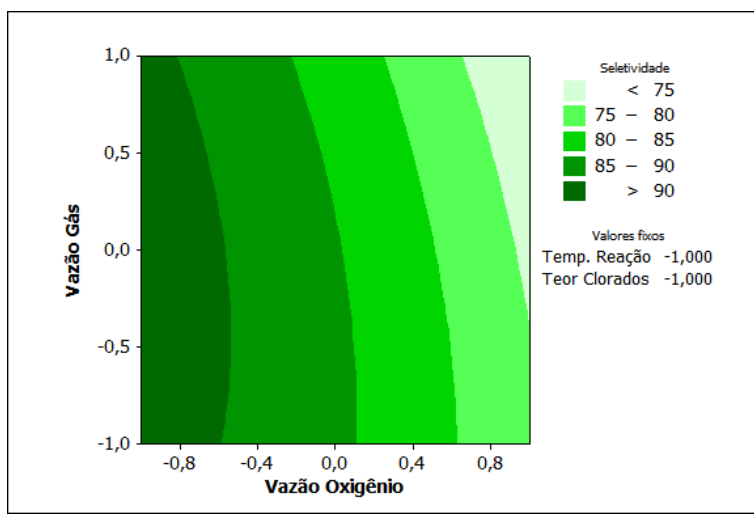

Situação 1: Temperatura mínima do processo ;Clorados mínimo no processo $S=85.28-9.35 \cdot x_{1}-1.59 \cdot x_{2}-1.18 \cdot x_{1} \cdot x_{2}-1.94 \cdot x_{1}^{2}-1.03 \cdot x_{2}^{2}$

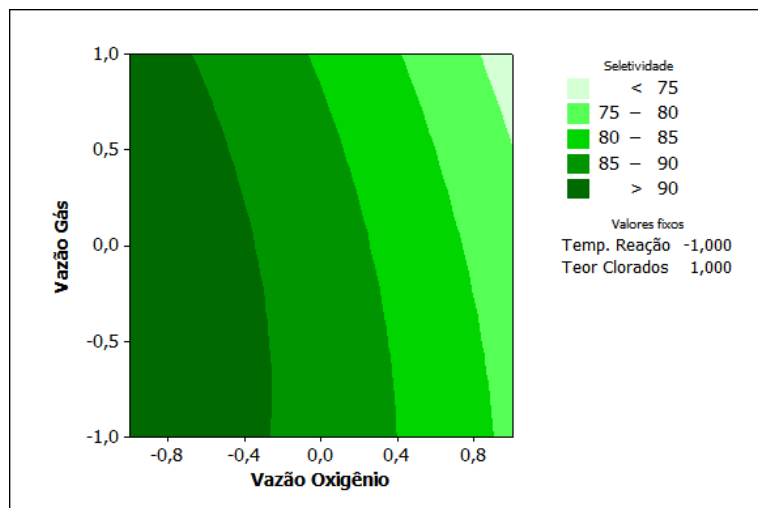

Situação 3: Temperatura mínima do processo ;Clorados máximo no processo $S=87.30-8.47 \cdot x_{1}-1.91 \cdot x_{2}-1.18 \cdot x_{1} \cdot x_{2}-1.94 \cdot x_{1}^{2}-1.03 \cdot x_{2}^{2}$

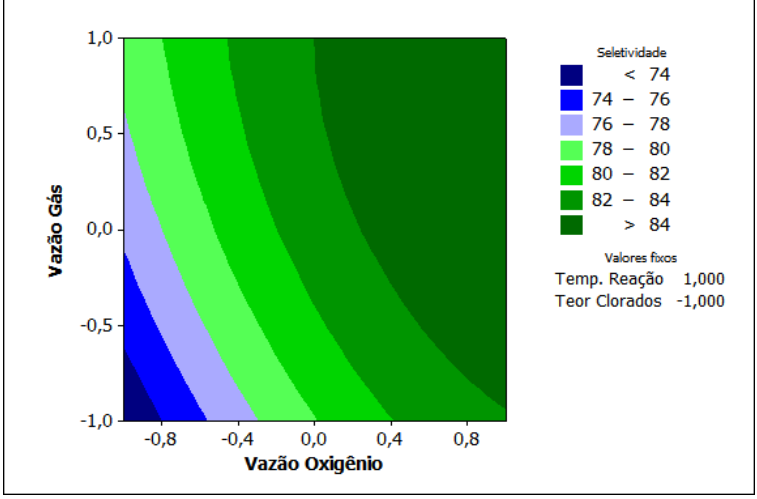

Situação 2: Temperatura no máximo do processo ; Clorados no mínimo do processo $S=82.96+4.69 \cdot x_{1}+2.05 \cdot x_{2}-1.18 \cdot x_{1} \cdot x_{2}-1.94 \cdot x_{1}^{2}-1.03 \cdot x_{2}^{2}$

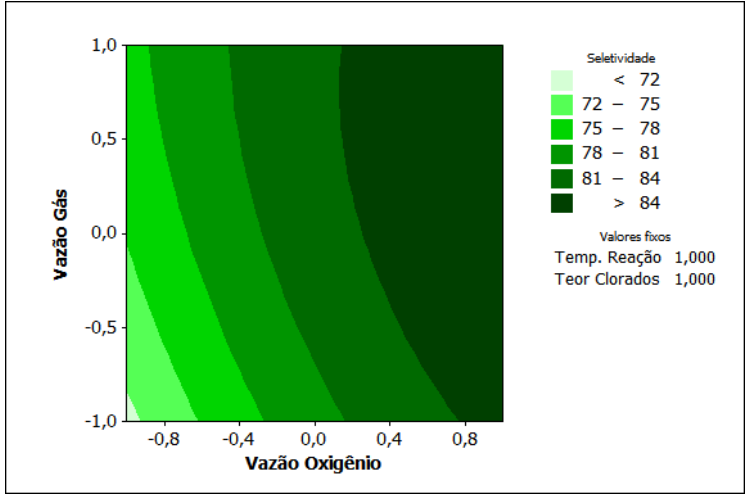

Situação 4: Temperatura máxima do processo ; Clorados máximo no processo; $S=82.70+5.57 \cdot x_{1}+1,73 \cdot x_{2}-1.18 \cdot x_{1} \cdot x_{2}-1.94 \cdot x_{1}^{2}-1.03 \cdot x_{2}^{2}$

Figura 61 - $1^{\text {a }}$ Análise Exploratória do modelo da equação 71 
Os modelos desdobrados representados pelas situações 1 a 4 da Figura 61 mostram claramente que a vazão de gás de reciclo possui pouca influência no resultado da seletividade da reação. A seletividade, por sua vez, tende a atingir valores máximos quando a temperatura da reação (ou temperatura do sitio ativo do catalisador) for a menor possível. Apesar de se mostrar pouco influente nos resultados da seletividade de reação, do ponto de vista conceitual, quanto maior for a vazão de gás de reciclo, que passa pelo leito de catalisador, maior tende a ser a seletividade da reação, pois o tempo de residência dos reagentes dentro dos poros do leito catalítico tende a ser o menor possível, aumentando-se a taxa de transferência de calor.

O efeito da temperatura é relevante para o comportamento das cinéticas das três reações envolvidas no processo e que foram inicialmente apresentadas na Figura 7. Aumentos da temperatura da reação trazem como consequências ao processo: Aumento da taxa de reação da principal, cuja cinética é representada por $\mathrm{K}_{1}$; aumento ainda mais rápido da taxa de reação da reação secundária, cuja cinética é representada por $\mathrm{K}_{2}$, causando decréscimo da seletividade e aumento ainda mais rápido da taxa de reação de combustão do óxido de etileno, cuja cinética é representada por $\mathrm{K}_{3}$. Consequentemente, um aumento da temperatura sempre ocasiona uma redução na seletividade da reação e o tempo de vida do catalisador.

Considerando que a temperatura da reação foi identificada como o fator de maior contribuição para o comportamento da seletividade do processo, nota-se que os modelos desdobrados para as situações 1 e 3 (que preveem a operação da unidade com baixas temperaturas) nos levam ao melhor resultado possível de seletividade, atingindo valores bem mais elevados que os modelos desdobrados 2 e 4 , que preveem a operação em elevadas temperaturas. Conforme apresentado na revisão bibliográfica deste trabalho, o mecanismo mais importante de envelhecimento do catalisador, a sinterização da prata, é acelerado pela temperatura (quanto maior a temperatura, mais rápida é a taxa de envelhecimento). Portanto, para 
minimizar o processo de sinterização da prata e maximizar a vida e o desempenho do catalisador, é sempre recomendável operar o catalisador na temperatura mais baixa possível necessária, para alcançar as taxas de produção desejadas.

Ainda analisando as situações 1 e 3 , é possível visualizar que a seletividade da reação tende a ser a máxima possível, quando a vazão de oxigênio caminha na direção do menor valor possível, mostrando a clara influência da vazão de oxigênio sobre os resultados do processo.

A situação prevista pelo modelo desdobrado 3 é aquela que nos leva a maior faixa possível de combinações entre as variáveis vazão de gás de reciclo e vazão de oxigênio, para obtenção de máxima seletividade da reação. Fica evidente também que os melhores resultados são obtidos quando trabalhamos com teores elevados de clorados na composição do gás de reciclo.

Ou seja, neste primeiro cenário analisado, podemos concluir que, do ponto de vista operacional, não é interessante o gerenciamento do processo através de manipulações na variável vazão de gás de reciclo e vazão de oxigênio, pois, na prática, é como se estivéssemos alterando apenas a variável vazão de oxigênio, o que se assemelha ao modelo cultural vigente atualmente no conceito de gestão do processo (atuação sobre uma única variável isoladamente). 
Tabela $29-2^{2}$ Análise exploratória do modelo e seus objetivos

\begin{tabular}{|c|c|}
\hline Objetivo & ição \\
\hline $\begin{array}{l}\text { Estudar os efeitos } \\
\text { das variáveis - } \\
\text { vazão de oxigênio } \\
\text { e temperatura da } \\
\text { reação - sobre o } \\
\text { resultado da } \\
\text { seletividade da } \\
\text { reação, mantendo- } \\
\text { se as demais } \\
\text { variáveis } \\
\text { selecionadas no } \\
\text { modelo empírico } \\
\text { (vazão de gás de } \\
\text { reciclo e teor de } \\
\text { clorados) em } \\
\text { faixas de operação } \\
\text { pré-fixadas. }\end{array}$ & $\begin{array}{l}\text { Realização de quatro análises diferentes que resultam na } \\
\text { obtenção de } 4 \text { novos modelos, os chamados modelos } \\
\text { desdobrados: } \\
\text { Situação 5: } \\
\text { - Vazão de gás de reciclo na faixa mínima de } \\
\text { operação; } \\
\text { - Teor de clorados na faixa mínima de operação } \\
\text { Situação } 6 \text { : } \\
\text { - Vazão de gás de reciclo na faixa máxima de } \\
\text { operação; } \\
\text { - Teor de clorados na faixa mínima de operação } \\
\text { Situação } 7 \text { : } \\
\text { - Vazão de gás de reciclo na faixa mínima de } \\
\text { operação; } \\
\text { - Teor de clorados na faixa máxima de operação } \\
\text { Situação } 8 \text { : } \\
\text { - Vazão de gás de reciclo na faixa máxima de } \\
\text { operação; } \\
\text { - Teor de clorados na faixa máxima de operação }\end{array}$ \\
\hline
\end{tabular}

A faixa mínima e a faixa máxima de operação das variáveis descritas na Tabela anterior foram codificadas, respectivamente com os níveis -1 e +1 , como mostrado na Tabela 30. 
Tabela 30 - Níveis das variáveis de processo em unidades codificadas e valores reais de processo ( $2^{\underline{a}}$ análise exploratória do modelo)

\begin{tabular}{|c|c|c|c|c|c|c|}
\hline \multirow{3}{*}{$\begin{array}{c}\text { Situação } \\
5\end{array}$} & \multirow{2}{*}{\multicolumn{2}{|c|}{ Variáveis Independentes }} & \multicolumn{4}{|c|}{ Variáveis Fixas } \\
\hline & & & \multirow{2}{*}{$\frac{\text { 1a Variável }}{x_{2}}$} & \multirow{2}{*}{$\begin{array}{c}\begin{array}{c}\text { Valor codificado } \\
\text { Valor real }\end{array} \\
-1 ; 179\end{array}$} & \multirow{2}{*}{$\frac{\text { 2a Variável }}{\mathrm{x}_{4}}$} & \multirow{2}{*}{$\begin{array}{c}\text { Valor codificado } \\
\text { Valor real } \\
-1 ; 0,04\end{array}$} \\
\hline & $x_{1}$ & $x_{3}$ & & & & \\
\hline 6 & $x_{1}$ & $x_{3}$ & $x_{2}$ & $1 ; 265$ & $x_{4}$ & $-1 ; 0,04$ \\
\hline 7 & $x_{1}$ & $x_{3}$ & $x_{2}$ & $-1 ; 179$ & $x_{4}$ & $1 ; 0,09$ \\
\hline 8 & $x_{1}$ & $x_{3}$ & $x_{2}$ & $1 ; 265$ & $\mathrm{x}_{4}$ & $1 ; 0,09$ \\
\hline
\end{tabular}

Onde:

$x_{1}=\quad$ vazão de oxigênio

$\mathrm{x}_{2}=\quad$ vazão de gás de reciclo

$x_{3}=$ temperatura da reação

$\mathrm{x}_{4}=\quad$ teor de clorados 
Modelo Geral: $\mathrm{S}=86.90-1.89 \cdot \mathrm{x}_{1}+0.07 \cdot \mathrm{x}_{2}-1.73 \cdot \mathrm{x}_{3}+0.44 \cdot \mathrm{x}_{4}-1.18 \cdot \mathrm{x}_{1} \cdot \mathrm{x}_{2}+7.02 \cdot \mathrm{x}_{1} \cdot \mathrm{x}_{3}+0.44 \cdot \mathrm{x}_{1} \cdot \mathrm{x}_{4}+1.82 \cdot \mathrm{x}_{2} \cdot \mathrm{x}_{3}-0.16 \cdot \mathrm{x}_{2} \cdot \mathrm{x}_{4}-$ $0.57 \cdot \mathrm{x}_{3} \cdot \mathrm{x}_{4}-1.94 \cdot \mathrm{x}_{1}^{2}-1.03 \cdot \mathrm{x}_{2}^{2}-2.05 \cdot \mathrm{x}_{3}^{2}-0.29 \cdot \mathrm{x}_{4}^{2}$

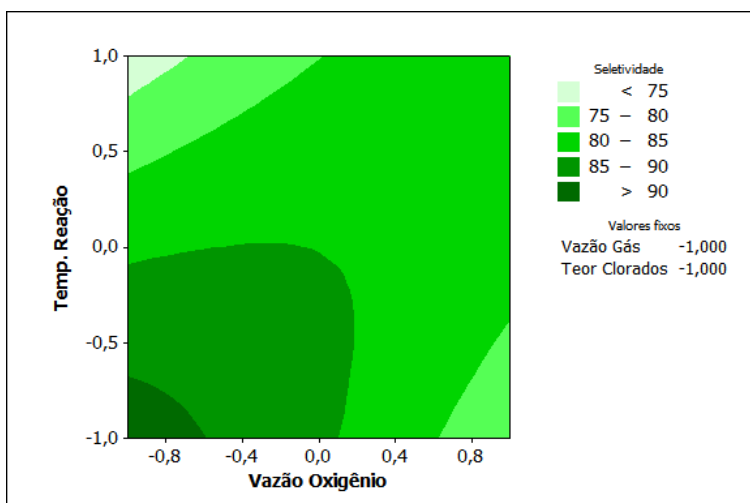

Situação 5: Vazão gás reciclo mínima do processo ; Clorados mínimo no processo ; $S=84.91-1.15 \cdot x_{1}-2.98 \cdot x_{3}+7.02 \cdot x_{1} \cdot x_{3}-1.94 \cdot x_{1}^{2}-2.05 \cdot x_{3}^{2}$

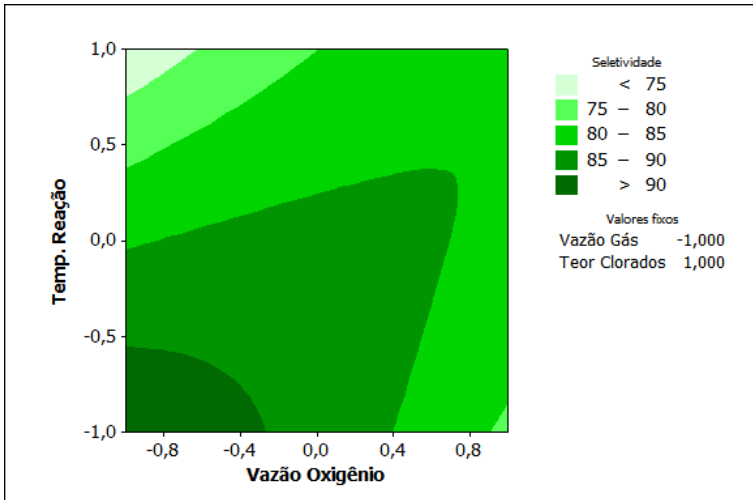

Situação 7: Vazão de gás de reciclo mínimo no processo ;Clorados máximo no processo

$S=86.11-0.27 \cdot x_{1}-4.12 \cdot x_{3}+7.02 \cdot x_{1} \cdot x_{3}-1.94 \cdot x_{1}^{2}-2.05 \cdot x_{3}^{2}$

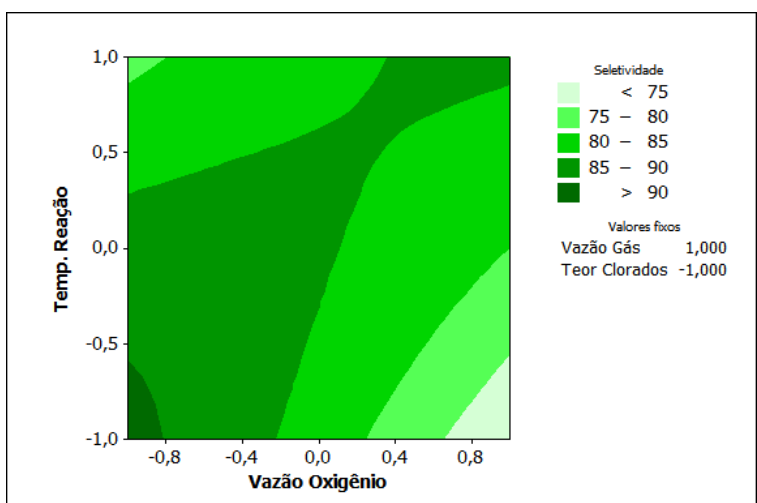

Situação 6: Vazão de gás de reciclo máximo no processo ; Clorados mínimo no processo ; $S=85.37-3.51 \cdot x_{1}+0,66 \cdot x_{3}+7.02 \cdot x_{1} \cdot x_{3}-1.94 \cdot x_{1}^{2}-2.05 \cdot x_{3}^{2}$

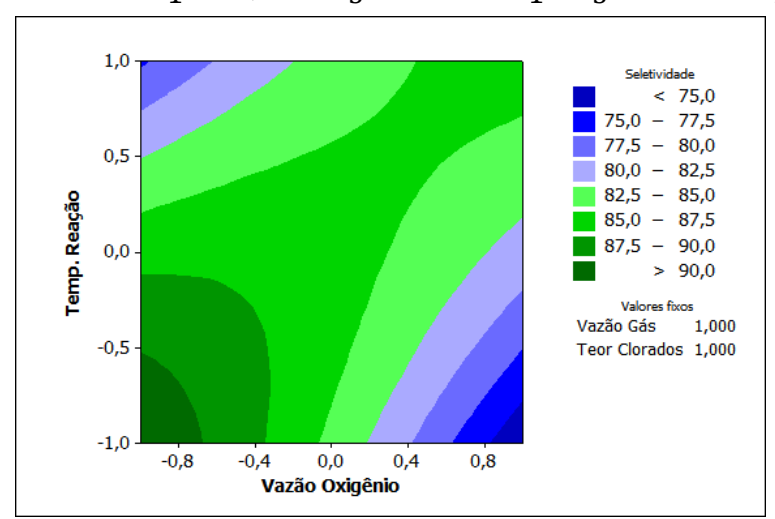

Situação 8: Vazão gás de reciclo máximo no processo ; Clorados máximo no processo ; $S=85.93-2.63 \cdot x_{1}-0.48 \cdot x_{3}+7.02 \cdot x_{1} \cdot x_{3}-1.94 \cdot x_{1}^{2}-2.05 \cdot x_{3}^{2}$

Figura 62 - 2ª Análise Exploratória do modelo da equação 71 
Os modelos desdobrados representados pelas situações 5 a 8 da Figura 62 envolvem as análises das variações do comportamento da seletividade da reação perante as duas variáveis de maior influência para o modelo proposto (temperatura da reação e vazão de oxigênio), fixando-se as demais variáveis em condições pré-definidas.

Esse cenário analisado é o único que resulta em quatro modelos desdobrados que proporcionam a obtenção de resultados de seletividades acima de 90\%, reforçando a necessidade de uma gestão eficiente sobre as duas variáveis mais críticas desse processo.

Também é interessante verificar que os quatro modelos desdobrados são os que apresentam as superfícies de resposta mais assímetricas possíveis, mostrando que pequenas alterações na temperatura da reação ou na vazão de oxigênio causam grandes impactos no resultado do processo.

$\mathrm{Na}$ situação em que as duas variáveis mais críticas são controladas em valores mais baixos possíveis, em associação a um elevado teor de clorados, temos a maior faixa possível de obtenção de seletividades acima de $90 \%$, o que representa uma condição interessante a se explorar do ponto de vista de gestão do processo, pois permite aos operadores uma ampla faixa de operação, que garante seletividades em valores elevados. É uma situação particularmente interessante, quando, por qualquer que seja a razão, a unidade apresente instabilidades operacionais que dificultem seu controle em uma específica condição de processo. 
Tabela $31-3^{\text {a }}$ Análise exploratória do modelo e seus objetivos

\begin{tabular}{|c|c|}
\hline Objetivo & Descrição \\
\hline $\begin{array}{l}\text { Estudar os efeitos das } \\
\text { variáveis - vazão de } \\
\text { oxigênio e teor de } \\
\text { clorados - sobre o } \\
\text { resultado da seletividade } \\
\text { da reação, mantendo-se } \\
\text { as demais variáveis } \\
\text { selecionadas no modelo } \\
\text { empírico (vazão de gás } \\
\text { de reciclo e temperatura } \\
\text { da reação) em faixas de } \\
\text { operação pré-fixadas. }\end{array}$ & $\begin{array}{l}\text { Realização de quatro análises diferentes que } \\
\text { resultam na obtenção de } 4 \text { novos modelos, os } \\
\text { chamados modelos desdobrados: } \\
\text { Situação 9: } \\
\text { - Vazão de gás de reciclo na faixa mínima de } \\
\text { operação; } \\
\text { - Temperatura da reação na faixa mínima de } \\
\text { operação } \\
\text { Situação 10: } \\
\text { - Vazão de gás de reciclo na faixa máxima } \\
\text { de operação; } \\
\text { - Temperatura da reação na faixa mínima de } \\
\text { operação } \\
\text { Situação 11: } \\
\text { - Vazão de gás de reciclo na faixa mínima de } \\
\text { operação; } \\
\text { - Temperatura da reação na faixa máxima de } \\
\text { operação } \\
\text { Situação 12: } \\
\text { - Vazão de gás de reciclo na faixa máxima } \\
\text { de operação; } \\
\text { operação }\end{array}$ \\
\hline
\end{tabular}

A faixa mínima e a faixa máxima de operação das variáveis descritas na Tabela anterior foram codificadas, respectivamente com os níveis -1 e +1 , como mostrado na Tabela 32. 
Tabela 32 - Níveis das variáveis de processo em unidades codificadas e valores reais de processo ( $3^{\underline{a}}$ análise exploratória do modelo)

\begin{tabular}{|c|c|c|c|c|c|c|}
\hline \multirow{3}{*}{$\begin{array}{c}\text { Situação } \\
9\end{array}$} & \multirow{2}{*}{\multicolumn{2}{|c|}{ Variáveis Independentes }} & \multicolumn{4}{|c|}{ Variáveis Fixas } \\
\hline & & & \multirow{2}{*}{ 1a Variável } & \multirow{2}{*}{$\begin{array}{c}\text { Valor codificado; } \\
\text { Valor real } \\
-1 ; 179\end{array}$} & \multirow{2}{*}{ 2a Variável } & \multirow{2}{*}{$\begin{array}{c}\text { Valor codificado; } \\
\text { Valor real } \\
-1 ; 218,6\end{array}$} \\
\hline & $\mathrm{x}_{1}$ & $\mathrm{x}_{4}$ & & & & \\
\hline 10 & $\mathrm{x}_{1}$ & $\mathrm{x}_{4}$ & $x_{2}$ & $1 ; 265$ & $x_{3}$ & $-1 ; 218,6$ \\
\hline 11 & $\mathrm{x}_{1}$ & $\mathrm{x}_{4}$ & $x_{2}$ & $-1 ; 179$ & $x_{3}$ & $1 ; 234,3$ \\
\hline 12 & $\mathrm{x}_{1}$ & $x_{4}$ & $x_{2}$ & $1 ; 265$ & $x_{3}$ & $1 ; 234,3$ \\
\hline
\end{tabular}

Onde:
$x_{1}=$ vazão de oxigênio
$x_{2}=$ vazão de gás de reciclo
$\mathrm{x}_{3}=$ temperatura da reação
$x_{4}=$ teor de clorados 
Modelo Geral: $\mathrm{S}=86.90-1.89 \cdot \mathrm{x}_{1}+0.07 \cdot \mathrm{x}_{2}-1.73 \cdot \mathrm{x}_{3}+0.44 \cdot \mathrm{x}_{4}-1.18 \cdot \mathrm{x}_{1} \cdot \mathrm{x}_{2}+7.02 \cdot \mathrm{x}_{1} \cdot \mathrm{x}_{3}+0.44 \cdot \mathrm{x}_{1} \cdot \mathrm{x}_{4}+1.82 \cdot \mathrm{x}_{2} \cdot \mathrm{x}_{3}-0.16 \cdot \mathrm{x}_{2} \cdot \mathrm{x}_{4}-$ $0.57 \cdot \mathrm{x}_{3} \cdot \mathrm{x}_{4}-1.94 \cdot \mathrm{x}_{1}^{2}-1.03 \cdot \mathrm{x}_{2}^{2}-2.05 \cdot \mathrm{x}_{3}^{2}-0.29 \cdot \mathrm{x}_{4}^{2}$

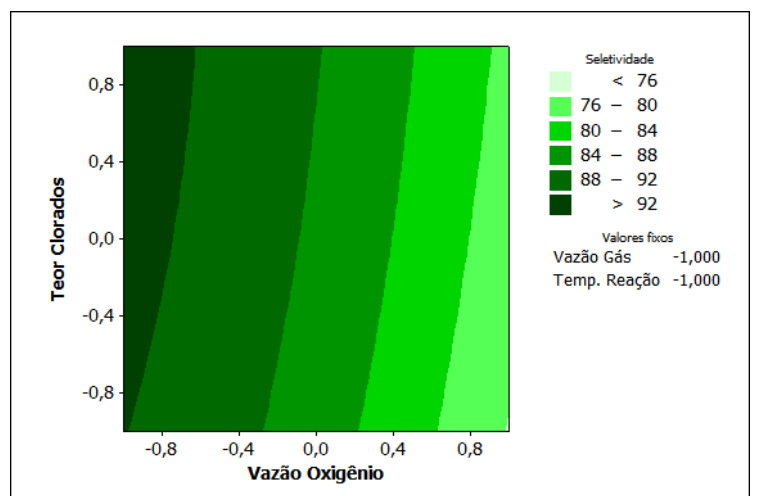

Situação 9: Vazão gás reciclo mínima do processo; Temperatura mínima do processo $S=87.44-7,73 \cdot x_{1}-1.48 \cdot x_{4}+0.44 \cdot x_{1} \cdot x_{4}-1.94 \cdot x_{1}^{2}-0,29 \cdot x_{4}^{2}$

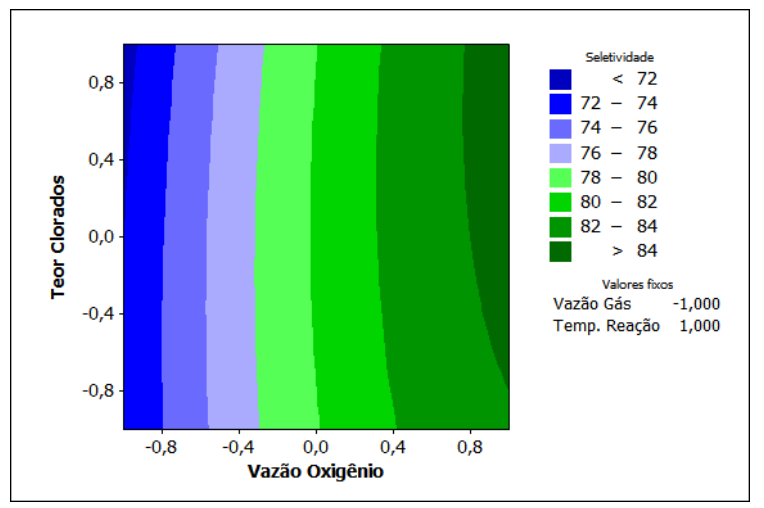

Situação 11: Vazão gás reciclo mínima do processo; Temperatura máxima do processo $S=80.20+6.31 \cdot x_{1}-0.03 \cdot x_{4}+0.44 \cdot x_{1} \cdot x_{4}-1.94 \cdot x_{1}^{2}-0,29 \cdot x_{4}^{2}$

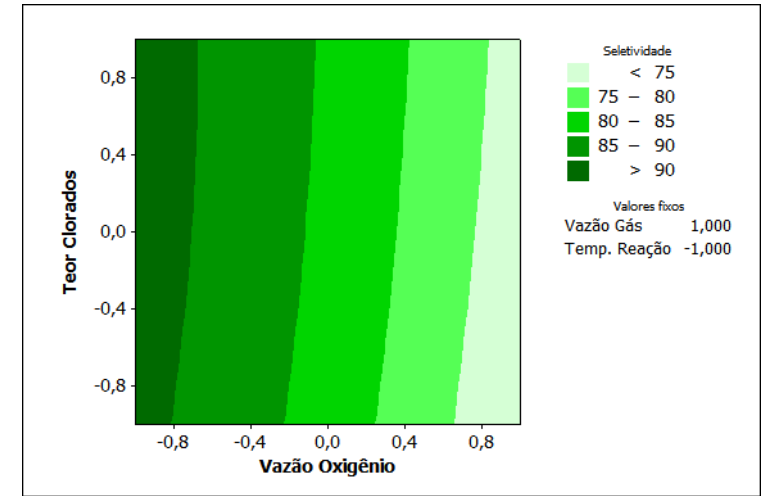

Situação 10: Vazão gás reciclo máxima do processo; Temperatura mínima do processo $S=83,80-10,09 \cdot x_{1}+0,85 \cdot x_{4}+0.44 \cdot x_{1} \cdot x_{4}-1.94 \cdot x_{1}^{2}-0,29 \cdot x_{4}^{2}$

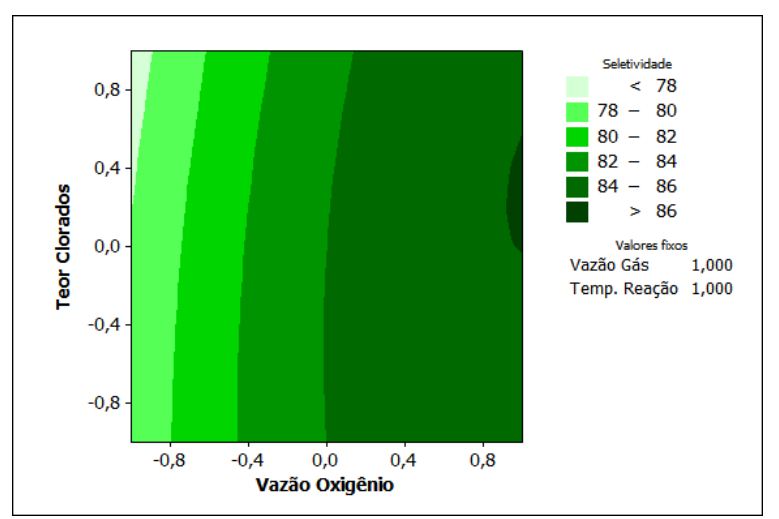

Situação 12: Vazão gás reciclo máxima do processo; Temperatura máxima do processo $S=83.98+3.95 \cdot x_{1}-0.29 \cdot x_{4}+0.44 \cdot x_{1} \cdot x_{4}-1.94 \cdot x_{1}^{2}-0,29 \cdot x_{4}^{2}$

Figura $63-3^{\text {a }}$ Análise Exploratória do modelo da equação 71 
Os modelos desdobrados representados pelas situações 9 a 12 da Figura 63 envolvem as análises das variações do comportamento da seletividade da reação em função do gerenciamento da variável teor de clorados e da variável vazão de oxigênio, quando mantemos as demais variáveis fixas em condições pré-definidas.

A situação 9 é de especial interesse, pois demonstra a possibilidade de ajustar o processo em condições que resultem em seletividades superiores a $92 \%$. Condições similares a essa serão visualizadas em mais duas situações, as quais serão analisadas mais adiante nesse trabalho.

Por outro lado, as situações 11 e 12 devem ser evitadas, uma vez que levam a resultados bastante baixos de seletividade da reação. Essas duas situações, em especial estão relacionadas a altas temperaturas de reação, e resultam em conclusões similares às situações 2 e 4 da Figura 61, cuja análise foi realizada anteriormente.

A situação 9 também mostra que a opção por gerenciar o teor de clorados e a vazão de oxigênio, mantendo-se principalmente a temperatura da reação em valores baixos, apresenta pouca flexibilidade do ponto de vista operacional, em relação à gestão da vazão de oxigênio, que deve ser gerenciada, obrigatoriamente em uma pequena faixa de valores. Por outro lado, não é uma tarefa complicada, uma vez que a vazão é controlada por válvulas automatizadas e respondem de forma adequada a variações no processo. Uma vez que essa situação permite que a variável teor de clorados (cujo controle é mais complicado) em uma faixa bastante razoável, é conveniente afirmar que essa situação é bastante interessante do ponto de vista da gestão do processo.

Outro ponto importante e que deve ser salientado na análise das situações mostradas na Figura 63 está no fato de que são analisadas faixas de operação para a variável teor de clorados, o que não necessariamente leva ao ponto ótimo de operação. Isso porque, as teorias relacionadas à atuação dos clorados sobre a adsorção do oxigênio no catalisador de prata prevê que existe um único ponto ótimo de operação que combina as variáveis estudadas nesse 
processo e não uma faixa de operação do teor de clorados. Em resumo, a faixa de operação mostrada, em especial na situação 9, precisa ser continuamente monitorada pelos operadores de processo, uma vez que pequenas instabilidades na vazão de fornecimento de matéria prima (ou pequenas alterações na qualidade das mesmas), ou até mesmo em um sistema de medição e vazão de gás de reciclo, ou temperatura são suficientes para prever um ajuste na concentração de clorados na composição do gás de reciclo.

Tabela $33-4^{a}$ Análise exploratória do modelo e seus objetivos

\begin{tabular}{|c|c|}
\hline Objetivo & Descrição \\
\hline $\begin{array}{l}\text { Estudar os efeitos das } \\
\text { variáveis - vazão de gás } \\
\text { de reciclo e temperatura } \\
\text { da reação - sobre o } \\
\text { resultado da seletividade } \\
\text { da reação, mantendo-se } \\
\text { as demais variáveis } \\
\text { selecionadas no modelo } \\
\text { empírico (vazão de } \\
\text { oxigênio e teor de } \\
\text { clorados) em faixas de } \\
\text { operação pré-fixadas. }\end{array}$ & $\begin{array}{l}\text { Realização de quatro análises diferentes que } \\
\text { resultam na obtenção de } 4 \text { novos modelos, os } \\
\text { chamados modelos desdobrados: } \\
\text { Situação 13: } \\
\text { - Vazão de oxigênio na faixa mínima de } \\
\text { operação; } \\
\text { - Teor de clorados na faixa mínima de } \\
\text { operação } \\
\text { Situação 14: } \\
\text { - Vazão de oxigênio na faixa máxima de } \\
\text { operação; } \\
\text { - Teor de clorados na faixa mínima de } \\
\text { operação } \\
\text { Situação 15: } \\
\text { - Vazão de oxigênio na faixa mínima de } \\
\text { operação; } \\
\text { - Teor de clorados na faixa máxima de } \\
\text { operação } \\
\text { Situação 16: } \\
\text { - Vazão de oxigênio na faixa máxima de } \\
\text { operação; } \\
\text { - Teor de clorados na faixa máxima de } \\
\text { operação }\end{array}$ \\
\hline
\end{tabular}


A faixa mínima e a faixa máxima de operação das variáveis descritas na Tabela anterior foram codificadas respectivamente com os níveis -1 e +1 como mostrado na Tabela 34.

Tabela 34 - Níveis das variáveis de processo em unidades codificadas e valores reais de processo (4를 análise exploratória do modelo)

\begin{tabular}{|c|c|c|c|c|c|c|}
\hline \multirow{3}{*}{$\begin{array}{c}\text { Situação } \\
13\end{array}$} & \multirow{2}{*}{\multicolumn{2}{|c|}{ Variáveis Independentes }} & \multicolumn{4}{|c|}{ Variáveis Fixas } \\
\hline & & & \multirow{2}{*}{$\frac{\text { 1a Variável }}{x_{1}}$} & \multirow{2}{*}{$\begin{array}{c}\text { Valor codificado; } \\
\text { Valor real } \\
-1 ; 3490\end{array}$} & \multirow{2}{*}{$\frac{\text { 2a Variável }}{\mathrm{x}_{4}}$} & \multirow{2}{*}{$\begin{array}{c}\text { Valor codificado; } \\
\text { Valor real } \\
-1 ; 0,04\end{array}$} \\
\hline & $x_{2}$ & $x_{3}$ & & & & \\
\hline 14 & $x_{2}$ & $x_{3}$ & $x_{1}$ & $1 ; 8575$ & $x_{4}$ & $-1 ; 0,04$ \\
\hline 15 & $x_{2}$ & $x_{3}$ & $\mathrm{x}_{1}$ & $-1 ; 3490$ & $x_{4}$ & $1 ; 0,09$ \\
\hline 16 & $x_{2}$ & $x_{3}$ & $x_{1}$ & $1 ; 8575$ & $x_{4}$ & $1 ; 0,09$ \\
\hline
\end{tabular}

Onde:

$x_{1}=$ vazão de oxigênio

$x_{2}=\quad$ vazão de gás de reciclo

$x_{3}=$ temperatura da reação

$\mathrm{x}_{4}=\quad$ teor de clorados 
Modelo Geral: $\mathrm{S}=86.90-1.89 \cdot \mathrm{x}_{1}+0.07 \cdot \mathrm{x}_{2}-1.73 \cdot \mathrm{x}_{3}+0.44 \cdot \mathrm{x}_{4}-1.18 \cdot \mathrm{x}_{1} \cdot \mathrm{x}_{2}+7.02 \cdot \mathrm{x}_{1} \cdot \mathrm{x}_{3}+0.44 \cdot \mathrm{x}_{1} \cdot \mathrm{x}_{4}+1.82 \cdot \mathrm{x}_{2} \cdot \mathrm{x}_{3}-0.16 \cdot \mathrm{x}_{2} \cdot \mathrm{x}_{4}-$ $0.57 \cdot \mathrm{x}_{3} \cdot \mathrm{x}_{4}-1.94 \cdot \mathrm{x}_{1}^{2}-1.03 \cdot \mathrm{x}_{2}^{2}-2.05 \cdot \mathrm{x}_{3}^{2}-0.29 \cdot \mathrm{x}_{4}^{2}$

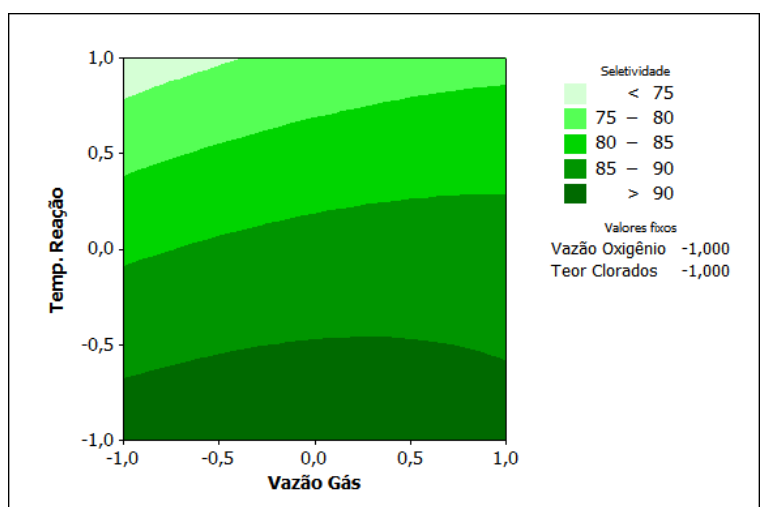

Situação 13: Vazão de oxigênio mínima do processo; Clorados mínimo do processo $S=86.56+1.42 \cdot x_{2}-8,18 \cdot x_{3}+1.82 \cdot x_{2} \cdot x_{3}-1.03 \cdot x_{2}^{2}-2.05 \cdot x_{3}^{2}$

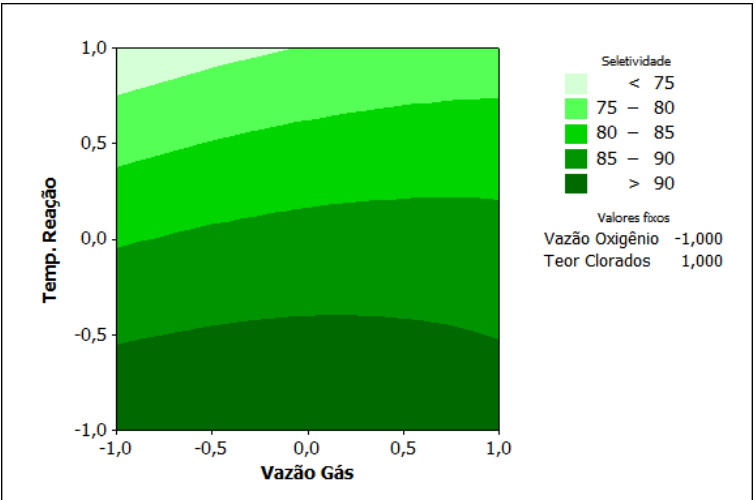

Situação 15: Vazão de oxigênio mínimo do processo; Clorados máximo do processo $S=85,56+1,09 \cdot x_{2}-9,32 \cdot x_{3}+1.82 \cdot x_{2} \cdot x_{3}-1.03 \cdot x_{2}^{2}-2.05 \cdot x_{3}^{2}$

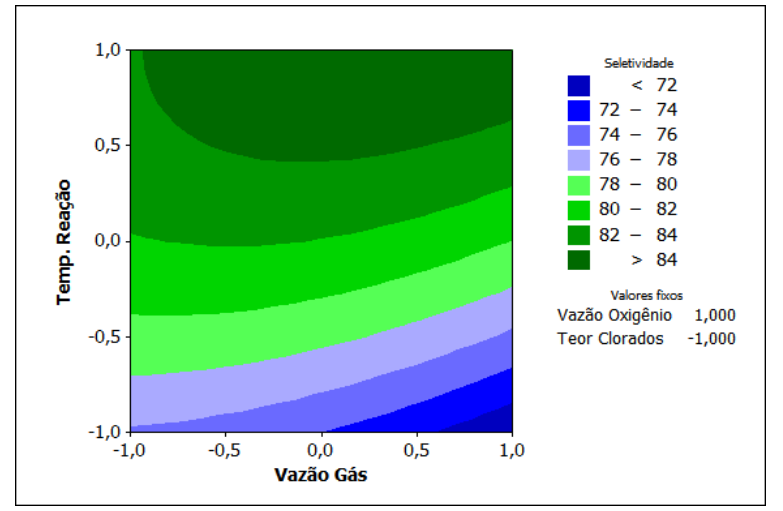

Situação 14: Vazão de oxigênio máximo do processo; Clorados mínimo do processo $S=81,90-0,95 \cdot x_{2}+5,86 \cdot x_{3}+1.82 \cdot x_{2} \cdot x_{3}-1.03 \cdot x_{2}^{2}-2.05 \cdot x_{3}^{2}$

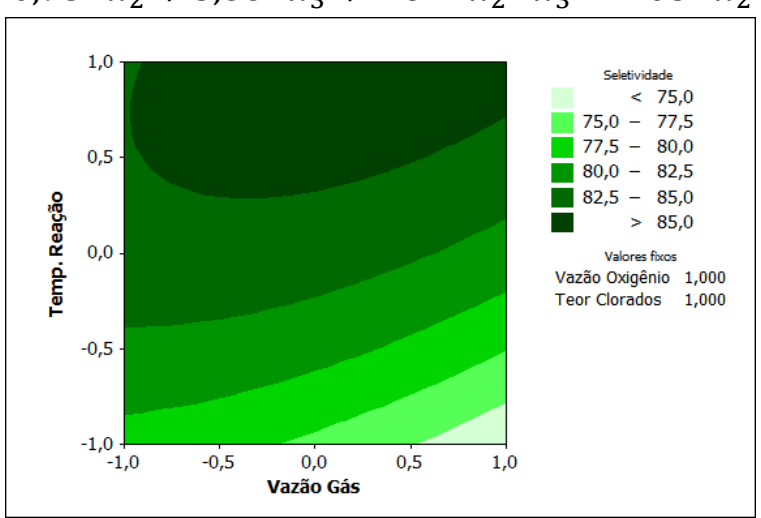

Situação 16: Vazão de oxigênio máximo do processo; Clorados máximo do processo $S=83.66-1.27 \cdot x_{2}+4.76 \cdot x_{3}+1.82 \cdot x_{2} \cdot x_{3}-1.03 \cdot x_{2}^{2}-2.05 \cdot x_{3}^{2}$

Figura 64 - 4ํㅗ Análise Exploratória do modelo da equação 71 
Os modelos desdobrados representados pelas situações 13 a 16 da Figura 64 representam a gestão do processo sobre a variável temperatura da reação e vazão de gás de reciclo, mantendo-se as demais variáveis dentro de valores pré-definidos.

Os resultados observados mostram duas situações (as de número 13 e 15), onde é possível se alcançar seletividades da ordem de $90 \%$, sendo que nas demais situações os resultados alcançados são bem inferiores (nesses dois últimos casos, a condição de operação com elevada vazão de oxigênio explica o baixo desempenho, reforçando os conceitos já discutidos anteriormente). Para as situações 13 e 15, evidencia-se uma pequena tendência de melhores resultados da seletividade para condições em que se propõe uma operação com vazões mais elevadas de gás de reciclo.

O aumento da vazão de gás de reciclo circulando pelo reator favorece o melhor desempenho do catalisador e o aumento da seletividade, afetando as concentrações dos reagentes na composição do gás de reciclo, em especial a de oxigênio. Nessas condições, haverá um menor tempo de residência no processo, resultando em uma menor conversão de oxigênio no sentido de formação dos produtos da reação secundária, aumentando-se a concentração de oxigênio na corrente de saída do reator, contribuindo para o aumento da seletividade.

Sob a óptica operacional, as situações propostas na Figura 64 não são de grande interesse visto que não levam aos melhores resultados possíveis, além do impacto nos resultados oriundos de variações na vazão de gás de reciclo ser bastante pequeno. Além disso, a vazão de gás de reciclo é parâmetro de extrema importância relacionada à segurança do processo produtivo (diminuir a vazão de gás de reciclo resulta no efeito inverso ao destacado no parágrafo anterior), contribuindo para aumento da temperatura do meio reacional, podendo, em uma situação limite, ocasionar um descontrole da reação. Por outro lado, o aumento da vazão deve obrigatoriamente ser realizado de forma gradual e cuidadosa, pois resulta no aumento da concentração do oxigênio na saída do reator, valor este que 
está diretamente relacionado ao limite de flamabilidade da corrente de gás de reciclo.

Tabela $35-5^{\underline{a}}$ Análise exploratória do modelo e seus objetivos

\begin{tabular}{|c|c|}
\hline Objetivo & Descrição \\
\hline $\begin{array}{l}\text { Estudar os efeitos das } \\
\text { variáveis - vazão de gás } \\
\text { de reciclo e teor de } \\
\text { clorados - sobre o } \\
\text { resultado da seletividade } \\
\text { da reação, mantendo-se } \\
\text { as demais variáveis } \\
\text { selecionadas no modelo } \\
\text { empírico (vazão de } \\
\text { oxigênio e temperatura } \\
\text { da reação) em faixas de } \\
\text { operação pré-fixadas. }\end{array}$ & $\begin{array}{l}\text { Realização de quatro análises diferentes que } \\
\text { resultam na obtenção de } 4 \text { novos modelos, os } \\
\text { chamados modelos desdobrados: } \\
\text { Situação 17: } \\
\text { - Vazão de oxigênio na faixa mínima de } \\
\text { operação; } \\
\text { - Temperatura da reação na faixa mínima de } \\
\text { operação } \\
\text { Situação 18: } \\
\text { - Vazão de oxigênio na faixa máxima de } \\
\text { operação; } \\
\text { - Temperatura da reação na faixa mínima de } \\
\text { operação } \\
\text { Situação 19: } \\
\text { - Vazão de oxigênio na faixa mínima de } \\
\text { operação; } \\
\text { - Temperatura da reação na faixa máxima de } \\
\text { operação } \\
\text { Situação } 20 \text { : } \\
\text { - Vazão de oxigênio na faixa máxima de } \\
\text { operação; } \\
\text { operação }\end{array}$ \\
\hline
\end{tabular}

A faixa mínima e a faixa máxima de operação das variáveis descritas na Tabela anterior foram codificadas, respectivamente com os níveis -1 e +1 , como mostrado na Tabela 36. 
Tabela 36 - Níveis das variáveis de processo em unidades codificadas e valores reais de processo ( $5^{\underline{a}}$ análise exploratória do modelo)

\begin{tabular}{|c|c|c|c|c|c|c|}
\hline \multirow{3}{*}{$\begin{array}{c}\text { Situação } \\
17\end{array}$} & \multirow{2}{*}{\multicolumn{2}{|c|}{ Variáveis Independentes }} & \multicolumn{4}{|c|}{ Variáveis Fixas } \\
\hline & & & \multirow{2}{*}{$\frac{\text { 1a Variável }}{x_{1}}$} & \multirow{2}{*}{$\begin{array}{c}\text { Valor codificado; } \\
\text { Valor real } \\
-1 ; 3490\end{array}$} & \multirow{2}{*}{$\frac{\text { 2a Variável }}{x_{3}}$} & \multirow{2}{*}{$\begin{array}{c}\begin{array}{c}\text { Valor codificado; } \\
\text { Valor real }\end{array} \\
-1 ; 218,6\end{array}$} \\
\hline & $x_{2}$ & $x_{4}$ & & & & \\
\hline 18 & $x_{2}$ & $\mathrm{x}_{4}$ & $x_{1}$ & $1 ; 8575$ & $x_{3}$ & $-1 ; 218,6$ \\
\hline 19 & $x_{2}$ & $x_{4}$ & $x_{1}$ & $-1 ; 3490$ & $x_{3}$ & $1 ; 234,3$ \\
\hline 20 & $x_{2}$ & $x_{4}$ & $x_{1}$ & $1 ; 8575$ & $x_{3}$ & $1 ; 234,3$ \\
\hline
\end{tabular}

Onde:

$x_{1}=$ vazão de oxigênio

$x_{2}=$ vazão de gás de reciclo

$x_{3}=$ temperatura da reação

$\mathrm{x}_{4}=\quad$ teor de clorados 
Modelo Geral: $\mathrm{S}=86.90-1.89 \cdot \mathrm{x}_{1}+0.07 \cdot \mathrm{x}_{2}-1.73 \cdot \mathrm{x}_{3}+0.44 \cdot \mathrm{x}_{4}-1.18 \cdot \mathrm{x}_{1} \cdot \mathrm{x}_{2}+7.02 \cdot \mathrm{x}_{1} \cdot \mathrm{x}_{3}+0.44 \cdot \mathrm{x}_{1} \cdot \mathrm{x}_{4}+1.82 \cdot \mathrm{x}_{2} \cdot \mathrm{x}_{3}-0.16 \cdot \mathrm{x}_{2} \cdot \mathrm{x}_{4}-$ $0.57 \cdot \mathrm{x}_{3} \cdot \mathrm{x}_{4}-1.94 \cdot \mathrm{x}_{1}^{2}-1.03 \cdot \mathrm{x}_{2}^{2}-2.05 \cdot \mathrm{x}_{3}^{2}-0.29 \cdot \mathrm{x}_{4}^{2}$
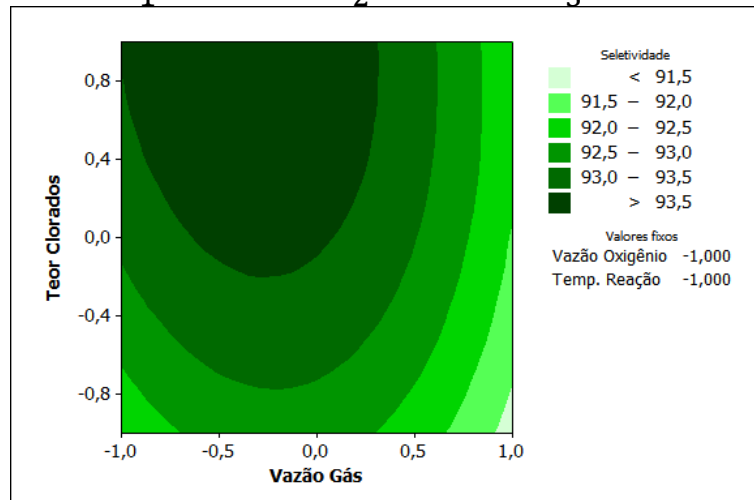

Situação 17: Vazão oxigênio mínima do processo ;Temperatura mínima do processo $S=93.55-0.57 \cdot x_{2}+0.57 \cdot x_{4}-0,16 \cdot x_{2} \cdot x_{4}-1.03 \cdot x_{2}^{2}-0,29 \cdot x_{4}^{2}$

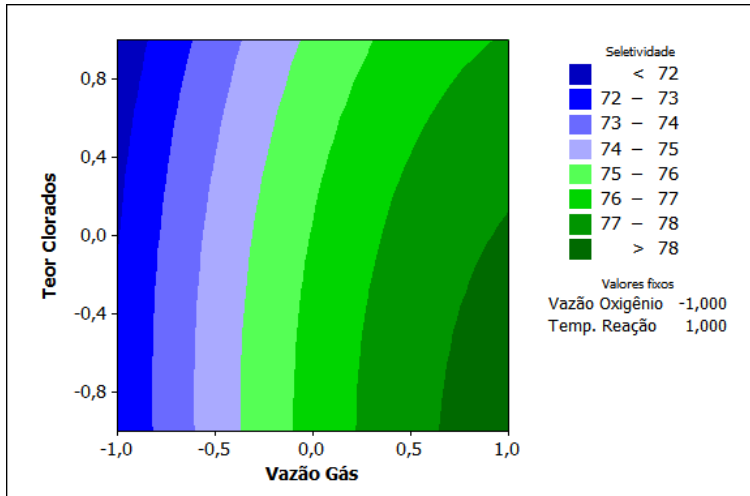

Situação 19: Vazão oxigênio mínima do processo ; Temperatura máxima do processo $S=76.06-3.07 \cdot x_{2}-0,57 \cdot x_{4}-0,16 \cdot x_{2} \cdot x_{4}-1.03 \cdot x_{2}^{2}-0,29 \cdot x_{4}^{2}$

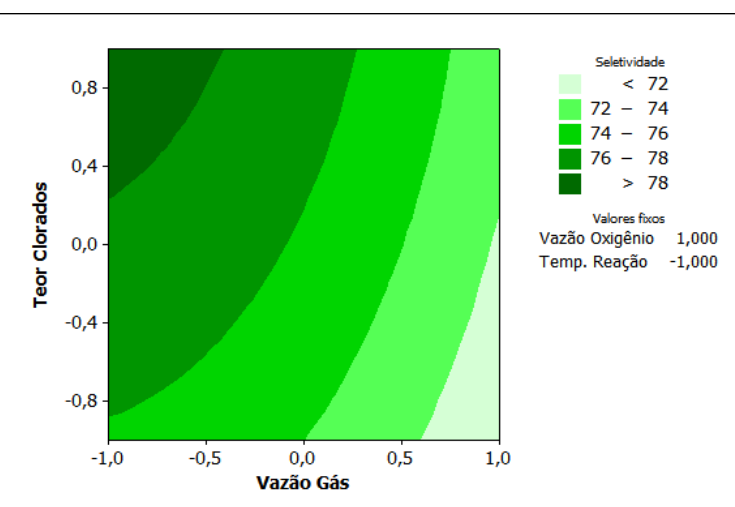

Situação 18: Vazão oxigênio máxima do processo ; Temperatura mínima do processo $S=75,73-2.93 \cdot x_{2}+1.45 \cdot x_{4}-0,16 \cdot x_{2} \cdot x_{4}-1.03 \cdot x_{2}^{2}-0,29 \cdot x_{4}^{2}$

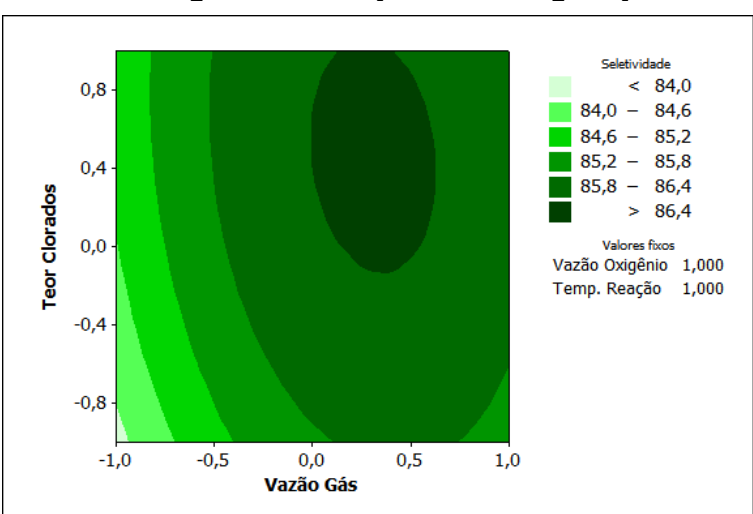

Situação 20: Vazão oxigênio máxima do processo ;Temperatura máxima do processo $S=86,31+0,71 \cdot x_{2}+0,31 \cdot x_{4}-0,16 \cdot x_{2} \cdot x_{4}-1.03 \cdot x_{2}^{2}-0,29 \cdot x_{4}^{2}$

Figura 65 - 5aㅗ Análise Exploratória do modelo da equação 71 
Os modelos desdobrados representados pelas situações 17 a 20 da Figura 65 mostram cenários onde obtemos resultados extremos em relação ao comportamento do processo: desde a condição que nos leva a menor seletividade possível (situação 18, onde temos todas as condições mais desfavoráveis de processo: vazão alta de oxigênio, temperatura alta da reação e baixo teor de clorados) até a condição de maior seletividade possível dentre todas as situações estudadas nesse trabalho (a situação 17 onde temos exatamente o oposto: baixa vazão de oxigênio, baixa temperatura da reação e elevado teor de clorados).

A situação 17 merece destaque uma vez que, é a condição mais atrativa do ponto de vista de resultado da seletividade da reação, além de ser exequível, com boa estabilidade, do ponto de vista operacional. Isso porque a obtenção desses resultados passa pela manutenção da temperatura da reação e da vazão de oxigênio nos menores valores possíveis de processo, o que é bastante viável, visto que são variáveis cujo controle é bastante robusto a ponto de se evitar grandes variações nesses valores.

O controle do teor de clorados, como já discutido anteriormente, não é simples, e nesse cenário passa a ser o parâmetro de maior atenção do ponto de vista operacional. Nota-se, na situação 17 , que existe uma faixa bastante razoável em que esse parâmetro pode variar, e mesmo assim, garantir os máximos valores da seletividade. Ou seja, a gestão do processo sob essa variável precisa ser constante, mas não necessariamente extremamente precisa.

Os cuidados a serem tomados estão relacionados a não perder o controle dessa variável, evitando a ocorrência de cenários onde seja evidenciado excesso ou falta de clorados atuando na superfície do catalisador, respectivamente conhecidos como supercloração e subcloração.

Do ponto de vista teórico, a subcloração pode resultar em uma situação que acarreta perda de seletividade, redução da produtividade em óxido de etileno, aumento das concentrações de oxigênio na entrada e saída do reator e necessidade de aumento da temperatura da reação, visando evitar excessivo 
aumento da concentração de oxigênio. Já a supercloração também leva a uma perda de seletividade, porém, com efeitos inversos aos descritos anteriormente.

Conclui-se, portanto, que a gestão contínua sobre o teor de clorados é a chave para se obter o melhor dos resultados possíveis.

Tabela 37 - 6ª Análise exploratória do modelo e seus objetivos

\begin{tabular}{|c|c|}
\hline Objetivo & Descrição \\
\hline $\begin{array}{l}\text { Estudar os efeitos das } \\
\text { variáveis - temperatura } \\
\text { da reação e teor de } \\
\text { clorados - sobre o } \\
\text { resultado da seletividade } \\
\text { da reação, mantendo-se } \\
\text { as demais variáveis } \\
\text { selecionadas no modelo } \\
\text { empírico (vazão de } \\
\text { oxigênio e vazão de gás } \\
\text { de reciclo) em faixas de } \\
\text { operação pré-fixadas. }\end{array}$ & $\begin{array}{l}\text { Realização de quatro análises diferentes que } \\
\text { resultam na obtenção de } 4 \text { novos modelos, os } \\
\text { chamados modelos desdobrados: } \\
\text { Situação 21: } \\
\text { - Vazão de oxigênio na faixa mínima de } \\
\text { operação; } \\
\text { - Vazão de gás de reciclo na faixa mínima de } \\
\text { operação } \\
\text { Situação 22: } \\
\text { - Vazão de oxigênio na faixa máxima de } \\
\text { operação; } \\
\text { - Vazão de gás de reciclo na faixa mínima de } \\
\text { operação } \\
\text { Situação } 23: \\
\text { - Vazão de oxigênio na faixa mínima de } \\
\text { operação; } \\
\text { - Vazão de gás de reciclo na faixa máxima } \\
\text { de operação } \\
\text { Situação } 24: \\
\text { - Vazão de oxigênio na faixa máxima de } \\
\text { operação; } \\
\text { - Vazão de gás de reciclo na faixa máxima }\end{array}$ \\
\hline
\end{tabular}


A faixa mínima e a faixa máxima de operação das variáveis descritas na Tabela anterior foram codificadas, respectivamente com os níveis -1 e +1 , como mostrado na Tabela 38.

Tabela 38 - Níveis das variáveis de processo em unidades codificadas e valores reais de processo ( $6^{\underline{a}}$ análise exploratória do modelo)

\begin{tabular}{|c|c|c|c|c|c|c|}
\hline \multirow{3}{*}{$\begin{array}{c}\text { Situação } \\
21\end{array}$} & \multirow{2}{*}{\multicolumn{2}{|c|}{ Variáveis Independentes }} & \multicolumn{4}{|c|}{ Variáveis Fixas } \\
\hline & & & 1a Variável & $\begin{array}{c}\text { Valor codificado; } \\
\text { Valor real }\end{array}$ & 2a Variável & $\begin{array}{l}\text { Valor codificado } \\
\text { Valor real }\end{array}$ \\
\hline & $x_{3}$ & $x_{4}$ & $x_{1}$ & $-1 ; 3490$ & $x_{2}$ & $-1 ; 179$ \\
\hline 22 & $x_{3}$ & $x_{4}$ & $x_{1}$ & $1 ; 8575$ & $x_{2}$ & $-1 ; 179$ \\
\hline 23 & $x_{3}$ & $x_{4}$ & $\mathrm{x}_{1}$ & $-1 ; 3490$ & $x_{2}$ & $1 ; 265$ \\
\hline 24 & $x_{3}$ & $x_{4}$ & $x_{1}$ & $1 ; 8575$ & $x_{2}$ & $1 ; 265$ \\
\hline
\end{tabular}

Onde:

$x_{1}=$ vazão de oxigênio

$x_{2}=$ vazão de gás de reciclo

$x_{3}=$ temperatura da reação

$\mathrm{x}_{4}=\quad$ teor de clorados 
Modelo Geral: $\mathrm{S}=86.90-1.89 \cdot \mathrm{x}_{1}+0.07 \cdot \mathrm{x}_{2}-1.73 \cdot \mathrm{x}_{3}+0.44 \cdot \mathrm{x}_{4}-1.18 \cdot \mathrm{x}_{1} \cdot \mathrm{x}_{2}+7.02 \cdot \mathrm{x}_{1} \cdot \mathrm{x}_{3}+0.44 \cdot \mathrm{x}_{1} \cdot \mathrm{x}_{4}+1.82 \cdot \mathrm{x}_{2} \cdot \mathrm{x}_{3}-0.16 \cdot \mathrm{x}_{2} \cdot \mathrm{x}_{4}-$ $0.57 \cdot \mathrm{x}_{3} \cdot \mathrm{x}_{4}-1.94 \cdot \mathrm{x}_{1}^{2}-1.03 \cdot \mathrm{x}_{2}^{2}-2.05 \cdot \mathrm{x}_{3}^{2}-0.29 \cdot \mathrm{x}_{4}^{2}$

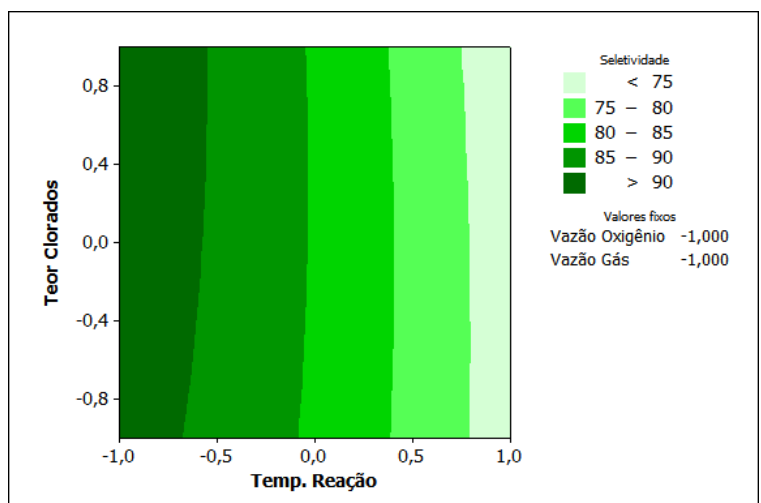

Situação 21: Vazão oxigênio mínima do processo; Vazão gás reciclo mínima do processo $S=84.57-10.57 \cdot x_{3}+0,16 \cdot x_{4}-0,57 \cdot x_{3} \cdot x_{4}-2.05 \cdot x_{3}^{2}-0.29 \cdot x_{4}^{2}$

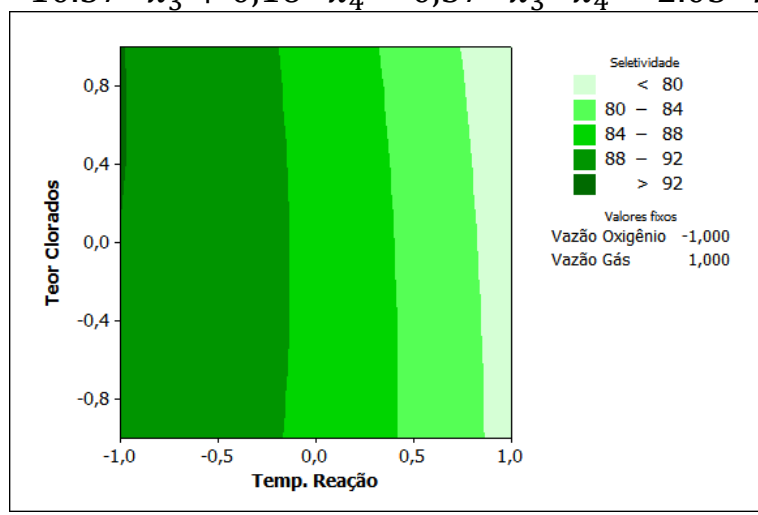

Situação 23: Vazão oxigênio mínima do processo; Vazão gás reciclo máxima do processo $S=87.07-6.93 \cdot x_{3}-0.16 \cdot x_{4}-0,57 \cdot x_{3} \cdot x_{4}-2.05 \cdot x_{3}^{2}-0.29 \cdot x_{4}^{2}$

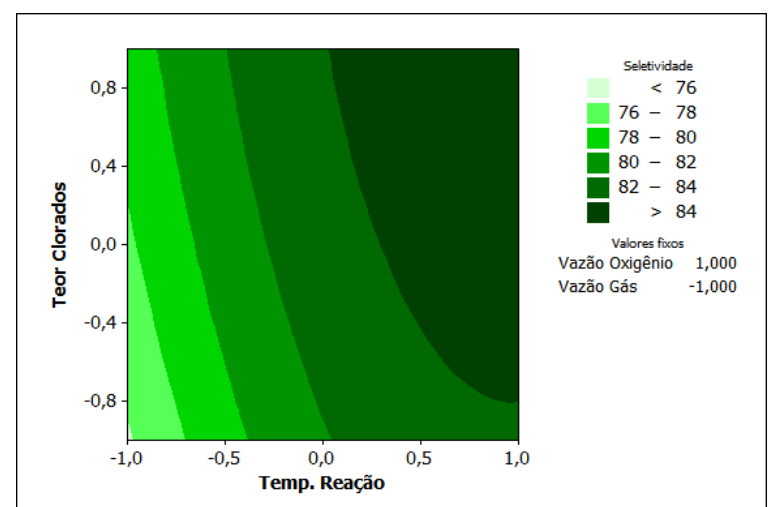

Situação 22: Vazão oxigênio máxima do processo; Vazão gás reciclo mínima do processo $S=83.15+3.47 \cdot x_{3}+1.04 \cdot x_{4}-0,57 \cdot x_{3} \cdot x_{4}-2.05 \cdot x_{3}^{2}-0.29 \cdot x_{4}^{2}$

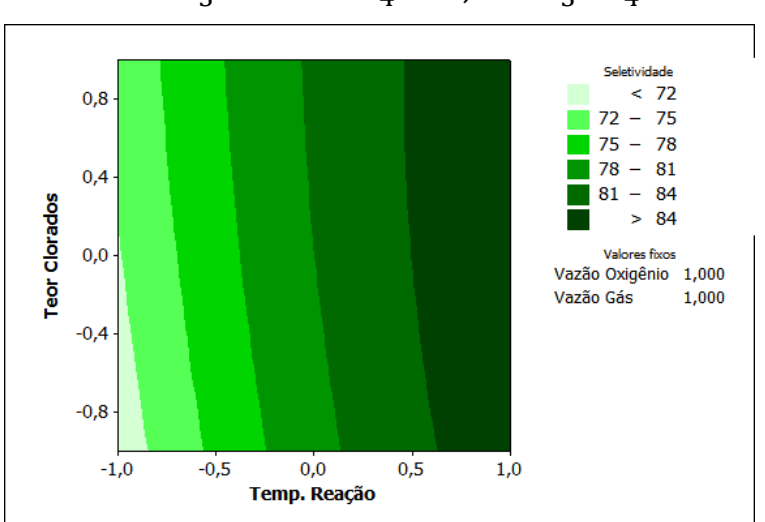

Situação 24: Vazão oxigênio máxima do processo; Vazão gás reciclo máxima do processo $S=80.93+7.11 \cdot x_{3}+0.72 \cdot x_{4}-0,57 \cdot x_{3} \cdot x_{4}-2.05 \cdot x_{3}^{2}-0.29 \cdot x_{4}^{2}$

Figura 66 - 6ª Análise Exploratória do modelo da equação 71 
Os modelos desdobrados representados pelas situações 21 a 24 da Figura 66 mostram comportamentos bastante diferentes da seletividade da reação em função das alterações nas variáveis de processo.

As situações 21 e 23 mostram claramente a influência da temperatura da reação sobre a seletividade do processo, com baixa influência da variável teor de clorados sobre os resultados. São nessas duas situações que os valores de seletividade tendem aos maiores valores dentre as quatro situações analisadas, alcançando os máximos resultados, no caso em que trabalhamos com baixas vazões de oxigênio e altas vazões de gás de reciclo (o efeito dessa última variável já foi explorado detalhadamente nos modelos apresentados na Figura 61).

Do ponto de vista teórico é conveniente que o par teor de clorados e temperatura da reação sempre seja ajustado simultaneamente à medida que o catalisador é utilizado e envelhece. Isso porque o número de sítios ativos de prata diminuiu na superfície do catalisador, sendo necessário o aumento da temperatura da reação, para manter a produtividade da reação de produção de óxido de etileno. Com aumento de temperaturas, os clorados tendem a não permanecer adsorvidos na superfície do catalisador. Consequentemente, para manutenção da concentração ideal de clorados na superfície do catalisador, torna-se necessário aumentar o teor de clorados que são adicionados ao processo na corrente de gás de reciclo.

A combinação desses fatores (baixa temperatura de reação, baixa vazão de oxigênio, alta vazão de gás de reciclo, com baixa influência do teor de clorados), resulta na terceira situação estudada que direciona o processo aos melhores resultados de seletividade.

Os modelos desdobrados representados pelas situações 22 e 24 só vem a reforçar a importância da variável vazão de oxigênio na gestão do processo. Pode-se observar que, nessas duas situações, quando se analisa 0 comportamento do processo em que a vazão de oxigênio trabalha em níveis 
elevados, o resultado é exatamente o oposto daquele obtido para as situações 21 e 23.

Do ponto de vista operacional, as análises demonstram que, para se chegar a uma situação de máxima seletividade da reação, a opção por gerenciamento contínuo e conjunto do teor de clorados e temperatura da reação, fixando-se a vazão de oxigênio e a vazão de gás de reciclo (situação 23) é interessante, factível e apresenta-se como adequada para melhoria dos resultados.

Analisando-se globalmente os modelos 24 desdobrados é possível definir as condições qualitativas que proporcionam a obtenção dos melhores resultados em relação à seletividade do processo, como mostrado na Tabela 39.

Tabela 39 - Resumo dos resultados da análise dos modelos desdobrados (direção a ser adotada para cada variável na busca da máxima seletividade)

\begin{tabular}{|c|c|c|}
\hline Variável & Direção de Atuação & $\begin{array}{c}\text { Efeito sobre a Seletividade do } \\
\text { processo }\end{array}$ \\
\hline $\begin{array}{c}\text { Vazão de } \\
\text { oxigênio }\end{array}$ & Menor possível & $\begin{array}{c}\text { Efeito significativo em favor } \\
\text { do aumento da seletividade }\end{array}$ \\
\hline $\begin{array}{c}\text { Temperatura da } \\
\text { reação }\end{array}$ & Menor possível & $\begin{array}{c}\text { Efeito muito significativo em } \\
\text { favor do aumento da } \\
\text { seletividade }\end{array}$ \\
\hline $\begin{array}{c}\text { Teor de } \\
\text { Clorados }\end{array}$ & $\begin{array}{c}\text { Tendendo a valores } \\
\text { elevados }\end{array}$ & $\begin{array}{c}\text { Efeito razoável em favor do } \\
\text { aumento da seletividade }\end{array}$ \\
\hline $\begin{array}{c}\text { Vazão de gás de } \\
\text { reciclo }\end{array}$ & Indiferente & $\begin{array}{c}\text { Praticamente não afeta o } \\
\text { desempenho da seletividade }\end{array}$ \\
\hline
\end{tabular}

Adicionalmente, faz-se necessário o monitoramento contínuo da concentração dos hidrocarbonetos contaminantes do etileno na corrente de gás de reciclo, mais especificamente o etano, uma vez que a concentração desse hidrocarboneto influência diretamente no balanço entre clorados sendo adsorvidos e removidos da superfície do catalisador de prata, como explicado em 3.7. 


\section{CONCLUSÕES}

Os resultados deste trabalho indicam que a seletividade da reação de produção de óxido de etileno é influenciada, de forma significativa, por um conjunto de variáveis que, caso gerenciadas conjuntamente, permitem a obtenção de resultados diferenciados para o processo.

Do ponto de vista estatístico, quatro fatores principais são apontados como importantes para o controle dos resultados de seletividade da reação, porém a gestão contínua sobre apenas três dessas variáveis (vazão de alimentação de oxigênio, temperatura da reação, teor de clorados no gás de reciclo) é realmente necessária para o processo de gestão.

As pesquisas teóricas relacionadas às variáveis que influenciam a seletividade das reações de oxidação do etileno enfatizam a importância da concentração de clorados na superfície do catalisador. Os resultados obtidos através do modelo de regressão desenvolvido indicam uma significância estatística desse parâmetro, mas este não se mostra o principal parâmetro de influência nos resultados (esse título ficou com a variável temperatura da reação).

O modelo de regressão desenvolvido, oriundo do tratamento estatístico dos dados coletados no processo produtivo estudado, é capaz de explicar cerca de $60 \%$ das variações do processo, indicando a existência de fatores sobre os quais não se tem o controle (gestão). São as chamadas variações ordinárias ou variações especiais do processo e que são características do mesmo.

Os valores de seletividade da reação obtidos através do modelo matemático proposto foram comparados com valores obtidos através de avaliação do processo via simulador, obtendo-se valores semelhantes e coerentes entre si, o que permitiu, do ponto de vista fenomenológico, a validação desse modelo.

O modelo de regressão também foi desdobrado em diversos modelos que permitem uma análise detalhada do comportamento do processo em situações 
que são aplicáveis ou factíveis do ponto de vista operacional. Esses modelos, analisados individualmente, indicam que a máxima seletividade para a reação de oxidação de etileno a óxido de etileno ocorre quando a operação da unidade é realizada com a menor temperatura possível para o processo, com a menor vazão de oxigênio e com altas concentrações de clorados no gás de reciclo, sendo independente o valor adotado para a vazão de gás de reciclo. Nessas condições, atenção especial deve ser à variável teor de clorados no gás de reciclo, a qual requer acompanhamento contínuo por parte dos operadores de processo.

\section{Sugestões para futuras pesquisas}

Não obstante as suas contribuições, este trabalho também possui suas limitações e também abre portas para futuras pesquisas. A principal contribuição para pesquisas futuras está relacionada ao fato do modelo matemático ter sido desenvolvido utilizando-se de um conjunto de dados de processo obtidos ao longo do tempo de operação de um único catalisador especifico. Considerando que o catalisador apresenta um tempo de via útil de aproximadamente quatro anos e que, após esse período, este deve ser substituído por uma nova carga de catalisador, fica a questão de quão robusto é o modelo desenvolvido para o gerenciamento do processo produtivo, quando se altera o catalisador do processo.

\section{Limitações deste trabalho}

Em relação ao modelo desenvolvido para a tomada de decisões no dia a dia da gestão do processo produtivo, deve-se ressaltar que a aplicabilidade prática necessita ser cautelosa, pois envolve um processo produtivo complexo, perigoso e governado por um conjunto de paradigmas operacionais desenvolvidos ao longo de 40 anos de produção de óxido de etileno.

O controle da concentração de clorados (fator F) na concentração de gás de reciclo se mostra bastante importante e relevante para o processo, porém esse controle não é realizado de forma automática (os operadores precisam perceber variações na seletividade para atuar no fator $F$ ). $O$ fato de uma 
variável importante como esta ser controlada de forma manual, não garante que os dados obtidos ao longo do estudo estivessem necessariamente em seu ponto ótimo ou próximo deste ponto, o que certamente aumenta a variabilidade dos resultados, contribuindo para uma maior imprecisão do modelo estatístico desenvolvido. 


\section{REFERÊNCIAS BIBLIOGRÁFICAS}

ASPEN PLUS STEADY STATE SIMULATION. Unit Operation Models Reference Manual. Version 10 chapter 5, p.1-32, 1981.

BREYFORD, F. W.; CUPELLO, J. M.; MEADOWS, B. Managing Six Sigma A practical Guide to Understanding, Assessing and Implementing the Strategy that Yields Bottom-Line Sucess. New York: John Wiley \& Sons, 2001

BOX, G. E. P.; HUNTER, W. G.; HUNTER, J. S. Statistics For Experimenters Design, Innovation, And Discovery. New York: John Wiley \& Sons, 2005

Buffoni, M. Projeto Revamp de eo - Tópicos para Elaboração do Elearnig da Unidade de Óxido de Eteno. Mauá: Célula Produtora ENGENHARIA DE PROCESSOS, 2008 (ESTUDO TÉCNICO, SEM NÚMERO)

BULLA, R. Dedução das Fórmulas de Seletividade. São Paulo. Oxiteno S.A Indústria e Comércio, 1979. (Estudo técnico, sem número).

CAMARGO, A.S. Estatística Básica e Avançada para Engenharia da Qualidade- Apostila do Curso Engenharia da Qualidade - PECE-USP. São Paulo, 1996 Capítulos 4, 10.

CARLSON, E. C. Don't Gamble With Physical Properties For Simulations. Chemical Engineering Progress, p.35-46, 1996.

CARVALHO, M. C. N. A. Estudo da Fase Ativa do Catalisador de Prata para a Oxidação de Etileno. 2005. 109 p. Tese (Doutorado) - Universidade Federal do Rio de Janeiro, Rio de Janeiro, 2005.

CLARK, J ; DOWNING. D. Estatística Aplicada. São Paulo: Ed. Saraiva., 1999, Capítulos 14,15,16.

CLARKE, P. A PCI View of EO/MEG Supply and Demand. Istanbul. PCI Xylenes \& Polyesters Ltd, 2011 (GEOTEM Presentation)

COOMBS, J.; KIM, D.; PALOMBO,L. Celanese Clearlake Ethylene Oxide Reactor Revamp, 1997.

CRI CATALYST. Shell EO-EG Process Licensees - Presentation and Discussion. Houston, Texas [1996]

DAUBERT, T. E. Chemical Engineering Thermodynamics. New York: McGraw Hill, Inc, 1985

FATTAHI, S. ; RAVANDI, S.A ; TAHERI, S.M. Cotton Yarn Enginnering Using Robust Regression and Criteria of Mallow's Cp. Fibers and Polymers v.11 No 7 p.1075-1082, 2010. 
HALCON INTERNATIONAL INC.. SD/HALCON Oxygen Based Ethylene Oxide Process Licensees' Meeting. New York City [1979]

HULBURT, H. M. Chemical Reactions Engineering Reviews. Washington, D.C American Chemical Society, 1975. p.26-49.

JUNIOR, J. C. Sistema Digital de Controle Distribuído (SDCD). Mauá. Oxiteno S.A Indústria e Comércio, 2012. (Estudo técnico, sem número).

KAGAWA, S ; IWAMOTO, M. ; SEIYAMA, T. What occurs on silver's surface. Chemtech, p.426-431, july, 1981.

KENETT, R. S. ; ZACKS, S. Modern Industrial Statistics - Design and Control of Quality and Reliability. Pacific Groove, Brooks/Cole Publishing Company,1998 Chap.8,10.

KENSON, E. R. ; LAPKIN, M. Kinetics and Mechanism of Ethylene Oxidation. Reactions of Ethylene and Ethylene Oxide on a Silver Catalyst. Journal of Physical Chemistry, v.74, No.7, p.1493-1502, 1970.

KILTY, P. A.; SACHTLER, W. M. H. The Mechanism of the Selective Oxidation of Ethylene to Ethylene Oxide. Catalysis Reviews, v10 issue 1, p.1-16, 1974.

KIRK-OTHMER. Encyclopedia of Chemical Technology. V10, p632-673, fifth edition, John Wiley \& Sons, 2007.

KLUGHERZ, P. D.; HARRIOT, P. Kinetics of Ethylene Oxidation on a Supported Silver Catalyst. AIChE Journal, v.17, No.4, p856-866, 1971

KUME, H. Métodos Estatísticos para a Melhoria da Qualidade. $10^{a}$ edição. São Paulo: Ed. Gente, 1993. p.77-91.

KUTNER, M. H. NACHTSHEIM, C. J. and NETER, J. Applied linear regression models. $4^{\mathrm{a}}$ ed. New York, McGraw-Hill, 2004.

LAFARGA, D.; AL-JUAINED, M. A.; BONDY, C. M.; VARMA, A. Ethylene Epoxidation on Ag-Cs / a-Al2O3 Catalyst: Experimental Results and Strategy for Kinetic Parameter Determination. Ind. Eng. Chem. Res. 39, p.2148-2156, 2000.

LEVENSPIEL, O Engenharia das Reações Químicas. Rio de Janeiro: Editora Edgard Blucher Ltda, 1999. v.1, p.318-319.

LIBANIO, N. F. Modelagem e Simulação do Processo de Produção de Óxido de Eteno. 1995. 81 p. Dissertação (Mestrado) - Escola Politécnica, Universidade de São Paulo, São Paulo, 1995. 
LIRA, S. A. Análise de Correlação: Abordagem Teórica e a construção dos coeficientes com aplicações. 2004. 209 p. Tese (Mestrado) - Universidade Federal do Paraná, Curitiba, 2004.

MANZI, J; KALID, R. Controle em Processos Químicos. Revista Brasileira de Engenharia Química, v.17, n.1, 1997.

MELLO, F. H. Simulação de Sistema de Absorção, Stripping e Reabsorção de Óxido de etileno. 2010. 108 p. Tese (Mestrado) - Universidade Estadual de Campinas, Campinas, 2010.

MONTGOMERY, D. Design and Analysis of experiments. $6^{a}$ ed. NJ, John Wiley e Sons, Inc., 2005.

MURRAY, K. E. A study of the oxidation of ethylene to ethylene oxide on a silver catalyst. CSIRO Australia, p.433-449, 1950.

NAKATSUJI, H.; NAKAI, H.; IKEDA, K.; YAMAMOTO, Y. Mechanism of the Partial Oxidation of Ethylene on an Ag Surface:Dipped Adcluster Model Study. Surface Science 384, p.315-333, 1997.

NASSER, R. Otimização das colunas de absorção de recuperação de acetona na produção de filter tow por meio de estudos fenomenológicos e análise estatística. 2009. Tese (Doutorado) - Universidade de São Paulo, São Paulo, 2009.

NAULT, L. G.; BOLME, D. W. ; JOHANSON, L. N. Reaction Rate Studies of Catalytic Oxidation of Ethylene. Industrial \& Engineering Chemistry Process Design and Development, v.1, No.4, p.285-292, 1962.

OPPE, F. H. Estudo da Desidratação da Glicerina por Destilação Trifásica em Coluna de Pratos Perfurados. 2012. 126 p. Tese (Doutorado) Universidade de São Paulo, São Paulo, 2012.

OXITENO S/A INDÚSTRIA E COMÉRCIO. Manual de Segurança e Manuseio de Óxido de etileno. Mauá, [2001]. 57 p.

OXITENO S/A INDÚSTRIA E COMÉRCIO. Empresa Inovadora em Catálise e Catalisadores - Prêmio FINEP de Inovação Tecnológica 2004. São Paulo, [2004]. $22 \mathrm{p}$.

PRAUSNITZ, J. M.; LICHTENTHALER, R. N.; AZEVEDO, E. G.. Molecular Thermodynamics of Fluid Phase Equilibria. $3^{\text {rd }}$ Edition New Jersey: Prentice Hall International Series, 1999

QUAGLIANO, J. V. ; VALLARINO, L. M. Química. Rio de Janeiro. Ed. Guanabara Dois, $3^{\text {a }}$ edição. 1985 Cap.26,. 
QUINTELLA, R. H. ; The Strategic Management of Technology in the Chemical and Petrochemical Industries. Pinter Publisher London and New York Chap. 4, p 63 -72, 1993.

RIBEIRO, L. G. Engenharia de Processos Aplicada à Otimização da Produtividade Industrial. Gestão Empresarial e Tecnológica para a Industrial Química - GETIQ. 2003

RODRIGUES, M. I. ; IEMMA, A. F. Planejamento de Experimentos e Otimização de Processos - Uma estratégia seqüencial de planejamento. Ed. Casa do Pão, $1^{\underline{a}}$ edição. 2005

SACHTLER, W. M H ; BACKX, C. ; VAN SANTEN, R. A. On the Mechanism of Ethylene Epoxidation. Catal. Rev.-SCl. Eng , v.23 (1\&2) p.127-149, 1981

SARAIVA, A. J. Engenharia de Processo nas Plantas Industriais. Salvador: Solisluna Editora, 2010

SCHOUTEN, E.P.S ; BORMAN, P.C ; WESTERTERP, K.R. Influence of reaction products on the selective oxidation of ethene. Chemical Engineering and Processing 35, p 107-120, 1996.

SCIENTIFIC DESIGN COMPANY, INC. EO/EG Licensee's Meeting. Seattle [1998]

SCIENTIFIC DESIGN COMPANY, INC. Project Design Basis for Oxiteno S/A Indústria e Comércio. Project number 1341. New York [1972].

SHELL INTERNATIONAL CHEMICAL B.V;. Shell EO/EG Process Memorandum 105. Amsterdam - The Netherlands, 2005.

SHELL OIL COMPANY, Matusz, M ; Mesters, C.M.A.M ; Buffum, J.E;. Ethylene Oxide Catalyst and Process. US 5380697, jan.10, 1995

SHELL OIL COMPANY, Evans, W ; Mesters, C.M.A.M. Ethylene Oxide Catalyst and Process. US 5597773, jan.28, 1997

SOUZA, A. A; FARIAS, R. F. Cinética Química - teoria e prática. Campinas. Ed. Átomo, 1aㅡ edição. 2008. Cap.1 e 8.

STOREY, R. E. Catalisador de Óxido de Alta Seletividade - Curso de Treinamento. Mauá: Célula Produtora, 2007: (Curso de Treinamento, CRI Catalyst Co, 2007)

STOREY, R. E. High Selectivity EO catalyst Training School. Oxiteno Mauá, CRI Catalyst Co, 2008).

SUGAHARA, S. Uma Experiência com Modelo Estatístico (MOS) para a Previsão da Temperatura Mínima Diária do Ar. Brazilian Journal of Geophysics 18, p 1-11, 2000. 
TERRON, L. R. Exercícios de Termodinâmica Química Aplicada I (1aㅗ parte). São Paulo, 1990 (Escola Politécnica da Universidade de São Paulo, 1990).

THE DOW CHEMICAL COMPANY. Ethylene Oxide User's Guide. [2008] 96 p VAN SANTEN, R. A ; GROOT, P. M. The Mechanism of Ethylene Epoxidation. Journal of Catalysis 98, p.530-539, 1986

VAN SANTEN, R. A.; KUIPERS, H. P. C. E. The Mechanism of Ethylene Epoxidation. Advances in Catalyst, v.35 p. 265-321, 1987

WERKEMA, M.C.C Ferramentas Estatísticas Básicas para o Gerenciamento de Processos. Belo Horizonte: Fundação Christiano Ottoni, 1995. v.2, p.181-184. 